\title{
CRUSTAL STRUCTURE AND LITHOSPHERIC DOMING: ASPECTS OF DEFORMATION ALONG AN OBLIQUELY CONVERGENT PLATE MARGIN, NEW ZEALAND
}

A thesis submitted for the degree of

Doctor of Philosophy

in

Geophysics

Institute of Geophysics, School of Earth Sciences

Victoria University of Wellington

Te Whare Wānanga o te Upoko o te Ika a Māui

Wellington, New Zealand July 2002 


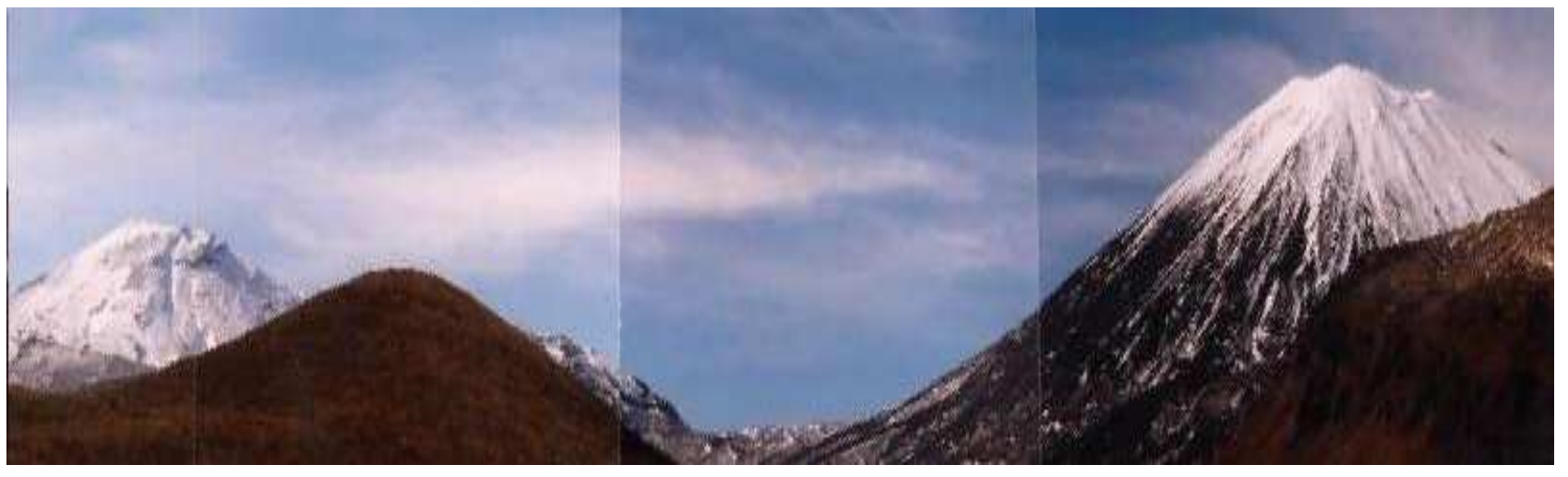

Fig. 1 Volcanoes of the southern Central Volcanic Region. The left peak is Tongariro and the right is Ngaruhoe. The photo is taken from the Mangetepopo road end facing east. 


\begin{abstract}
Lithospheric deformation along and adjacent to the Pacific-Australian Plate boundary through New Zealand has resulted in different expressions in North and South Islands. This thesis investigates some aspects of crustal and upper mantle structure in New Zealand and is divided into two distinct parts. The first examines the structure of the obliquely compressional crustal plate boundary in South Island using seismic techniques; the second focuses on the domed topography of central North Island and its relationship to mantle processes.
\end{abstract}

High density active source, one and three-component, seismic data from a transect across the Southern Alps provides information on the deformation of the crust across the Australia-Pacific plate boundary of South Island. These data show 0-0.08 s ( $\sim 0.25 \%)$ delay times between the radial and transverse directions for shear waves (Sg and SmS phases), with maximum possible delays of $140 \mathrm{~ms}$ and the fast direction aligned with the transverse direction (approximately parallel to the plate boundary). The transect is perpendicular to the Alpine Fault, which is slightly oblique to the fast mantle directions determined from SKS phases. The small values of crustal splitting may result from the oblique angle of the ray paths to the actual crustal structure at depth, or the complex nature of the deformation as observed at the surface, which though on a small scale can be strongly anisotropic, may not add constructively over a large region.

Poisson's ratio, determined from forward modelling of both $\mathrm{P}$ and $\mathrm{S}$ phases, shows low values of $0.21-0.24$ for the crust of South Island. A broad region of low values $(\sigma=0.15)$ exists at 10-20 km depth under the Southern Alps, which corresponds to a previously identified body of low $\mathrm{V}_{p}$ and high resistivity. The low $\sigma$ is interpreted as low pore fluid pressure and high silica composition rocks. This contrasts with previous interpretations of 
high pore fluid pressure at this depth.

The topography of central North Island, New Zealand, describes a $250 \mathrm{~km}$ wide and $\sim 500 \mathrm{~m}$ high dome. Exhumation estimates from mudstone porosity measurement indicate an increase in exhumation from $\sim 500 \mathrm{~m}$ at the coast to $2 \mathrm{~km}$ in the region of the present topographic high. Combining these values gives an estimate of rock uplift of over $2.5 \mathrm{~km}$ for central North Island, since $4 \mathrm{Ma}$, a rate of $0.6 \mathrm{~mm} / \mathrm{yr}$. Tectonic uplift of $1.25 \mathrm{~km}$ indicates that $\sim 50 \%$ of the rock uplift occurs in response to exhumation. An independent local estimation of differential erosion in central North Island gave $300 \mathrm{~m}$ of exhumation since at least $500 \mathrm{ka}$, a rate of $\geq 0.6 \mathrm{~mm} / \mathrm{yr}$. Using a digital elevation model of New Zealand the fluvial incision of the landscape was calculated and $\sim 169 \mathrm{~m}$ of rebound can be attributed to incision. Contouring maximum incision elucidates a region of high incision $\sim 50 \mathrm{~km}$ south of the present centre of domed rock uplift. Using incision as a proxy for rock uplift, it is hypothesised that the incision signal is recent and demonstrates the southward migration of the centre of rock uplift. Rebound of sedimentary basins due to a reduction in plate coupling forces can also account for some of the observed rock uplift.

Buoyancy forces required to create the pattern and magnitude of rock uplift are investigated using a $3 \mathrm{D}$ loading model of the lithosphere. Strong upward forces (65 MPa) are required under the Central Volcanic Region, combined with broad uplift (36 MPa) over western North Island, to fit the observed rock uplift. Low Pn velocities under the Central Volcanic Region indicate temperatures $500^{\circ} \mathrm{C}$ hotter than that of normal mantle. This temperature anomaly corresponds to $60 \mathrm{~kg} / \mathrm{m}^{3}$ less dense than normal mantle, which is consistent with the change in density of $66 \mathrm{~kg} / \mathrm{m}^{3}$ estimated from the loading model and assuming the density change occurs over a $100 \mathrm{~km}$ depth range. The southern extent of buoyancy forces does not correspond well to regions of high seismic attenuation in the lithosphere but instead with the region of high incision. 


\section{ACKNOWLEDGEMENTS}

I thank Tim Stern, Martha Savage and Rob Davies for their support and supervision during this project. Thank you also to Tim Little who provided supervision during periods of absence by my main supervisors. Editorial advice and constructive criticism on the thesis were kindly made by Martin Scherwath, Wanda Stratford and Lynn and Tim Pulford.

I am grateful to Vaughan Stagpoole and Rob Funnell for organising the use of the IGNS porosity dataset. Helium-porosity measurements for this study were made by Murray Helm of Core Laboratories Australia Ltd and porosity thin sections were made by Stewart Bush, V.U.W. This project would not have been possible without the hard work of the 1996 SIGHT Project team.

I used software: Demtool by Rob Davies and Claritas $T M$ by Jonathan Ravens, thankyou both for you help and willingness to answer questions about these programs.

I would like to thank my friends and student colleges for their support, discussion and great "hacky sack" sessions: Etienne Audoine, Adrian Benson, Nancy Bertler, Annemarie Christophersen, Mathieu Duclos, Alex Gerst, Tony Harrison, Sonja Hofmann, Richard Jennings, Vicki Miller, Al Richardson, Michelle Salmon, Martin Scherwath, Les Singh, Dougal Townsend, Wanda Stratford and Ralph Wahrlich. In particular I would like to thank Annemarie and Wanda for being excellent long-term office mates.

I was awarded a Victoria University of Wellington PhD Scholarship and also the Jim Ansell Scholarship. I would like to thank the scholarships committee and also the New Zealand Geophysics Society.

Finally I would like to thank my family for their long distance support and encouragement. Especially to my sister Jane for the provision of food parcels and stories from abroad. 
Abstract $\quad$ iii

$\begin{array}{lll}\text { Acknowledgements } & \text { v }\end{array}$

1 Introduction $\quad 1$

1.1 Collision . . . . . . . . . . . . . . . . . . . . 1

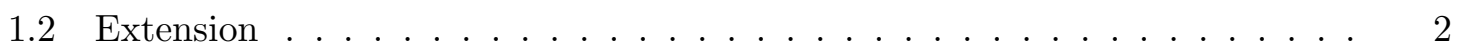

1.3 Thesis Outline . . . . . . . . . . . . . . . . . . . 4

2 Crustal structure of the Southern Alps, New Zealand $\quad 7$

2.1 Tectonic and geological background . . . . . . . . . . . . . . 7

2.2 Dataset . . . . . . . . . . . . . . . . . . . . . 12

2.3 Wave phases . . . . . . . . . . . . . . . . . . 12

2.4 Basic seismic processing . . . . . . . . . . . . . . . . 18

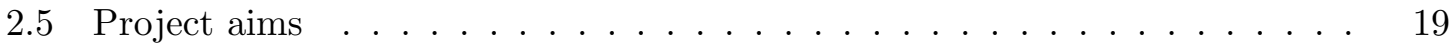

3 Anisotropy under the Southern Alps $\quad 21$

3.1 Anisotropy theory . . . . . . . . . . . . . . . . . . . . . . . 21

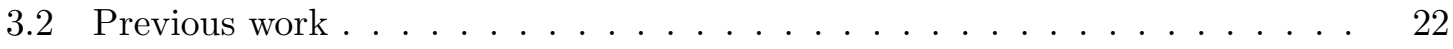

3.2.1 SKS studies of South Island . . . . . . . . . . . . . . . . . . 22

3.2.2 Upper mantle anisotropy under the Southern Alps . . . . . . . . . . 24

3.2.3 Laboratory analyses of Haast schist . . . . . . . . . . . . . . . . . 24

3.2.4 Active source crustal shear wave splitting experiment from Greenland 26

3.3 Crustal structure under the Southern Alps . . . . . . . . . . . . . . . . 27

3.4 Origin of the transverse component . . . . . . . . . . . . . 27

3.5 Wave Phases . . . . . . . . . . . . . . . . . . . . . . . 29

3.6 Data Selection . . . . . . . . . . . . . . . . . . . . 29

3.7 Anisotropy analysis . . . . . . . . . . . . . . . . . . . . . . 31

$3.7 .1 \quad$ Single trace . . . . . . . . . . . . . . . . . . . . . . . . 31

3.7.2 Silver and Chan method . . . . . . . . . . . . . . . . 32 
3.7.3 Controlling the initial polarization . . . . . . . . . . . . 35

3.8 Deconvolution . . . . . . . . . . . . . . . . . . . . . . . . . 39

3.9 Cross-correlation . . . . . . . . . . . . . . . . . . . . 44

3.10 No Splitting Experiment . . . . . . . . . . . . . . . . . . 51

3.11 Discussion . . . . . . . . . . . . . . . . . . 57

3.12 Summary . . . . . . . . . . . . . . . . . . 60

4 Seismic velocity modelling and Poisson's ratio 63

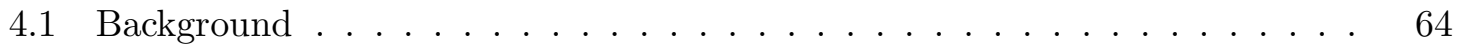

4.1 .1 Poisson's ratio . . . . . . . . . . . . . . . . . . 64

4.1.2 Poisson's ratio from seismic data, previous work . . . . . . . . 66

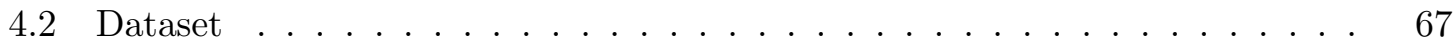

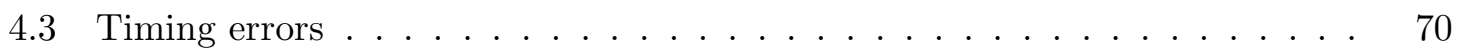

$4.4 \quad$ P-wave modelling . . . . . . . . . . . . . . . . . . . 71

4.4.1 Discussion of $\mathrm{P}$-wave model . . . . . . . . . . . . . . . . 72

4.5 S-wave velocity modelling . . . . . . . . . . . . . . . . . . 73

4.6 Poisson's ratio model . . . . . . . . . . . . . . . . . . . . . . . . 73

4.7 Poisson's ratio from $1 \mathrm{D}$ analysis $\ldots \ldots \ldots \ldots \ldots$

4.8 Poisson's ratio from $\mathrm{Pg}$ and $\mathrm{Sg}$ phases $\ldots \ldots \ldots \ldots$

4.9 Discussion . . . . . . . . . . . . . . . . . . . . . 82

4.10 Summary . . . . . . . . . . . . . . . . . . 87

$5 \quad$ Tectonic and geologic background, central North Island $\quad 89$

5.1 Tectonics and Background . . . . . . . . . . . . . . . 89

$5.1 .1 \quad$ Back-arc extension and volcanism . . . . . . . . . . . . 91

5.1 .2 Wanganui Basin . . . . . . . . . . . . . . . . . . . 92

5.1 .3 Marlborough Sounds . . . . . . . . . . . . . . . . . . . . 95

5.1 .4 Compressional plate driven tectonics . . . . . . . . . . . . . . . 97

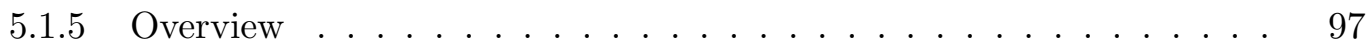

5.2 Creating the Digital Elevation Model $(\mathrm{DEM}) \ldots \ldots \ldots$. . . . . . . 98

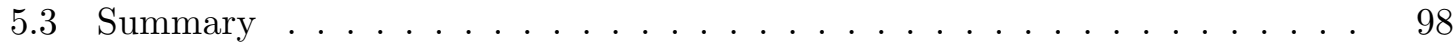


6 Uplift, Exhumation and Rock Uplift 101

6.1 Exhumation of North Island . . . . . . . . . . . . . . . . . . . . . . 102

6.1.1 Dataset and sample locations . . . . . . . . . . . . . . . . . 104

6.2 Exhumation . . . . . . . . . . . . . . . . . . . . . 105

6.2.1 Analysis and results of exhumation calculations . . . . . . . . . . 107

6.3 Surface uplift . . . . . . . . . . . . . . . . . . . . . 107

6.4 Rock uplift . . . . . . . . . . . . . . . . . . . . . . . . 110

6.5 Tectonic uplift . . . . . . . . . . . . . . . . . . . . 111

6.6 Differential erosion calculations from Mt. Hauhungatahi . . . . . . . . . . 111

6.6 .1 Results . . . . . . . . . . . . . . . . . . . . 114

6.7 Exhumation by fluvial incision . . . . . . . . . . . . . . . 117

6.7 .1 Analysis . . . . . . . . . . . . . . . . . . . . . 117

6.7.2 Results of isostatic incision and erosion calculations . . . . . . . 122

6.8 Conclusions . . . . . . . . . . . . . . . . . . . . . . . . 123

7 Investigation of deformation, North Island $\quad \mathbf{1 2 5}$

7.1 Source processes of lithospheric doming . . . . . . . . . . . . . 127

7.2 Brief overview of some regions of lithospheric doming . . . . . . . . . . 127

7.2 .1 Yellowstone Hotspot . . . . . . . . . . . . . . . . . . . . . 127

$7.2 .2 \quad$ Appennines, Italy $\ldots \ldots \ldots$

7.2 .3 Spitsbergen . . . . . . . . . . . . . . . . . . . . . . . 128

7.2.4 West Antarctica and South Island, New Zealand . . . . . . . . . . 129

7.3 Central North Island, New Zealand . . . . . . . . . . . . . . . . . . . . . 129

$7.4 \quad$ Flexural modelling . . . . . . . . . . . . . . . . . . . . . . . . . . . 132

7.4 .1 Boundary conditions . . . . . . . . . . . . . . . . . 132

$7.4 .2 \quad$ Local estimates of $\mathrm{Te} \ldots \ldots \ldots \ldots$

7.4.3 Analysis and results . . . . . . . . . . . . . . . . 138

7.5 Mantle buoyancy . . . . . . . . . . . . . . . . . . . . . . . . . . . . . 140

7.6 Rebound of basin sediments . . . . . . . . . . . . . . . . . 143

7.6.1 Pre-erosion sediment thickness . . . . . . . . . . . . . . . . . 144

7.6.2 Local isostatic rebound calculations . . . . . . . . . . . . . . . 144

7.7 Discussion - source of mantle up-welling . . . . . . . . . . . . . . 146

7.8 Summary . . . . . . . . . . . . . . . . . . . . . . . 148

$\begin{array}{llr}8 & \text { Summary } & 149\end{array}$

8.1 South Island crustal structure from active source seismology . . . . . . . . . 149

8.2 North Island domed rock uplift . . . . . . . . . . . . . . . . . 150 
9 References $\quad 153$

$\begin{array}{ll}\text { A Incidence angle and azimuth of PmP arrivals } & 163\end{array}$

B Splitting results on deconvolved data 165

$\begin{array}{ll}\text { C Deconvolved Data used in Cross-correlation } & 167\end{array}$

$\begin{array}{ll}\text { D Summary of pick information for velocity modelling } & 171\end{array}$

E Rangitikei River terraces $\quad \mathbf{1 7 5}$

E.0.1 Regional setting . . . . . . . . . . . . . . . . . 176

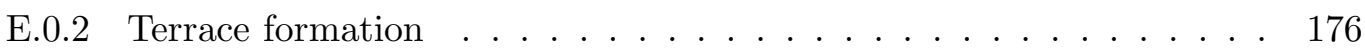

E.0.3 Method of identification of planar regions from the DEM . . . . . 178

E.1 Summary . . . . . . . . . . . . . . . . . . . . . . . . . . . . . . 182

$\begin{array}{lr}\text { F Mudstone porosity analyses, method and results } & 183\end{array}$

F.0.1 Mudstone porosity determination . . . . . . . . . . . . . . . . 183 


\section{FIGURES}

1 Image of volcanoes of the Central Volcanic Region . . . . . . . . . . ii

1.1 Tectonic layout of New Zealand . . . . . . . . . . . . . . . . . 3

1.2 Tilting of the Rangitikei River terraces . . . . . . . . . . . . . 5

2.1 Spatial relationship between the deformation phases of Southern Alps . . . 9

2.2 Model of deformation for Southern Alps . . . . . . . . . . . . . . . . . . . . 10

2.3 Preliminary seismic interpretation along Transect II . . . . . . . . . . . . . 10

2.4 Compressional velocity versus metamorphic grade for rocks of the Southern

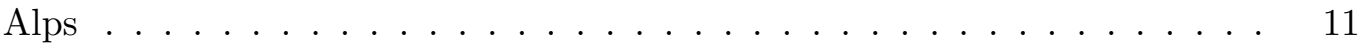

2.5 Layout of lines and transects, 1996 SIGHT Project . . . . . . . . . . . . 13

2.6 Terranes of South Island . . . . . . . . . . . . . . . . . . . . . 14

2.7 Wave phases recorded at STN1124 . . . . . . . . . . . . . 17

2.8 Azimuth and incidence angle of PmP arrival, STN1096 . . . . . . . . . 18

3.1 SKS fast directions and delay times . . . . . . . . . . . . . . . . . 23

3.2 Wave velocity versus angle between polarization and axis of symmetry, Haast

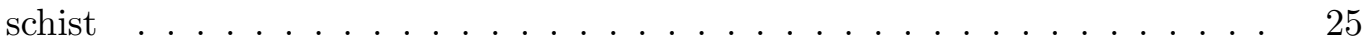

3.3 Schematic of shear wave polarization versus schist orientation . . . . . . . 26

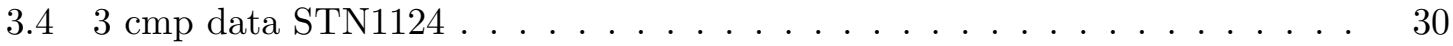

3.5 Trace and particle motion, trace offset $76892 \mathrm{~m}$, STN1124 . . . . . . . 33

3.6 Covariance matrix, offset $76892 \mathrm{~m}$, STN1124 . . . . . . . . . . . . . . . 34

3.7 Fast orientations from Silver and Chan method . . . . . . . . . . . . . . 35

3.8 Initial polarization azimuth from Silver and Chan method . . . . . . . . . 35

3.9 Stacking of the data, 5 trace stack, STN1124 _ . . . . . . . . . . . . . 37

3.10 Results of Silver and Chan method with fixed initial polarization . . . . . . 39

3.11 Comparison of standard and deconvolved data, STN1124 _ . . . . . . . . 43

3.12 Fast directions from Silver and Chan method, deconvolved data . . . . . . . 44

$3.13 \mathrm{SmS}$ arrival on radial component, STN1096 . . . . . . . . . . . . . 45

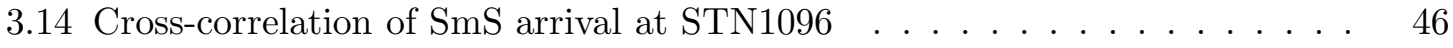


3.15 SmS arrival on radial component, STN1124, used in cross-correlation calculation, Figure 3.16. . . . . . . . . . . . . . . . . 47

3.16 Cross-correlation of seismic data, STN1124 f . . . . . . . . . . . . 48

$3.17 \mathrm{SmS}$ arrival on radial component, STN1136 . . . . . . . . . . . . . . . 49

3.18 Cross-correlation of $\mathrm{SmS}$ arrival at STN1136 . . . . . . . . . . . . . 50

3.19 Cross-correlation of deconvolved seismic data, STN1124 . . . . . . . . . 52

3.20 Cross-correlation of SmS arrival at STN1096 using deconvolved data . . . . 53

3.21 Cross-correlation of SmS arrival at STN1136 using deconvolved data . . . . 54

3.22 No splitting experiment, three identical components with random noise . . 55

3.23 Covariance matrix for unsplit data . . . . . . . . . . . . . . . 56

3.24 Spatial relationship of raypaths to the Haast schist . . . . . . . . . . . . 59

4.1 Crustal P-wave velocity model along Transect I . . . . . . . . . . . . . . . 68

4.2 Crustal P-wave velocity model along Transect II . . . . . . . . . . . . . . . 69

4.3 Ray coverage for Poisson's ratio modelling . . . . . . . . . . . . . . . . 72

4.4 Crustal P-wave velocity model, Transect I . . . . . . . . . . . . . . . . . . . 74

4.5 Crustal S-wave velocity model, Transect I . . . . . . . . . . . . . . 75

4.6 Model of Poisson's ratio of the crust under the Southern Alps, Transect I . 77

4.7 Ray coverage for 1D model of Poisson's ratio, STN1124 . . . . . . . . . . 79

4.8 Seismic data, PmP and SmS phases with picks, STN1136 . . . . . . . . 80

$4.91 \mathrm{D}$ estimates of $\mathrm{V}_{p} / \mathrm{V}_{s} \ldots \ldots \ldots \ldots \ldots \ldots$

4.10 Low Poisson's ratio, high conductivity and slow Vp anomaly under the Southern Alps . . . . . . . . . . . . . . . . . . . 84

$4.11 \mathrm{~V}_{p} / \mathrm{V}_{s}$ versus angle of incidence for the Haast schist $\ldots \ldots \ldots$. . . . 87

5.1 Generalised tectonic map of North Island . . . . . . . . . . . . . . . . . 90

5.2 Generalised geology of Wanganui Basin . . . . . . . . . . . . . . . . 94

5.3 Wanganui Basin depocentre and active volcanism migration, North Island . 96

6.1 Relationship between rock, surface and tectonic uplift and exhumation . . . 102

6.2 Exhumation surface from collated dataset . . . . . . . . . . . . . . . 106

6.3 Contoured exhumation . . . . . . . . . . . . . . . . . . . . . . 108

6.4 Short wavelength topography $(>50 \mathrm{~km})$ of Nth Island . . . . . . . . . . . 109

6.5 Long wavelength topography $(>200 \mathrm{~km})$ of Nth Island . . . . . . . . . 110

6.6 Topographic cross section with filtered topography . . . . . . . . . . . . 111

6.7 Rock uplift of North Island since the Miocene . . . . . . . . . . . . . . . . . 112

6.8 Topography of the Mt. Hauhungatahi region . . . . . . . . . . . . . . . . . 113

6.9 Topographic cross section from Mt Hauhungatahi to the west . . . . . . . 115 
6.10 Topography of Central North Island, used in incision calculation . . . . . . 116

6.11 Surface of summit elevations ～. . . . . . . . . . . . . . . . . . 118

6.12 Incision erosion . . . . . . . . . . . . . . . . . . . . . . . 120

6.13 Predicted regional uplift from incision erosion . . . . . . . . . . . . . . . 121

7.1 Summary of uplift and tilt rates f . . . . . . . . . . . . . . 126

7.2 Summary of seismic attenuation and Pn velocities under central North Island 131

7.3 Flexure models with uplift confined to the TVZ, Te $=15,25 \mathrm{~km} \ldots \ldots$

7.4 Flexure models with uplift under TVZ and the western attenuating region . 136

7.5 Flexural model with uplift under the TVZ and N-W central North Island . 137

7.6 Comparison of rock uplift estimations and flexural model results . . . . . . 139

7.7 Cross section of the CVR . . . . . . . . . . . . . . . . . . . . . 141

7.8 Schematic of model for rebound in response to sediment unloading . . . . . 143

7.9 Estimation of the original sediment thickness of Wanganui Basin . . . . . 145

C.1 SmS arrival on radial component, STN1096; data is deconvolved . . . . . 168

C.2 SmS arrival on radial component, STN1136; data is deconvolved . . . . . 169

E.1 Rangitikei River valley morphology . . . . . . . . . . . . . . . . . . 177

E.2 Rangitikei River terrace identification with slope vectors . . . . . . . . . 179

E.3 Back-stripping of slope with time . . . . . . . . . . . . . . . . . 181 


\section{TABLES}

3.1 Results of Silver and Chan method, A and B results . . . . . . . . . . 36

3.2 Results of Silver and Chan method, A and B results, continued. . . . . . . . 38

3.3 Results of Silver and Chan method with fixed initial polarization, STN1124 40

3.4 Silver and Chan method results, fixed initial polarization, STN1136, SP10

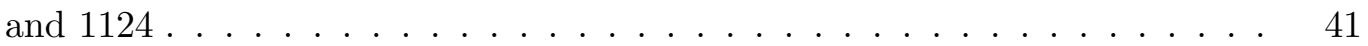

3.5 Results of Silver and Chan method on $\mathrm{SmS}$ arrivals, fixed initial polarization azimuth, STN1096. . . . . . . . . . . . . . . 42

4.1 Results of 1D Poisson's ratio analyses f . . . . . . . . . . . . . . 78

4.2 Estimates of Poisson's ratio from $\mathrm{Pg}$ and $\mathrm{Sg} \ldots \ldots \ldots$. . . . . . . . 81

A.1 Azimuth and Incidence angle for PmP arrivals calculated from particle motion164

B.1 Deconvolved data analysed with the Silver and Chan mehtod . . . . . . 165

B.2 Silver and Chan results on data processed with deconvolution, STN1096 . 166

B.3 Silver and Chan results on data processed with deconvolution, STN1136 . . 166 
CHAPTER 1

\section{INTRODUCTION}

Uplift of continental regions is most commonly linked to, and understood in, collisional zones (Molnar and Lyon-Caen, 1988). Both rock and surface uplift can, however, be observed in regions undergoing extension, geothermal activity and normal faulting, but the mechanism for uplift is not so apparent. The oblique collisional regime forming the rock uplift of the Southern Alps in South Island and domed rock uplift occurring in the extensional regime of North Island makes New Zealand an ideal location to compare and contrast these vertical modes of deformation.

\subsection{Collision}

In compressional tectonic regimes the structure of crustal deformation at depth is often inferred from either surface structures (e.g. Little et al., 2002) or from seismic reflectors and velocity structure (e.g. Meissner, 1986; Kleffmann et al., 1998). The use of seismic anisotropy can elucidate crustal structure at depth, by indicating the orientation of aligned foliation planes (Godfrey et al., 2001; Takanashi et al., 2001) or fluid filled cracks that occur in the top 10-15 km of the crust (Crampin, 1994). Shear wave splitting analysis usually utilizes earthquake sources as these can provide strong impulsive shear wave energy. However, the coverage of the data is limited to the raypath between earthquake and receiver and the coverage of earthquakes is unpredictable. Active source experiments can eliminate this problem as the coverage of the data is controlled. However, the shear waves produced with active source experiments are usually weak and a high fold dataset is required to help reduce this problem. An active source experiment based in Greenland identified seismic anisotropy 
from both waves refracted in the crust $(0.2 \mathrm{~s})$ and compressional waves converted into shear waves at the Moho $(0.15 \mathrm{~s})$ demonstrating that crustal shear wave splitting can be measured from active source experiments (Guest et al., 1993).

Further information about the deformation of the crust may be obtained by examining variations in Poisson's ratio. Poisson's ratio is dependent on the composition of the crust (Christensen, 1996), the presence of fluid, pore fluid pressure (Spencer and Nur, 1976) and also the aspect ratio of the fluid filled pores (Marquis and Hyndman, 1992). Estimates of Poisson's ratio can be obtained by combining compressional and shear wave velocity models for a region, allowing for ray coverage over the same area of crust. Poisson's ratio is often estimated using receiver functions from large earthquakes as both the compressional and shear wave arrival information are derived from the same record. However, as with earthquake shear wave splitting determinations, this method has limited coverage.

In 1996, a high resolution, active source seismic experiment was undertaken across South Island, New Zealand, as part of the South Island GeopHysical Transect project (SIGHT). This high resolution dataset allows detailed imaging of the crustal structure at depth across and adjacent to the obliquely convergent Australian-Pacific Plate boundary (Figure 1.1). Recording of good shear wave seismic data onto three-component stations enables the investigation of crustal shear wave splitting across the Southern Alps. Coincident velocity modelling of compressional and shear wave phases across the plate boundary provide the basis for a 2 D Poisson's ratio estimate, which can highlight variations in crustal lithology and pore fluid pressure.

\subsection{Extension}

Rock uplift over broad regions, not directly associated with compressional tectonics, is often attributed to thermal and/or mantle processes. Information about the magnitude and timing of rock uplift in such regions has been estimated using a variety of methods including tilting of fluvial terraces (Smith and Braile, 1994), sediment stratigraphy (Watts et al., 2000; Williams and Gostin, 2000), vitrinite reflectance (Vågnes and Amundsen, 1993) and dating of volcanics (Pierce and Morgan, 1992; Vågnes and Amundsen, 1993). Many 


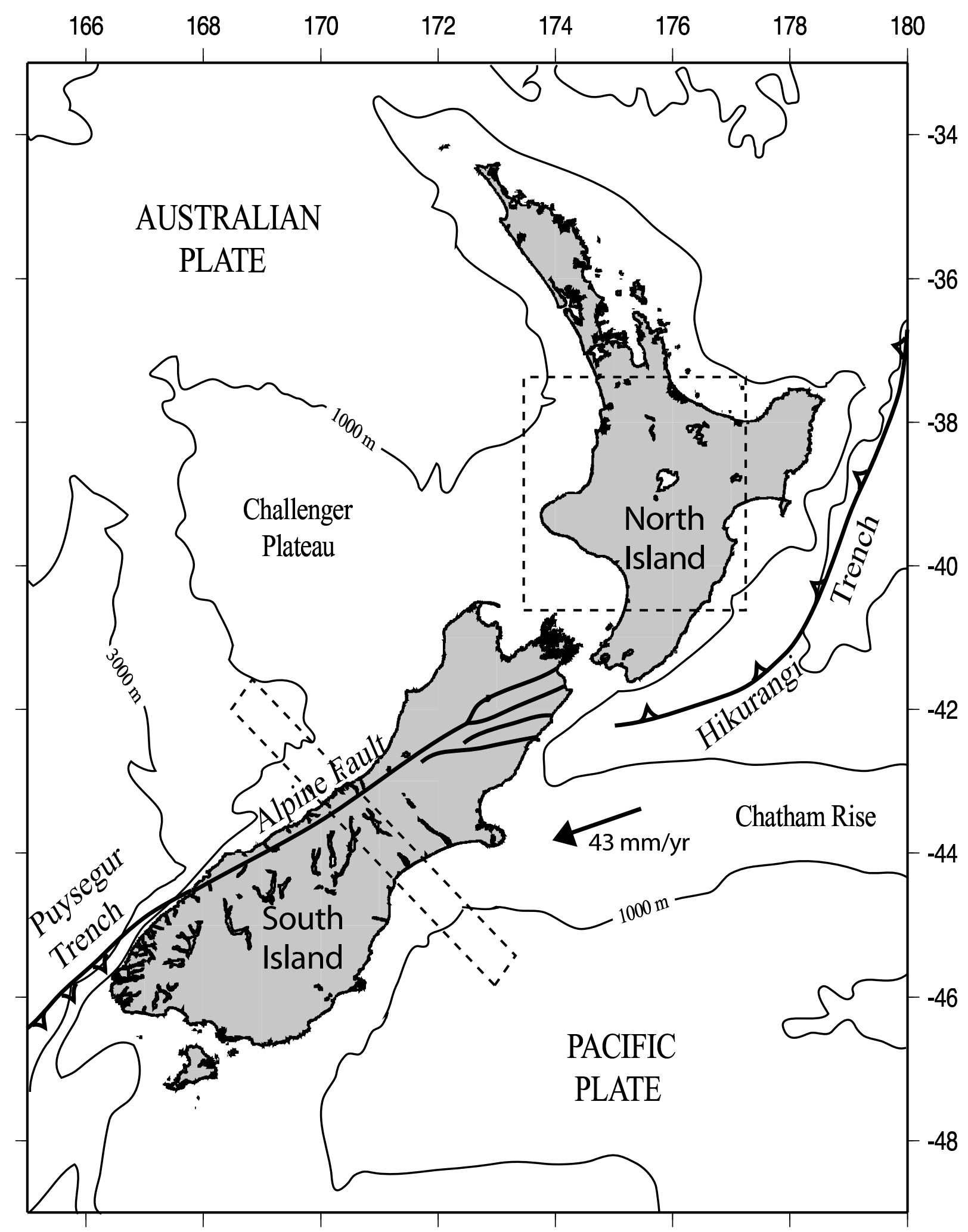

Fig. 1.1 Tectonic layout of New Zealand showing the two study areas of this thesis (outlined with dashed lines). The dashed region in South Island outlines the extent of the seismic coverage used from the 1996 SIGHT project. Exhumation, surface and rock uplift are estimated for the area shown in North Island. The plate boundary between the Australian and Pacific plates is marked by the solid black line. Bathymetry is shown by thin lines at 1000 and $3000 \mathrm{~m}$ depth. 
regions show good constraint on the pattern of rock uplift, however, the source of the uplift is usually poorly constrained. Watts et al. (2000) ascribe the observed rock uplift in England to flexural rebound due to erosion of sediments. Domed uplift on the Snake River plain, in the USA, is attributed to a hotspot and possibly a mantle plume, based on evidence for spatial and temporal progression of volcanism and vertical deformation (Pierce and Morgan, 1992; Smith and Braile, 1994). In Spitsbergen the source of the domed uplift is attributed to an instability in the mantle due to the contact of hot and cold material (Vågnes and Amundsen, 1993).

Indications of rock uplift or surface tilting were first identified in North Island, New Zealand, through tilting of fluvial terraces and lithologic units of the Rangitikei valley (Te Punga, 1952) (Figure 1.2). Raised marine terraces around the coastline of North Island demonstrate rock uplift since at least the Quaternary, at rates of $\sim 0.4 \mathrm{~mm} / \mathrm{yr}$ (e.g. Pillans, 1990a). Exhumation estimates from mudstone porosity analyses describe a dome shape, with increasing exhumation to around $2 \mathrm{~km}$ in central North Island (Stagpoole, 1997; Armstrong et al., 1998).

North Island provides an excellent location to study exhumation and rock uplift in an extensional setting. The cover lithology of North Island is a thick sequence of generally shallow marine strata, which has accumulated over the last $5 \mathrm{Ma}$, exposed above sea level due to the onset of rock uplift. The porosity-depth relationship of the marine strata allow us to estimate the amount of exhumation. Publicly available bore hole stratigraphy data combined with surface sampling of mudstones creates a detailed database over a broad region from which to calculate exhumation (Figure 1.1 shows region of study in North Island). Recent compilation of 1:25 000 topographic $25 \mathrm{~m}$ contour data into a Digital Elevation Model (DEM) of New Zealand has created a good dataset from which to investigate incision erosion and surface uplift.

\subsection{Thesis Outline}

This thesis is divided into two distinct sections. Chapters 2-4 investigate the crustal deformation in central South Island using seismic data recorded as part of the 1996 South 


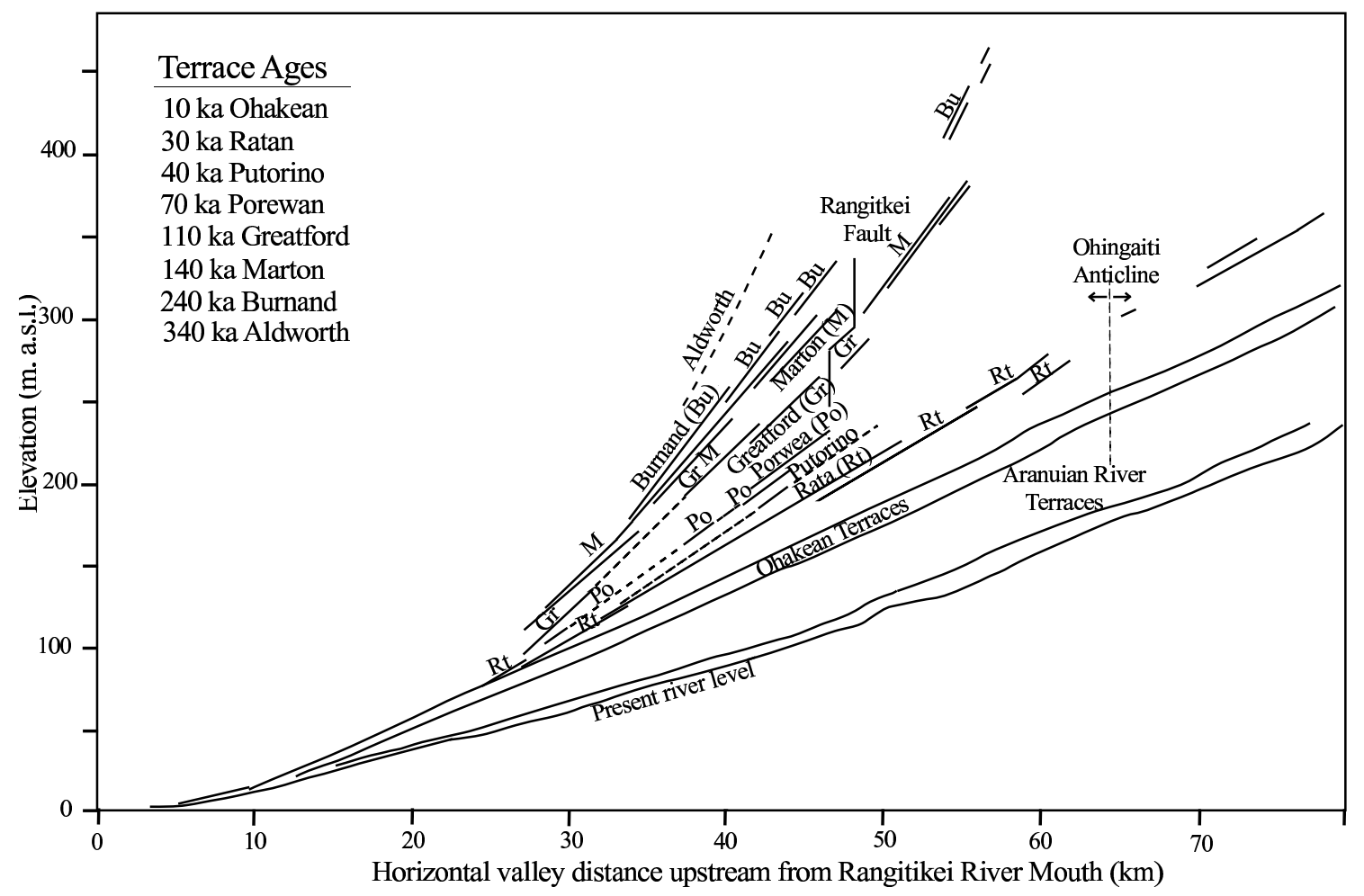

Fig. 1.2 Profile in the downstream direction of the elevation of the fluvial terraces of the Rangitikei River. Figure shows the increase in surface tilt of the terraces with age. The ages of the terraces are minimum reported ages and are sourced from Pillans et al. (1993) for the Ohakean terraces and Pillans (1994) for other terraces. Figure after Milne (1973c).

Island GeopHysical Transect project (SIGHT). An outline of the SIGHT project, the seismic dataset and the tectonic setting of South Island are included in Chapter 2. Shear wave splitting methods are then employed to investigate the component of seismic anisotropy seen in the crust (Chapter 3). Crustal velocity modelling using forward modelling techniques is undertaken to create a $2 \mathrm{D}$ image of compressional and shear wave speeds across South Island. These velocity models are combined to create an image of Poisson's ratio (Chapter 4).

The second half, chapters 5-7, looks at vertical motions of central North Island. Chapter 5 investigates the tectonic setting of North Island and introduces the DEM of New Zealand and how it was created. In the following chapter (Chapter 6) an estimate of exhumation across central North Island is obtained using a porosity-depth relationship for mudstones. These data are combined with the surface morphology to estimate the pattern 
and magnitude of rock uplift. Flexure modelling is then undertaken to calculate the upward forces required to best fit the estimated rock uplift (Chapter 7). Assuming the cause of uplift is due to thermally altered mantle, the extent and depth of the thermal anomaly can be estimated. A secondary model of rock uplift due to the release of coupling along the plate interface resulting in sedimentary basin rebound is also investigated.

Chapter 8 is a summary of the findings of this thesis. 


\section{CRUSTAL STRUCTURE OF THE SOUTHERN ALPS, NEW ZEALAND}

Oblique collision between the Australian and Pacific Plates in South Island has resulted in significant deformation both at the surface and at depth in the crust. To determine the structure of the crustal deformation at depth, seismic methods are employed. Directional changes in shear wave velocity and the relative differences between compressional and shear wave velocities give insight into the structure, composition and fluid pressure in the crust below the Southern Alps.

This chapter provides an introduction into the regional tectonic and geologic regime of South Island, and includes an outline of the seismic experiment, the dataset and what we expect to be able to determine from these data.

\section{$2.1 \quad$ Tectonic and geological background}

South Island lies across the Pacific-Australian Plate boundary where the Chatham Rise is colliding with the Challenger Plateau (Figure 1.1). This collisional boundary is marked by the Alpine Fault, which runs obliquely across South Island. The Alpine Fault has undergone $480 \mathrm{~km}$ of dextral displacement since its inception in the late Oligocene-Early Miocene (Wellman, 1953; Kamp, 1986). Prior to 6.4 Ma, motion along the plate boundary was predominantly strike slip. A change in the pole of rotation resulted in an increased component of convergence between the two plates (Walcott, 1998). This change in the plate motion vector coincides with the postulated timing of rapid uplift of the Southern 
Alps (Tippett and Kamp, 1993).

Since the late Miocene (6.4 Ma), plate motion across the Alpine Fault has resulted in $90 \mathrm{~km}$ of shortening and $230 \mathrm{~km}$ of dextral motion (Walcott, 1998). In the southern part of South Island convergence is being taken up through subduction of the Australian oceanic lithosphere and low intensity deformation distributed over a $200 \mathrm{~km}$ region east of the Alpine Fault. To the north a series of transform faults and over-thrusting accommodates the plate convergence (Walcott, 1998). This study focuses on the central portion of South Island where the deformation occurs along a narrow zone $\sim 50 \mathrm{~km}$ wide at the surface. The compression is predominantly accommodated through uplift along the Alpine Fault. In central South Island the Alpine Fault appears at small scales to be a single, dominantly dextral, strike slip fault. On a scale of $1-10 \mathrm{~km}$ however the fault is a complex series of oblique thrust segments joined by right-lateral sub-vertical faults (Norris and Cooper, 1995)(e.g. Figure 2.1).

The rocks of what is today South Island have undergone at least two phases of uplift and deformation as recorded by the petrography of the rocks. Mesozoic deformation between $80-$ 190 Ma has resulted in uplift of 3-20 km (Tippett and Kamp, 1993). By the mid-Cretaceous, greenschist facies rocks were exposed to erosion in the Otago region (Brown, 1967). Later deformation during the Cenozoic was focused along the Alpine Fault. As a result of collision and high rainfall (and high erosion) on the western side of the Southern Alps the Haast schist in the Pacific Plate margin was, and continues to be, obducted and upturned (Wellman, 1979; Grapes and Watanabe, 1992; Tippett and Kamp, 1993)(Figures 2.2 and 2.3). This uplift and erosion has exposed high grade metamorphic rocks at the surface. The highest grade rocks lie adjacent to the Alpine Fault and are amphibolite grade mylonitic rocks forming a narrow band $1 \mathrm{~km}$ across. This narrow zone of faulted rocks appears from seismic data to increase in width to $\sim 7.5 \mathrm{~km}$ wide at a depth of $25 \mathrm{~km}$ (Kleffmann et al., 1998). The metamorphic grade decreases away from the fault into a band of schist $\sim 20 \mathrm{~km}$ wide (Grapes, 1995) and into meta-sedimentary greywacke rocks further to the east.

Cenozoic deformation recorded by the foliation of the Haast schist is denoted as S3 in Figure 2.2 and is oriented approximately parallel to the strike of the Alpine Fault. The 


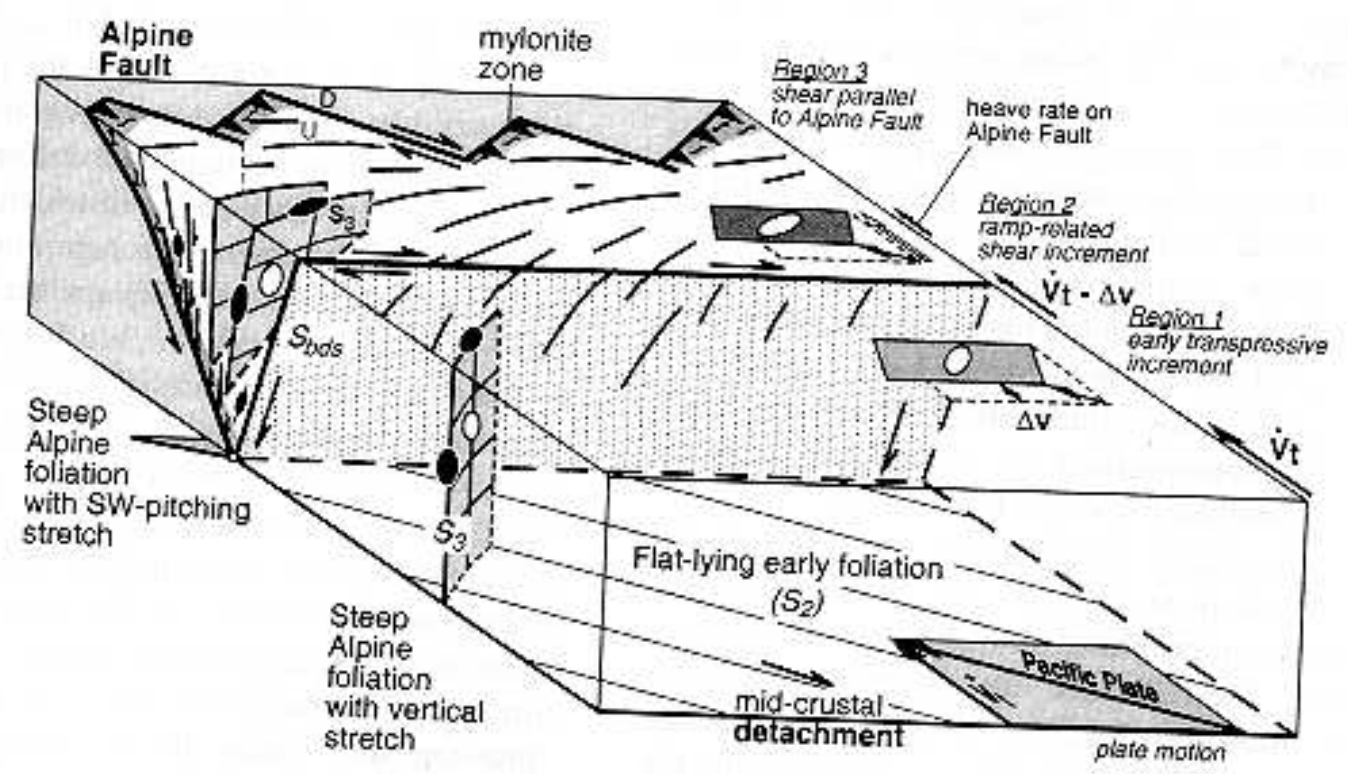

FIG. 2.1 Schematic diagram of the spatial relationship between the deformation phases in Southern Alps. There are several phases of deformation denoted by S2, S3 and Sbds. The phase of deformation recorded by rocks, which passed through the brittle-ductile zone, is Sbds and indicates an escalator style of uplift (shown in Figure 2.2). S2 was an originally subhorizontal phase of deformation, which has been over-printed by Cenozoic deformation (S3), and is recorded by foliation in the Haast schist. This illustrates the complex nature of the crustal structure and it is unknown how these different phases of deformation will influence the anisotropy of the rocks. Figure from Little et al. (2002).

thermal isograds from mineral assemblages in the Haast schist have a vertical to $70 \pm 20^{\circ}$ dip to the east and also strike approximately parallel to the Alpine Fault (Grapes and Watanabe, 1992). The present-day fault zone is near vertical close the surface, but its dip is thought to shallow to $\sim 33^{\circ}$ eastwards at around $25 \mathrm{~km}$ depth (Kleffmann et al., 1998). The earlier Mesozoic phase of deformation (S2) has been refolded by the S3 phase (Figure 2.2).

Below the Southern Alps is thought to be a crustal root, which could mark the turning point of the Pacific crust as it is brought up towards the surface (Kleffmann et al., 1998)(Figure 2.3). This root zone may also be a region where lower crust is removed before the upper crustal rocks are brought up to the surface (Scherwath, Melhuish, Stern and Molnar, 2002). Rocks from the brittle-ductile transition zone at depth have preserved a record of the style of deformation, which they have undergone as they passed through the root zone. These rocks show a foliation direction thought to be responsible for moving blocks of rock up the 


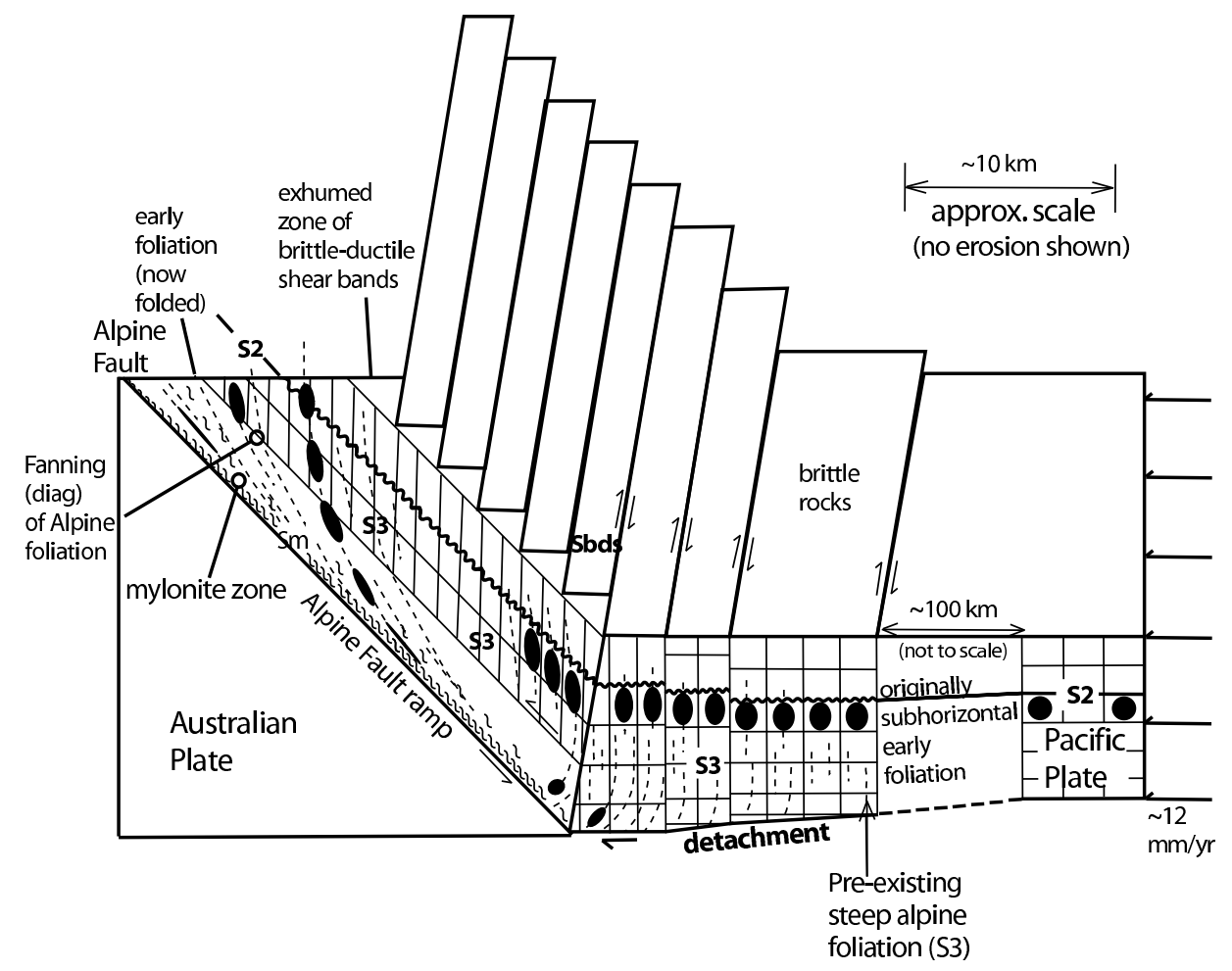

Fig. 2.2 Model of deformation and uplift of the Southern Alps from Little et al. (2002). The phases of deformation S2, S3 and Sbds are the same as those in Figure 2.1.

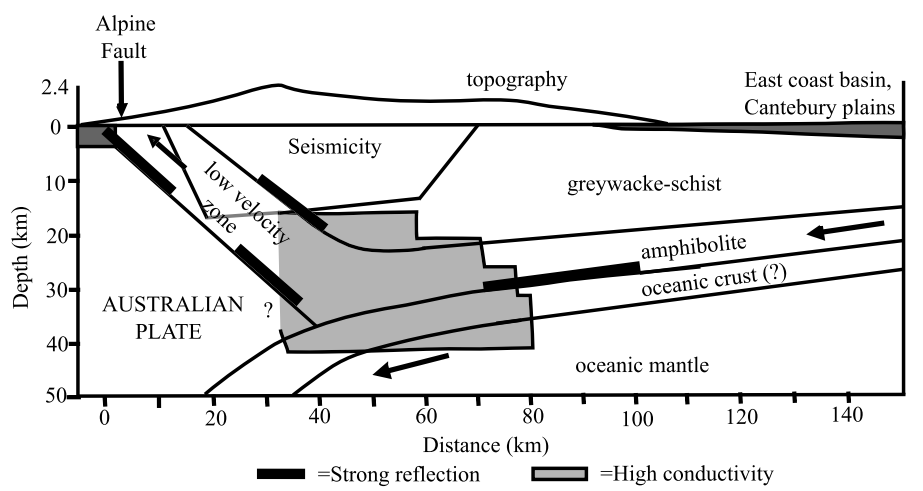

Fig. 2.3 Schematic cross section showing the preliminary interpretation along a deep crustal seismic transect (Transect II of the SIGHT project see Figure 2.5). The grey box denotes the location of the body of high resistivity. From Davey et al. (1998) \& Kleffmann et al. (1998). 


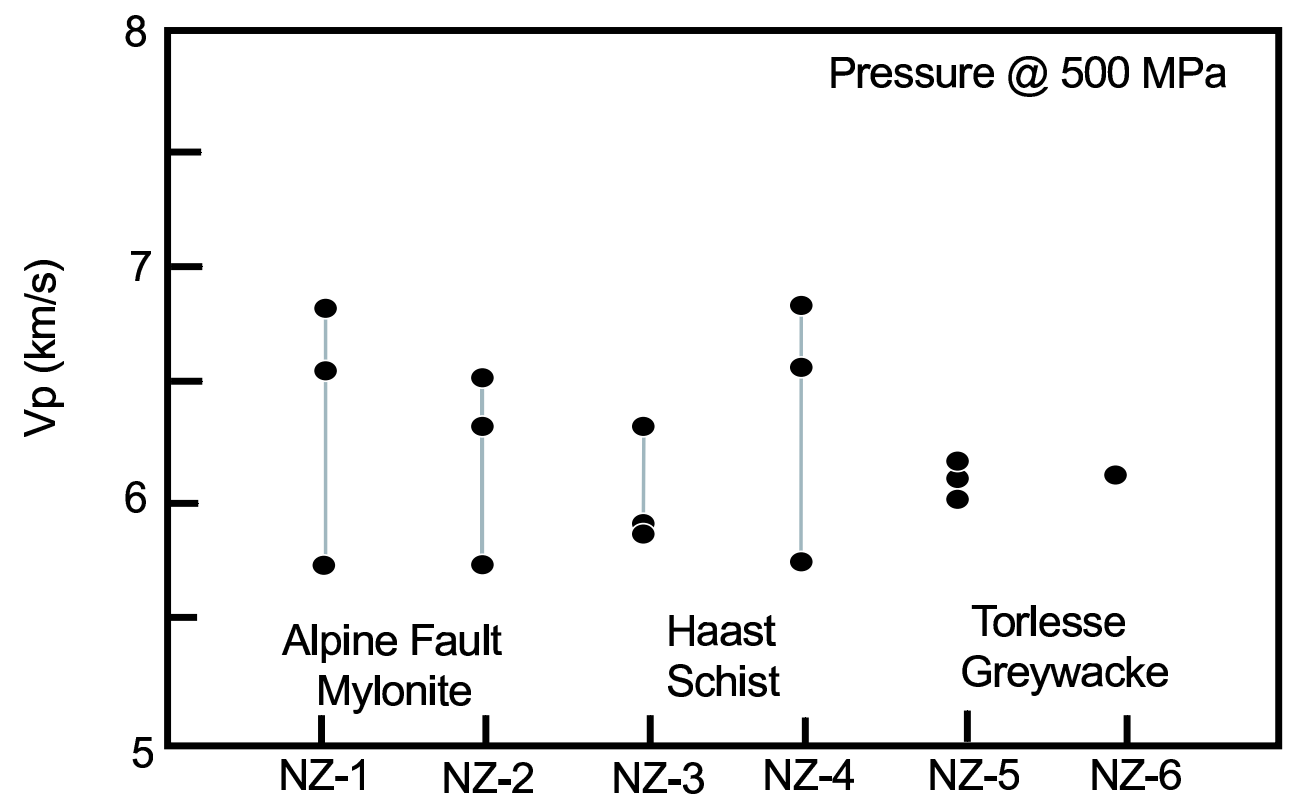

FIG. 2.4 Compressional velocity of 6 rock samples increasing in metamorphic grade from across the Southern Alps, east of the Alpine Fault. The three points for each sample denote the velocities parallel to the axis of symmetry and two directions perpendicular. From Okaya et al. (1995).

'ramp' of the Alpine Fault to the surface. In a similar way to escalator steps, the blocks move upwards but are not rotated (Sbds in Figure 2.2) (Little et al., 2002). This results in most of the deformation occurring within the turning or root zone.

Seismic P-wave anisotropy for rock samples of the Southern Alps, measured in laboratory experiments, indicates anisotropy in the foliated Haast schist and mylonitic rocks while the Torlesse greywacke to the east is isotropic (e.g. Okaya et al., 1995) (Figure 2.4). Laboratorybased shear wave splitting measurements show that splitting is more strongly influenced by the angle of wave polarization to the foliation plane than the degree of metamorphism for rocks of schist and mylonite grade (Godfrey et al., 2001). The rocks of the Southern Alps experienced several phases of deformation (as summarised in Figure 2.2); it is unknown how these different phases will influence the seismic anisotropy. It is expected that most of the anisotropy will originate from the foliation of the anisotropic Haast schist and amphibolite grade rocks. 


\subsection{Dataset}

Three-component data were collected across the Southern Alps of New Zealand as part of the 1996 SIGHT (South Island GeopHysical Transect) project. The dataset used in this study was recorded by 24 three-component REFTEK ${ }^{T M}$ stations, on Transect 1, located across the Southern Alps and 101 vertical component stations extending across the island (Figure 2.5). These stations recorded airgun shots from two lines ranging from both the east and west coasts to $200 \mathrm{~km}$ offshore. This study focuses on data from shots of Line $1 \mathrm{~W}$ (western line of shots), which consisted of 4039 airgun shots let off at intervals of 50 s. Data from Line $1 \mathrm{E}$ were examined but the shear wave arrivals were weak and emergent. This resulted in significant errors in determining the onset of wave phases, and these Line $1 \mathrm{E}$ data were not used in further analyses. Low shear wave energy from the east is likely to result from the greater offset between the shots and the three-component stations.

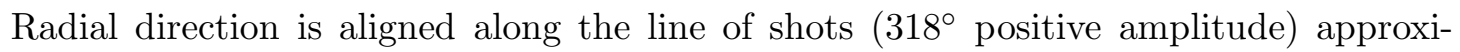
mately perpendicular to the Alpine Fault with transverse parallel to the fault $\left(228^{\circ}\right.$ positive).

Three-component stations were concentrated across the Southern Alps to best image the Alpine Fault Zone. Two three-component stations were situated to the west of the Alpine Fault on the Australian Plate: stations SP16 and SP14 (Figure 2.5). These provide a comparison for waves passing only through the Australian Plate to those that pass through the Alpine Fault zone into the Pacific crust. Stations 1224-1248 lie on the Haast schist and along with stations 1020-1136 are spread across the Southern Alps. Further to the east stations 0924 and 0828 are situated in the foot hills of the Alps on meta-sedimentary greywacke lithology of the Torlesse terrane (Figures $2.5 \& 2.6$ ).

\subsection{Wave phases}

Onshore - offshore data from west coast shots show strong impulsive compressional and moderately strong shear wave arrivals (Figure 2.7). Compressional wave arrivals that are refracted in the crust $(\mathrm{Pg})$ are recorded at all stations from the minimum offset to $\sim 90 \mathrm{~km}$. 


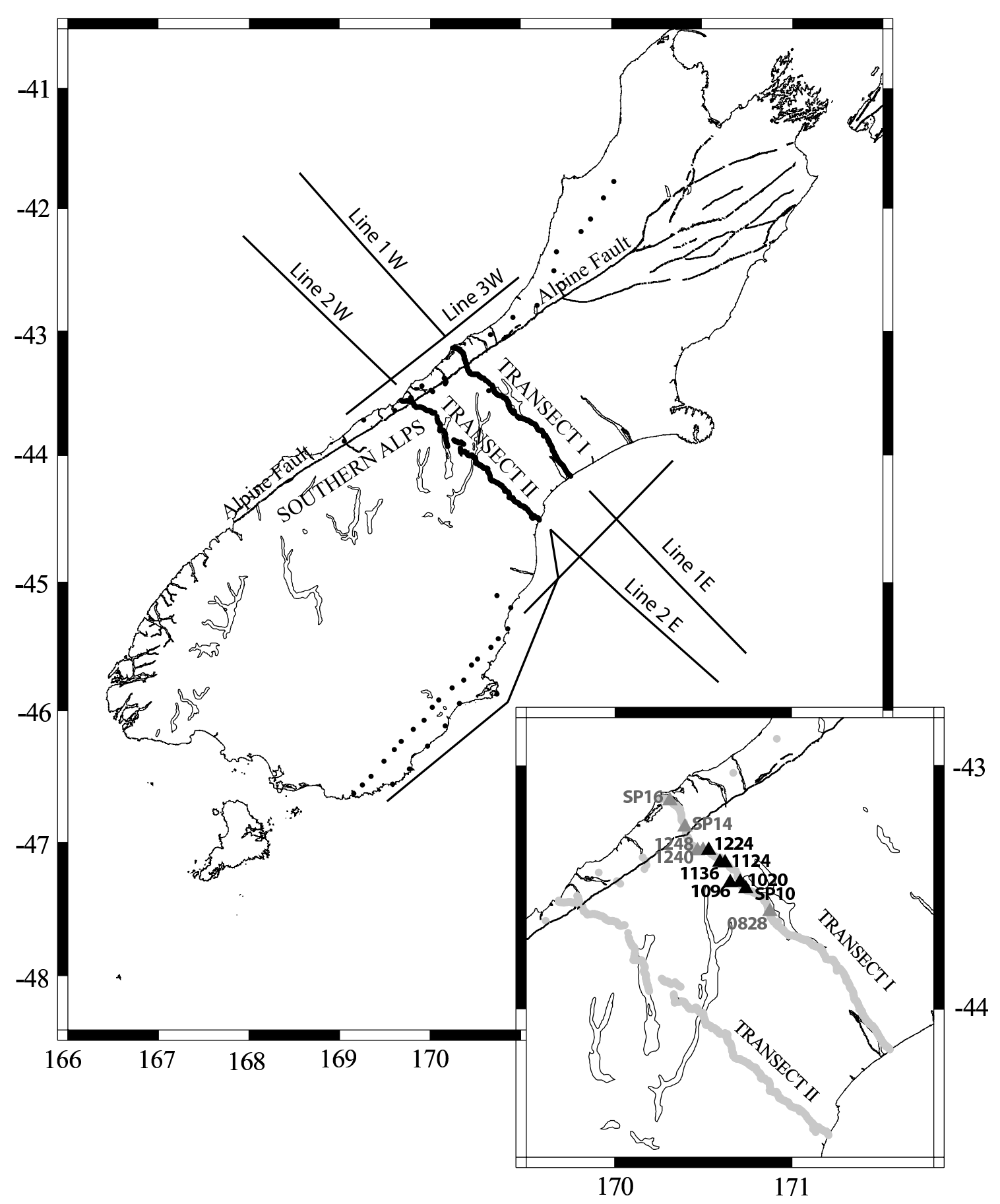

FIG. 2.5 Layout of lines and transects for the 1996 SIGHT Project. The triangle symbols identify the three-component stations along Transect I, the black triangles are those used for anisotropy estimations. 


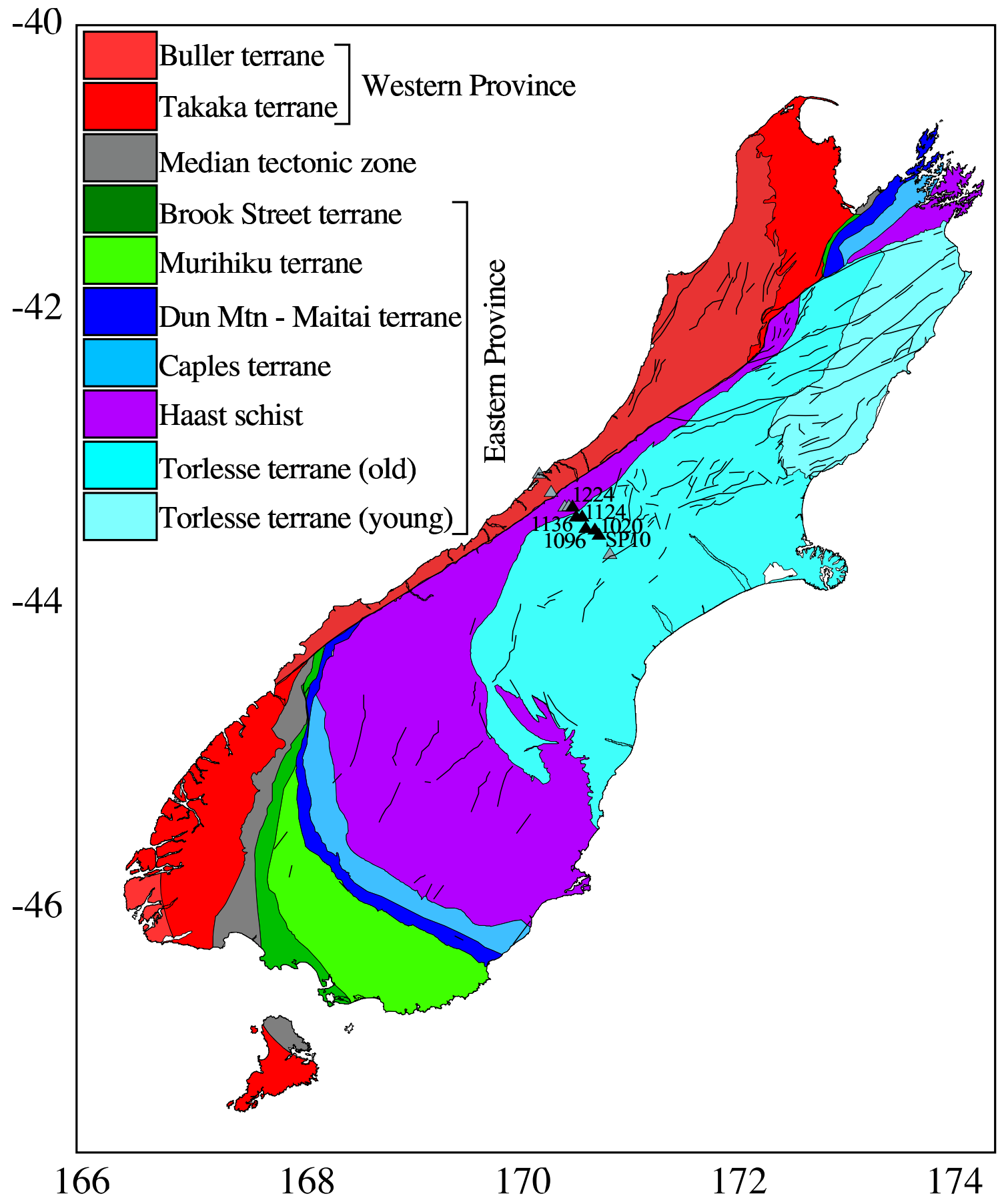

Fig. 2.6 Terrane boundaries of South Island. Three-component stations are marked as triangles. Black triangles are the stations used for anisotropy analysis, others are coloured grey. 
Compressional waves reflected from the Moho $(\mathrm{PmP})$ and lower crustal reflected compressional waves $(\mathrm{PlP})$ were also strong. $\mathrm{PlP}$ arrivals merged with the $\mathrm{PmP}$ at offsets greater than $100 \mathrm{~km}$; at smaller offsets the two phases interfere with each other, and with the coda of $\mathrm{Pg}$, making the signal more emergent and less clear (Figure 2.7). Headwave arrivals from the mantle $(\mathrm{Pn})$ are less impulsive than the other compressional wave phases and are not recorded at all stations. Where they are recorded they show a fast apparent velocity and appear at offsets greater than $110 \mathrm{~km}$.

The shear wave arrivals are not as strong and impulsive as the compressional wave arrivals and are not seen over the same range of offsets. Moho reflected shear waves (SmS) are the strongest S-wave arrivals and are recorded at offsets between $60-100 \mathrm{~km}$ with the most impulsive arrivals at around $75 \mathrm{~km}$ offset. The presence of these strong reflections demonstrate that the Moho provides a strong first order discontinuity under the Southern Alps of New Zealand. Lower crustal shear wave reflections (SlS) are not recorded at most stations although there is a faint SIS arrival recorded on the radial component at station 1124. The SIS phase arrives marginally earlier than SmS. Implications for misidentification for SmS/SlS will be discussed later in the S-wave velocity modelling section. Shear headwave arrivals from the mantle (Sn) were weak or not recorded and have not been used in this study. At larger offsets $(>100 \mathrm{~km})$ a multiple of the PmP phase is identified by its apparent velocity.

The incidence angles of the waves were estimated using the particle motion of PmP arrivals from the three-component stations; allowance was made for free surface effects (for method see Figure 2.8). Incidence angles varied slightly from station to station, showing a range from $4-30^{\circ}$ with the majority of values lying around $21^{\circ}$, within the shear wave window (Table A). The shear wave window is the range of incidence angles that are sufficiently close to vertical that an un-split shear wave arrival will appear to have linear particle motion (e.g. Savage, 1999). 


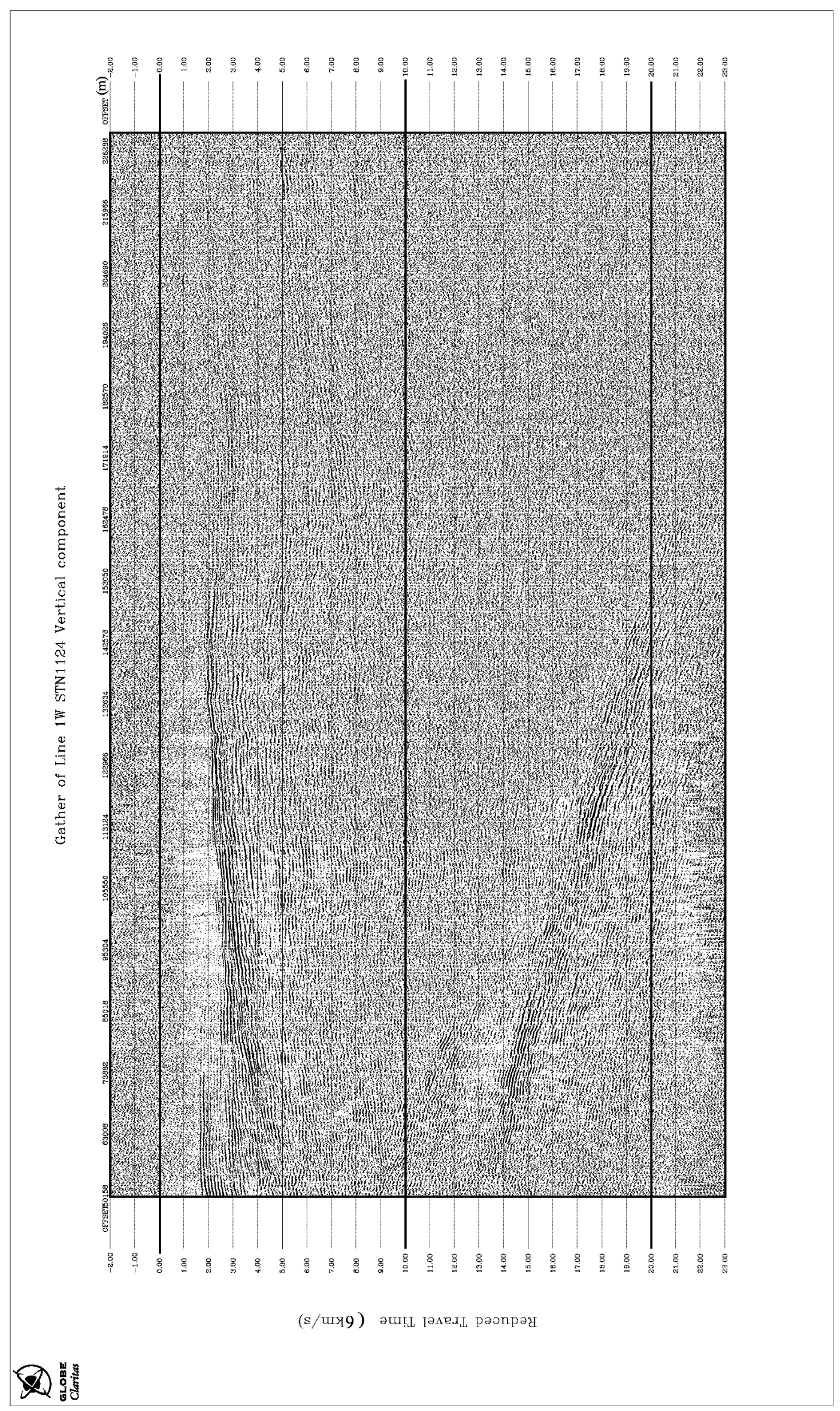




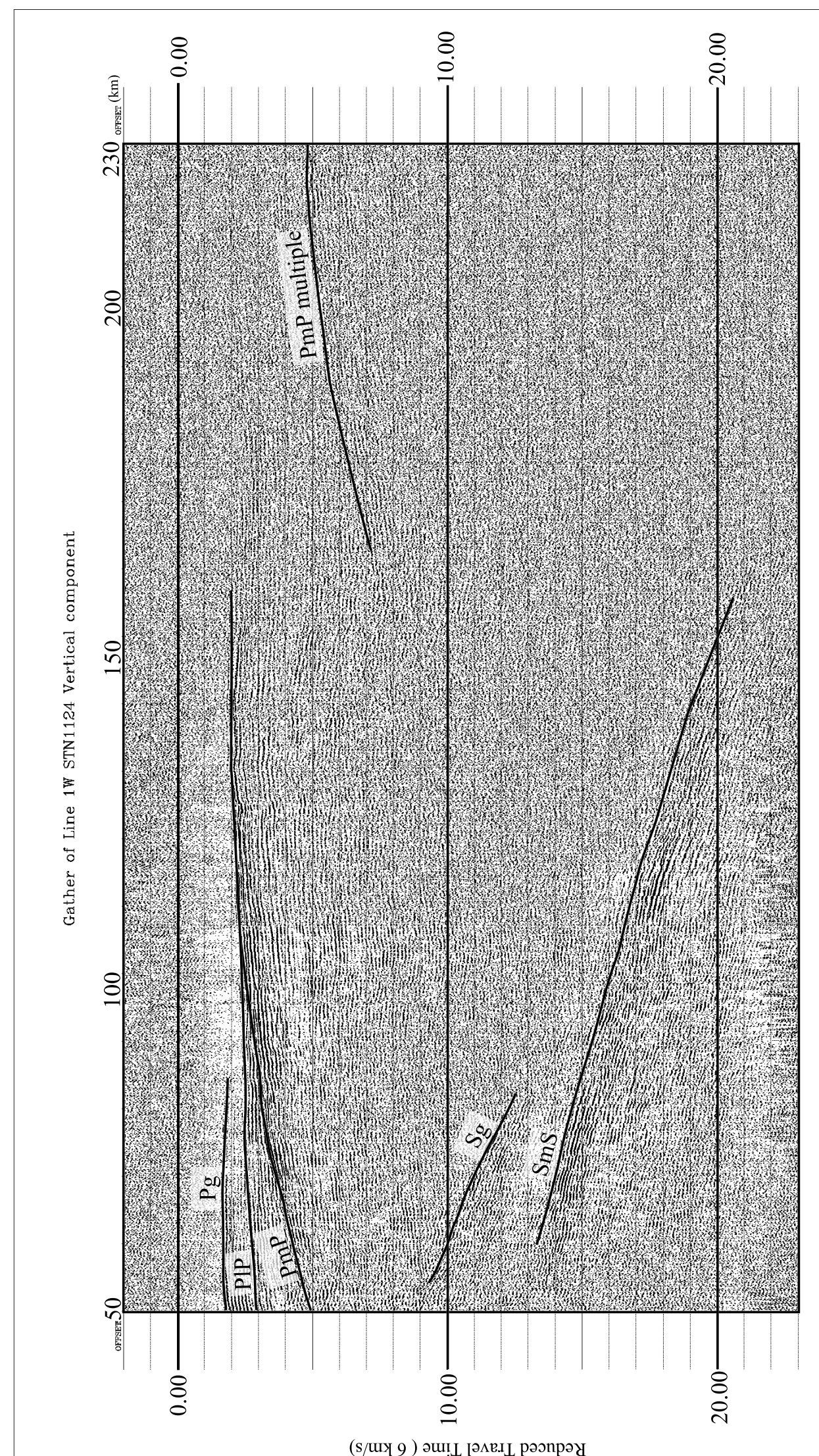

路

Fig. 2.7 Data from station 1124, showing PmP, PIP, SmS, Sg, Pg and a PmP multiple. The data is filtered with an $A G C$ window of $4 \mathrm{~s}$. 
Azimuth

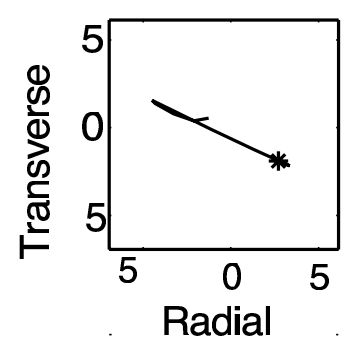

Incidence Angle

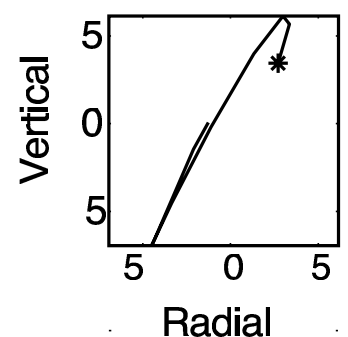

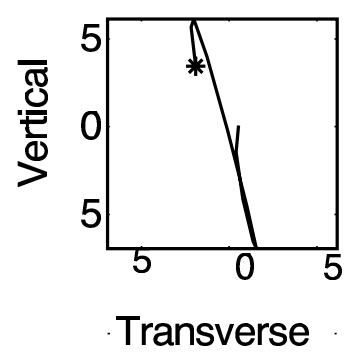

Fig. 2.8 Particle motion of the PmP arrival indicating the azimuth and incidence angle, STN1096 offset 118,991 m. The particle motion of the PmP phase arrival was observed in time increments of $0.1 \mathrm{~s}$, here we show from 12.2-12.4 s. The most linear particle motion was identified and a line was fitted to the data over this time interval. The azimuth of this line on the radial/transverse image gives the azimuth of the in-coming wave. The incidence angle is calculated in the same way, except an allowance was made for the amplification in the vertical direction due to the free surface using a $2 D$ plane wave approximation (see Neuberg and Pointer, 2000). The azimuth and angle of incidence are $335^{\circ}$ and $19.27^{\circ}$ respectively for this trace and average values of $\sim 331 \pm 12^{\circ}$ were obtained from all stations (Table $A$.

\subsection{Basic seismic processing}

Prior to processing, these data showed strong periodic increase in noise with increasing offset for each individual station. This noise may have resulted from climatic or cultural sources and was removed from the data by filtering with a 4-12 $\mathrm{Hz}$ bandpass filter and balancing of the data; balancing scales individual traces by a constant scalar so that the average amplitude of each trace is the same. Balancing does not change the frequency content of the data.

Automatic Gain Control (AGC) was used for presentation of the data and to aid identification of later arrivals. The AGC scales the data over a given time window so that the average amplitude of the data within the window is the same. Here the average amplitude was scaled to a value of 1 over a time window of length $1 \mathrm{~s}$. AGC filtering was not used on the data before either shear wave splitting analysis or picking of first arrivals, as this function changes the frequency content and relative amplitudes of the data.

For S-wave analysis, the data were displayed with a reduced travel time using a linear move-out velocity (of $4.2 \mathrm{~km} / \mathrm{s}$ ). P-wave arrivals were displayed with a $6 \mathrm{~km} / \mathrm{s}$ reduced travel time. Conversion of the data to a reduced travel time of $4.2 \mathrm{~km} / \mathrm{s}$ required a static 
shift of the data, increasing the trace length to $80 \mathrm{~s}$.

Initial analyses were done using single traces, and where the traces show a low signal to noise ratio they were summed to improve the signal.

\subsection{Project aims}

The high resolution dataset including strong shear wave phases enables the investigation of shear wave splitting in the crust. If splitting is detected then this will provide some insight into the orientation of the crustal structure at depth. Good coverage of shear wave arrivals enables detailed velocity modelling of $\mathrm{Sg}$ and $\mathrm{SmS}$ phases from west coast shots. Compressional wave velocity modelling has already been undertaken along Transect I of the SIGHT project by van Avendonk et al. (1999). Ray paths for both the compressional and shear waves cover the same region of crust and allow the estimation of $\mathrm{V}_{p} / \mathrm{V}_{s}$ ratio and more importantly Poisson's ratio underneath the Southern Alps. Poisson's ratio is sensitive to rock composition, pore fluid pressure and aspect ratio of the pores. 
CHAPTER 3

\section{ANISOTROPY UNDER THE SOUTHERN ALPS}

Seismic anisotropy identified by shear wave splitting of SKS phases in New Zealand shows some of the largest delay times seen in the world. The crustal component of this splitting signal is unknown and SKS splitting is often ascribed purely to mineral alignment of the mantle. Shear wave splitting measurement from active source data enable us to investigate the crustal component of splitting and yield information about the deformation at depth under the Southern Alps. Due to the usually weak nature of S-wave arrivals from active source experiments the data were analysed with a suite of techniques to increase the confidence of the results.

\subsection{Anisotropy theory}

Seismic anisotropy occurs when seismic waves travel through a medium that has directional variations in velocity. These velocity variations result from the alignment of minerals, such as olivine crystals in the mantle (Silver and Chan, 1991), pervasive orientations of cracks in the uppermost crust (Crampin, 1994; Miller and Savage, 2001), structural alignment of fault rocks and re-mineralization fabrics (e.g. Okaya et al., 1995).

These rock properties can result in shear wave splitting where shear waves polarized in one direction travel faster than another, even though they have identical ray paths. The polarization of a shear wave that is least hindered, and hence travels the most rapidly, is called the fast direction $(\phi)$. The time lag between the fastest arrival and the slower phase, polarized orthogonally, is the lag or delay time $(\delta \mathrm{t})$. This delay time is dependent on 
the strength of anisotropy in the rock, the length of the ray path through the anisotropic material and also on the orientation of the wave propagation to the mineral symmetry axis.

The initial polarization of a shear wave $(\hat{\phi})$, prior to splitting, is perpendicular to the initial propagation direction of the S-wave; for marine seismic sources it is assumed to be aligned along the back-azimuth from the source to the station and is created at the sea floor in a P-S conversion. The initial S-wave polarization is determined from split shear wave arrivals by removing $\delta$ t from the fast arrival to recreate the waveform before it was split. Shear wave splitting recorded in the Southern Alps from SmS and Sg phases is likely to result from the alignment of minerals and foliation in the schist at depth, although there may be some contribution from near surface cracks.

\subsection{Previous work}

\subsubsection{SKS studies of South Island}

SKS shear wave studies across South Island indicate strong mineral alignment, due to shear in the mantle, adjacent to the plate boundary (Klosko et al., 1999; Audoine et al., 2000). Phase conversion, on leaving the liquid outer core, and near vertical incidence means that recorded SKS shear wave splitting is sourced in the mantle and crust directly below the station (e.g. Savage, 1999). The long wave lengths of these S-waves and the relatively short path length of these waves through the crust indicates that the recorded anisotropy is most likely sourced from the mantle. The crustal contribution to shear wave splitting in New Zealand is unknown. Klosko et al. (1999) determined 0.6-2.2 s delay times under the Southern Alps with the fast directions aligned sub-parallel to the plate boundary over the South Island (Figure 3.1). Long delay times were attributed to strong mineral alignment of olivine crystals from mantle shear in the depth range 40-400 km (Klosko et al., 1999). Recent work focusing on the north of South Island also demonstrates strong shear wave splitting of SKS phases, with alignment of fast directions along the same orientation as seen to the south (Audoine et al., 2000; Audoine, 2002). 


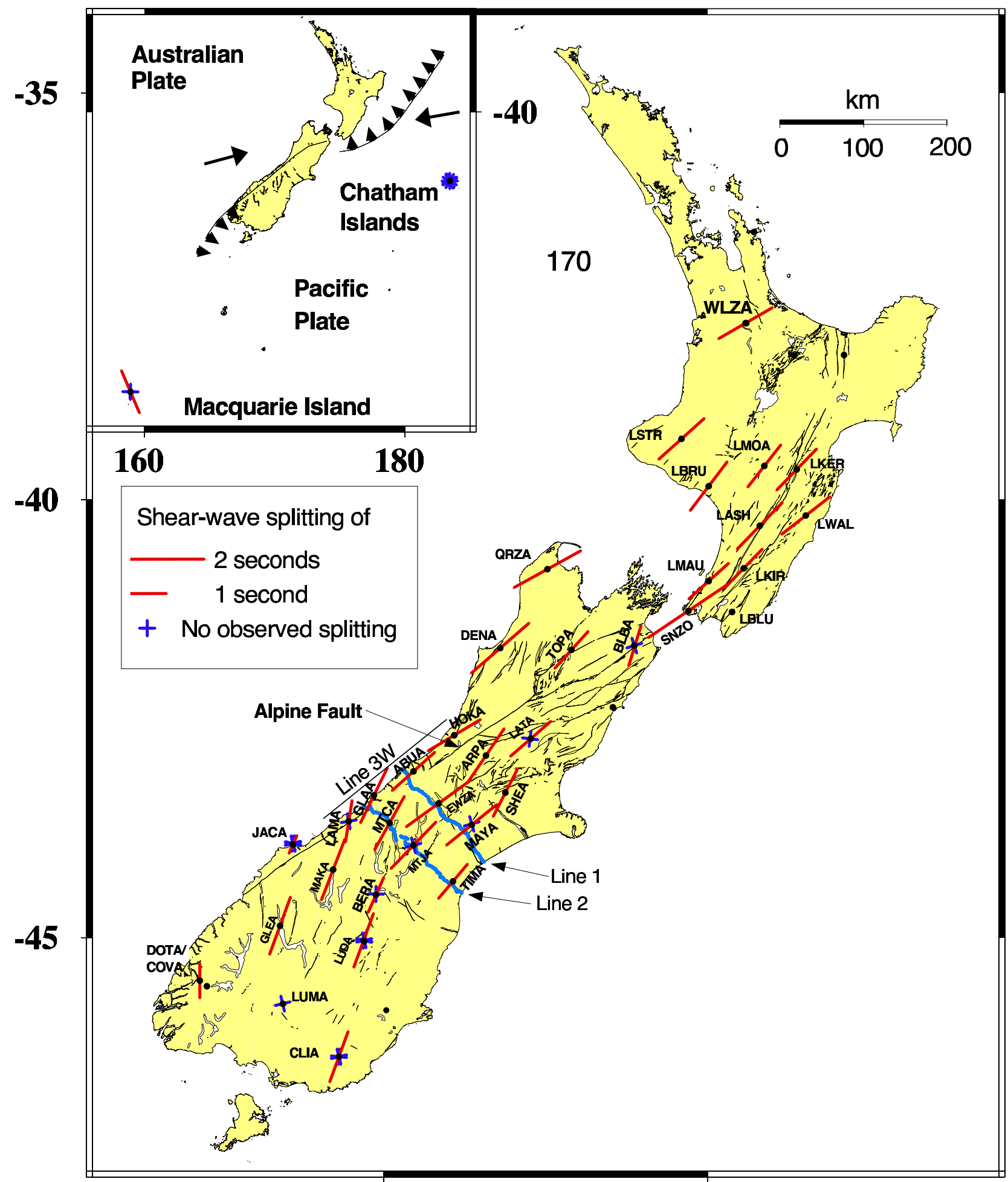

170 175

FIG. 3.1 SKS results from Klosko et al. (1999) and Marson-Pidgeon et al. (1999). The length of the bar indicates the delay time while the orientation indicates the fast direction recorded at the station. Figure from Molnar et al. (1999). 


\subsubsection{Upper mantle anisotropy under the Southern Alps}

Pn arrivals travelling through the upper mantle under the Southern Alps show strong anisotropy of at least $10 \pm 3 \%, 20 \mathrm{~km}$ west of the Alpine Fault. Perpendicular to the Alpine Fault, along SIGHT Transect II, the Pn phases show a speed of $7.8 \mathrm{~km} / \mathrm{s}$ (Scherwath, Melhuish, Stern and Molnar, 2002) while those travelling parallel recorded along Line 3W have a faster speed of $\sim 8.6 \mathrm{~km} / \mathrm{s}$. The existence of anisotropy was initially identified by combining forward and inverse velocity modelling along Transect II and Line 3W (Figure 2.5). Laboratory measurements suggest that to produce a Pn anisotropy of $\geq 10 \%$, some degree of dynamic recrystallization is required (e.g. Ribe, 1992). This strong alignment in the upper mantle may indicate a weak rheology under South Island.

\subsubsection{Laboratory analyses of Haast schist}

Laboratory measurements of surface samples of the Haast schist and mylonitic rocks from the Southern Alps show strong P and S-wave anisotropy (Figures 2.4 \& 3.2) (Okaya et al., 1995; Godfrey et al., 2001). The strength of measured anisotropy and metamorphic grade decreases to the east into the isotropic Torlesse greywacke of the Otago and Canterbury regions (Figure 2.4) (Okaya et al., 1995). Variations in the angle of wave propagation relative to the foliation of the schist have a greater influence on recorded anisotropy, than does metamorphic grade, with speeds varying between $5-7 \mathrm{~km} / \mathrm{s}$ for P-waves and $2.5-4 \mathrm{~km} / \mathrm{s}$ for S-waves (Godfrey et al., 2001).

Laboratory measurements by both Takanashi et al. (2001) and Godfrey et al. (2001) on schist rocks show a singularity where the fast shear wave arrival will change from radially polarized (SV) to transverse $(\mathrm{SH})$ at about $50^{\circ}$ to the axis of symmetry of the schist (Figure 3.2). At this angle no shear wave splitting will be observed. Velocity differences between the two horizontal components create a complex wavefront that cannot be modelled as circular, or even elliptical, in the case of strong mineral alignment (Takanashi et al., 2001). Takanashi et al. (2001) indicate that where there are discrete regions of anisotropy through which the waves pass, there is a strong likelihood of the S-wave signal becoming lost due to the complex form of the wave created each time the wave passes through an anisotropic 


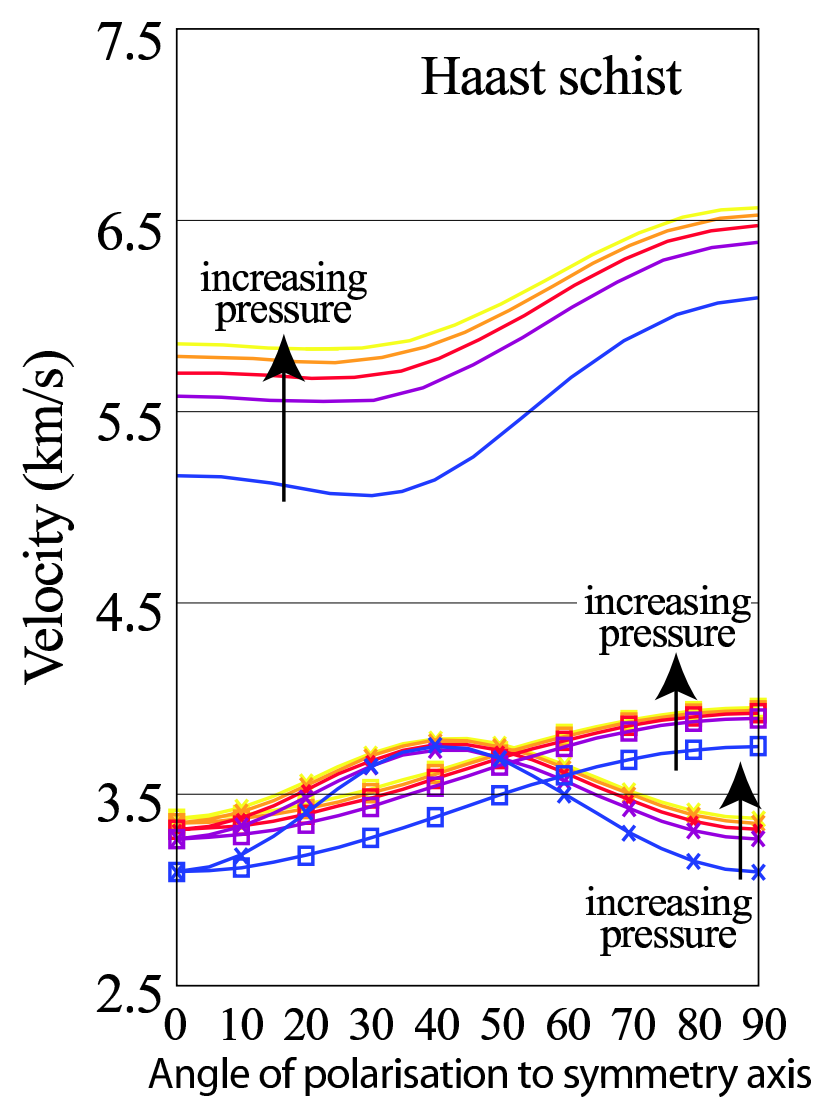

FIG. 3.2 Compressional and shear wave velocity vs angle between polarization and the symmetry axis for the Haast schist. Lines with no symbol are quasi-compressional $\left(q V_{p}\right)$ wave velocities, lines with crosses are quasi-shear wave velocities $\left(q V_{S V}\right)$ and lines with open squares are the true shear wave velocities $\left(V_{S H}\right)$. The colour range is consistent between $P$ and $S$-waves and represents measurements at different pressures, from $1 \mathrm{kbar}$ in blue to $9 \mathrm{kbar}$ in yellow, the lines increment by $2 \mathrm{kbar}$. Note at around $50^{\circ}$ to the axis there is a singularity, where no splitting is observed. Figure from Godfrey et al. (2001).

medium.

For low confining pressures, representing rocks in the near surface, the orientation of cracks may result in anisotropy. But this effect rapidly decreases with depth as the cracks are closed by pressure and mineral alignment becomes the major source of seismic anisotropy (Crampin, 1994; Godfrey et al., 2001). Research by Takanashi et al. (2001) has shown that the strength of alignment of mica minerals has a much greater effect on S-wave anisotropy, whereas crack alignment has a more significant effect on P-wave anisotropy.

Orientation of wave propagation versus mineral alignment will have a significant effect on the amount of shear wave splitting recorded. Line $1 \mathrm{~W}$ recordings are expected to show 
a)

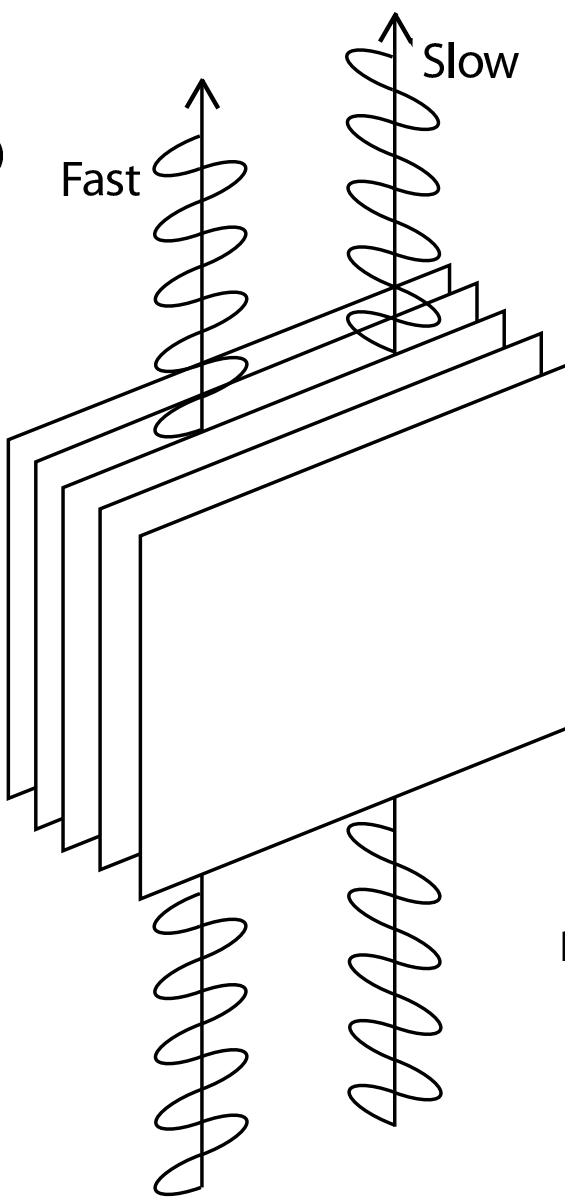

b)

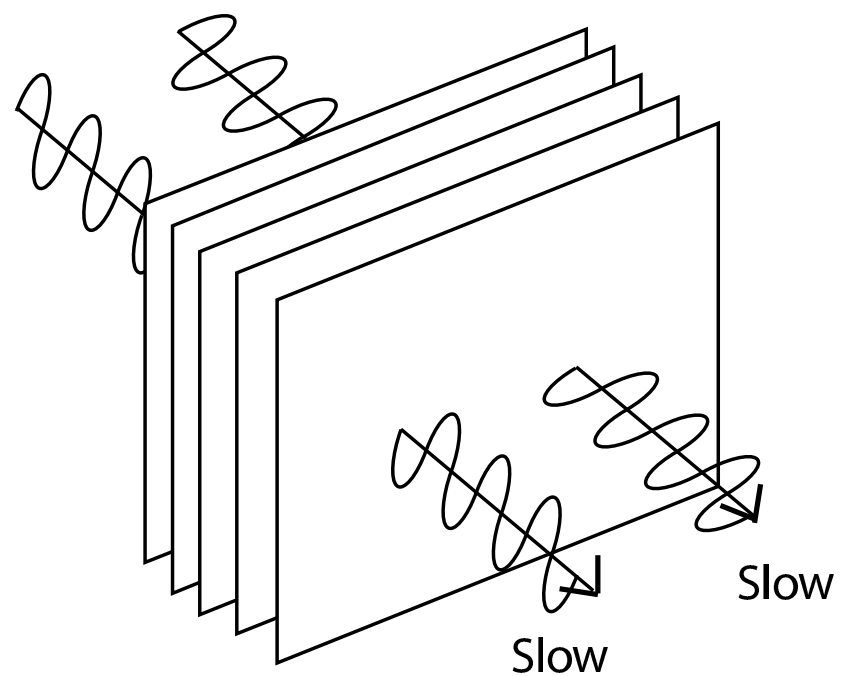

FIG. 3.3 Orientation of schist foliation to $S$-waves in the near surface of the Alpine Fault region. A) Waves from the west coast shots will pass approximately parallel to the foliation of the Alpine Schist as the waves approach the surface, resulting in increasing splitting measurements, B) At depth the waves will pass close to perpendicular to the foliation, resulting in little or no splitting.

little S-wave splitting, as both the radial and transverse components oscillate approximately parallel to the schist foliation at depth. As the waves reflect or refract towards the surface they are oriented close to parallel to the foliation, resulting in shear wave splitting with the fast direction aligned with the transverse component (Figure 3.3).

\subsubsection{Active source crustal shear wave splitting experiment from Green- land}

Crustal S-wave data recorded during a refraction experiment in Greenland identified shear wave splitting with the SH component recorded as the fast direction (Guest et al., 1993). The 
delay between $\mathrm{SH}$ and $\mathrm{SV}$ components was recorded as $\sim 0.2 \mathrm{~s}$, increasing with offset between the source and receivers. The geology of the Greenland shelf varies from basement through volcanic and intrusive rocks and overlying sediments; the area has undergone extension and rifting (Guest et al., 1993). It is the extensional setting, which results in alignment of minerals and cracks, to which the anisotropy is attributed. The Greenland experiment highlights the fact that active source data can identify shear wave splitting, and through these measurements provide information about the crustal structure at depth.

\subsection{Crustal structure under the Southern Alps}

The structure of the Southern Alps is complex with several phases of over-printed deformation (e.g. Figures $2.1 \& 2.2$ ). There are several overlying features that are expected to influence S-wave anisotropy in the crust: these are the main Haast schist foliation, which on a simplistic level is thought to increase in dip eastward close to the Alpine Fault; the vertical shearing, recorded in the brittle-ductile shears, which allows the Alpine Fault rocks to be exhumed towards the surface in a step-like fashion as recorded by the rocks that have passed through the brittle-ductile zone (Little et al., 2002); and finally the earlier phase of deformation, which was originally sub-horizontal, deformed by later uplift and phases of deformation. This early phase is likely to have the least influence on the anisotropy of the rocks as it has been over-printed by later deformation. The Haast schist foliation and the brittle-ductile shears are both close to vertically aligned near the surface and may provide a constructive influence on the anisotropy. However, at depth the dip of the Alpine fault and associated fault rocks is thought to become more horizontal (Kleffmann et al., 1998) while the brittle-ductile shear bands are thought to remain close to vertical (Little et al., 2002). These different dips may result in destructive interference.

\subsection{Origin of the transverse component}

The source of wave energy is purely compressional, originating from airgun shots. Initial motion is expected to be compressional with a radial (SV) component created at the sea 
floor, polarized in the plane of propagation. However, these data show strong transverse component energy in both the $\mathrm{P}$ and S-wave arrivals. There are three possible sources of SH energy (polarized $90^{\circ}$ to SV) (Guest and Thomson, 1992): 1) Lateral inhomogeneities or dipping reflectors, 2) Shear waves may split when they pass through an anisotropic medium, with one orientation hindered more than any other, creating a slow and fast wave oriented according to the alignment of the anisotropy. In many cases this will create a transverse component with energy out of the plane of initial polarization. 3) Through the reflection of the waves off an anisotropic medium, even if the material through which the waves are travelling is isotropic.

$\mathrm{P}$-wave arrivals reflected off the Moho indicate that the $\mathrm{P}$-wave energy is arriving at an azimuth of $\sim 331 \pm 12^{\circ}$, estimated from particle motion diagrams (Figure 2.8, Table A), while the azimuth of the line of shots is $318^{\circ}$. This is a possible indication of shallow dipping reflectors. However, as the dip is minimal this is unlikely to be sufficient to create the strong transverse component seen here.

Therefore the transverse component is more likely to be sourced from either reflection off, or transmission through, an anisotropic body. Pn speeds indicate that the upper mantle is strongly anisotropic directly west of the Southern Alps (Scherwath, Melhuish, Stern and Molnar, 2002). This suggests that for SmS arrivals the transverse component may have originated from reflection of the wave off the Moho. Laboratory measurements of the Haast schist show strong $\mathrm{P}$ and S-wave anisotropy indicating that the transverse component may also be created by the reflection off, or the passage of the waves through, this anisotropic material. Two stations lie to the west of the Alpine Fault and would provide a comparison of arrivals that have not passed through the anisotropic region. However, $\mathrm{Sg}$ is not recorded at these stations and the SmS arrivals are not coherent on either horizontal component. Hence there is no clear evidence for the origin of the transverse component.

If the transverse component is created upon reflection off the Moho, or as a result of the shear waves passing through the Haast schist, then recorded shear wave splitting will be sourced purely on the upward path of the wave.

In this study three-component REFTEK ${ }^{T M}$ stations located along Transect I, across 
the Southern Alps (Figure 2.5), are used to investigate the amount of shear wave splitting from SmS and Sg phases. The delay times and fast directions provide some insight into the component of anisotropy sourced from the crust, from which inferences about crustal structure of the Alpine Fault and Haast schist foliation at depth can be made.

\subsection{Wave Phases}

Shear wave analysis is undertaken primarily using wide angle shear wave reflections from the Moho (SmS) and also S-waves refracted in the crust $(\mathrm{Sg})$. The SmS phases were recorded at the three-component stations over a range of offsets from 70-100 km, with impulsive arrivals between 70-80 km (Figure 2.7). A second region of strong amplitude SmS arrivals, which were only recorded at a few stations, occurs at an offset of $\sim 100 \mathrm{~km}$. However, these were emergent arrivals with the strongest amplitudes up to 1 sec after the start of the S-wave arrival. Sg arrivals were recorded at only a few stations over a range of offsets from 50-70 km. There were no clear $\mathrm{Sn}$ or PmS arrivals recorded at the three-component stations.

\subsection{Data Selection}

Data at each station were divided into the three-components, vertical, radial $\left(\mathrm{Az} 318^{\circ}\right)$ and transverse $\left(\mathrm{Az} 228^{\circ}\right)$ and were stacked by offset using CLARITAS ${ }^{T M}$. Stacked trace plots allow clear identification of the different phases and enable determination of the clearest S-wave arrivals (e.g. Figure 2.7). Data from six of the 24 three-component stations of Transect I were selected for analysis, as they showed clear impulsive SmS arrivals from Line $1 \mathrm{~W}$ shots. Traces at offsets that showed strong impulsive arrivals in the stacked plots were analysed further using single trace shear wave splitting methods (Sections 3.7.2 \& 3.7.3). Selected stations for shear wave splitting analysis were: STNSP10, STN1020, STN1096, STN1124, STN1136 and STN1224 (Figure 2.5). 

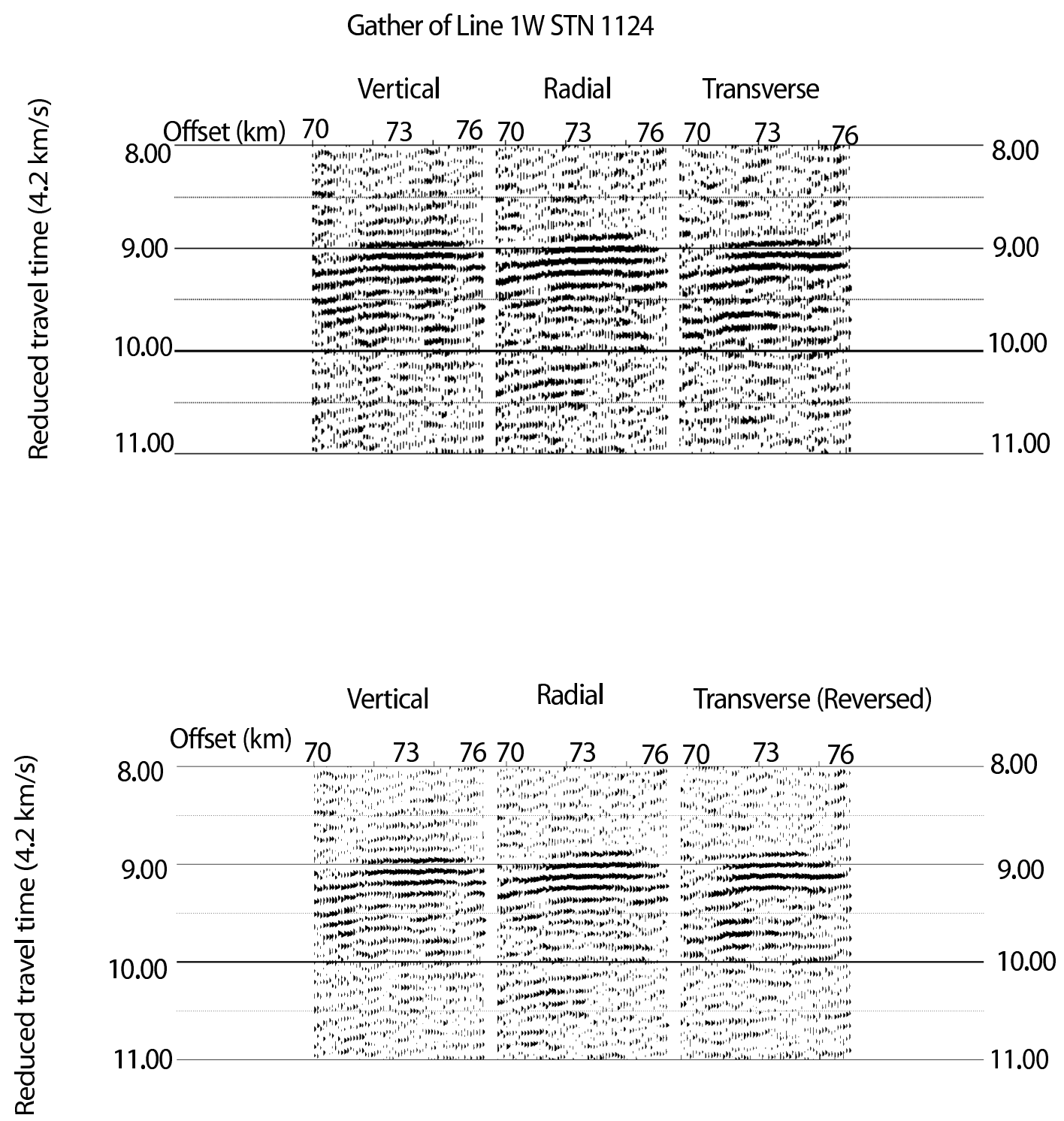

FIG. 3.4 a)Stacked seismic data from ST1096, showing $\operatorname{SmS}$ arrival on the vertical (left), radial $\left(318^{\circ}\right)$ (centre) and transverse $\left(048^{\circ}\right)$ (right) components, b) As above, with the transverse component reversed in polarity. 


\subsection{Anisotropy analysis}

Very few studies have reported crustal shear wave splitting from active source experiments due to the weak, emergent nature of S-wave phases. Three component crustal seismic data from Transect I of the SIGHT project record strong S-wave arrivals over a range of offests and appear ideal for S-wave splitting analysis. However, due to difficulties usually experienced with these data, and the absence of a standard method with which to analyse these short wavelength data, we will employ a range of methods. These include the Silver and Chan (1991) method created for analysis of long wavelength earthquake source phases, cross correlation of stacked seismic data and deconvolution; a method usually used to increase the impulsiveness of stacked active source data.

\subsubsection{Single trace}

Transect I is aligned sub-perpendicular to the Alpine Fault and also approximately perpendicular to the foliation of the anisotropic Haast schist at the surface. If all the anisotropy seen by these shear waves originates from the schist, then it is expected that the radial will be the slow direction and the transverse component will be fast. As the waves approach the surface the radially polarized energy will oscillate across the foliation planes while the transverse component vibrates within the plane of foliation (Figure 3.3). At depth the angle between the wave and foliation plane will be greater, resulting in less splitting (Figure 3.3). We expect to see a combination of these cases with some splitting having the fast direction aligned with the transverse component.

Initially the stacked data for the radial and transverse components were investigated by eye to determine the fast direction and delay time based on the assumption that the fast and slow directions will be oriented in the radial and transverse directions respectively. To estimate the delay time packets of energy rather than the first arrivals were compared, due to the emergent nature of the data (for example the packets of energy on the horizontal components in Figure 3.4 were compared). This gave a delay of $60-90 \mathrm{~ms}$ (maximum $0.25 \%$ anisotropy if splitting occurred only along the upward ray path) with the fast direction aligned with the transverse component (Figure 3.4). These delays are approximately $5 \%$ 
of those seen in SKS analyses in South Island. The delay of 60-90 ms is close to half the period $(\mathrm{T})$ of the data. This indicates that cycle skipping may be occurring due to the emergent nature of the first arrivals. Cycle skipping is where the delay time is mis-correlated by a multiple of half or one cycle of the data; this is often a problem for high frequency data. The data are re-plotted with the transverse component flipped (negative amplitudes filled with black rather than positive); this shows the arrivals on the radial and transverse component are almost synchronous (Figure 3.4).

\subsubsection{Silver and Chan method}

The method of Silver and Chan (1991) was employed to calculate the fast direction and delay time of shear wave splitting in the dataset. This method calculates the covariance matrix of particle motion "corrected" for splitting for all values of $\phi$ and $\delta$ t in increments of 1 degree and 0.05 s respectively. For each possible pairing of $\phi$ and $\delta$ t the delay time is removed from the fast direction to correct for anisotropy (Figure 3.5). The pair of values that yield the most singular covariance matrix is the best result and is denoted in Figure 3.6 as a star. This pair is the one that best corrects for anisotropy and will return the most linear pre-split particle motion. If splitting is present then the recorded particle motion will be either elliptical or cruciform, depending on the length of delay time. Diagnostic plots of the original uncorrected particle motion, corrected particle motion and a contour plot in $\phi-\delta$ t space, show the quality of the result (Figures $3.5 \& 3.6$ ).

Results were compared and graded manually for linearity of corrected particle motion and uniqueness of the solution of the covariance matrix. They were graded into 4 groupings, A-D; A is a good fit and D poor. Only the A and B grade results were analysed further.

Initial analyses were undertaken using single traces, however, due to the low signal to noise ratio of the data, further analyses were undertaken using five adjacent traces summed together (Figure 3.9).

The results of the Silver and Chan (1991) method show variations in $\hat{\phi}$ and $\delta \mathrm{t}$ (Figures 3.7 $\& 3.8$, Table 3.1). Figure 3.6a shows the ambiguous nature of the $\phi$ result, with a broad $95 \%$ confidence interval and several minima, and highlights the possibility of cycle skipping when 
STN1124 Trace Offset 76892

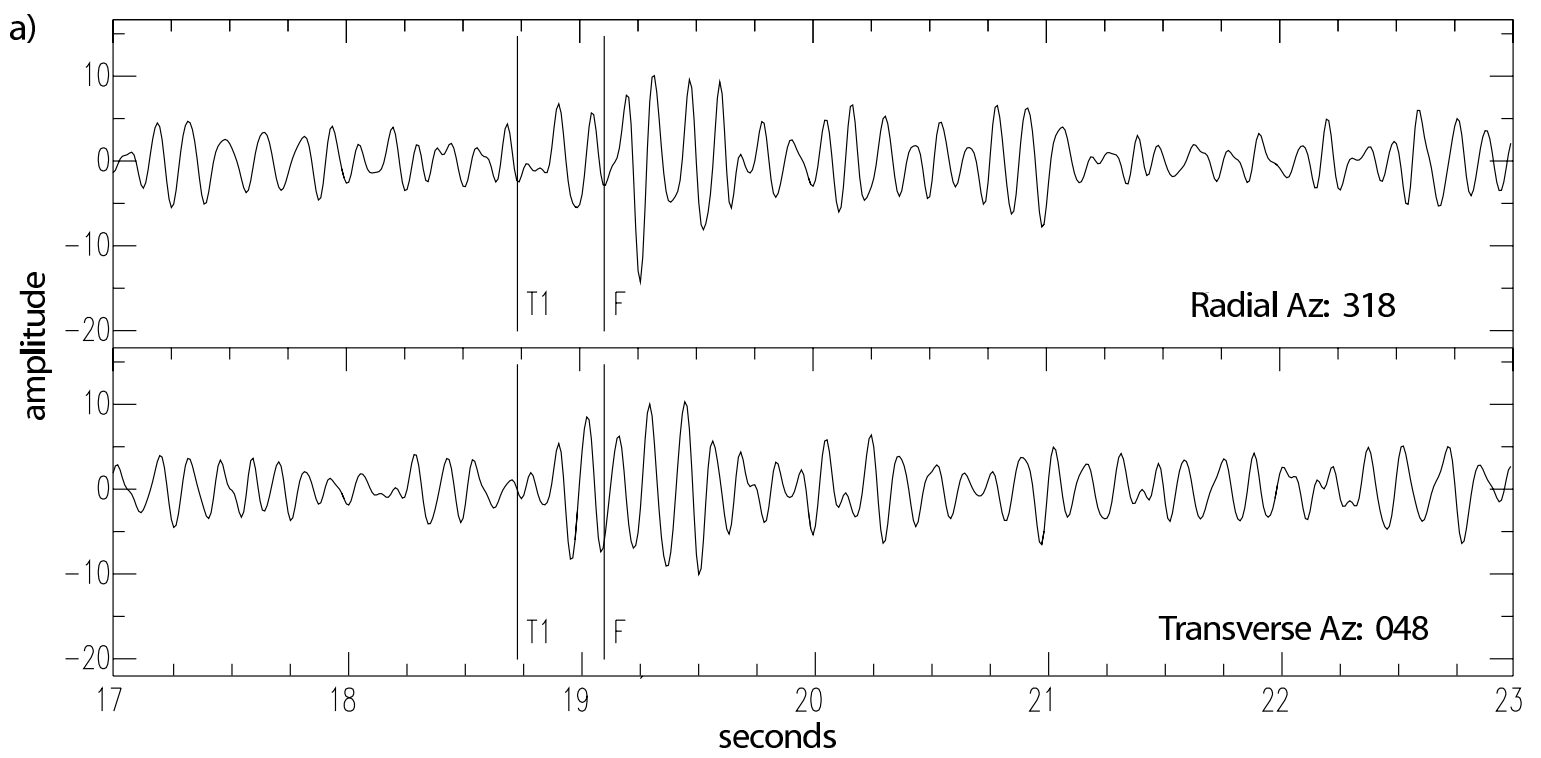

b)

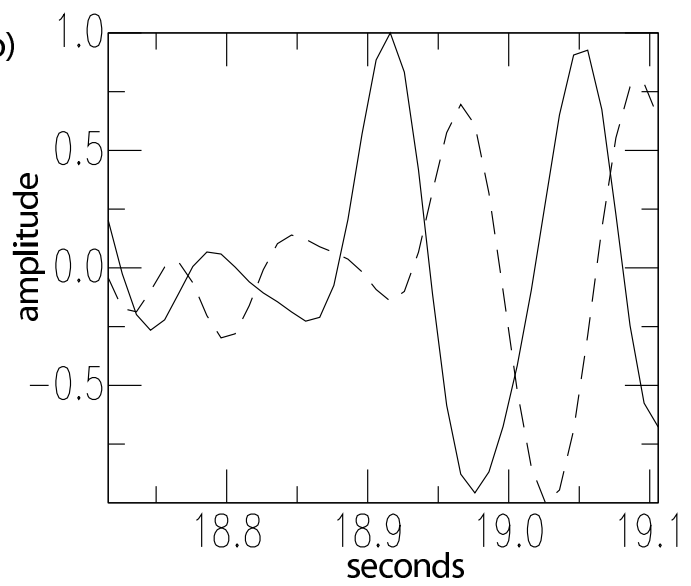

c)

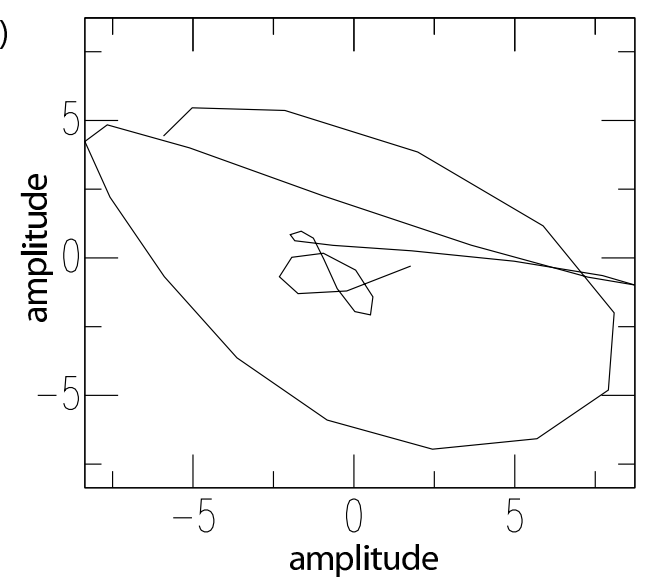

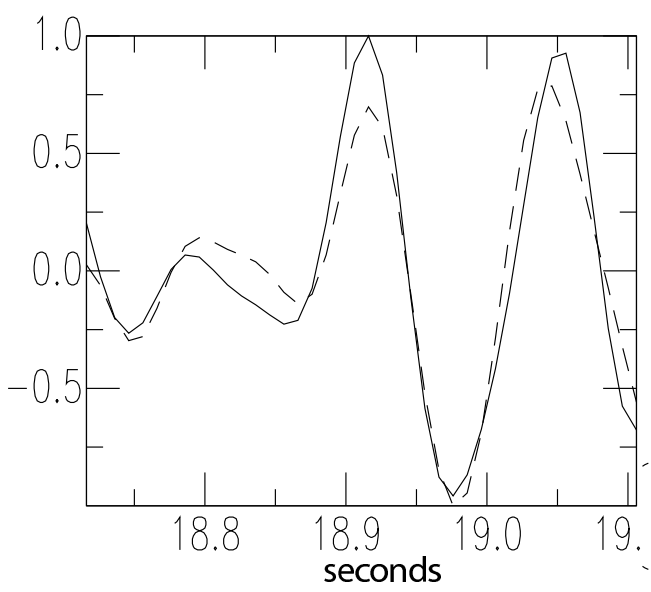

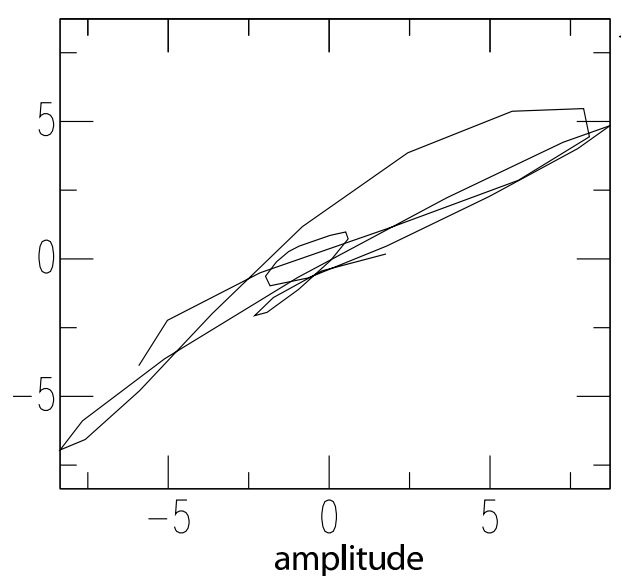

FIG. 3.5 a) SmS arrival, trace offset $76892 \mathrm{~m}$, station 1124, b) waveforms within $\mathrm{T} 1$ and $F$ lines (Figure a) rotated into the fast and slow directions before (left) and after (right) correction for splitting, c) particle motion diagram for the waveforms shown in (b) before (left) and after (right) calculated shear wave splitting is removed from the data. 

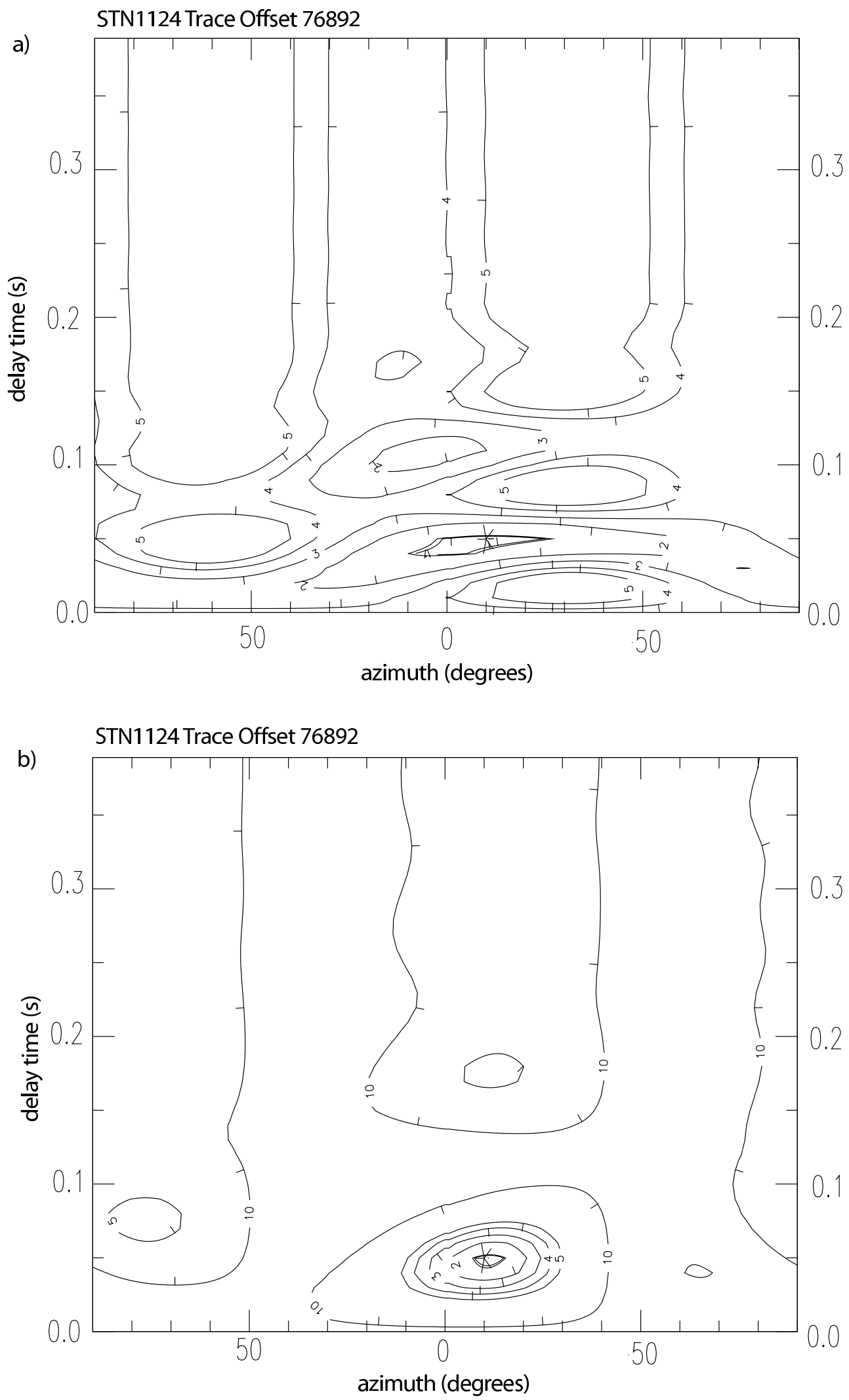

Fig. 3.6 a) Contour plot of the confidence of result from Silver and Chan (1991). The best fit $\phi$ and $\delta t$ are shown with a star and the $95 \%$ confidence interval is shown by a double contour. b) as above with the initial polarization direction oriented to radial $\left(318^{\circ}\right)$. The azimuth is the fast direction azimuth. 


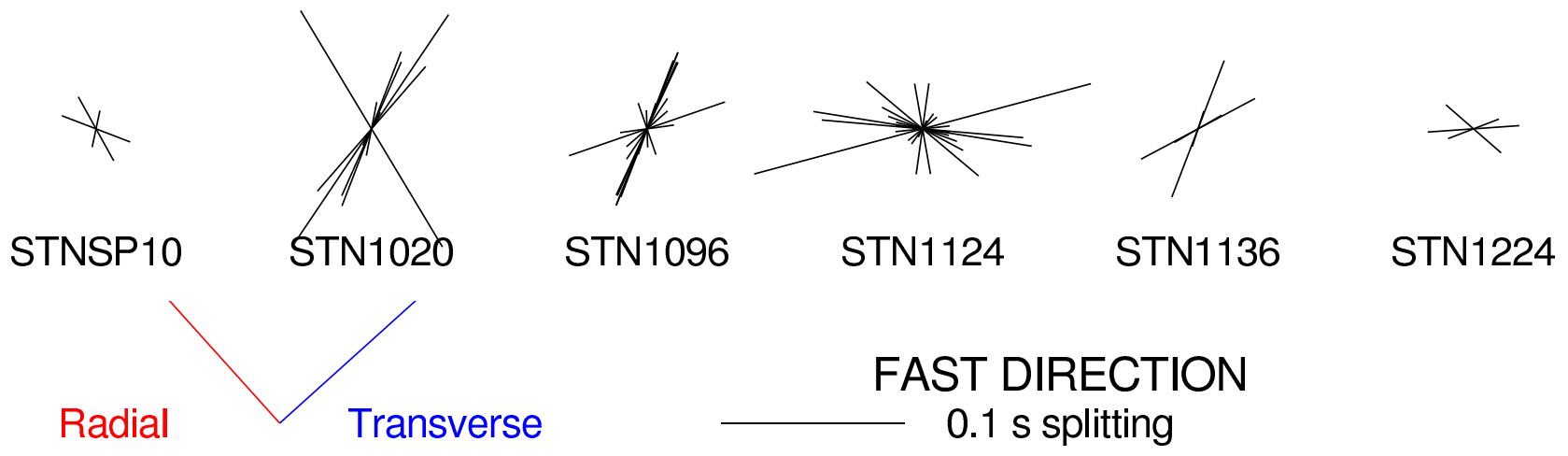

Fig. 3.7 Fast orientations from the Silver and Chan (1991) method. Only A results of Table 3.1 are displayed.

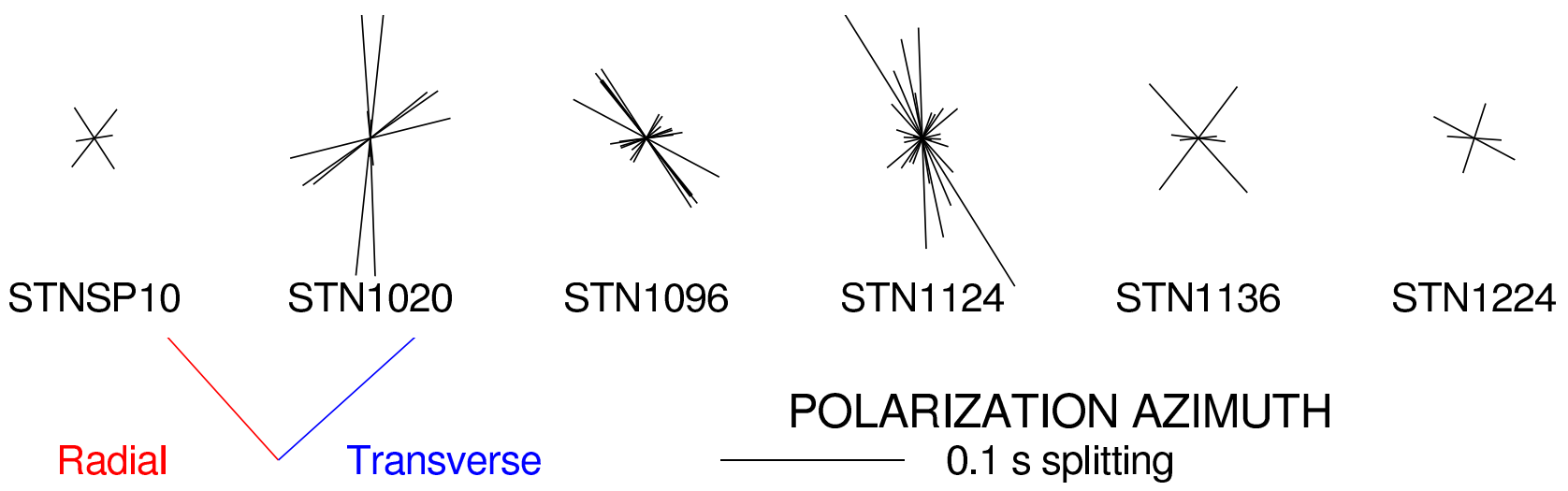

FIG. 3.8 Initial polarization azimuth from the Silver and Chan (1991) method. Only A results of Table 3.1 are displayed.

calculating the delay time. Inconsistent results at each station indicate there maybe either cycle skipping, or this method is not suitable for emergent active source data. At STN1096 there are consistent results for values calculated from five traces summed. However, for much of the data the widely varying initial polarization values suggest scattering in the near surface, most likely in response to randomly oriented cracks in the near surface.

\subsubsection{Controlling the initial polarization}

Further analyses were made using a variation on the Silver and Chan (1991) method where the initial polarization is set manually. The assumption was made that the initial polarization direction of the incoming wave would be aligned with the radial direction along the line from the shots to the stations. P-wave arrivals reflected off the Moho show a back 


\begin{tabular}{|l|l|l|l|r|}
\hline Offset $(\mathrm{m})$ & $\phi\left(^{\circ}\right)$ & $\delta \mathrm{t}(\mathrm{s})$ & $\hat{\phi}\left(^{\circ}\right)$ & no. traces \\
\hline STN 1020 \\
\hline 84557 & 028 & 0.02 & 003 & 1 \\
84502 & 011 & 0.03 & 354 & 1 \\
84666 & 021 & 0.09 & 055 & 1 \\
84823 & 034 & 0.15 & 356 & 1 \\
85040 & 024 & 0.08 & 051 & 1 \\
86840 & 041 & 0.09 & 076 & 1 \\
83304 & 329 & 0.15 & 006 & 1 \\
\hline
\end{tabular}

\begin{tabular}{|l|l|l|l|l|}
\hline \multicolumn{2}{|l|}{ STN 1096 } \\
\hline 75029 & 082 & 0.03 & 028 & 1 \\
75549 & 023 & 0.03 & 073 & 1 \\
76017 & 071 & 0.09 & 298 & 1 \\
77032 & 049 & 0.03 & 083 & 1 \\
77520 & 358 & 0.02 & 051 & 1 \\
72824 & 034 & 0.04 & 081 & 5 \\
74451 & 341 & 0.03 & 036 & 5 \\
75235 & 019 & 0.03 & 069 & 5 \\
76844 & 022 & 0.09 & 322 & 5 \\
77121 & 022 & 0.09 & 327 & 5 \\
77385 & 021 & 0.08 & 321 & 5 \\
77945 & 024 & 0.08 & 322 & 5 \\
78217 & 025 & 0.08 & 323 & 5 \\
\hline
\end{tabular}

\begin{tabular}{|l|l|l|l|l|}
\hline \multicolumn{2}{|l|}{ STN 1124 } \\
\hline 71521 & 310 & 0.08 & 337 & 1 \\
73248 & 278 & 0.03 & 288 & 1 \\
79017 & 036 & 0.02 & 273 & 1 \\
80010 & 051 & 0.02 & 077 & 1 \\
83038 & 027 & 0.01 & 282 & 1 \\
74754 & 279 & 0.12 & 358 & 5 \\
75524 & 298 & 0.05 & 050 & 5 \\
76892 & 350 & 0.05 & 318 & 5 \\
79398 & 084 & 0.03 & 020 & 5 \\
82754 & 075 & 0.19 & 328 & 5 \\
113661 & 008 & 0.05 & 351 & 5 \\
114392 & 275 & 0.11 & 348 & 5 \\
119132 & 284 & 0.03 & 028 & 5 \\
119367 & 290 & 0.04 & 035 & 5 \\
\hline
\end{tabular}

TABLE 3.1

Shear wave splitting parameters calculated using the Silver and Chan (1991) method on SmS phases, $A$ and $B$ quality result only are tabulated above. $\phi$ is the fast direction, $\delta t$ is the delay time, $\hat{\phi}$ is the initial polarization azimuth.

Results are for either single trace data or for traces that are a sum of five adjacent traces. Note that radial component is oriented $318^{\circ}$, and the polarization azimuth from $P$-wave arrivals is $334^{\circ}$. 
a)

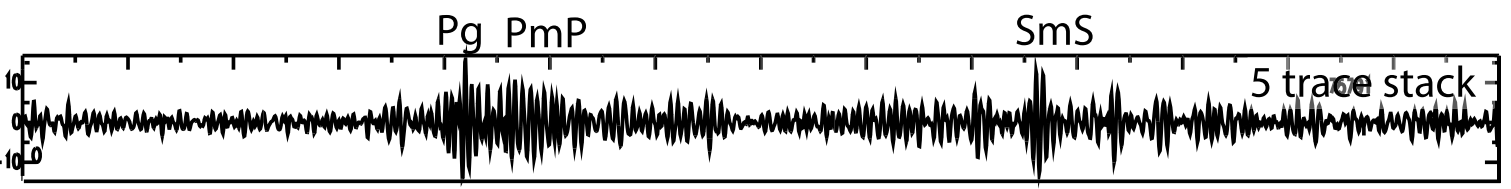

b)

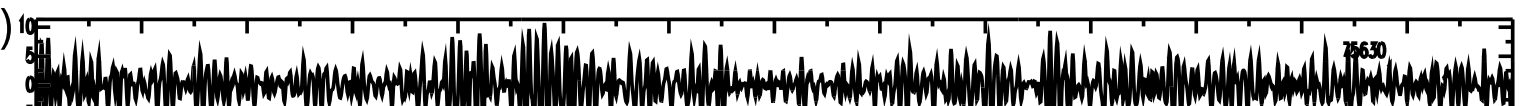

(․․

을 C

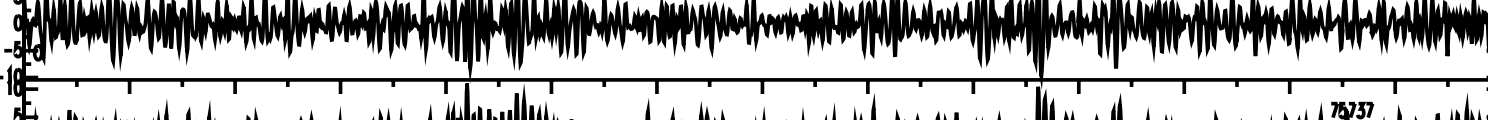

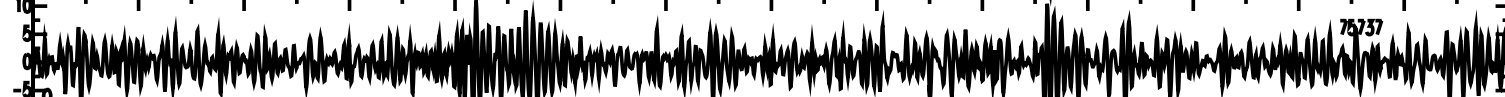

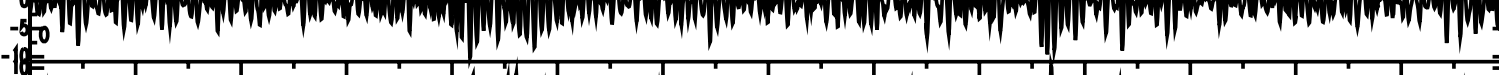
of

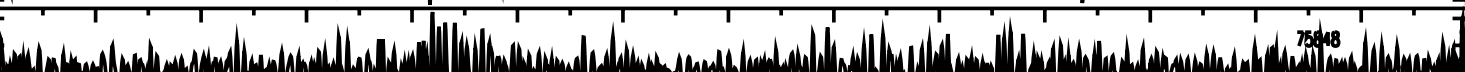
-
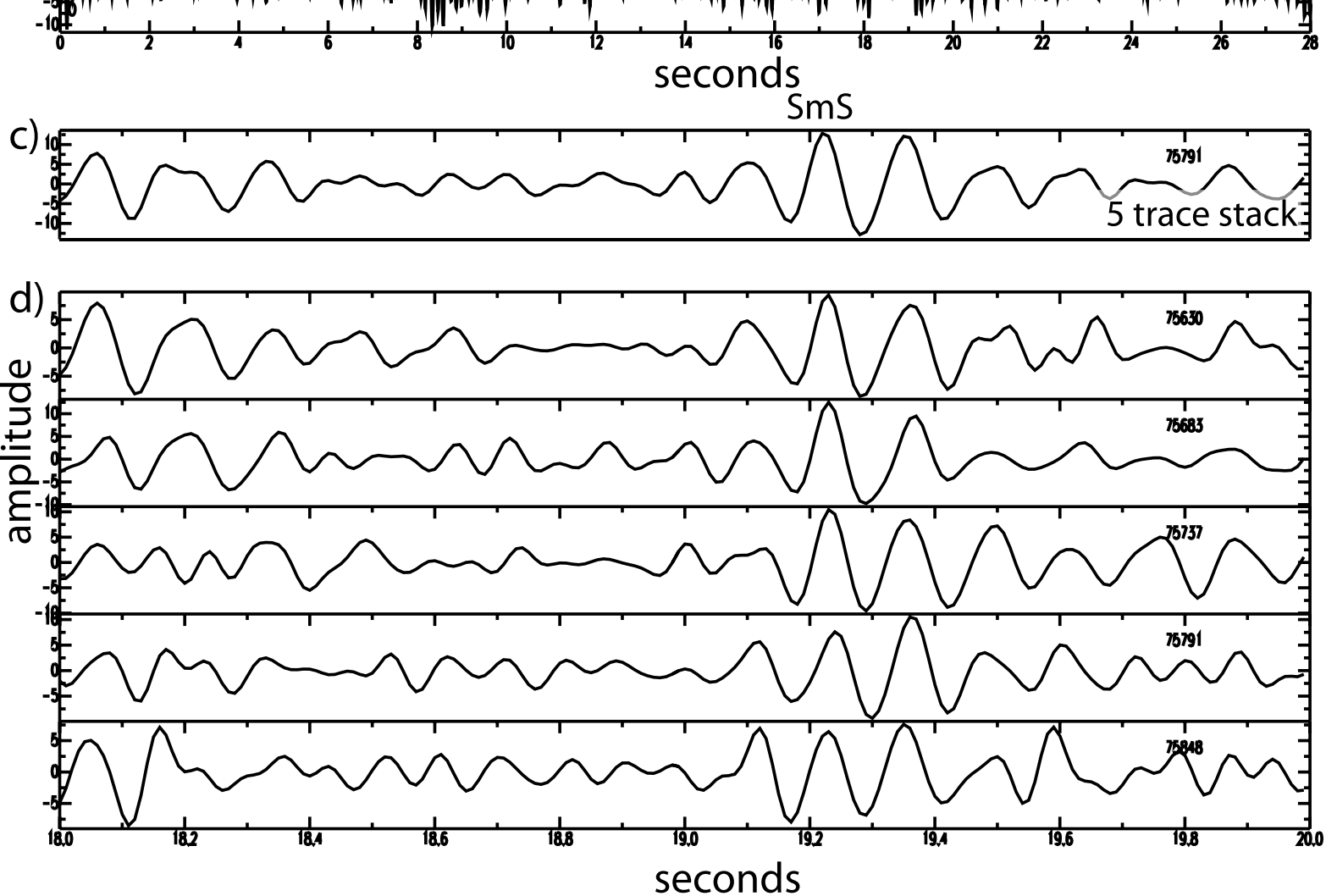

FIG. 3.9 a) Trace produced by stacking the 5 traces in (b) together. Note there is an improvement in signal to noise ratio but little change in the impulsiveness of the waveform. Figure c) is a sample of the 5 summed traces focusing around the $\mathrm{SmS}$ arrival d) is the 5 traces summed to create c). The data are recorded on the radial component, station 1124 . 


\begin{tabular}{|l|r|r|r|r|}
\hline Offset $(\mathrm{m})$ & $\phi\left(^{\circ}\right)$ & $\delta \mathrm{t}(\mathrm{s})$ & $\hat{\phi}\left(^{\circ}\right)$ & no. traces \\
\hline \multicolumn{4}{|l|}{ STN SP10 } \\
\hline 87492 & 291 & 0.04 & 327 & 5 \\
88267 & 331 & 0.04 & 038 & 5 \\
88536 & 012 & 0.02 & 081 & 5 \\
\hline
\end{tabular}

\begin{tabular}{|l|l|l|l|l|}
\hline \multicolumn{4}{|l|}{ STN 1136 } \\
\hline 76844 & 060 & 0.03 & 277 & 5 \\
77945 & 021 & 0.08 & 318 & 5 \\
78217 & 018 & 0.02 & 084 & 5 \\
81686 & 062 & 0.07 & 037 & 5 \\
\hline
\end{tabular}

\begin{tabular}{|l|l|l|l|l|}
\hline \multicolumn{2}{|l|}{ STN 1224 } \\
\hline 68171 & 311 & 0.04 & 018 & 5 \\
73177 & 069 & 0.03 & 274 & 5 \\
73741 & 086 & 0.05 & 298 & 5 \\
\hline
\end{tabular}

TABLE 3.2

Results of Silver and Chan method, $A$ and $B$ results, continued.

azimuth of $331 \pm 12^{\circ}$; the radial component is aligned along the line of stations and shots at $318^{\circ}$ indicating that the initial polarization azimuth is approximately aligned along the radial direction. Setting the initial polarization orientation to radial improved the quality of the covariance matrix results markedly (Figure 3.6b). To test whether the fixed initial polarization provides the best results, the initial polarization was varied systematically over a $180^{\circ}$ range. Results are shown in Figure 3.10 and Tables 3.3, 3.4 and 3.5 and are graded A-D using the same relative scale as used for the Silver and Chan (1991) method.

Delay times are consistent at $\sim 0.05 \mathrm{~s}$ despite variations in both $\phi$ and the initial polarization azimuth. This value is in agreement with that determined without the initial polarization fixed and is equal to about $1 / 2$ the period. The average $\phi$ of all A graded results is $291 \pm 48^{\circ}$ and the average A grade initial polarization value is $99 \pm 48^{\circ}$. Broadly it appears that the fast directions of STNSP10 and STN1224 are aligned in the radial direction, STN1096 and STN1136 in the transverse direction and STN1124 appears to be a null value of splitting. The best results have the initial polarization aligned approximately with radial $\left(138-318^{\circ}\right)$ as is expected from the azimuth of the incoming waves (Appendix A). 
FAST DIRECTION

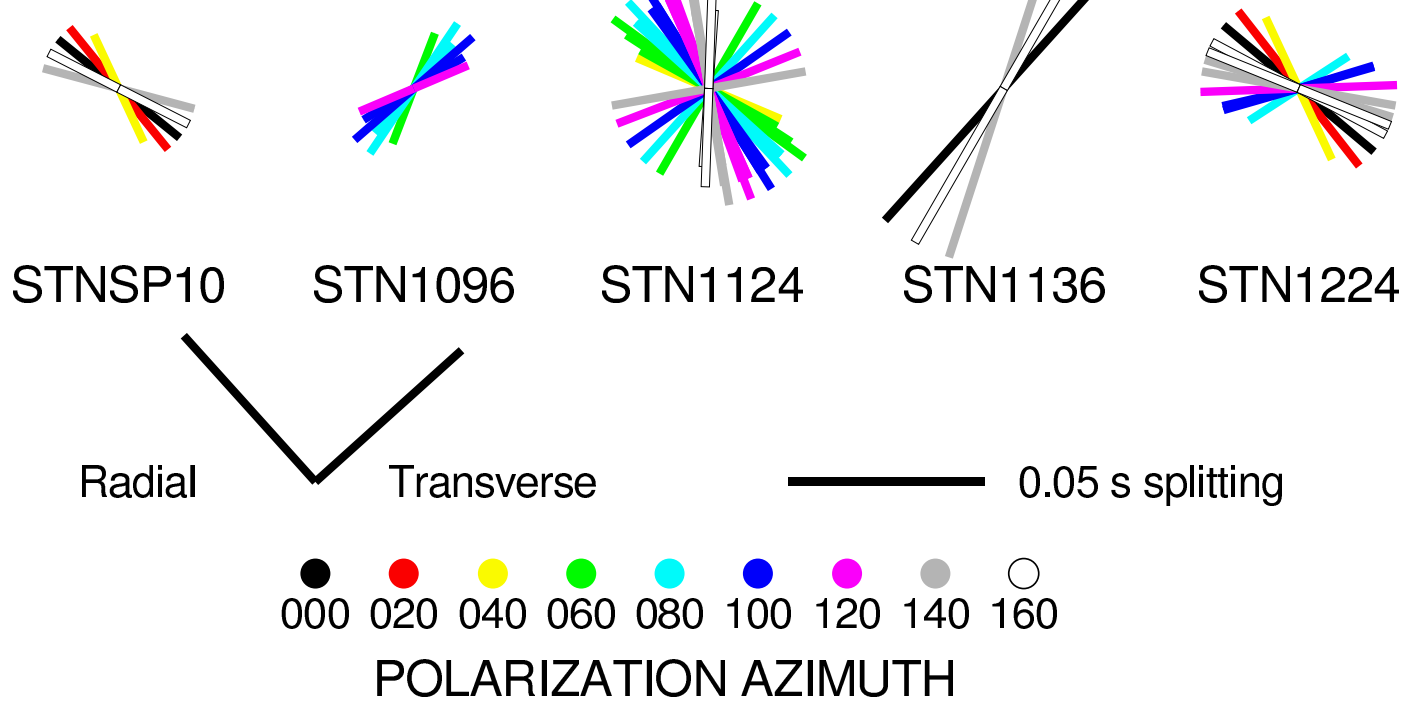

FIG. 3.10 Results of Silver and Chan method with fixed initial polarization. The bars are scaled by delay time and coloured according to the value to which the initial polarization was set. Only A results are displayed.

The uncertainty produced by the delay of $1 / 2 \mathrm{~T}$, which may result from cycle skipping, is a continuing problem as if this value is a result of cycle skipping then there may not be any real splitting recorded by the data. In the following section the impulsiveness of the first arrival is improved through deconvolution to further reduce the possibility of cycle skipping.

\subsection{Deconvolution}

Deconvolution is generally used on near vertical active source stacked datasets to reduce the number of multiples and reverberations. The aim of this process is to compress the seismic wavelet into a spike (Yilmaz, 1987). Deconvolution works by assuming that each new seismic wave arriving at the station will arrive at a random time and that only multiples in the data will have the same wavelength. Autocorrelation of the waveform allows the user to pick a gap around the first arrival and then select a wavelength that best matches the frequency of the multiples. The deconvolution then uses this autocorrelated waveform to 


\begin{tabular}{|c|c|c|c|c|c|c|c|c|c|}
\hline \multicolumn{10}{|c|}{ STN 1124} \\
\hline Offset (m) & $\hat{\phi}\left(^{\circ}\right)$ & $\overline{\phi\left({ }^{\circ}\right)}$ & $\delta \mathrm{t}(\mathrm{s})$ & Grade & Offset (m) & $\hat{\phi}\left(^{\circ}\right)$ & $\overline{\phi\left({ }^{\circ}\right)}$ & $\delta \mathrm{t}(\mathrm{s})$ & Grade \\
\hline \multirow[t]{9}{*}{75524} & $\overline{000}$ & 286 & $\overline{0.1}$ & $\mathrm{D}$ & \multirow[t]{9}{*}{76892} & 000 & $\overline{019}$ & 0.03 & $\bar{D}$ \\
\hline & 020 & 281 & 0.04 & D & & 020 & 000 & 0.11 & D \\
\hline & 040 & 293 & 0.04 & A & & 040 & 016 & 0.1 & D \\
\hline & 060 & 303 & 0.05 & A & & 060 & 305 & 0.05 & D \\
\hline & 080 & 314 & 0.05 & A & & 080 & 317 & 0.05 & $\mathrm{C}$ \\
\hline & 100 & 325 & 0.05 & A & & 100 & 328 & 0.05 & A \\
\hline & 120 & 336 & 0.05 & A & & 120 & 340 & 0.05 & A \\
\hline & 140 & 347 & 0.05 & $\mathrm{C}$ & & 140 & 351 & 0.05 & A \\
\hline & 160 & 357 & 0.05 & $\mathrm{D}$ & & 160 & 004 & 0.04 & A \\
\hline \multirow[t]{9}{*}{79398} & $\overline{000}$ & $\overline{026}$ & 0.02 & $\overline{\mathrm{D}}$ & \multirow[t]{9}{*}{99000} & $\overline{000}$ & 293 & 0.03 & $\bar{D}$ \\
\hline & 020 & 270 & 0.03 & D & & 020 & 357 & 0.03 & D \\
\hline & 040 & 286 & 0.04 & $\mathrm{C}$ & & 040 & 015 & 0.04 & $\mathrm{C}$ \\
\hline & 060 & 299 & 0.04 & A & & 060 & 030 & 0.05 & A \\
\hline & 080 & 312 & 0.05 & A & & 080 & 042 & 0.05 & A \\
\hline & 100 & 324 & 0.05 & A & & 100 & 055 & 0.05 & A \\
\hline & 120 & 336 & 0.05 & A & & 120 & 068 & 0.05 & A \\
\hline & 140 & 350 & 0.04 & A & & 140 & 080 & 0.05 & A \\
\hline & 160 & 003 & 0.04 & D & & 160 & 275 & 0.04 & D \\
\hline
\end{tabular}

\begin{tabular}{|l|l|l|l|l|}
\hline 113661 & 000 & 014 & 0.04 & $\mathrm{C}$ \\
& 020 & 012 & 0.12 & $\mathrm{D}$ \\
& 040 & 296 & 0.06 & $\mathrm{D}$ \\
& 060 & 306 & 0.06 & $\mathrm{~A}$ \\
& 080 & 317 & 0.06 & $\mathrm{~A}$ \\
& 100 & 328 & 0.06 & $\mathrm{~A}$ \\
& 120 & 339 & 0.06 & $\mathrm{~A}$ \\
& 140 & 350 & 0.06 & $\mathrm{~A}$ \\
& 160 & 002 & 0.05 & $\mathrm{~A}$ \\
\hline
\end{tabular}

TABLE 3.3

Results of Silver and Chan method on $\mathrm{SmS}$ arrivals, with fixed initial polarization azimuth, STN1124. Note radial is aligned with azimuth $138^{\circ}$. 


\begin{tabular}{|c|c|c|c|c|c|c|c|c|c|}
\hline \multicolumn{5}{|l|}{ STN 1136} & \multicolumn{5}{|c|}{ STN SP10 } \\
\hline Offset $(\mathrm{m})$ & $\hat{\phi}\left(^{\circ}\right)$ & $\phi\left(^{\circ}\right)$ & $\delta \mathrm{t}(\mathrm{s})$ & Grade & Offset (m) & $\hat{\phi}\left(^{\circ}\right)$ & $\overline{\phi\left({ }^{\circ}\right)}$ & $\delta \mathrm{t}(\mathrm{s})$ & Grade \\
\hline \multirow[t]{9}{*}{77121} & 000 & 042 & 0.09 & $\mathrm{~A}$ & 87492 & 000 & 309 & 0.04 & $\mathrm{~A}$ \\
\hline & 020 & 055 & 0.09 & $\mathrm{C}$ & & 020 & 321 & 0.04 & $\mathrm{~A}$ \\
\hline & 040 & 067 & 0.09 & $\mathrm{D}$ & & 040 & 335 & 0.03 & $\mathrm{~A}$ \\
\hline & 060 & 003 & 0.16 & $\mathrm{D}$ & & 060 & 347 & 0.03 & D \\
\hline & 080 & 022 & 0.15 & $\mathrm{D}$ & & 080 & 324 & 0.09 & $\mathrm{D}$ \\
\hline & 100 & 061 & 0.02 & D & & 100 & 079 & 0.03 & D \\
\hline & 120 & 006 & 0.09 & $\mathrm{C}$ & & 120 & 274 & 0.04 & $\mathrm{D}$ \\
\hline & 140 & 018 & 0.09 & A & & 140 & 285 & 0.04 & A \\
\hline & 160 & 030 & 0.09 & A & & 160 & 297 & 0.04 & A \\
\hline
\end{tabular}

\begin{tabular}{|l|l|l|l|l|l|l|l|l|l|l|}
\hline \multicolumn{10}{|c|}{ STN 1224 } \\
\hline 68455 & 000 & 303 & 0.05 & $\mathrm{C}$ & 69272 & 000 & 310 & 0.05 & $\mathrm{~A}$ \\
& 020 & 316 & 0.04 & $\mathrm{C}$ & & & 020 & 322 & 0.05 & $\mathrm{~A}$ \\
& 040 & 333 & 0.03 & $\mathrm{D}$ & & & 040 & 335 & 0.04 & $\mathrm{~A}$ \\
& 060 & 026 & 0.02 & $\mathrm{D}$ & & 060 & 350 & 0.03 & $\mathrm{D}$ \\
& 080 & 057 & 0.03 & $\mathrm{~A}$ & & & 080 & 058 & 0.02 & $\mathrm{D}$ \\
& 100 & 074 & 0.04 & $\mathrm{~A}$ & & & 100 & 078 & 0.03 & $\mathrm{D}$ \\
& 120 & 086 & 0.05 & $\mathrm{C}$ & & 120 & 273 & 0.04 & $\mathrm{C}$ \\
& 140 & 279 & 0.05 & $\mathrm{C}$ & & & 140 & 287 & 0.05 & $\mathrm{~A}$ \\
& 160 & 291 & 0.05 & $\mathrm{C}$ & & 160 & 298 & 0.05 & $\mathrm{~A}$ \\
\hline
\end{tabular}

\begin{tabular}{|l|l|l|l|l|}
\hline 73741 & 000 & 295 & 0.05 & $\mathrm{C}$ \\
& 020 & 317 & 0.05 & $\mathrm{D}$ \\
& 040 & 067 & 0.11 & $\mathrm{D}$ \\
& 060 & 087 & 0.12 & $\mathrm{D}$ \\
& 080 & 055 & 0.03 & $\mathrm{D}$ \\
& 100 & 073 & 0.04 & $\mathrm{~A}$ \\
& 120 & 088 & 0.05 & $\mathrm{~A}$ \\
& 140 & 280 & 0.05 & $\mathrm{~A}$ \\
& 160 & 292 & 0.05 & $\mathrm{~A}$ \\
\hline
\end{tabular}

TABLE 3.4

Results of Silver and Chan method on SmS arrivals, with fixed initial polarization azimuth, STN1136, STNSP10 and STN1224. 


\begin{tabular}{|l|r|r|r|r|l|l|r|r|r|c|}
\hline \multicolumn{10}{|c|}{ STN 1096 } \\
\hline Offset $(\mathrm{m})$ & $\hat{\phi}\left(^{\circ}\right)$ & $\phi\left(^{\circ}\right)$ & $\delta \mathrm{t}(\mathrm{s})$ & Grade & \multicolumn{1}{|c|}{ Offset $(\mathrm{m})$} & $\hat{\phi}\left(^{\circ}\right)$ & $\phi\left(^{\circ}\right)$ & $\delta \mathrm{t}(\mathrm{s})$ & Grade \\
\hline 74556 & 000 & 308 & 0.03 & $\mathrm{C}$ & 75133 & 000 & 053 & 0.1 & $\mathrm{C}$ \\
& 020 & 330 & 0.03 & $\mathrm{D}$ & & 020 & 069 & 0.09 & $\mathrm{C}$ \\
& 040 & 358 & 0.03 & $\mathrm{~B}$ & & 040 & 002 & 0.03 & $\mathrm{D}$ \\
& 060 & 021 & 0.03 & $\mathrm{~A}$ & & 060 & 019 & 0.04 & $\mathrm{C}$ \\
& 080 & 041 & 0.03 & $\mathrm{~A}$ & & 080 & 034 & 0.04 & $\mathrm{~A}$ \\
& 100 & 058 & 0.03 & $\mathrm{~A}$ & & & 100 & 049 & 0.04 & $\mathrm{~A}$ \\
& 120 & 076 & 0.04 & $\mathrm{~B}$ & & 120 & 067 & 0.03 & $\mathrm{~A}$ \\
& 140 & 272 & 0.04 & $\mathrm{C}$ & & 140 & 085 & 0.03 & $\mathrm{~B}$ \\
& 160 & 290 & 0.03 & $\mathrm{D}$ & & 160 & 038 & 0.1 & $\mathrm{D}$ \\
\hline
\end{tabular}

TABLE 3.5

Results of Silver and Chan method on SmS arrivals, fixed initial polarization azimuth, STN1096.

remove signal of the multiple frequency from the data.

Deconvolution is undertaken here to try to reduce the multiplicity of the data and to create a more impulsive wavelet. Processing was done on the three stations with the clearest SmS signal: STN1096, STN1124 and STN1136. Parameters used in deconvolution include the gap, which is the length of the time window around the first arrival, and the length, which governs the length of filter used on the data. These parameters were varied to best improve the seismic signal; the final values used were a gap of $108 \mathrm{~ms}$ and a filter length of $620 \mathrm{~ms}$. This process reduced the number of multiples though the data still retained an emergent waveform (Figure 3.11). These deconvolved traces were then analysed using the Silver and Chan (1991) method (Section 3.7.2) and the cross-correlation method (Section 3.9). Results of the Silver and Chan (1991) method are shown in Figure 3.12 and in table format in Appendix C. These results are consistent with those from data which has not been deconvolved, again with the fast direction aligned with the transverse orientation for STN1096 and STN1136. STN1124 shows an approximately northward oriented fast direction, which appears much more constrained than that obtained from the data prior to deconvolution. However, it is noted that the range of offsets used for the deconvolved data analysis was smaller than for non-deconvolved data. 


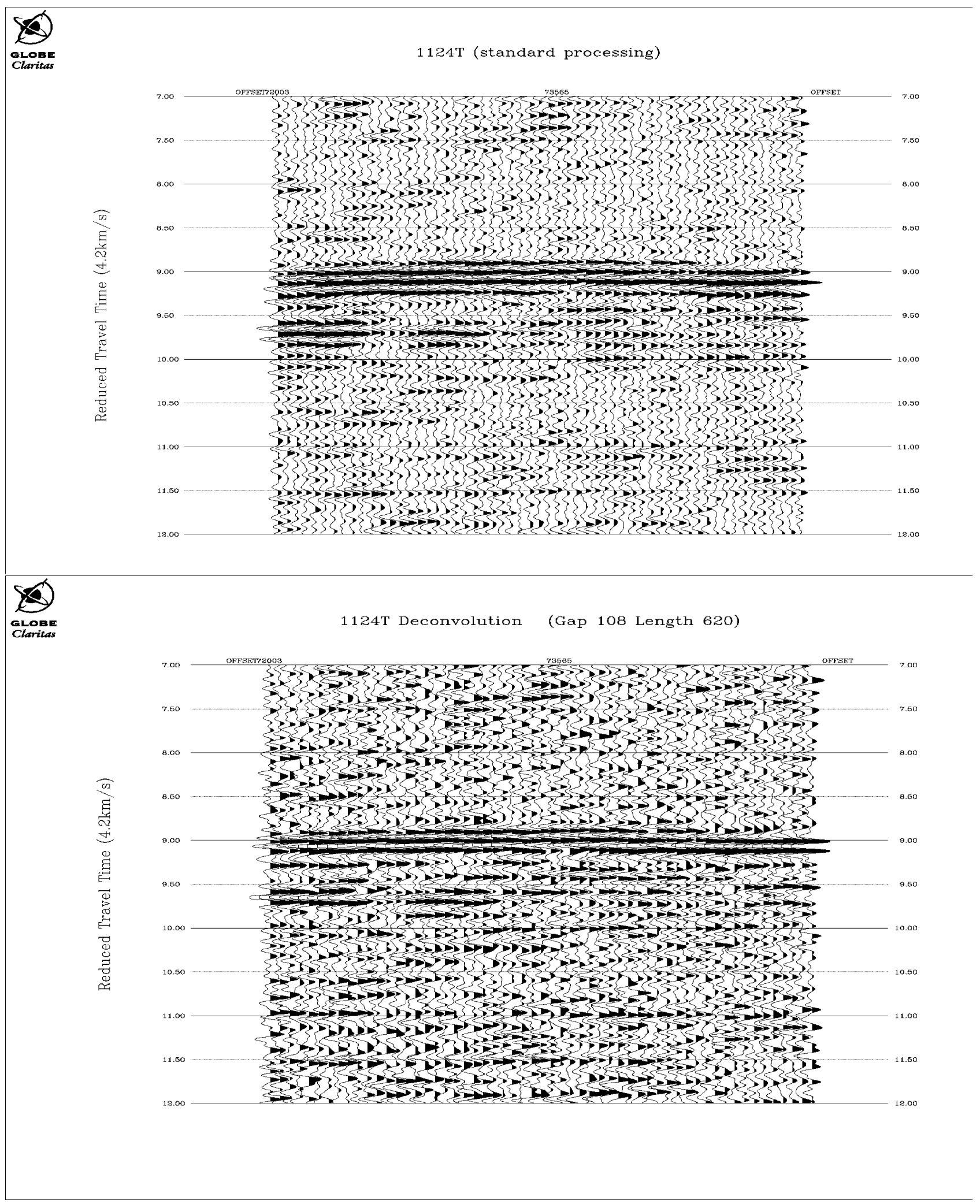

FiG. 3.11 a) Seismic data, transverse component STN1124, processed using standard techniques, b) above data processed using deconvolution, with a gap width of $108 \mathrm{~ms}$ and a window length $620 \mathrm{~ms}$. 


\section{DECONVOLVED DATA}

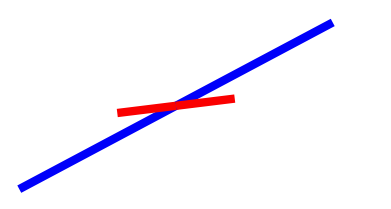

STN1096

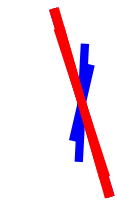

STN1124

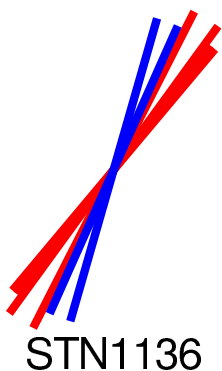

STN1136

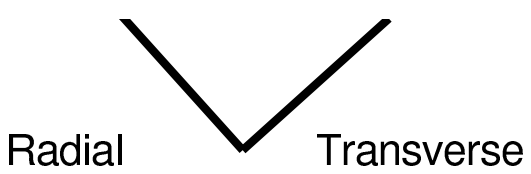

FAST DIRECTION $\longrightarrow 0.05$ s splitting

Fig. 3.12 Fast directions determined from Silver and Chan (1991) method, using deconvolved data. Only A results are shown. Lines in blue are analysed with the standard method, those in red have the initial polarization fixed to radial.

\subsection{Cross-correlation}

Radial and transverse components from STN1096, STN1124 and STN1136 were crosscorrelated using a cross covariance equation to calculate the shear wave splitting delay time. The input data and results of the cross-correlation are plotted with delay versus offset for STN1096 (Figure 3.13 \& 3.14), STN1124 (Figure $3.15 \&$ 3.16) and STN1136 (Figure $3.17 \&$ 3.18). Data from STN1096 show poor results, due to reverberations from the coda of the Sg arrival (Figure 3.13). Cross-correlation results from stations 1124 and 1136 (Figures $3.15,3.16,3.17 \& 3.18$ ) are non-unique with the most likely delay time solutions between $60 \mathrm{~ms}$ with the radial component fast and $120 \mathrm{~ms}$ with the transverse component fast; identified by the largest amplitude of cross-correlation (darkest blue or lightest red) over a range of offsets. The emergent, multiple, nature of the data has resulted in the waveforms correlating well over a range of delay times.

Deconvolved data (Figure 3.11 and Appendix C) are used in the cross-correlation analysis to determine the delay time (Figures 3.20, 3.19 and 3.21). Due to the improved input data quality the results of the cross-correlation show a reduced range of possible delay times and that the fast direction is aligned with the transverse component. Using the average deconvolved cross-correlation amplitude the best delay times for STN1096 are 0.04 and $0.09 \mathrm{~s}$, 0 and $0.06 \mathrm{~s}$ for STN1124 and 0.08 and $0.14 \mathrm{~s}$ for STN1136. The lower values, for each 


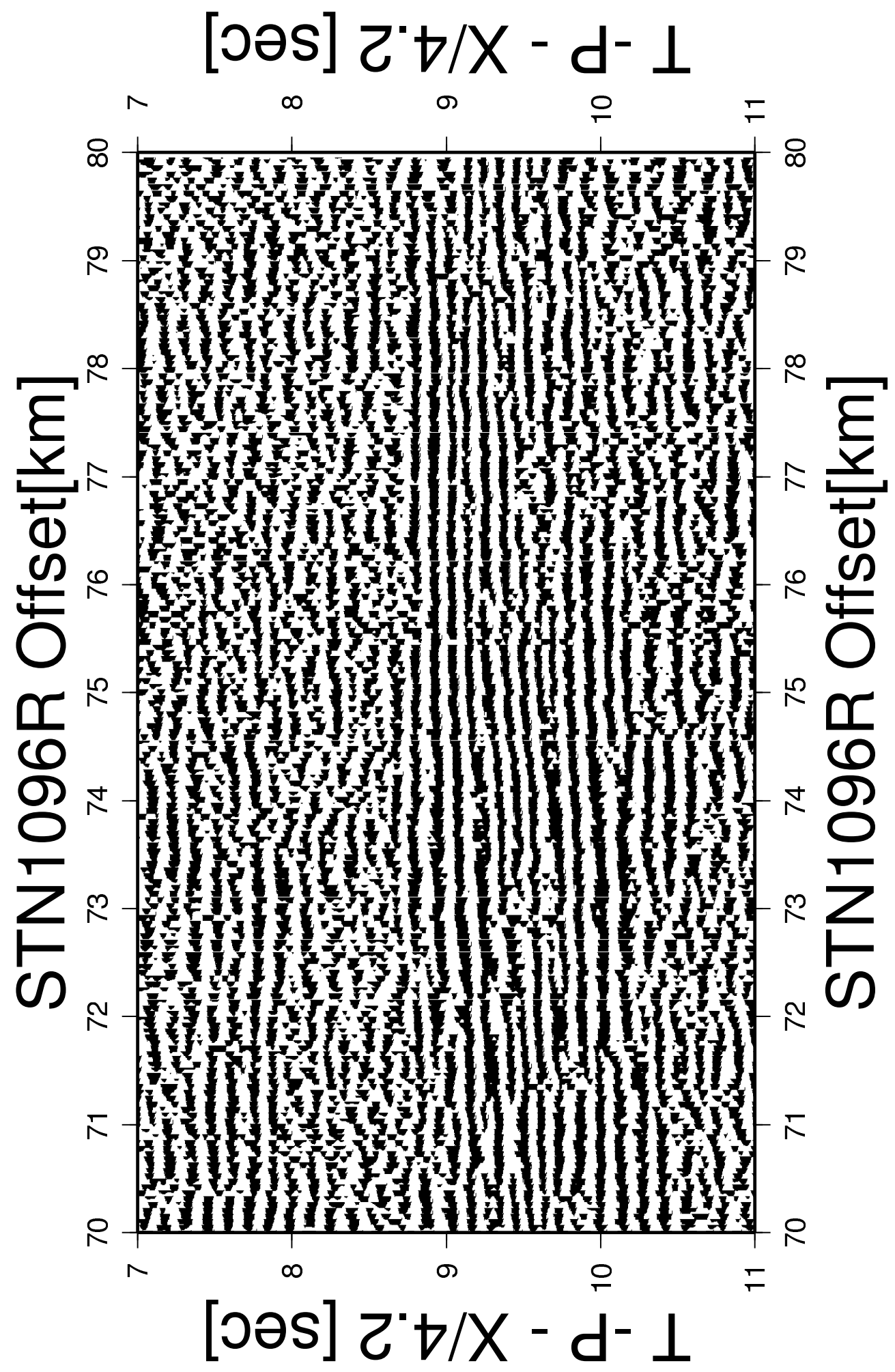

Fig. 3.13 SmS arrival on the radial component of STN1096. The window of data shown is that used in the cross correlation calculation shown in the following figure. 


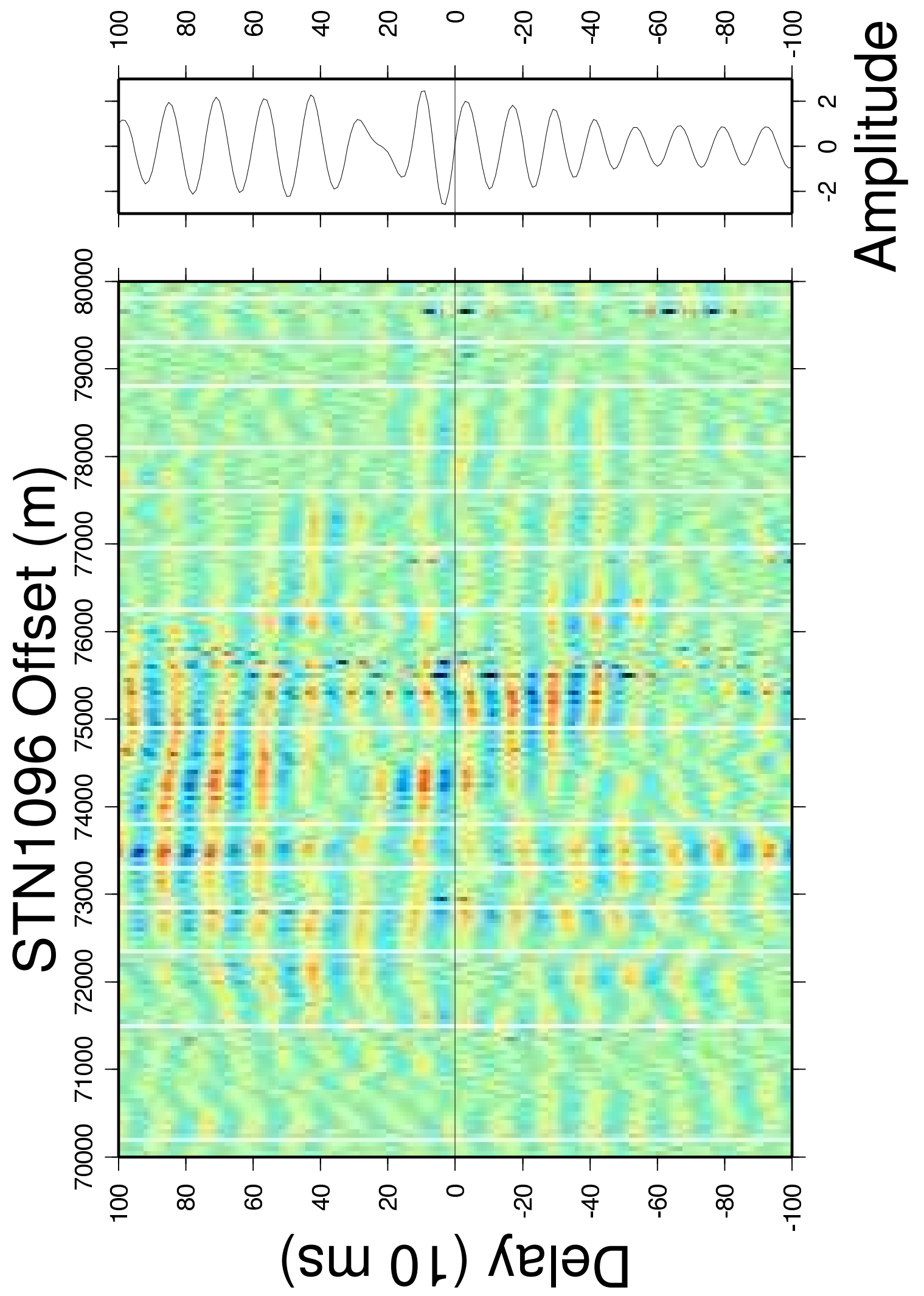

Fig. 3.14 Cross-correlation of the radial (318) and transverse (048) components recording an $S m S$ arrival at STN1096. The cross-correlation was done using a maximum delay time of \pm 1 s.Dark blue or light red indicate strong correlation between the horizontal components, yellow is a poor correlation. The multiplicity of these data is strong and as a result a clear delay time cannot be picked. Positive delay times indicate when the transverse component is fast, negative when radial is fast. The amplitude is the average amplitude for all crosscorrelated traces, and the largest amplitudes indicate the best correlation, here between $120 \mathrm{~ms}$ (transverse fast) and -60 ms (radial fast). 


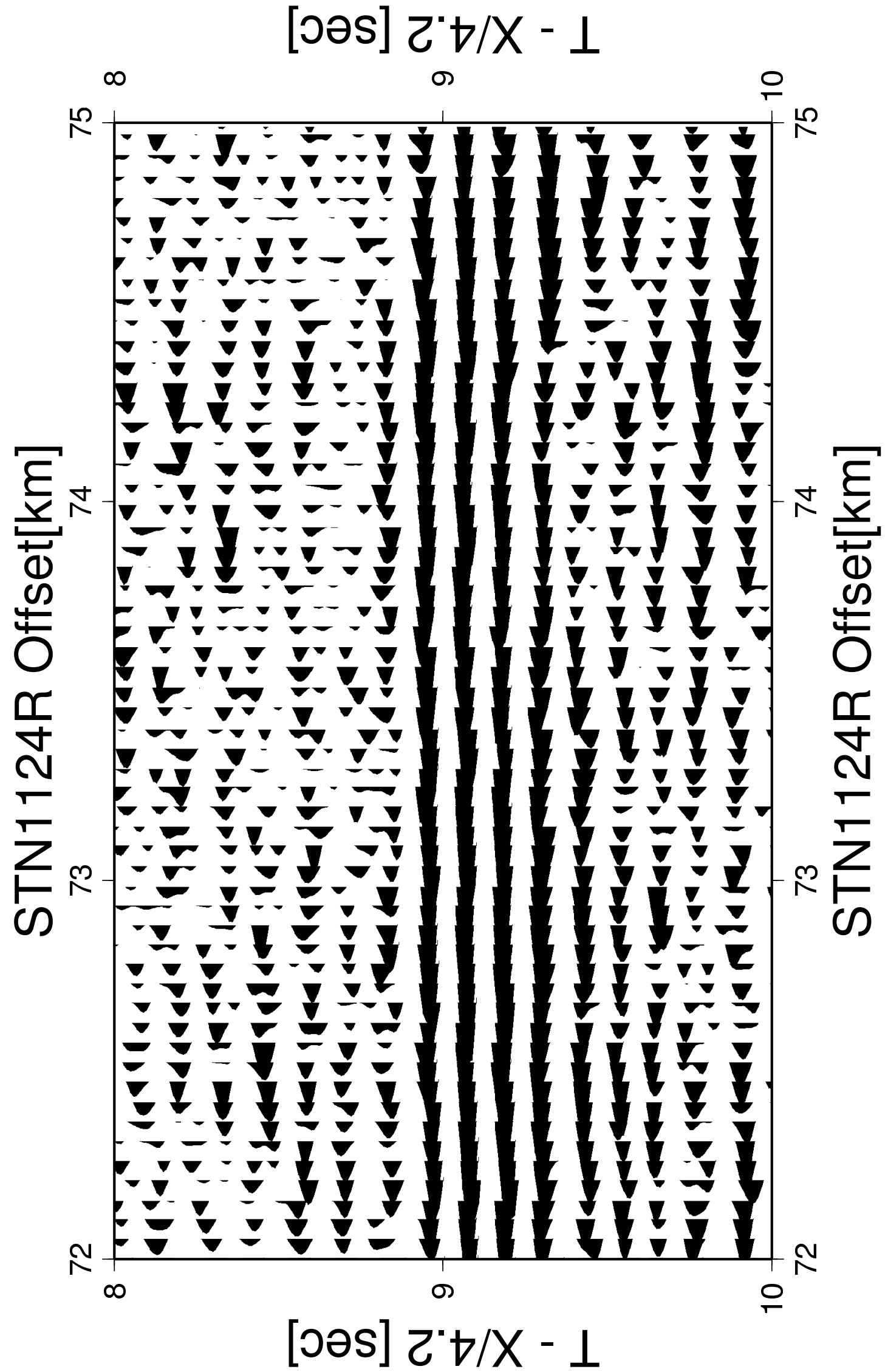

FIG. 3.15 SmS arrival on radial component, STN1124, used in cross-correlation calculation, Figure 3.16 . 


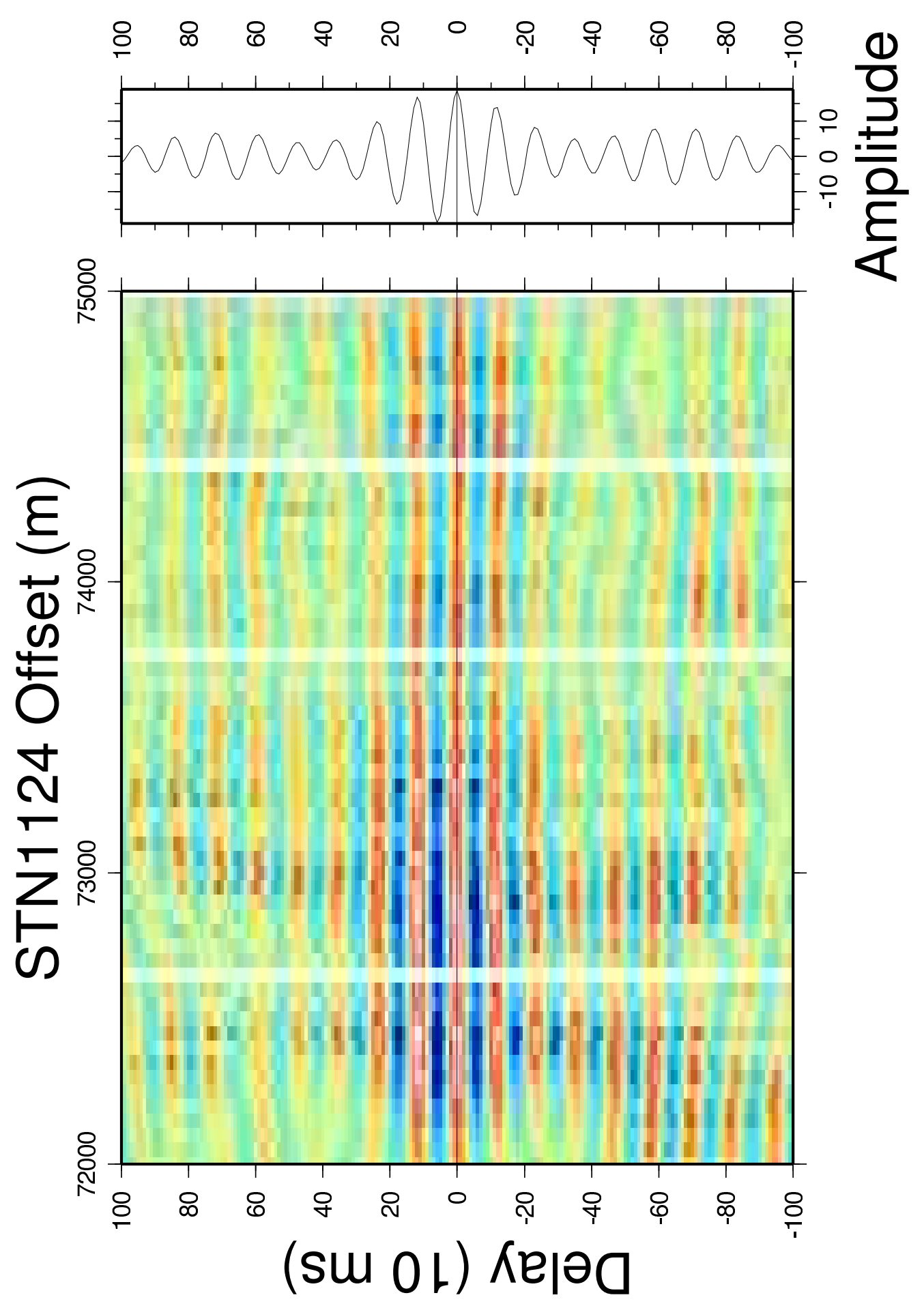

Fig. 3.16 Cross-correlation of horizontal components, STN1124. 


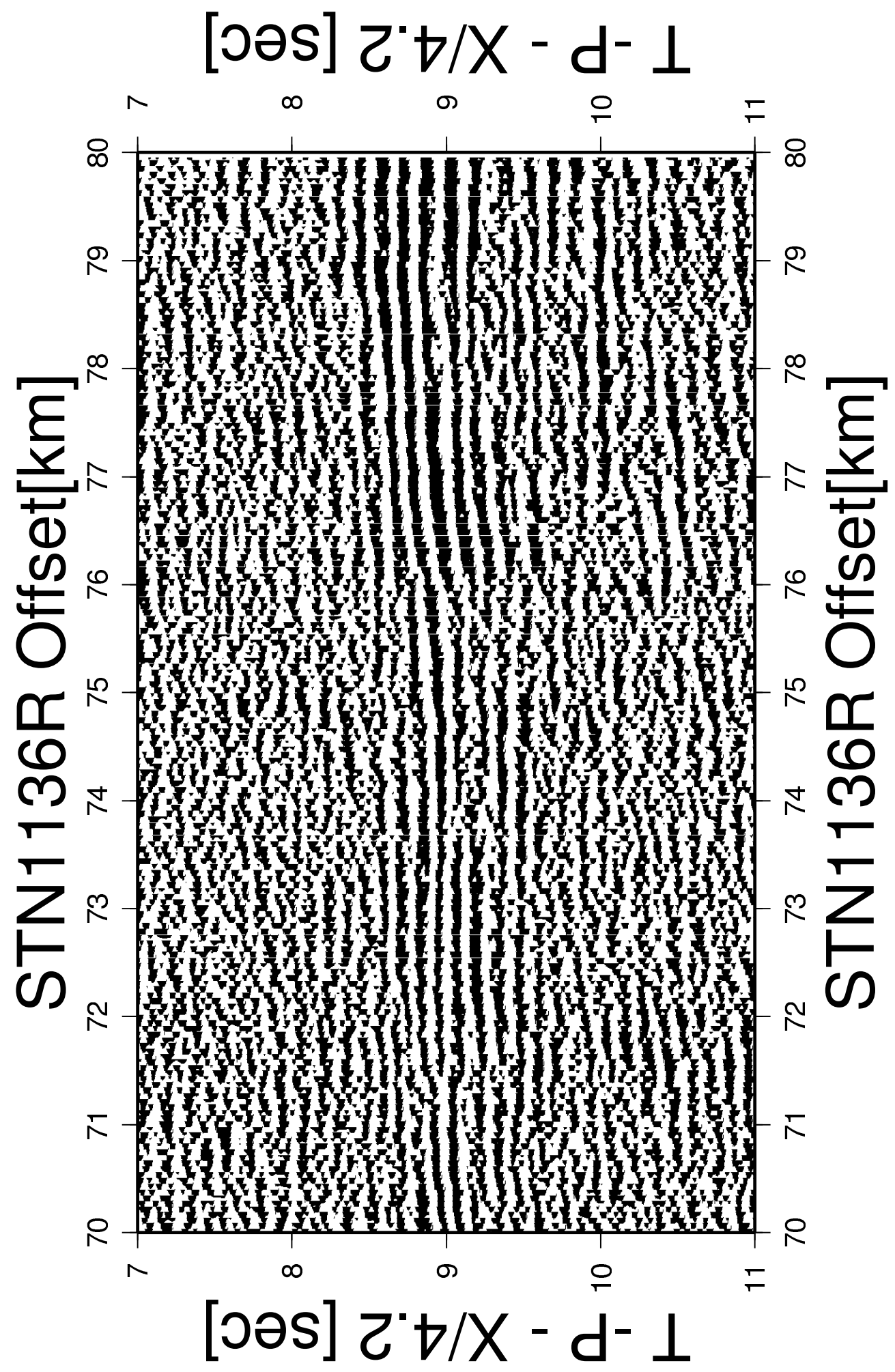

Fig. 3.17 SmS arrival on the radial component of STN1136. The window of data shown is that used in the cross correlation calculation shown in the following figure. 


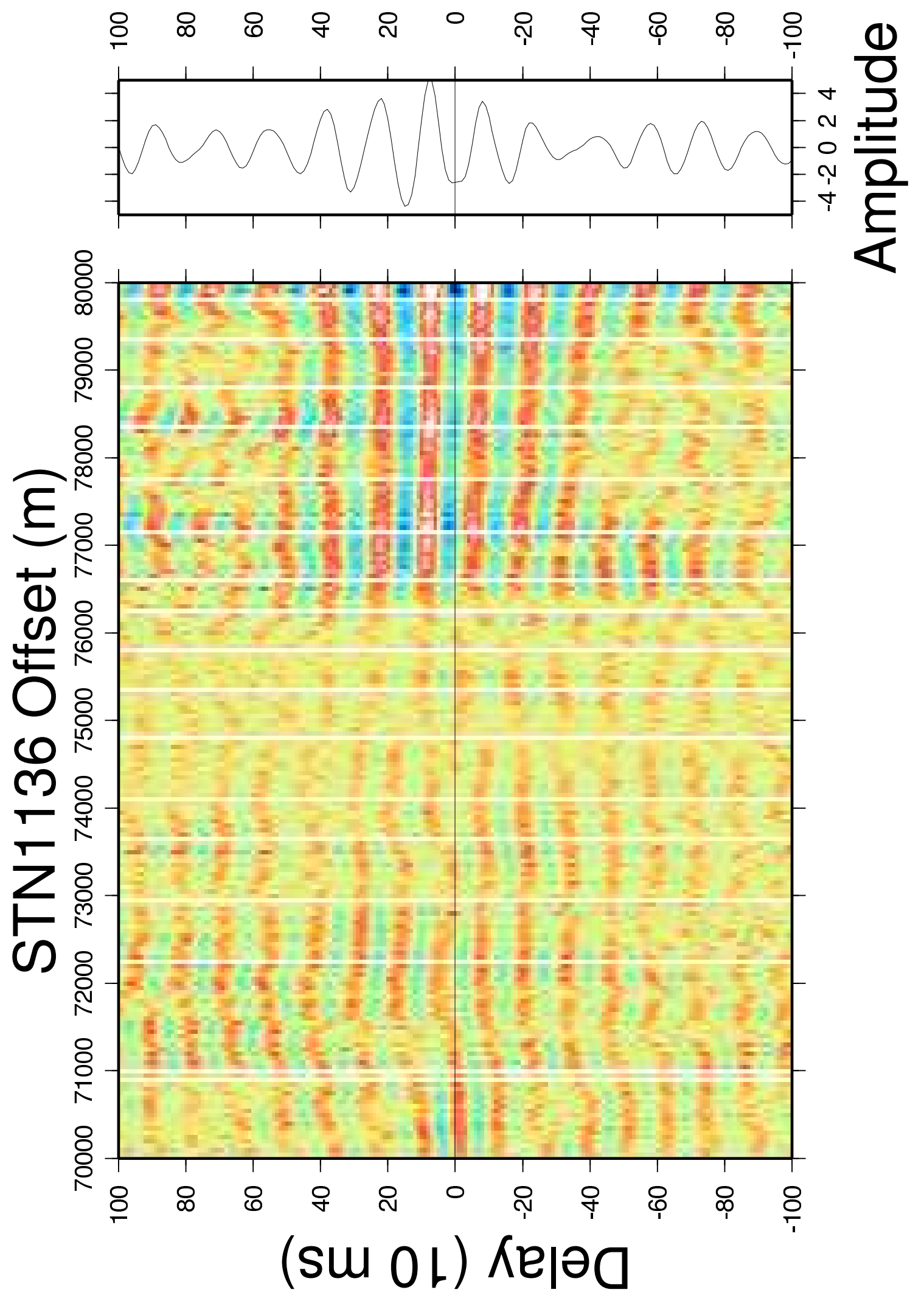

Fig. 3.18 Cross-correlation of the radial (318) and transverse (048) components recording a SmS arrival at STN1136. The cross-correlation was done using a maximum delay time of $\pm 1 \mathrm{~s}$. 
station, show marginally stronger correlation.

Deconvolution appears to improve the certainty of the delay time and the presence of splitting. However, it is noted that deconvolution can change the frequency of the data. It is assumed here that the shear wave arrival recorded on the two horizontal components will have the same wavelength but be delayed by the lag time. Deconvolution will correct both components in the same manner, if they are identical but delayed by less than the gap length. If the two components differ in original frequency, or arrivals on one component are not seen on the other, the deconvolution will correct the waveforms in a different way resulting in the increased possibility of incorrect cross-correlation.

The variation in delay times between the different stations indicate that either the source of splitting is very localised, close to the surface, probably resulting from aligned cracks, or due to slight angular variations between the raypaths to each station and the axis of symmetry of the Haast schist (e.g. Figure 3.2). A further possibility is that anisotropy produced as the waves pass through different structures at depth may add constructively along some ray paths while other raypaths lead to constructive interference. The true source of the splitting at each of these three stations cannot be determined with certainty, however, some of these possible sources are discussed below.

\subsection{No Splitting Experiment}

As a final step, analysis of an unsplit waveform using the Silver and Chan (1991) method was undertaken to determine how the program functions in the absence of splitting. A transverse component waveform was taken from station 1124, at an offset of $72623 \mathrm{~m}$. This trace was copied to be used as the radial component so that no splitting is present in the data. An error occurs in the program if both horizontal traces are identical. Noise was taken from the transverse trace prior to the $\mathrm{P}$-wave arrivals and prior to the $\mathrm{S}$-wave arrivals and these samples of noise were added to the "radial" and transverse components respectively to overcome this problem (Figure 3.22). The two horizontal traces have the exact same time of arrival for the $\mathrm{SmS}$ phase as they are a copy of each other and hence shear wave splitting analysis should result in a null or zero splitting value. 


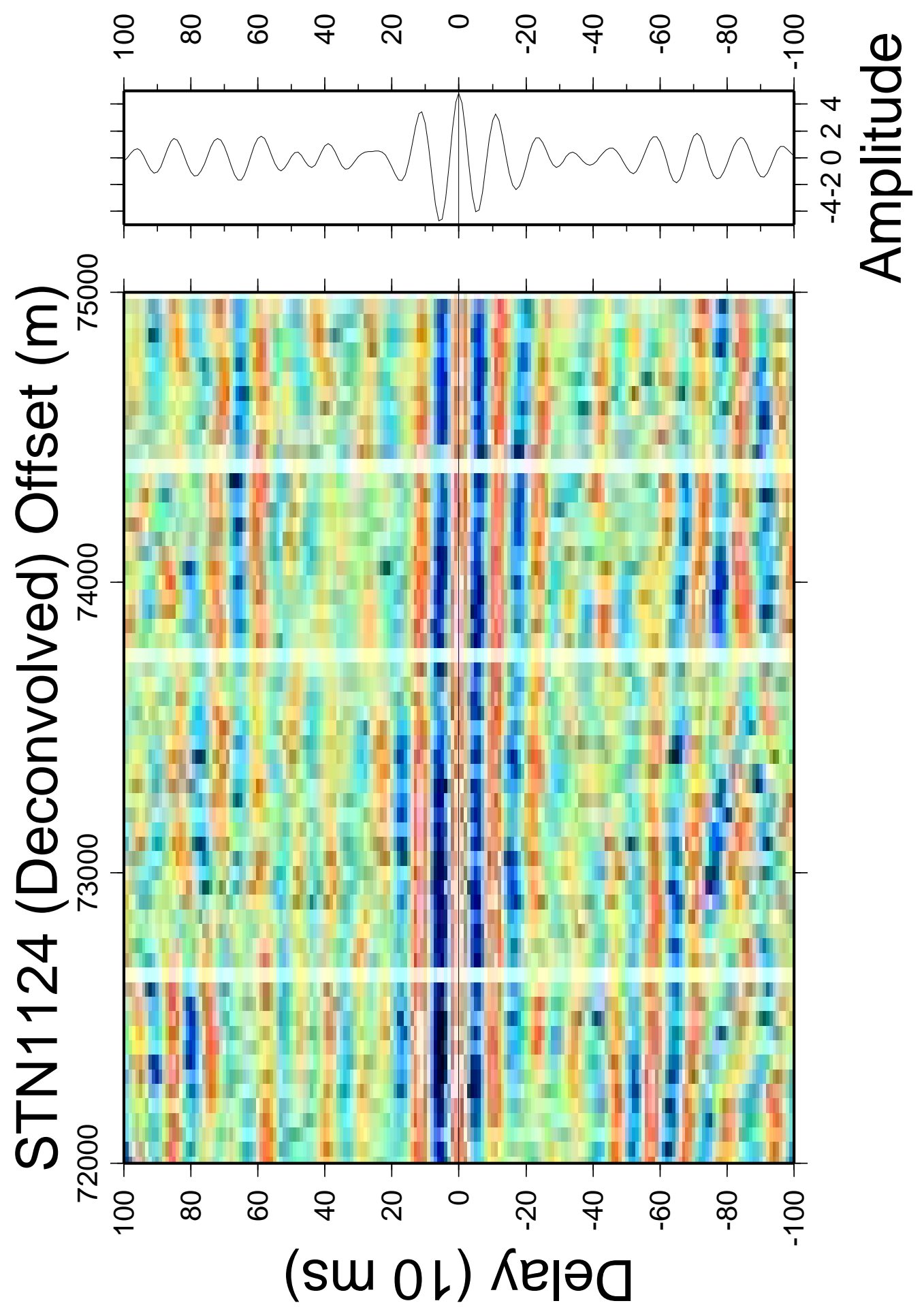

Fig. 3.19 Cross-correlation of deconvolved radial $\left(318^{\circ}\right)$ and transverse $\left(048^{\circ}\right)$ components recording a SmS arrival, STN1124. Horizontal regions of dark blue-light red indicate strong correlation between the horizontal component waveforms. The multiplicity has been improved through deconvolution resulting in clearer cross-correlation result. The main correlation appears to be with transverse fast and a $\delta t$ of $\sim 0.06 \mathrm{~s}$ or zero delay - no splitting. 

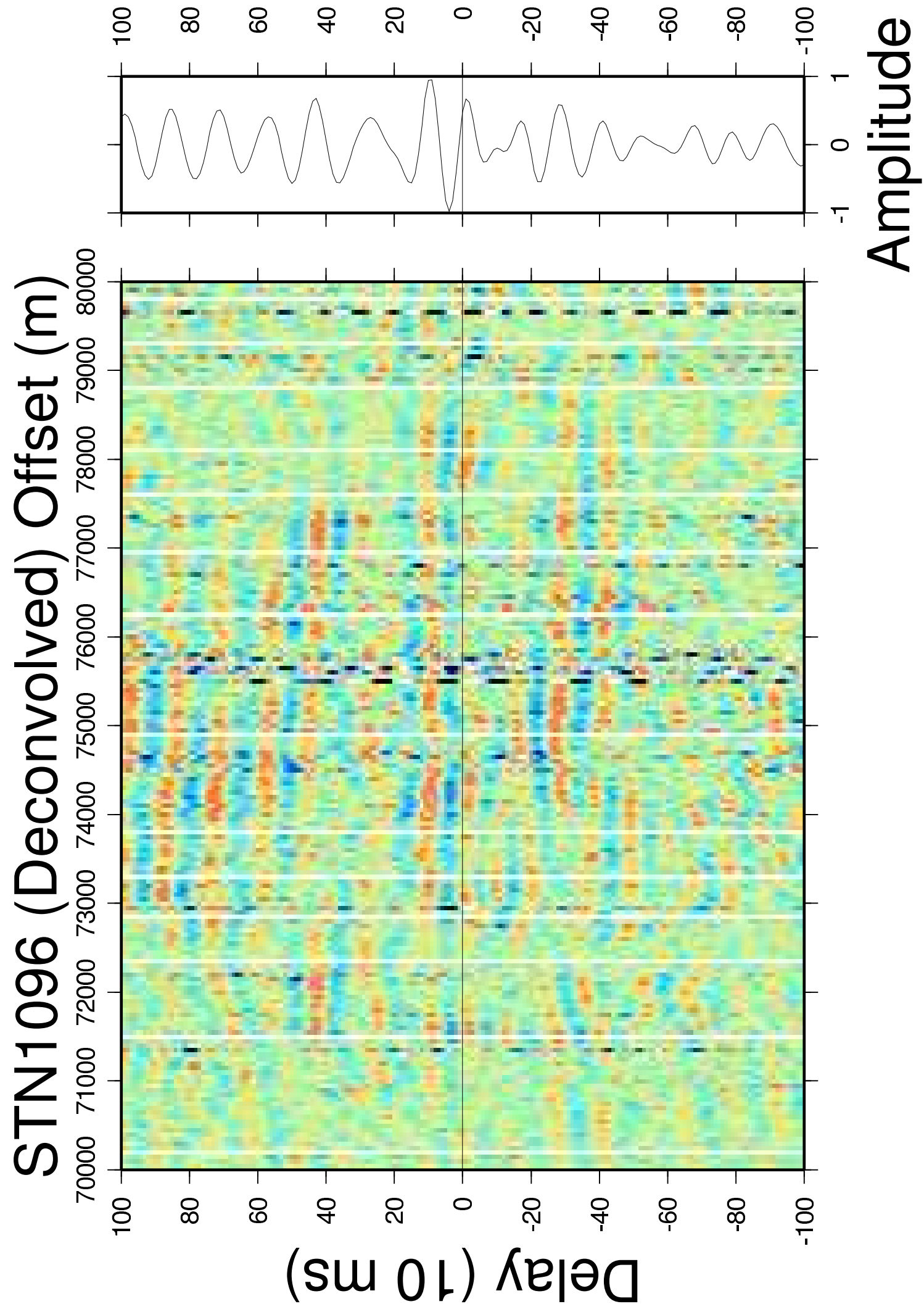

FIG. 3.20 Cross-correlation of SmS arrival at STN1096 using deconvolved data. The crosscorrelation was done using a maximum delay time of $\pm 1 \mathrm{sec}$. 


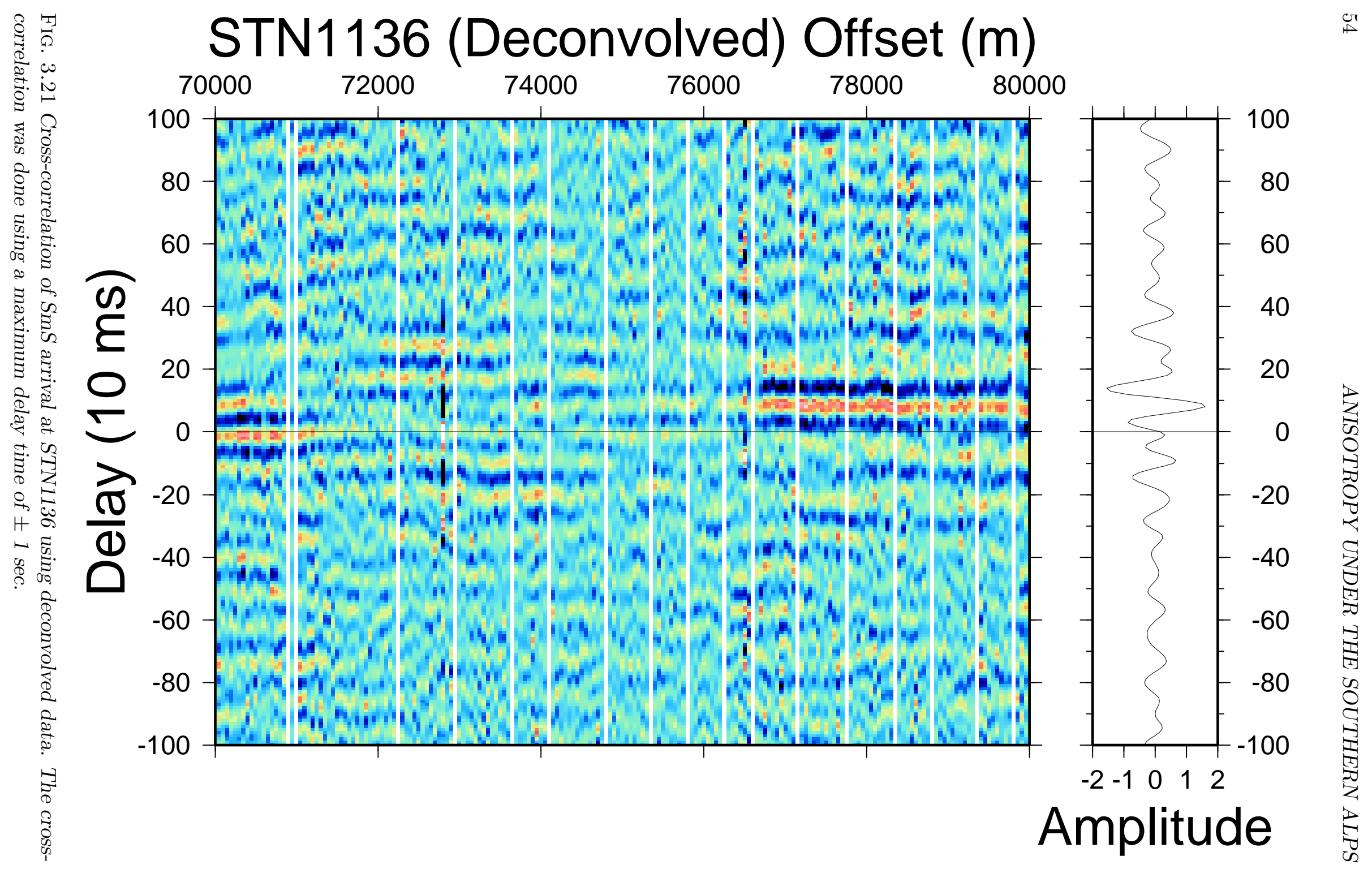




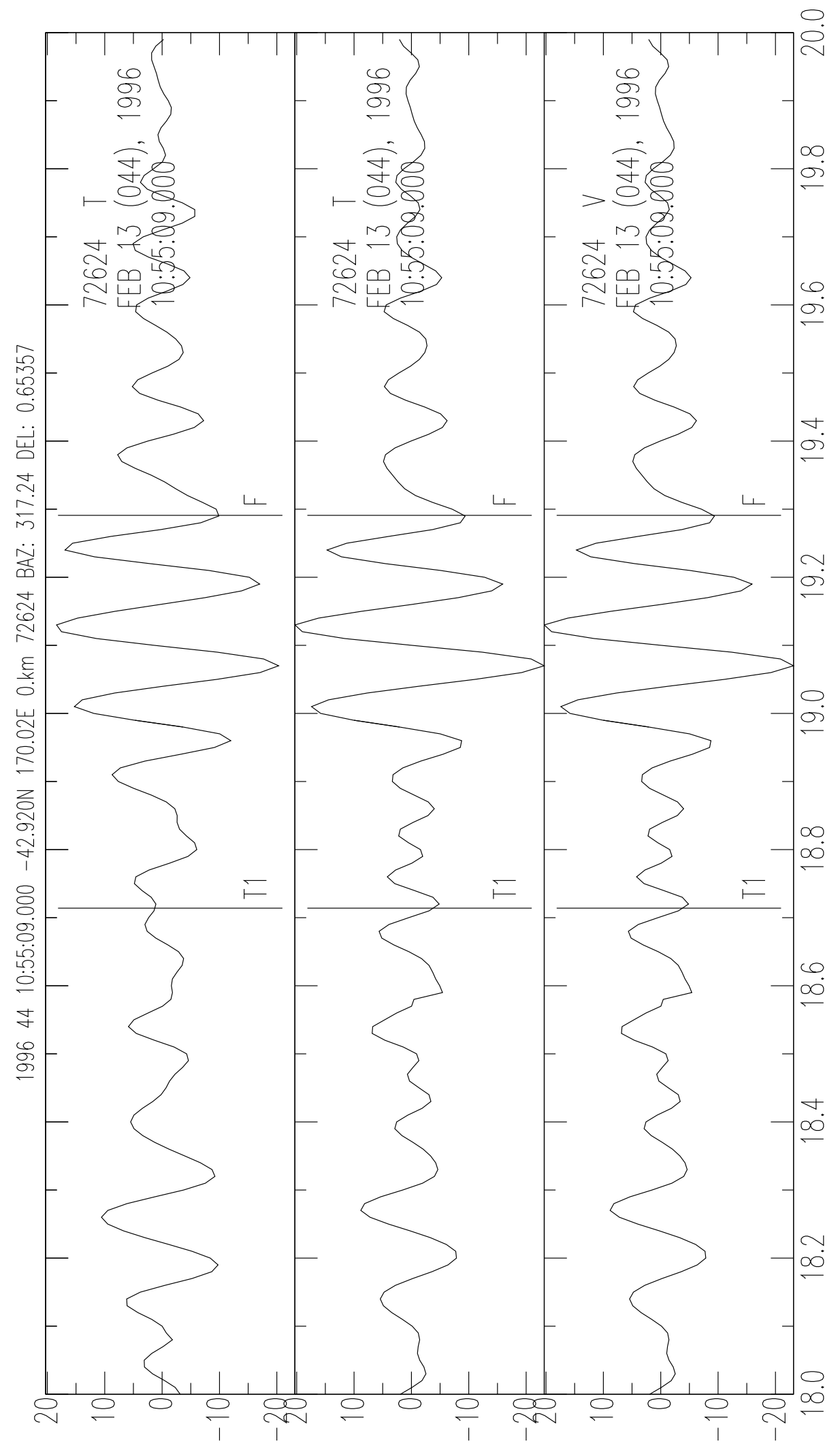

FIG. 3.22 No splitting experiment. The top two traces are copies of the transverse component recorded at an offset of $72624 \mathrm{~m}$. The top two traces have had random noise added, which was a sample of data from -2 to $-4 \mathrm{~s}$ and 14-16 s respectively. The "radial" component is the top trace, transverse (centre) and vertical is the lower trace and is not used by the Silver and Chan (1991) method. 

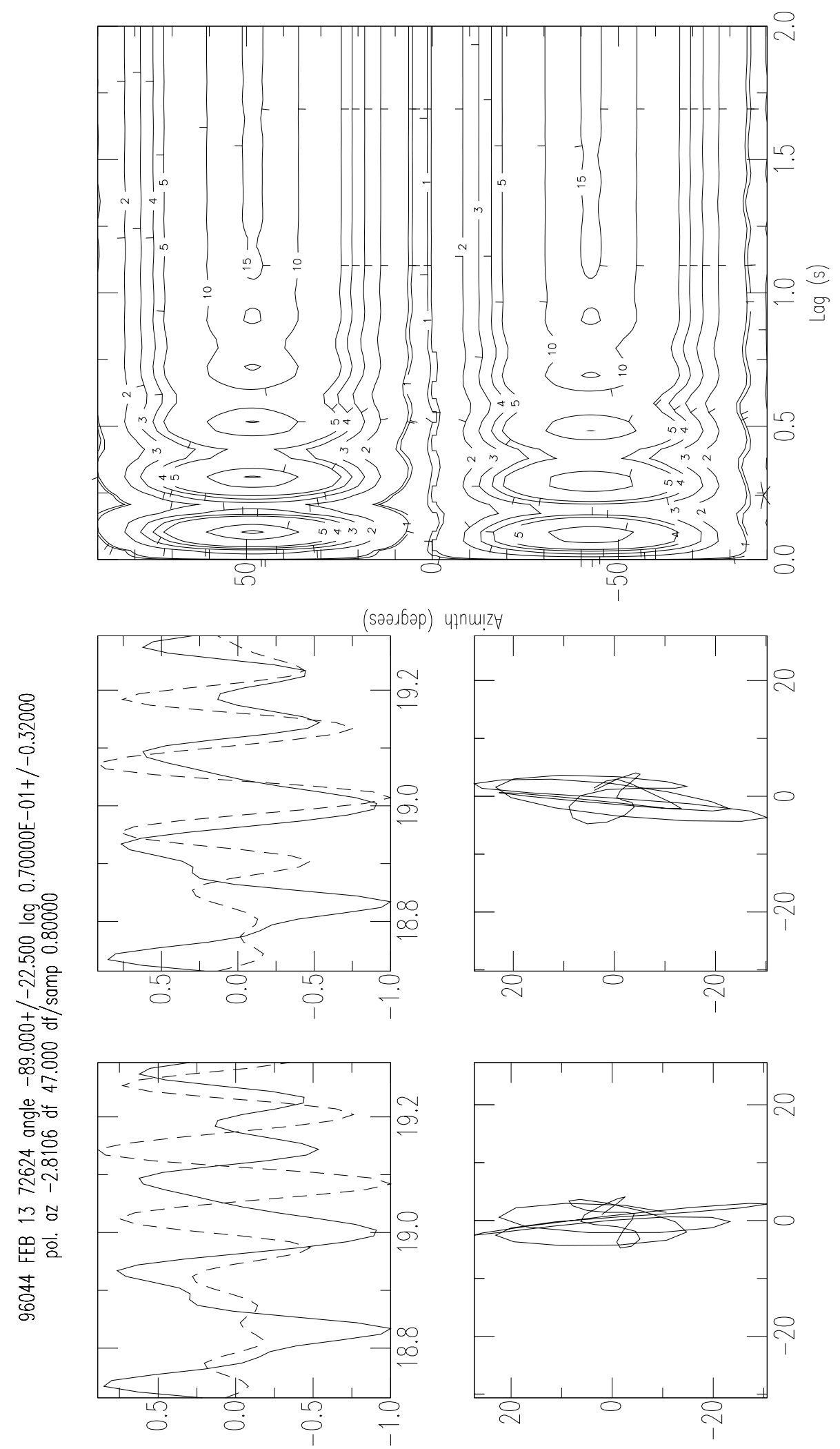

Fig. 3.23 Covariance matrix calculated using the Silver and Chan (1991) method for two identical components with random noise added, see Figure 3.22. The calculated delay time of $0.07 \mathrm{~s}$ is very similar to results of previous calculations of our data and is around $1 / 2$ the period. The covariance matrix shows a strong null result, contrasting with results from previous analyses. 
The resulting covariance matrix shows a null result with a full range of possible delay times (Figure 3.23). These results are similar to that seen at several stations, but despite the poor fit of the covariance matrix for the analyses in the previous sections, there is a better fit of the covariance matrix than is seen from the no splitting experiment. This suggests that the delay times recorded in previous sections may be due to real delay times and not the result of cycle skipping. Using the Silver and Chan (1991) method and incrementally changing the fixed initial polarization azimuth, for the data with no splitting, a series of different fast directions and delay times are gained all roughly 1 or $1 / 2$ of the period $(\mathrm{T})$.

\subsection{Discussion}

Shear wave splitting of between 0-0.08 s (Possibly up to $0.14 \mathrm{~s}$ ) is identified from active source seismic data with raypaths travelling across the plate boundary, South Island. There appears to be no trend with offset, as the results for STN1124 indicate no splitting while stations to both the east and west show splitting of 0.04-0.08 s with the fast component aligned with the transverse component (approximately parallel with the plate boundary).

Variations in shear wave splitting parameters with both spatial location and backazimuth are observed in several studies (e.g. Sheehan et al., 1997; Polet and Kanamori, 2002). These variations in splitting were observed using SKS and SKKS measurements in both the Colorado Plateau, Great Basin and in California. The California study showed that the variations in splitting were not aligned with the San Andreas Fault and were attributed to an older phase of deformation. The results compared well with the current stress regime in the near surface (Polet and Kanamori, 2002). The study of Sheehan et al. (1997) attributed the changes in delay time and fast directions to lateral variations in the source region of anisotropy. However, Sheehan et al. (1997) also note that the anisotropy may also be the result of a complicated symmetry system or multiple layer anisotropy.

The crustal rocks of the Southern Alps have been shown to demonstrate strong shear wave splitting when analysed in a laboratory (Okaya et al., 1995; Godfrey et al., 2001). The spatial variation in splitting and small delay times recorded from this dataset are likely to be due to a number of factors. Here we focus on simple sources for the variation in shear 
wave splitting. It is noted however, that as for the Californian study, more complex models may exist to explain the observations.

The first factor is the geometry of the experiment and ray paths relative to the foliation plane and structure of the Southern Alps. Laboratory measurements have shown that where the shear waves pass normal to the foliation plane of the schist rocks $\left(0^{\circ}\right.$ to the symmetry axis), both the radial and transverse components are inhibited by the same amount, resulting in no apparent splitting (Figure 3.2). A singularity also occurs when the shear waves are passing through the schist foliation at $\sim 50^{\circ}$ to the symmetry axis (Godfrey et al., 2001) also resulting in no splitting. In the Southern Alps the foliation of the mylonites and schist close to the Alpine Fault are measured to be close to vertical and are thought to decrease in dip with depth, towards the east. Waves passing through this package of rocks arrive obliquely at the surface. Particle motions of $\mathrm{Pg}$ and $\mathrm{PmP}$ arrivals were estimated (an allowance for the free surface was made) and the incident angles of arrival ranged from 12-20 (Figure 2.8).

Laboratory measurements by Godfrey et al. (2001) indicate a maximum of $0.8 \mathrm{~s}$ delay for waves passing through $20 \mathrm{~km}$ of the Haast schist. The high value of splitting would require the schist to be oriented uniformly over a broad region. It is likely that as the waves steepen towards the surface and the schist has a lower gradient with depth, the actual amount of splitting will be much less than $0.8 \mathrm{~s} / 20 \mathrm{~km}$. For an $80^{\circ}$ easterly dip of the Alpine Fault and associated foliation near the surface and a $17^{\circ}$ westerly dipping angle of incidence of the waves to the surface, an angle of $63^{\circ}$ to the symmetry axis is gained. This angle corresponds to $0.2 \mathrm{~s}$ of splitting over the thickness of the Haast schist $(20 \mathrm{~km})$ (Godfrey et al., 2001). This is greater than that estimated from the dataset (e.g. Figure 3.21). The angle of incidence would need to vary from $\sim 48^{\circ}$ at STN1096 to $50^{\circ}$ at STN1124 and back to $\sim 48^{\circ}$ at STN1136 to fit the observed splitting at these stations.

The second possible contributing factor to the low splitting values is that there are several phases of deformation recorded by these rocks (Little et al., 2002) and each of these may have some influence on the anisotropy. Rocks exhumed at the surface that were part of the brittle-ductile zone at depth show repeated veining and fractures. These fractures are approximately $30 \mathrm{~cm}$ apart and crop out over a region of several kilometres. These features 


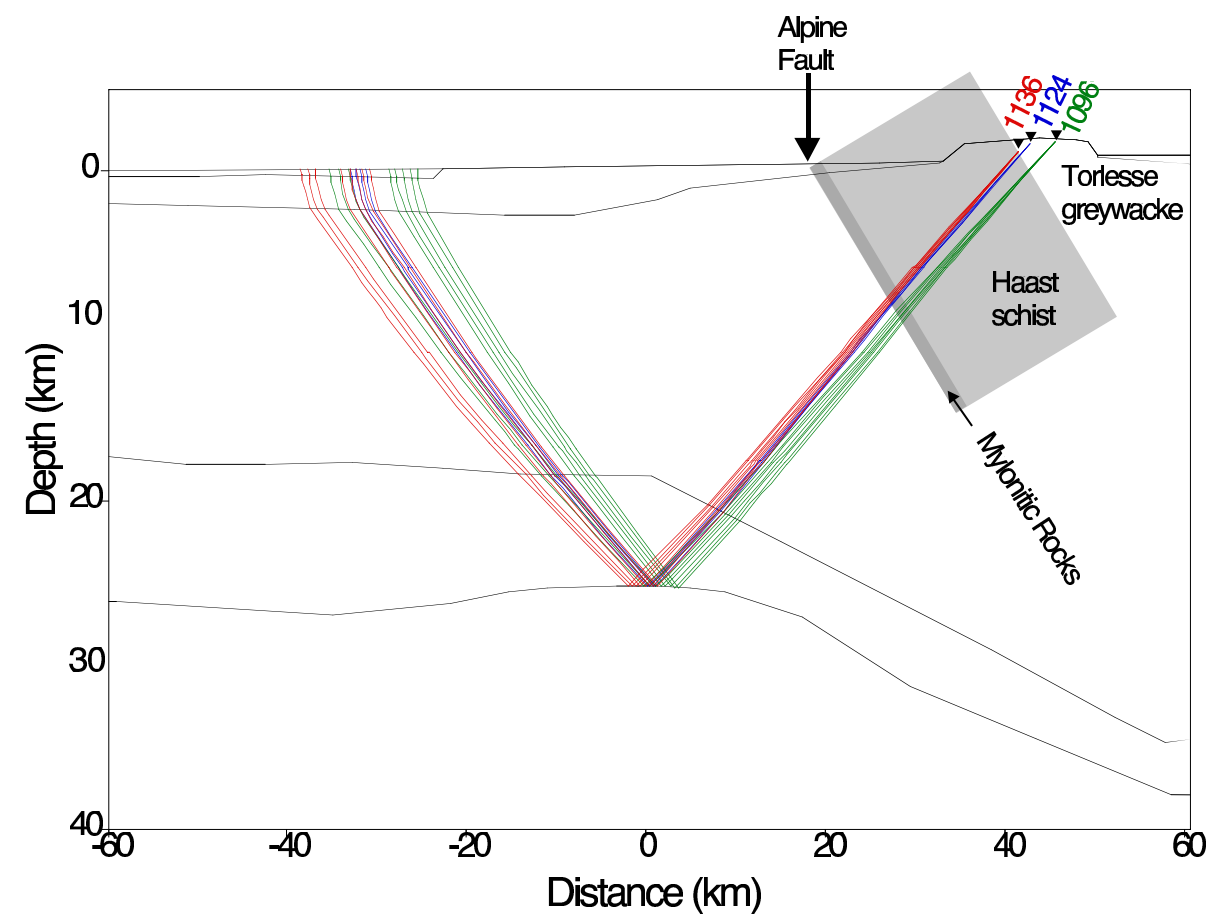

FIG. 3.24 Spatial relationship of raypaths to the Haast schist. The light grey box indicates the location of the Haast schist at the surface and is projected both above the surface and down to where it intersects the ray paths into stations: 1096, 124 and 1136. The raypaths are coloured according to station, green - 1096, blue - 1124 and red - 1136. The dark grey box denotes the approximate thickness of the mylonitic, amphibolite grade rocks. The ray paths are from $S$-wave modelling undertaken in the following chapter.

are roughly parallel to the Alpine Fault but dip vertically and in some cases towards the Alpine Fault (Little et al., 2002). Though these features are only preserved in the brittleductile region, the stresses causing these features will effect the whole of the Southern Alps (Figure 2.2). How pervasive these structures are and the influence they will have on shear wave splitting is unknown. However, if both the mineral alignment of the schist and the fracture alignment of the brittle-ductile transition zone influence the shear wave splitting, then the oblique nature of the two structures may cause any splitting to be cancelled out at some stations while others may still record splitting. However, again this would most likely require a slightly different angle of ray path into each station.

Finally, scattering and/or variations in anisotropy may result from oriented fractures in the top $10 \mathrm{~km}$ of the crust (Crampin, 1994). If there are changes in the localised stressfield then the fractures may influence one station and not the adjacent ones. Rocks of the 
Southern Alps are highly deformed and fractured, increasingly so towards the Alpine Fault. If the fractures are sufficiently pervasive, the S-waves are likely to be scattered in the near surface making the first arrivals less clear, and possibly the orientations of the wave motion less distinct. Where the waves are scattered there are likely to be reverberations increasing the noise of the data and hence increasing the possibility of the coda of the first arrival obscuring delayed arrivals.

It is difficult to distinguish between lateral variations in anisotropy and angular variations in the raypaths below the stations from this dataset. For lateral variations in anisotropy the anisotropic region must be located close to the surface to influence STN1096 and STN1136 but not STN1124 (Figure 3.24) and the close spacing of STN1124 and STN1136 $(1.3 \mathrm{~km})$ would indicate very localised spatial changes in anisotropy. It appears more likely that the recorded splitting is the result of slight differences in raypath angle to the symmetry axis of the Haast schist and other structures at depth.

\subsection{Summary}

The results from shear wave splitting analysis for the crust of the Southern Alps indicate 0$0.08 \mathrm{~s}$ of splitting with the transverse component fast. Consistent results are obtained using both single trace methods of Silver and Chan (1991) and stacked data methods. Best results are obtained using a combination of deconvolution and cross correlation on stacked data. The delay time was in most cases close to half or one period of the data, which indicates the possibility of cycle skipping and the possible absence of real splitting. STN1096 shows splitting of $0.04 \mathrm{~s}$, STN1124 indicates no splitting and STN1136 has 0.08 s of splitting with the fast direction aligned with the transverse component.

Low or zero delay times for the crust are unexpected as these rocks have been shown to be strongly anisotropic when measured in the laboratory (Godfrey et al., 2001). To create the observed splitting from a $20 \mathrm{~km}$ thick body of uniformly dipping Haast schist the incidence angle of the SmS waves to the axis of symmetry needs to vary from $48^{\circ}$ for rays into STN1096 to $50^{\circ}$ at STN1124 and back to $48^{\circ}$ at STN1136. However, this region has seen multiple phases of deformation (Little et al., 2002) and these differently oriented structures 
may obscure or cancel out any splitting that has occurred. Either slight differences in the angle of the ray path through the anisotropic rocks for each station, or spatial variations in anisotropy on the scale of $1 \mathrm{~km}$ need to be invoked to produce the observed variations in delay time. 


\section{SEISMIC VELOCITY MODELLING AND POISSON'S RATIO}

Poisson's ratio can provide information on the composition and pore fluid pressure of the crust (Spencer and Nur, 1976; Marquis and Hyndman, 1992; Christensen, 1996). Resistivity and seismic studies across South Island indicate a region of high conductivity and low compressional seismic wave velocity under the Southern Alps (Smith et al., 1995; Stern et al., 2001; Wannamaker et al., in press). The anomalous properties of this region have been attributed to the presence of fluids, released through prograde metamorphism, under high pore fluid pressure (Kleffmann, 1999; Stern et al., 2001; Wannamaker et al., in press) and also the interconnectivity of pore fluid (Vry, in prep.). Investigation of the range and variation in Poisson's ratio can provide constraints on these hypotheses and possible insights into the processes occurring at depth in the deforming crust.

Estimates of Poisson's ratio can be made through combining P and S-wave velocities for waves that pass through the same region of crust. Models of P-wave velocities for both Transects I and II have been made (van Avendonk et al., 1999; Scherwath, Stern, Davey, Davies, Kleffmann and Okaya, submitted 2002) (Figure 2.5). The P-wave velocity model of Transect I is converted into S-wave speeds and forward modelling is undertaken using Sg and $\mathrm{SmS}$ phases. From these models spatial variations in Poisson's ratio in the crust under the Southern Alps can be illuminated. Furthermore, Poisson's ratio is also investigated using velocities measured at individual stations to determine a 1D mean Poisson's ratio along narrow ray paths, to verify the results from the $2 \mathrm{D}$ analysis. 


\subsection{Background}

\subsubsection{Poisson's ratio}

Poisson's ratio $(\sigma)$ is the ratio of radial to axial strain, and is a measure of how a material responds to compression and shear. Values range from 0.5 for a fluid to 0 for material that has an infinite resistance to shear. Poisson's ratio can be determined from compressional and shear seismic velocities $\left(\mathrm{V}_{p}\right.$ and $\left.\mathrm{V}_{s}\right)$ using the relation (Holbrook et al., 1988):

$$
\sigma=\frac{1}{2}\left[1-\left(\frac{V_{p}^{2}}{V_{s}^{2}}-1\right)^{-1}\right]
$$

Within the crust values range from 0.15 in low $\mathrm{V}_{p}$ zones, as is seen under the Black Forest Germany (Holbrook et al., 1988), to values of 0.32 for mafic composition rocks (Christensen, 1996). In young crustal regions an average value of 0.25 is observed and is attributed to felsic composition crust (Zandt and Ammon, 1995).

Crustal Poisson's ratio is sensitive to variations in lithology (Christensen, 1996) through which the waves travel and also the presence of fluids, pore fluid pressure (Spencer and Nur, 1976) and the aspect ratio of the pores (Marquis and Hyndman, 1992). In addition, apparent variations in Poisson's ratio can result from seismic anisotropy (Godfrey et al., 2001; Takanashi et al., 2001). A reliable Poisson's ratio is difficult to estimate from seismic data in regions of strong anisotropy (Godfrey et al., 2001). Results of the previous chapter indicate that there is minimal or no shear wave splitting for crustal raypaths through the Southern Alps, and hence the method was deemed appropriate to be used in this region.

Christensen (1996) examined a wide range of rock types, including monomineralic rocks, to determine their Poisson's ratio. For plutonic rocks a trend was observed where Poisson's ratio increased corresponding to a reduction in silica content. Values increase from 0.24 for a granite to 0.29 for a gabbro. Poisson's ratio for rocks of increasing metamorphic grade corresponds well with expected values for changing mineral compositions, and also there is a general trend of increasing Poisson's ratio with rock density. Iron and magnesium may also have some effect, e.g. enstatite $\left(\mathrm{MgSiO}_{3}\right)$ has $\sigma=0.24$ and orthoferrosilicate $\left(\mathrm{Fe}_{2} \mathrm{SiO}_{4}\right)$ has $\sigma=0.336$. There is no simple trend between mafic and felsic rocks, however, in the 
range of $55-77$ wt\% $\mathrm{SiO}_{2}$ most rocks showed a trend of increasing Poisson's ratio with decreasing silica content (Christensen, 1996).

Spencer and Nur (1976) investigated the effect of pore fluid pressures on $\mathrm{V}_{p} / \mathrm{V}_{s}$. In dry granite samples they found that with increasing pressure and temperature Poisson's ratio also increases. At a given temperature the confining pressure has a greater effect on $\mathrm{V}_{p}$ than $\mathrm{V}_{s}$. However, with low pore fluid pressures and low confining pressure there is a decrease in the bulk modulus and in $\mathrm{V}_{p}$, while the shear modulus and $\mathrm{V}_{s}$ are only affected by temperature of the crystalline matrix. Carcione and Cavallini (2002) show that dry samples tend to have lower $\sigma$ than fluid filled samples.

At low pore fluid pressure low $\mathrm{V}_{p}$ and almost unchanged $\mathrm{V}_{s}$ result in a decrease in Poisson's ratio with increasing pressure and temperature (Spencer and Nur, 1976; Carcione and Cavallini, 2002). Increasing the pore fluid pressure but keeping the confining pressure and temperature unchanged results in a decrease in $\mathrm{V}_{s}$ while $\mathrm{V}_{p}$ is less affected. This equates to an increase in Poisson's ratio (Spencer and Nur, 1976; Carcione and Cavallini, 2002). This trend of increasing Poisson's ratio continues until at high temperatures the bulk modulus of the pore water decreases and results in a drop in $\mathrm{V}_{p}$ (Spencer and Nur, 1976).

Measurement of rocks with dry and fluid filled fractures show similar trends to those observed for samples with fluid filled pores, as long as the rocks retain some overall coherence. The compressional velocity increases markedly with water saturation, while shear wave velocity is not greatly effected (Nur and Simmons, 1969). (O'Connell and Budiansky, 1974) showed that compressional velocity is much more sensitive to water saturation than shear wave velocity using formulae that calculate the elastic properties of cracked rocks. $V_{p} / V_{s}$ ratio for granite, at $0.5 \mathrm{GPa}$, appears to reach a minimum at around $10 \%$ water saturation, above this point both the shear and compressional wave velocities decrease rapidly, with reduction of shear wave velocity occurring more rapidly (Watanabe, 1993). In essence it appears that the velocity of the compressional waves is dependent on the compressibility of the whole rock including the fluids, which are much less compressible than air, while the shear waves transmit through the matrix of the rock and hence are not as strongly influenced by the fluids, up to the point where the rock matrix becomes entirely fractured 
and the shear wave velocity drops. This means that up to a point an increase in fluids will result in a reduction of Poisson's ratio, After this point, as the pressure and fluid content increases, the Poisson's ratio will start to increase.

These trends of Poisson's ratio with pressure, temperature and pore pressure are not as straight forward as they are portrayed above, because the shape of the pores can also influence Poisson's ratio (Marquis and Hyndman, 1992). The aspect ratio of fluid filled pores can have a greater influence on P-wave velocity, and hence Poisson's ratio, than the volume of pore space in a rock. Thin pores of aspect ratio less than 0.01 will increase Poisson's ratio while more equidimensional pores will decrease it by up to 0.05 (Marquis and Hyndman, 1992).

\subsubsection{Poisson's ratio from seismic data, previous work}

Many researchers have used wide angle reflection and refraction data to model compressional and shear wave velocities within the crust. Some researchers have continued further to combine these models to calculate Poisson's ratio in the crust and mantle. Price and Morgan (2000) used inversion techniques to produce 2D, P and S-wave models to investigate the location and composition of the $\mathrm{W}$ and Flannan mantle reflectors under Scotland. They combined both wide angle reflection, refraction and near vertical reflection data to locate the reflectors and determine the velocity of these reflecting bodies. They determined a Poisson's ratio of $0.25 \pm 0.01$ for the mantle and $0.29 \pm 0.02$ for the reflecting bodies, which is consistent with peridotite and eclogite respectively.

Holbrook et al. (1988) used Poisson's ratio as a possible indicator of changes in lithology in the crust in Germany. They estimated Poisson's ratios from 0.25 in the upper crust, to 0.22-0.23 in the mid crust and 0.24-0.3 in the lower crust. However, there was a region of exceptionally low Poisson's ratio of 0.15 in the mid crust of the Black Forest area, corresponding to an area of low $\mathrm{V}_{p}$. This low $\mathrm{P}$ velocity region was not seen in the $\mathrm{S}$-wave data and was attributed by Holbrook et al. (1988) as resulting from a high quartz content in this region and fluids at low pore fluid pressure.

Local studies on crustal velocities and Poisson's ratio have been undertaken by Eberhart- 
Phillips and Bannister (in press) and Kleffmann (1999). Eberhart-Phillips and Bannister used seismic tomographic inversions to identify changes in crustal velocity and investigate $\mathrm{V}_{p} / \mathrm{V}_{s}$ throughout South Island, New Zealand. Along the approximate line of Transect 1 , they identify a region of low $\mathrm{V}_{p} / \mathrm{V}_{s}$ of $1.65(\sigma=0.21)$ under the central part of the Alps and $\mathrm{V}_{p} / \mathrm{V}_{s}$ of around $1.7(\sigma=0.24)$ in the surrounding area. Research by Kleffmann (1999) from the SIGHT project, using active source data along Transect II, shows an average Poisson's ratio of 0.22 for the crust. In the adjacent region east of Lake Pukaki Kleffmann (1999) estimated a mean Poisson's ratio of 0.21 which he attributed to be an average Poisson's ratio for the greywacke and schist rocks east of the Southern Alps.

Determination of Poisson's ratio is limited by the need to obtain coincident P and Swaves (Holbrook et al., 1988). Receiver function methods improve this problem as $\mathrm{V}_{p} / \mathrm{V}_{s}$ can be determined from the same trace (e.g. Zandt and Ammon, 1995; Zhu and Kanamori, 2000). These methods require either teleseismic arrivals or impulsive crustal events and coverage is limited by the recorded events. Here, the use of active source P and S-wave velocity models across the Southern Alps are employed to create a detailed view of Poisson's ratio across the plate boundary. The $\mathrm{P}$ and $\mathrm{S}$-wave velocity models will be non-unique solutions for the data, and as a result the calculated Poisson's ratio will also be non-unique.

\subsection{Dataset}

To estimate Poisson's ratio for the crust a coverage of both $\mathrm{P}$ and $\mathrm{S}$ phases is required. Due to the weakness of the S-wave arrivals from the east coast shots, as a result of large offsets, only data recording the west coast shot arrivals are investigated (Figure 4.3). The most impulsive phases for which both $\mathrm{P}$ and $\mathrm{S}$-wave equivalents are recorded over a range of stations are the Moho reflections PmP, SmS and the crustal refractions Pg and Sg. Sn and SIS are either too weak or not recorded and as a result these phases and their P-wave equivalents are not used in this study.

$\mathrm{PmP}$ arrivals at each receiver gather can be identified from $\sim 50 \mathrm{~km}$ to over $100 \mathrm{~km}$ offset. At close offsets the PmP arrivals merge with PIP, resulting in the first arrival of $\mathrm{PmP}$ being obscured in the coda of PlP. To reduce the error in picking the onset of PmP 


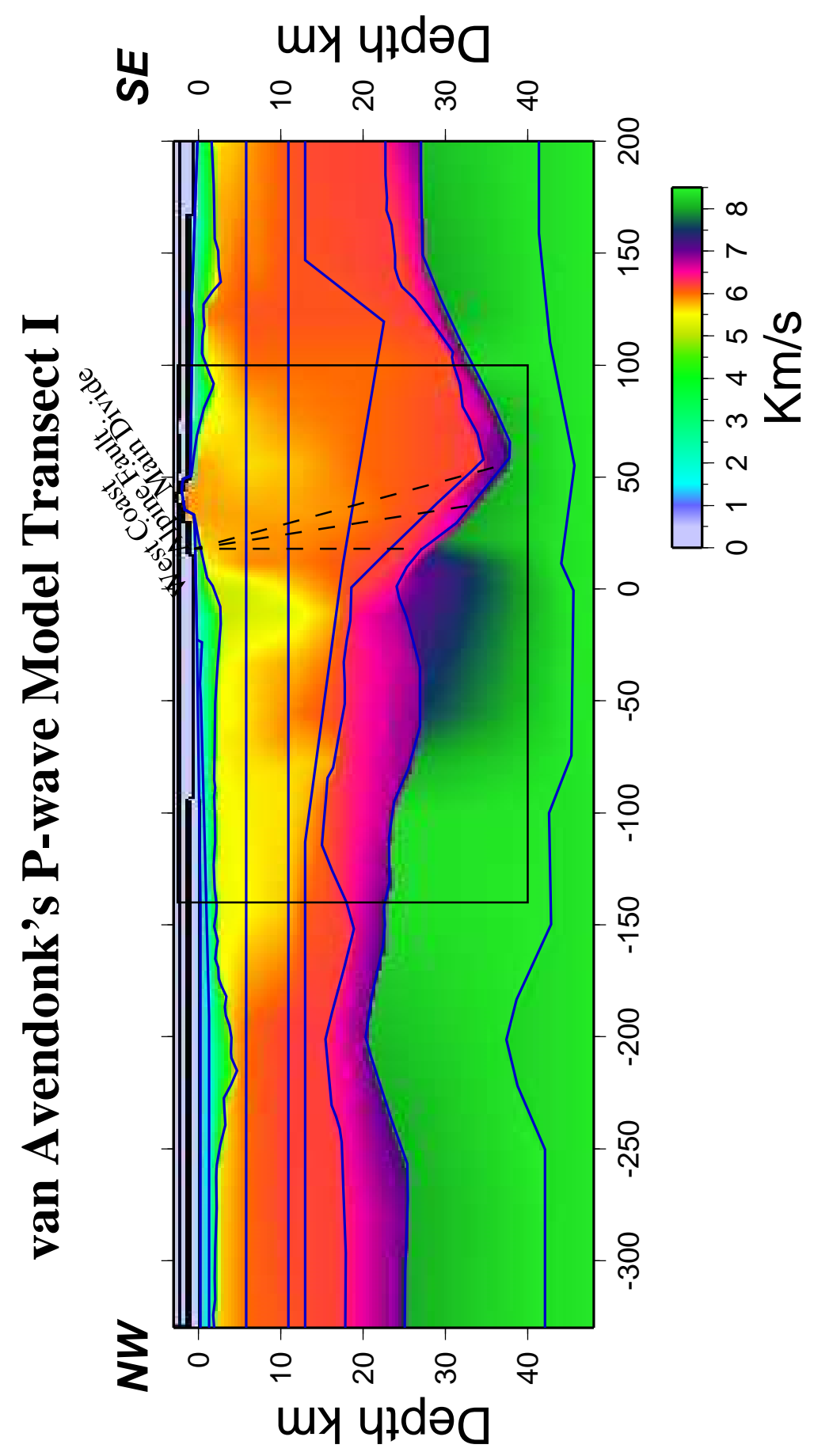

Fig. 4.1 P-wave inversion velocity model of the crust under the Southern Alps (van Avendonk et al., 1999). The model is aligned along Transect I of the SIGHT project and runs $N W$ - SE. The box indicates the region velocity modelling from this thesis Figures 4.4, 4.5 and 4.6. 


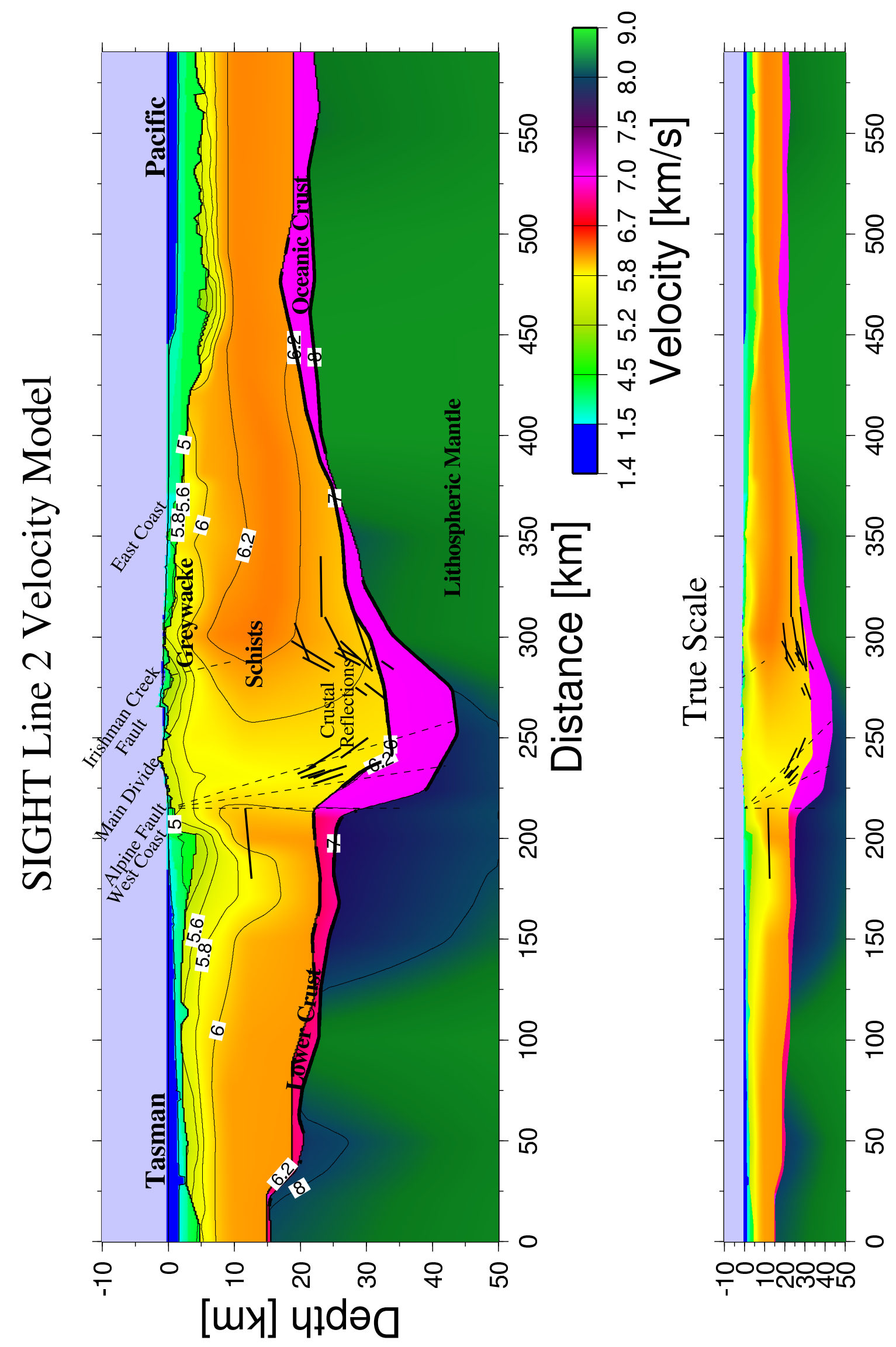

FIG. 4.2 P-wave velocity model of the crust under the Southern Alps. The model is aligned along Transect II of the SIGHT project and runs NW - SE. The dipping dashed lines represent possible orientations of the Alpine Fault zone at depth. This is the inversion model of Scherwath, Stern, Davey, Davies, Kleffmann and Okaya (submitted 2002). 
arrivals, it was picked at offsets where PIP arrived concurrently with PmP. At most stations SIS phase arrivals could not be identified, but where they are recorded they are weak and arrive earlier than SmS. Where the initial onset of $\mathrm{SmS}$ is emergent it may be possible that some SlS energy is arriving prior to the $\mathrm{SmS}$ and could be mis-identified as the $\mathrm{SmS}$ phase. If SIS has been picked rather than $\mathrm{SmS}$ it will result in apparently faster S-wave velocities and lower Poisson's ratio. However, where the arrival of SmS is impulsive and clear the travel times are comparable to those that have been picked for more emergent arrivals. SmS phases were picked predominantly between $60-70 \mathrm{~km}$ and at stations with strong signal up to offsets of over $100 \mathrm{~km}$.

$\mathrm{Sg}$ and $\mathrm{Pg}$ were strongest and most impulsive at close offsets, becoming weak at offsets of around $70 \mathrm{~km}$, and hence were not picked at higher offsets.

All arrival times were picked from the vertical component data, even where horizontal components were available, to provide consistency between the stations. The average error in the picks is $\pm 0.2 \mathrm{~s}$ for $\mathrm{PmP}$ and $\mathrm{Pg}, \pm 0.3 \mathrm{~s}$ for $\mathrm{SmS}$ and $\mathrm{Sg}$. The full list of pick offsets and estimated errors is included in Appendix D.

\subsection{Timing errors}

Consistency in timing between picks at different stations was checked to identify clock errors in the data. Pg arrivals were used as they were the most impulsive arrivals and were recorded at all but a few stations. The Pg picks were plotted for all stations on the same plot to identify trends with offset and identify picks that did not fit these trends. This method assumes the upper crust to be either homogeneous or at least smooth. Only two stations appeared to have clock errors; at station 1372 the Pg arrival was 1 second later than the surrounding stations and station 1328 was earlier by $0.2 \mathrm{~s}$. The data for both stations were adjusted accordingly. All other Pg arrivals were within $0.1 \mathrm{~s}$, which is the estimated accuracy of the P-wave picks. 


\section{$4.4 \quad \mathrm{P}$-wave modelling}

Velocity modelling of the crust has been previously undertaken across the Southern Alps of New Zealand from data collected as part of the SIGHT project. A 2D compressional velocity model was developed by van Avendonk et al. (1999) for the crust and upper mantle along Transect I. The model interfaces were initially located using forward modelling of near vertical reflection data. The velocities were then calculated using inversion techniques. The researcher's aim was to not bias the model with any preconceived ideas of crustal structure, and as a result the model is smooth (Figure 4.1). P-wave velocity modelling was undertaken along Transect II by Scherwath, Stern, Davey, Davies, Kleffmann and Okaya (submitted 2002). This model was also developed using forward and inversion techniques, however, the starting model was constrained by previous information on the crustal structure (Figure 4.2).

All velocity modelling in this study was undertaken using forward modelling with MacRay ${ }^{T M}$ software (Luetgert, 1992). For the modelling presented here, initially the model velocities and interfaces of van Avendonk et al. (1999) were used. However, there was significant disagreement between our picks and the modelled $\mathrm{P}$-wave arrivals, in part due to the smooth nature of the model. The model of van Avendonk et al. (1999) was fitted with a wider range of phases from onshore explosion data and also Lines $1 \mathrm{~W}$ and $1 \mathrm{E}$. This model was modified here using forward modelling techniques to fit our west coast PmP and Pg picks. The final model is shown in Figure 4.4. Due to the limited ray coverage of strong S-wave arrivals, parts of the model space of van Avendonk et al. (1999) could not be constrained (Figure 4.3). Modelling was undertaken using simultaneous modelling of both Pg and PmP arrives. Pn was not modelled because there were no Sn arrivals recorded. However, a comparison of measured and predicted Pn arrivals showed good agreement, within the $\pm 0.2 \mathrm{~s}$ error of picked Pn arrivals. Stations in a region west of the Alpine Fault, between STN1328 - STN1396, were locally arriving late. This suggests inhomogeneity in the shallow crust and due to the chosen resolution of the model these arrivals were not modelled. Arrivals at stations immediately adjacent to these locally slow stations were within the error of the picked arrivals.

The model $\mathrm{x}$-coordinate $0 \mathrm{~km}$ is defined as the west coast; the surface trace of the Alpine 


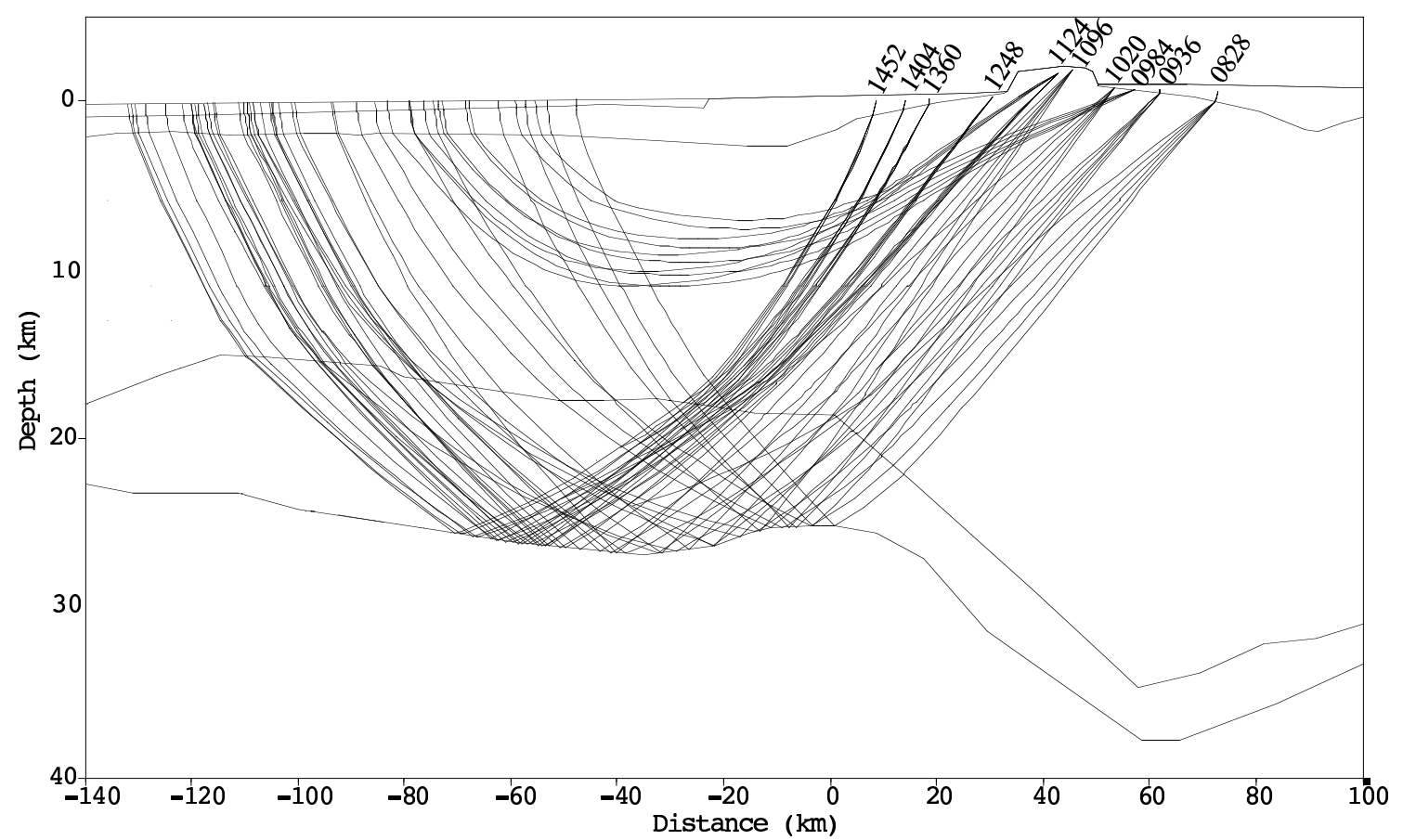

Fig. 4.3 Ray coverage of Moho reflected phases used in crustal modelling. The direct arrivals shown are $\mathrm{Sg}$ phases only, $\mathrm{Pg}$ is not shown but is recorded at all stations. A selection of stations are displayed. P, $S$ and Poisson's ratio modelling is undertaken using this ray coverage. Note that only west coast receiver gathers are used in this study.

Fault lies at model $18 \mathrm{~km}$ (Figure 4.4). The model is aligned along the line of Transect I, approximately NW - SE (Figure 2.5).

\subsubsection{Discussion of $\mathrm{P}$-wave model}

A low velocity region centred around the west coast, coloured in green on Figure 4.4, was constrained mainly from slow Pg arrival times into stations close to the west coast. The region of slowest velocity has not been well constrained, but the edges of this low velocity region have been constrained by both Pg and PmP. A similar but less marked basin and a slow velocity region are also seen to the south on Transect II (Figure 4.2) (Scherwath, Stern, Davey, Davies, Kleffmann and Okaya, submitted 2002). This low velocity region, on Transect I, may indicate that the basin off the west coast is much deeper than previously proposed, up to around $4 \mathrm{~km}$ deep. Previous seismic reflection studies placed the sediment/basement interface at $2.57 \mathrm{~km}$ (Sircombe and Kamp, 1998; Nathan et al., 1986). However, the low crustal $V_{p}$ may also be the result of cracks and fluids in the upper crust, as 
the edge of the Australian Plate has been shown to be down-flexing underneath the weight of the Pacific Plate (Harrison, 1999) and this may result in the tensional opening of aligned fluid filled cracks.

\subsection{S-wave velocity modelling}

The final $\mathrm{P}$-wave velocity model was converted into S-wave velocities using a standard $\mathrm{V}_{p} / \mathrm{V}_{s}$ ratio of $1.732(\sigma=0.25)$ except in regions of water where the velocity was left unchanged. The velocity conversion was done partly using MacRay ${ }^{T M}$ and partly manually as MacRay ${ }^{T M}$ appeared to not handle sharp velocity contrasts. The velocities of the model were then altered using forward modelling techniques to fit $\mathrm{Sg}$ and $\mathrm{SmS}$ arrivals; as maintained above some ambiguity exists over the occurrence of SlS as the S-wave data are not impulsive, but the reflections were modelled purely as SmS. Only velocities were altered during the modelling, as changing the layer depths would cause a misfit of the $\mathrm{P}$-wave data. Simultaneous modelling of $\mathrm{Sg}$ and $\mathrm{SmS}$ converged into the S-wave model shown in Figure 4.5.

\subsection{Poisson's ratio model}

The $\mathrm{P}$ and $\mathrm{S}$ velocity models were converted into raster grids in MacRay ${ }^{T M}$ (Luetgert, 1992). These raster files were then converted into Generic Mapping Tool (GMT) format files (Wessel and Smith, 2002), with a cell dimension of $1 \mathrm{~km}$ horizontally by $0.4 \mathrm{~km}$ vertically. Poisson's ratio was calculated from these two grid files using GRDMATH, a mathematical function of GMT, using the approximation for Poisson's ratio (Equation 4.1) from Holbrook et al. (1988). The model of Poisson's ratio is shown in Figure 4.6.

The grid of Poisson's ratio was clipped using GRDCLIP (GMT function) to change any values that lie outside the allowable range of values (0-0.5) to become undefined. These extraneous values occur where there was air or water in the model; these regions are shown in grey in Figure 4.6. The values in the model range from 0.05 through to 0.28 . The bright blue and red values along the sediment crust interface adjacent to the Southern Alps are 


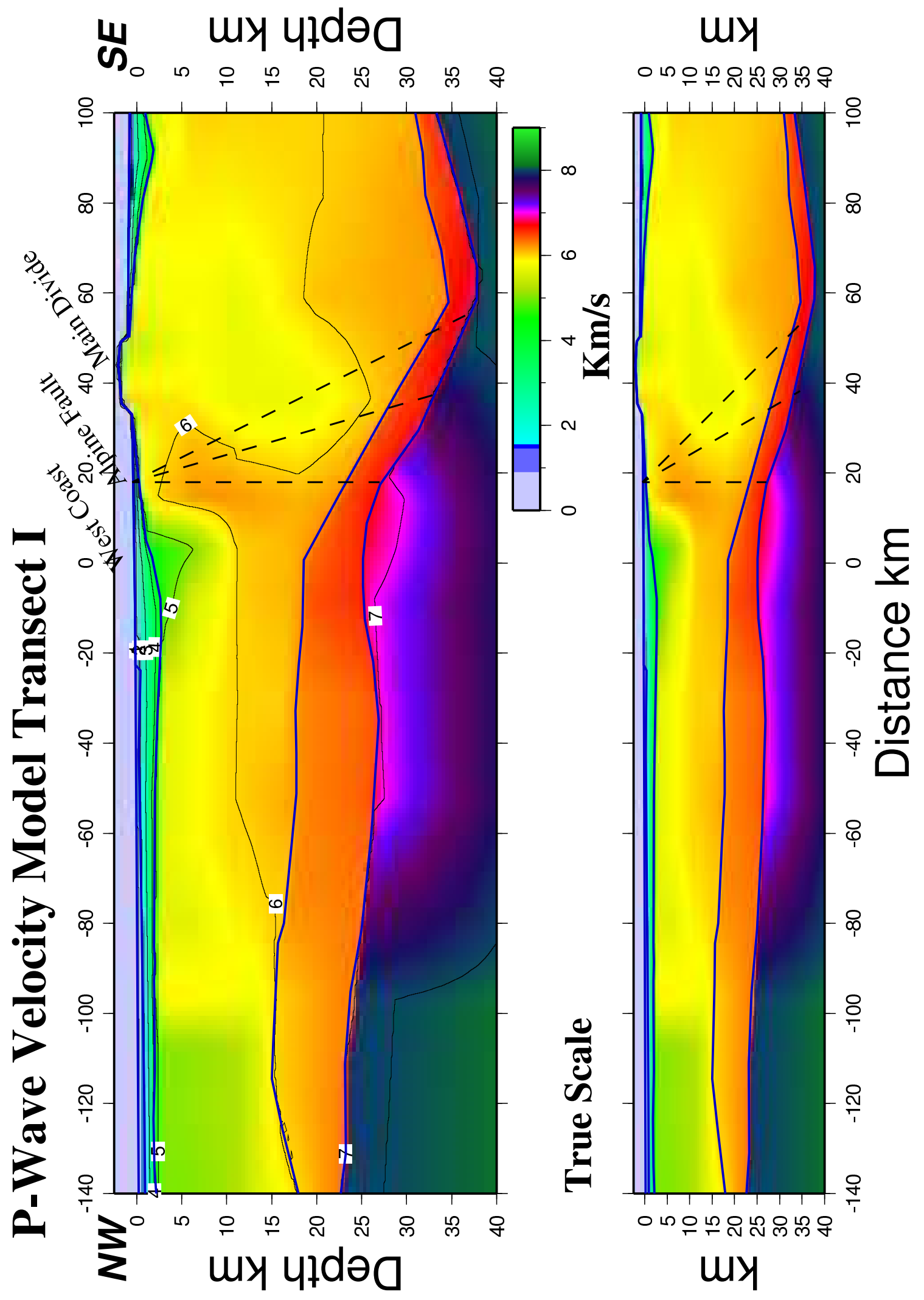

Fig. 4.4 P-wave velocity model of the crust under the Southern Alps. The model is aligned along Transect I of the SIGHT project and runs NW - SE. The dipping dashed lines represent possible orientations of the Alpine Fault zone at depth and are included here as a reference. 


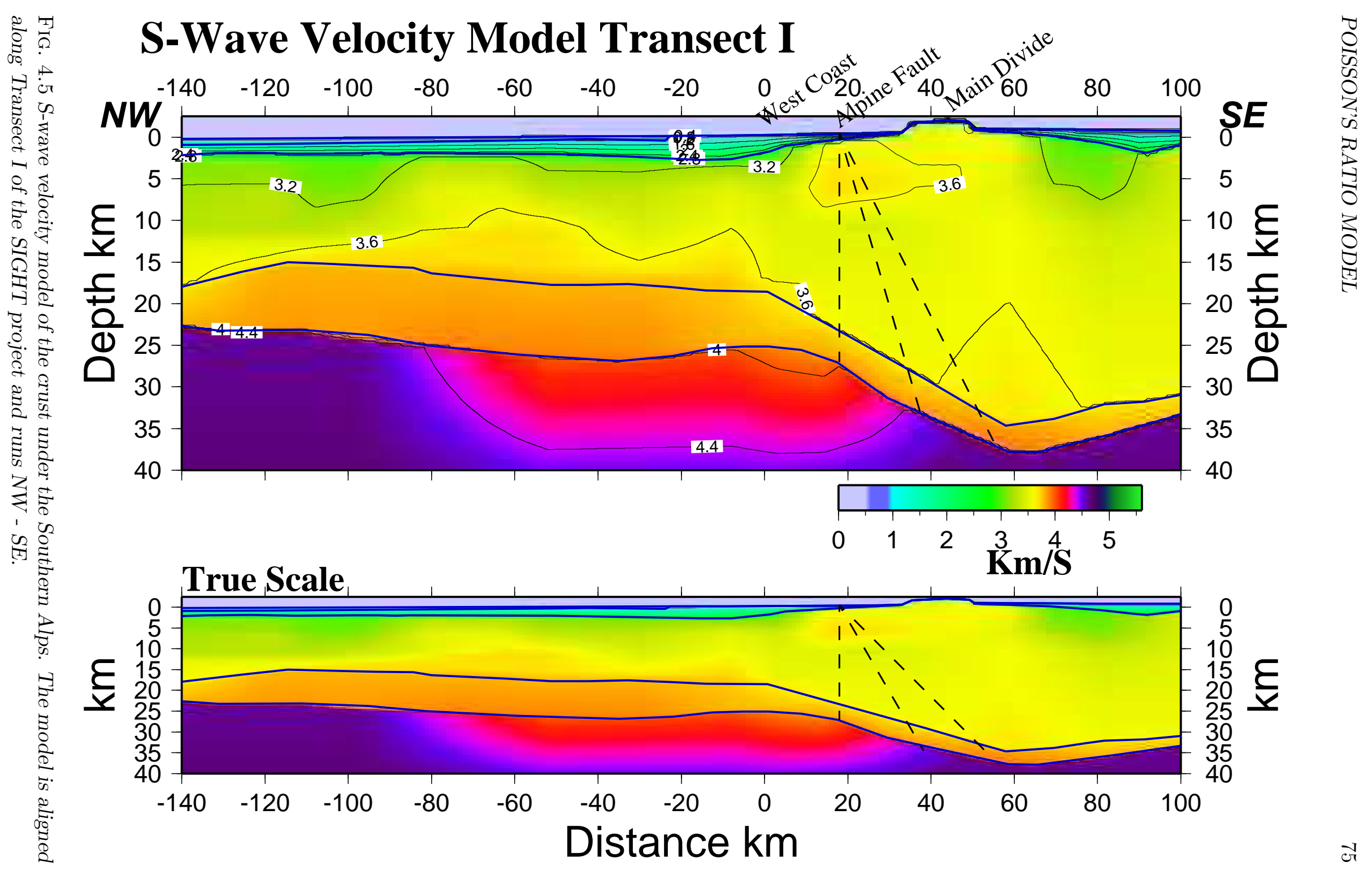


artifacts of using a grid to sample the data. These cells lie on the overlap between the sediment and crust or sediment and water and contain unrealistic Poisson's ratio values. The coverage of the $\mathrm{P}$ and $\mathrm{S}$-waves are not consistent across the model as the region close to the west coast is sampled predominantly by Pg but not Sg. To overcome the problem of varied data coverage Poisson's ratio was modelled in 1D from PmP and SmS phases over a narrow range of offsets at individual stations, which provides a mean Poisson's ratio over a ray path. Poisson's ratio is also estimated from $\mathrm{Pg}$ and $\mathrm{Sg}$ phases to further elucidate the low values gained in the upper crust off the west coast of South Island. Discussion of 1D and 2D modelling follows (Section 4.9).

The depth and shape of the Moho has been taken directly from the work of van Avendonk et al. (1999). The depth of the Moho was raised by $3 \mathrm{~km}$, and the arrivals into STN1124 were re-modelled, to investigate what magnitude errors could be expected from a mis-located reflector. This error analysis indicated that raising the Moho could produce a Poisson's ratio up to 0.05 higher than previously modelled. The vertical error in the location of the Moho is probably around $\pm 3 \mathrm{~km}$ and hence an error of \pm 0.05 in Poisson's ratio could be expected for the results shown here.

\subsection{Poisson's ratio from $1 \mathrm{D}$ analysis}

Estimation of Poisson's ratio in 1D was undertaken where the $\mathrm{P}$ and $\mathrm{S}$-waves sample the same region of crust. At offsets between 115-140 km PmP is the most impulsive arrival and it is un-obscured by the coda of PlP. At some stations $\mathrm{SmS}$ is also sufficiently impulsive and un-obscured by SlS over the same range of offsets to be picked with confidence. In total there were four stations with both PmP and SmS arrivals impulsive over the same range of offsets; these are: STNSP10, STN1096, STN1124 and STN1136.

Poisson's ratio was estimated using the assumption that the SmS and PmP phases, recorded over the same narrow offset range, will travel along the same or close to the same ray path and are reflected off the same layer (in this case the Moho). The assumption of similar ray paths for $\mathrm{P}$ and $\mathrm{S}$ phases was verified using ray tracing techniques. The total length of the raypath, estimated using ray tracing techniques, for both $\mathrm{SmS}$ and $\mathrm{PmP}$ 


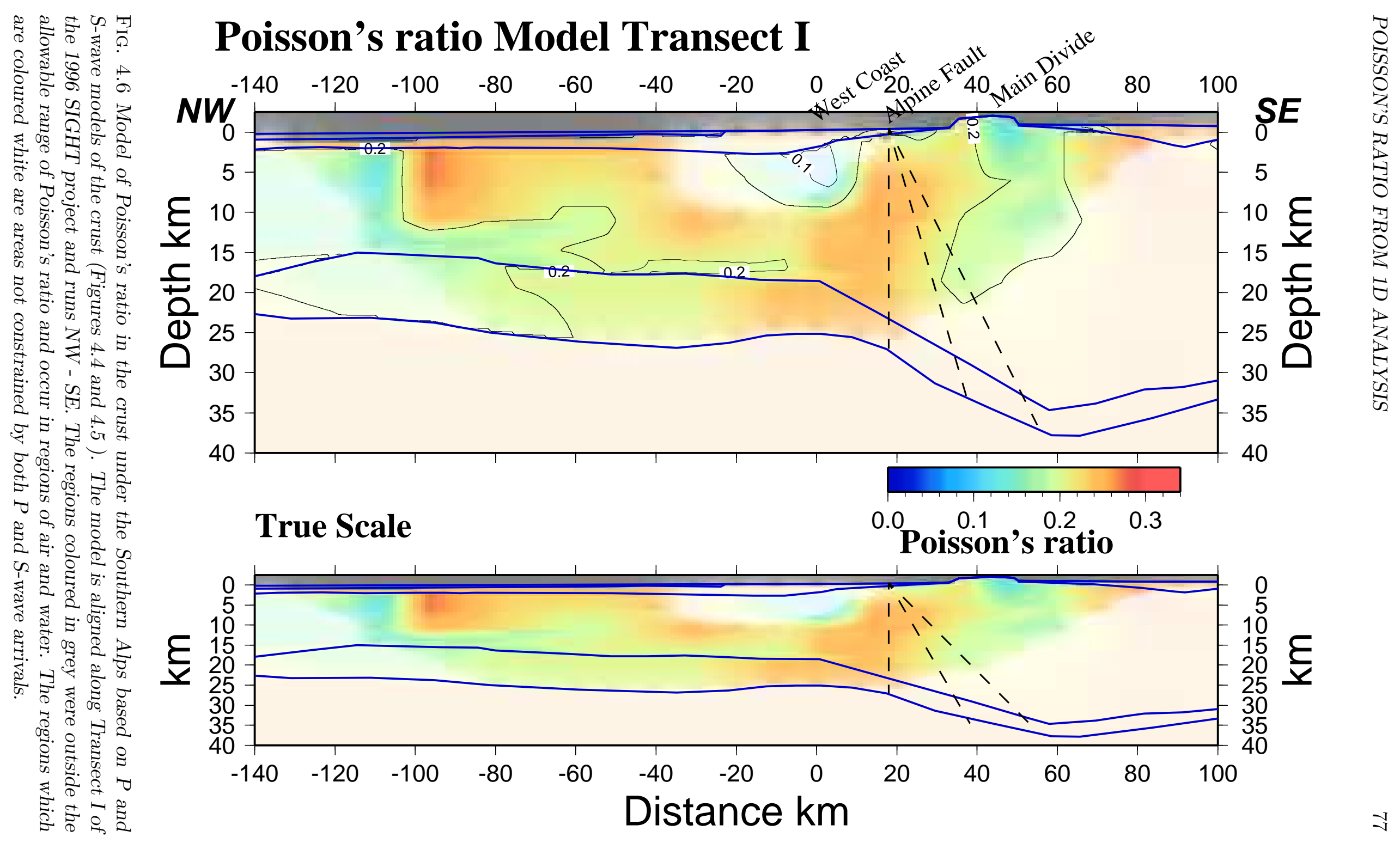


Results of 1D Poisson's ratio analysis

\begin{tabular}{|l|c|c|c|}
\hline Station & Offset $(\mathrm{km})$ & Poisson's ratio $(\sigma)$ & Error $( \pm \sigma)$ \\
\hline SP10 & 120 & 0.22 & 0.01 \\
\hline 1096 & 120 & 0.24 & 0.01 \\
\hline 1124 & 140 & 0.21 & 0.01 \\
\hline 1136 & 120 & 0.22 & 0.01 \\
\hline
\end{tabular}

TABLE 4.1

Results of the 1D Poisson's ratio analysis. The stations are ordered by location with SP10 lying furthest east away from the shots through to STN1136, which lies furthest west. The errors are calculated by propagating the pick error through Equation 4.1.

phases differed by up to $1 \mathrm{~km}$. The error produced from a $1 \mathrm{~km}$ difference in path length is smaller than that introduced by picking errors. However, despite the similar length of ray path for PmP and SmS, the dip of the reflector $\left(2-5^{\circ}\right)$ (as seen from the 2D model) results in a difference of up to $10 \mathrm{~km}$ horizontally and $0.5 \mathrm{~km}$ vertically in the point of reflection off the Moho for the PmP and SmS phases. We need to assume laterally homogeneity over this distance to relate these phases.

Figure 4.7 shows the raycoverage at STN1136, and Figure 4.8 shows the picks used for 1D Poisson's ratio calculation at STN1136. Using an average velocity along the entire ray path (d) the travel times $\left(\mathrm{T}_{p} \& \mathrm{~T}_{s}\right)$ of the $\mathrm{P}$ and the $\mathrm{S}$-waves respectively, can be compared with $\mathrm{V}_{p} / \mathrm{V}_{s}$.

$V_{s}=d / T_{s}$
$V_{p}=d / T_{p}$

Assuming the path lengths are the same for S and P-waves

$V_{s} T_{s}=V_{p} T_{p}$

$V_{p} / V_{s}=T_{s} / T_{p}$ 


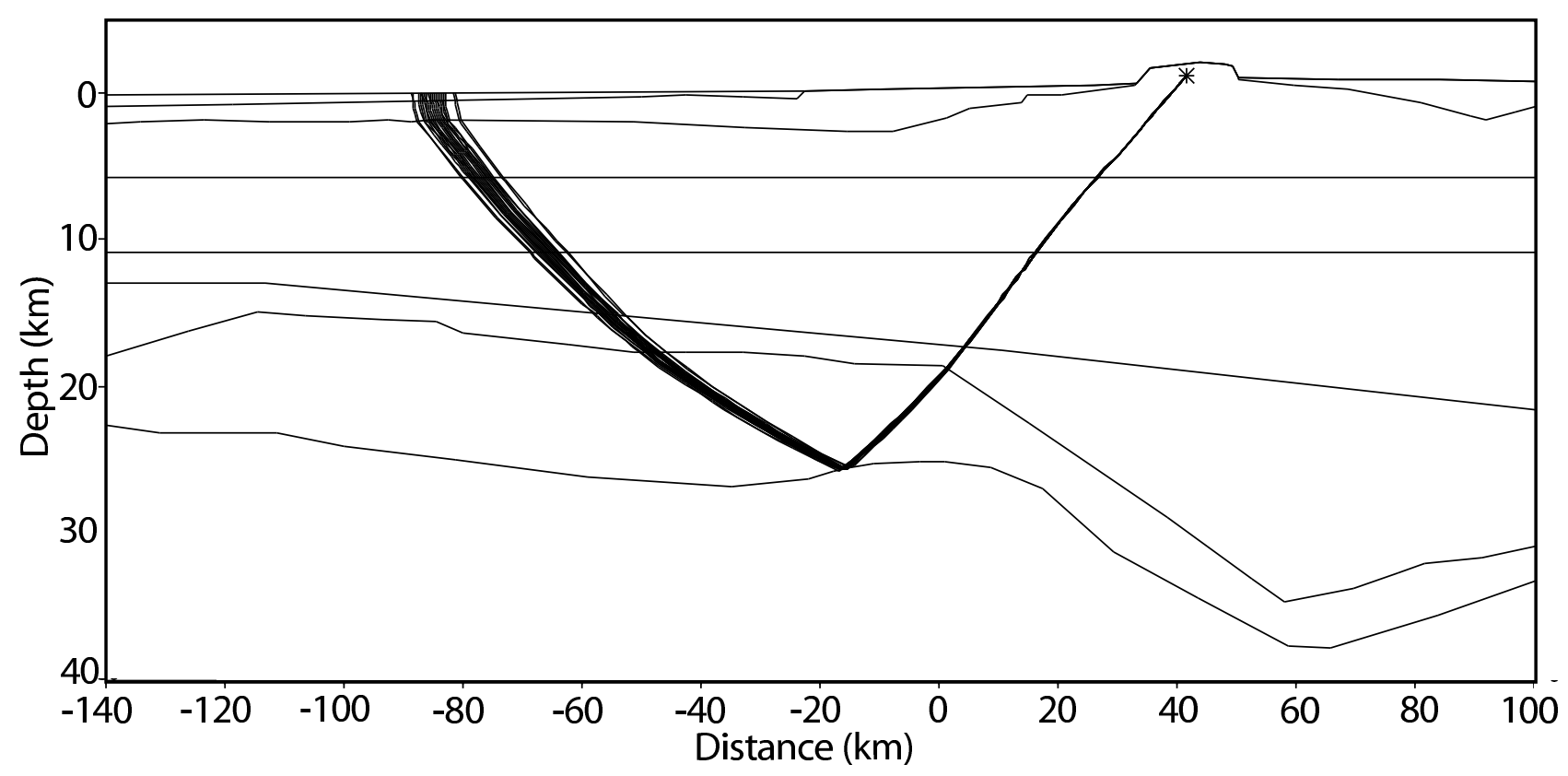

FIG. 4.7 Ray coverage for 1D model of Poisson's ratio from station 1136. The horizontal line indicates the model velocity boundaries for the $2 D \mathrm{P}, S$ and Poisson's ratio models of Figures 4.4, 4.5 and 4.6.

The results indicate low values of Poisson's ratio (average $\sigma=0.22$ ) and do not show any clear trends with spatial location of the stations (Figure 4.9 and Table 4.1). The error in Poisson's ratio are calculated from the travel time picking uncertainty.

\subsection{Poisson's ratio from $\mathrm{Pg}$ and $\mathrm{Sg}$ phases}

The velocities of both Pg and Sg phases are calculated from the gradient of a line fitted, using a linear regression, to picked arrivals. Poisson's ratio, from the Pg and $\mathrm{Sg}$ velocities, was estimated using Equation 4.1. Strong Pg and Sg arrivals were only recorded at STN1124 and STN1136, and results from these stations are shown in Table 4.2. Due to the scatter in the picked arrivals at STN1136 the errors in Poisson's ratio are calculated in two ways. For STN1124 the errors were calculated, as above, from the travel time pick uncertainty which gives an error of \pm 0.01 . Error can also be calculated from the velocity estimation, and for station 1136 the standard deviation of the linear regression to the velocities was greater than the pick uncertainty. Hence for STN1136 the error value is greater (Table 4.2). 

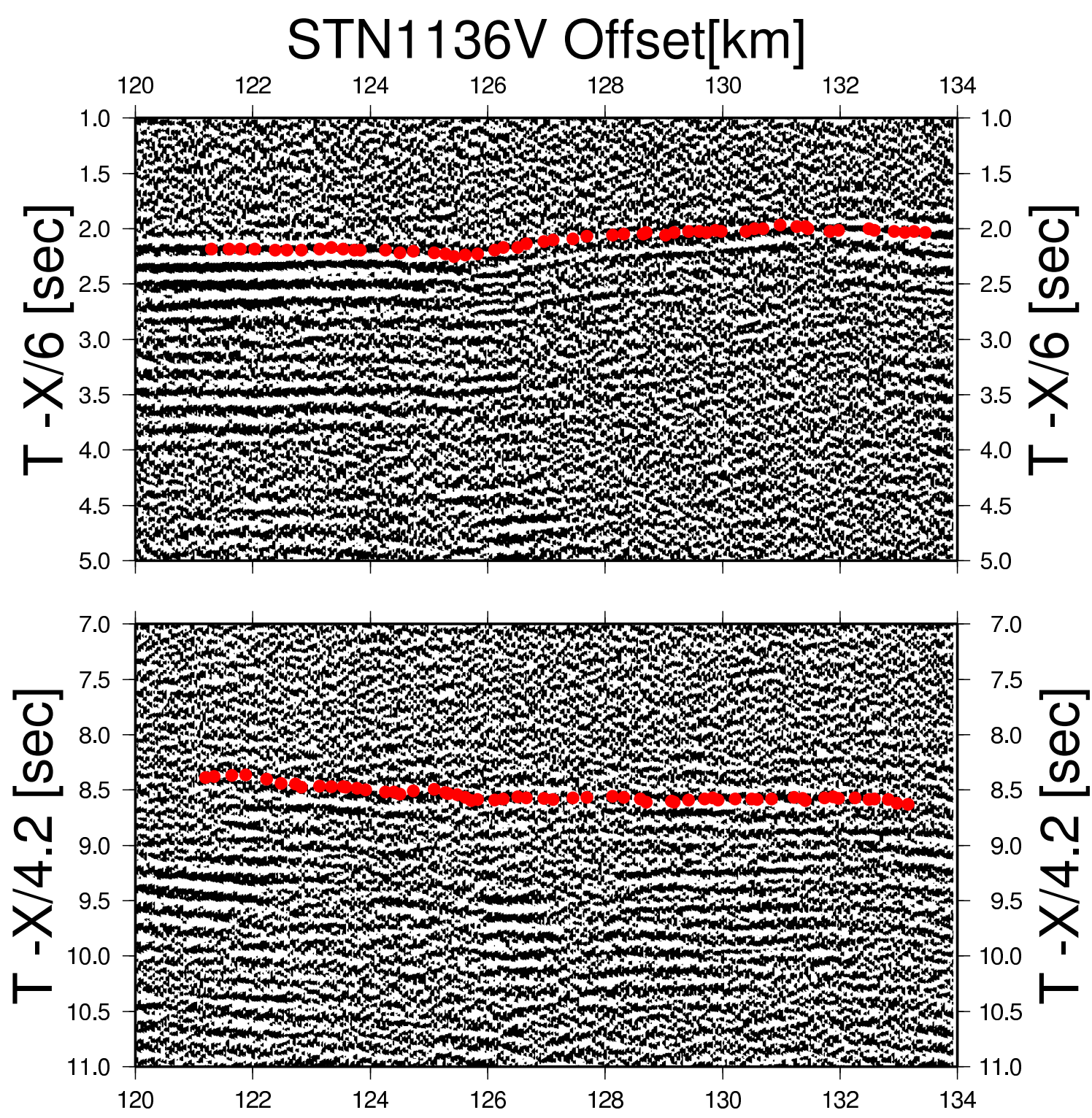

FIG. 4.8 Seismic data from STN1136 with picks for PmP and SmS phases. The upper image is the PmP arrival and the lower image is the $\mathrm{SmS}$ arrival. The red dots in both images are the picks used in the $1 D$ Poisson's ratio estimation over-laid on the seismic data. The $P$ and $S$-wave data are displayed with a reduced travel time of $6 \mathrm{~km} / \mathrm{s}$ and $4.2 \mathrm{~km} / \mathrm{s}$ respectively. 


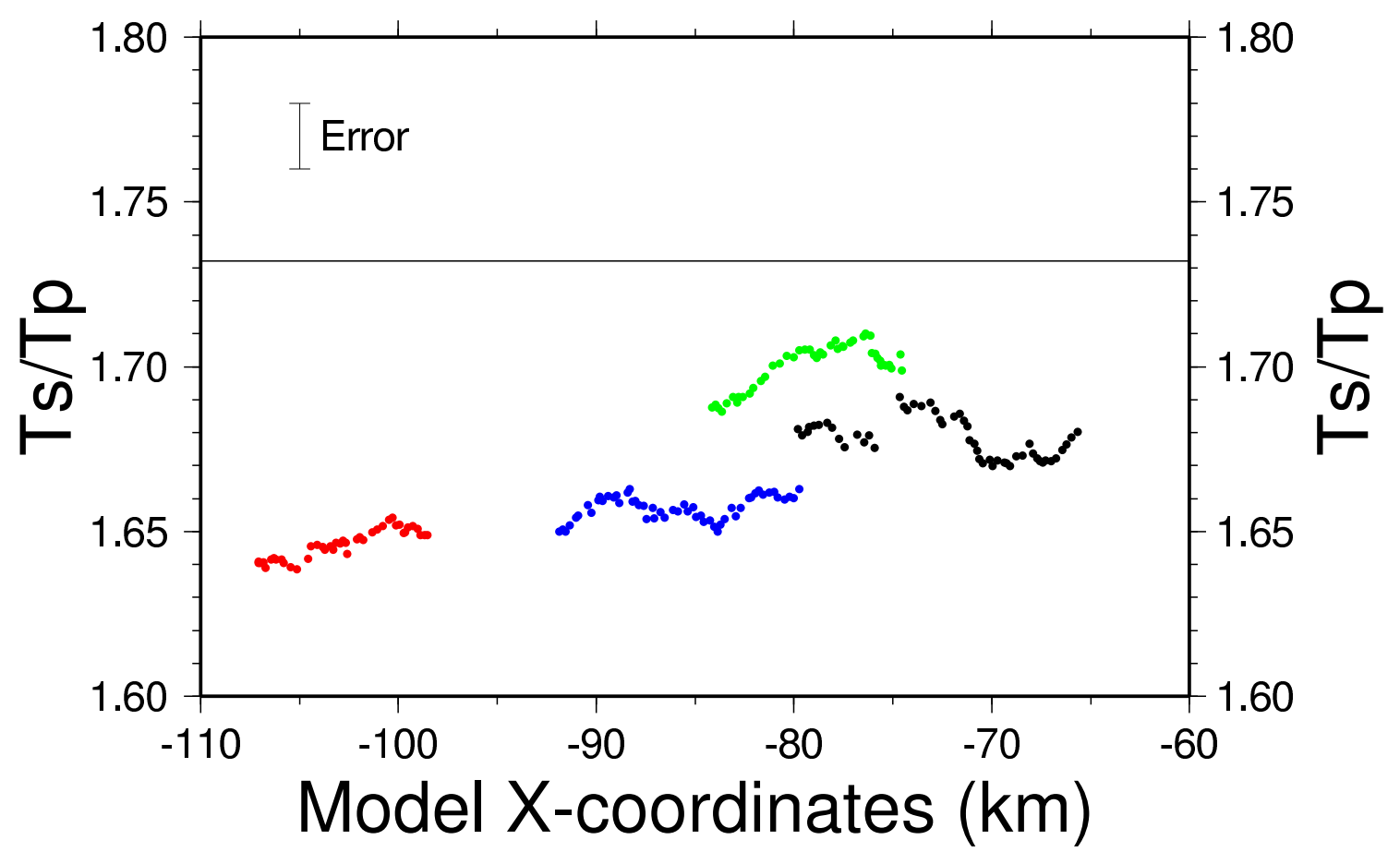

Fig. $4.91 D$ estimates of $V_{p} / V_{s}$ from PmP and $S m S$ phases. The vertical axis is the ratio of the travel times for the $P$ and $S$-waves, which is equivalent to $V_{p} / V_{s}$ assuming that both phases have the same raypath length. The horizontal line indicates a $V_{p} / V_{s}$ ratio of 1.732 which equates to a Poisson's ratio of 0.25 , an average value for crustal rocks. Data points are from STNSP10 (black), STN1096 (green), STN1124 (red) and STN1136 (blue). Error $( \pm 0.01)$ is shown by the error bar and is calculated from picking uncertainty. Mean values for each station are shown in Table 4.1.

Poisson's ratio estimates from $\mathrm{Pg} \& \mathrm{Sg}$

\begin{tabular}{|l|c|c|c|}
\hline Station & Offset $(\mathrm{km})$ & Poisson's ratio $(\sigma)$ & Error $( \pm \sigma)$ \\
\hline 1124 & $50-82$ & 0.20 & 0.01 \\
\hline 1136 & $50-78$ & 0.16 & 0.03 \\
\hline
\end{tabular}

TABLE 4.2

Estimates of Poisson's ratio from $\mathrm{Pg}$ and $\mathrm{Sg}$ velocities. The reported error for STN1124 is the error in Poisson's ratio calculated from the pick uncertainty. The error for STN1136 is the standard deviation of the linear regression to the velocities, and has been converted to Poisson's ratio. 
Poisson's ratios determined from $\mathrm{Pg}$ and $\mathrm{Sg}$ confirm the presence of low values of $\sigma$ in the upper crust. These values appear to be significantly lower than those estimated from Moho reflection phases and indicates that Poisson's ratio is decreasing towards the surface. This trend is in agreement with the $2 \mathrm{D}$ velocity modelling.

\subsection{Discussion}

A summary of crustal values of Poisson's ratio compiled by Zandt and Ammon (1995), using receiver function analyses, show that Poisson's ratio values lie in the range $0.23-0.3$ with the lowest reported value of 0.18 . However, a value of 0.15 has been estimated for a low $\mathrm{V}_{p}$ region underneath the Black Forest in Germany (Holbrook et al., 1988) and also in the Coso geothermal region, California (Lees and $\mathrm{Wu}, 2000$ ). Both 1D and 2D modelling across the Southern Alps also indicate low values of Poisson's ratio. 1D mean Poisson's ratios, estimated using PmP and SmS, lie between 0.21-0.24. The two estimates from the midupper crust, using $\mathrm{Pg}$ and $\mathrm{Sg}$, are $0.2 \pm 0.01$ and $0.16 \pm 0.03$. These values are in agreement with 2D modelling which also identifies regions of low Poisson's ratio, possibly as low as $\sim 0.14$, in the near surface to the east of the Southern Alps.

Low Poisson's ratio and $\mathrm{V}_{p}$ seen in the mid crust in the Black Forest, Germany is interpreted to occur as a result of a quartz rich rock composition combined with fluids at low pore fluid pressure (Holbrook et al., 1988). Another region of low Poisson's ratio $(\sigma=0.18)$ has been determined in the Altiplano, Bolivia (Zandt et al., 1994) and is attributed to felsic composition of the crust and high temperatures. Zandt et al. (1994) argue that the felsic composition of the crust may occur as a result of crustal shortening and thickening processes. In California low values of Poisson's ratio $\left(\sigma_{\min }=0.15, \sigma_{\text {ave }}=0.22\right)$ are identified at a depth of $1.5-3 \mathrm{~km}$ from a micro earthquake study and is attributed to be a result of the geothermal system in the region (Lees and $\mathrm{Wu}, 2000$ ). It appears that the low Poisson's ratio and $V_{p}$ seen under the Southern Alps in New Zealand are likely to be the result of both a quartz rich rock composition and fluids at low pore fluid pressure. An average Poisson's ratio for the crust to the east of the Southern Alps showed low values $\sigma=0.21-0.22$ (Kleffmann, 1999). These low values were interpreted to be average values for rocks of 
greywacke lithology in this region.

Low Poisson's ratio identified off the west coast of South Island (model $\mathrm{x}=0 \mathrm{~km}$ ) is sampled more effectively by Pg than by Sg. The extremely low Poisson's ratio of 0.10 is most likely a result of the poor Sg sampling. However, 1D modelling using $\mathrm{Sg}$ and $\mathrm{Pg}$ phases confirm the presence of low Poisson's ratios in the upper crust, with values as low as $0.16 \pm 0.03$. 2D modelling of PmP and SmS phases sample the edge of this low Poisson's ratio region and confirm the presence of values as low as 0.2. This region of low Poisson's ratio corresponds to the location of a sedimentary basin formed due to the down-warping of the Australian plate under the load of the Southern Alps (Harrison, 1999). Low P-wave velocities are likely to result from the tensional opening of aligned fluid filled cracks in the shallow crust as it is deflected downwards. The cracks would be close to the surface and hence will have low pore fluid pressure. Combined with a high fluid content in the rocks this can result in low Poisson's ratio (Watanabe, 1993; Spencer and Nur, 1976).

Magnetotelluric research on the Southern Alps elucidate a region of high conductivity from $10 \mathrm{~km}$ to $30 \mathrm{~km}$ depth (Wannamaker et al., in press). Seismology studies indicate a low P-wave velocity zone in the crust at about the same depth (Smith et al., 1995; Kleffmann, 1999; Stern et al., 2001)(Figure 4.10). They attribute this region of low P-wave velocity and high conductivity to abundant fluids, released through prograde metamorphism, under high pore fluid pressure.

Corresponding with the location of this body of low $\mathrm{P}$-wave velocities is a region of low Poisson's ratio of $\sim 0.15$, from the surface to a depth of $20 \mathrm{~km}$ (Figure 4.10). The upper margin of this body is sampled by both $\mathrm{P}$ and S-waves, but the total depth extent is not constrained by the dataset. For a region of low $\mathrm{V}_{p}$ and low Poisson's ratio any fluids that are present are more likely to be at low rather than high pore fluid pressure (Spencer and Nur, 1976). An increase in silica content under the Southern Alps is also a possibility for decreased Poisson's ratio as the collisional setting may result in similar processes as are inferred in the Altiplano region (Zandt et al., 1994). Marquis and Hyndman (1992) demonstrate that fluid filled pores with an aspect ratio of between 0.01 and 1 will result in low Poisson's ratio while thin pores of aspect ratio less than 0.01 will result in an increase 


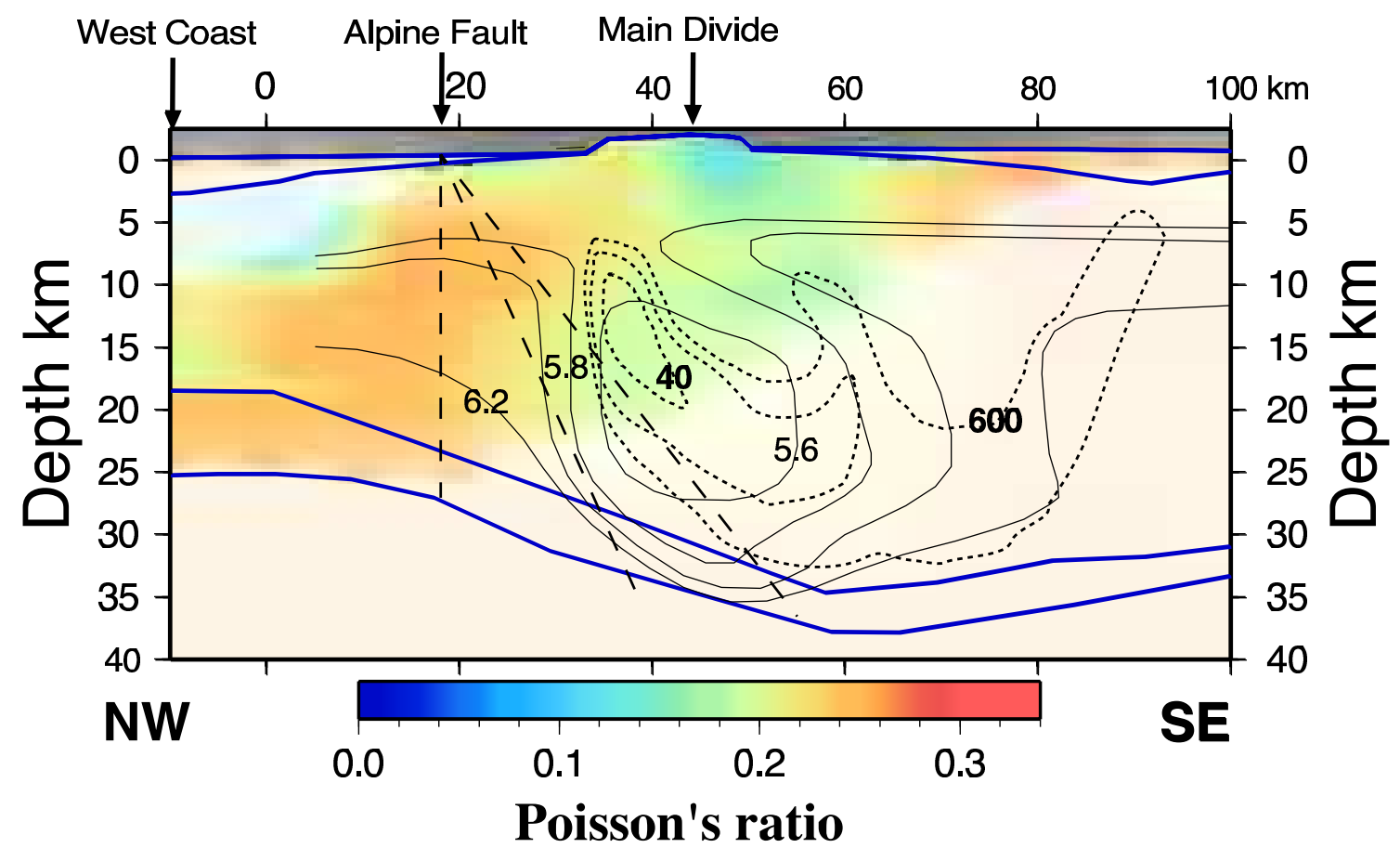

Fig. 4.10 Low Poisson's ratio (this study), high conductivity (Wannamaker et al., in press) and slow Vp (Kleffmann et al., 1998; Stern et al., 2001) anomaly under the Southern Alps. Dashed lines are the contours of apparent resistivity estimated along Transect I (40, 100 and $600 \mathrm{ohm}-\mathrm{m}$ contours are displayed). The thin lines are contours of wave speed $(\mathrm{km} / \mathrm{s})$ from Transect II, projected onto Transect I. The colours describe Poisson's ratio along Transect $I$, the strength of the data represents the raycoverage, with pale colours indicating no ray coverage.

in Poisson's ratio. Despite the fact that the Southern Alps is a region of compression and the unlikeliness that pores will be equidimensional, recent evidence indicates that pores are not strongly deformed (Vry, in prep.) and therefore may contribute to the low Poisson's ratio under the Southern Alps.

Crustal deformation, pore fluid and silica content in the crust of the Southern Alps appear to be related. Fluids are released during metamorphic dehydration reactions as the rocks pass through the crustal root zone. The location of the body of high conductivity (Wannamaker et al., in press) may indicate that the region of connectivity between the pores is limited to the middle to upper crust and is offset to the west of the crustal root zone where the fluids are thought to be released (Vry, in prep.). This indicates that though the fluid is released in the root zone, it may be trapped in pores that are not inter-connected; if the pores were connected fluid would escape to the surface directly above the root zone. As the 
fluids are brought towards the surface the fluid in the pores will expand eventually creating fluid connection between the pores at about $20 \mathrm{~km}$ depth (Vry, in prep.). This should result in an increase in conductivity. Once the pores are inter-connected the fluid can flow up towards the surface reducing pore fluid pressure and hence $\sigma$. Near the surface the pressure drop enables the precipitation of quartz into veins and creates a higher silica region near the surface. The coincident location of a high conductivity, low $\mathrm{V}_{p}$, low Poisson's ratio body offset in the direction of plate motion above the root zone supports the model of Vry (in prep.) for delayed inter-connectivity of pore fluid.

Contrasting this is the proposal of Kleffmann et al. (1998), Wannamaker et al. (in press) and Stern et al. (2001) for fluids under lithostatic pressure in the crust, released through prograde metamorphism. As the fluid filled rocks are moved up the ramp of the Alpine fault to the surface the rocks pass through the brittle-ductile transition and the fluid pressure is reduced to hydrostatic pressure, at about $10 \mathrm{~km}$ depth (Wannamaker et al., in press). This drop in pressure is thought to be reflected by the change to near-vertical configuration of the high conductivity body (Wannamaker et al., in press). This model does not fit with the Poisson's ratio estimates as high pore fluid pressure in the crust (e.g. Kleffmann et al., 1998; Stern et al., 2001; Wannamaker et al., in press) below $10 \mathrm{~km}$ would result in high Poisson's ratio (Spencer and Nur, 1976), which is the opposite to what is observed. This indicates that the lowering of pore fluid pressure may occur deeper than $10 \mathrm{~km}$, or that the model of delayed inter-connectivity of pores, which corresponds to the location of the body of high conductivity is more appropriate.

The upper part of the high conductivity body, as imaged by magnetotelluric studies, does not extend up to the surface, contrasting with the low Poisson's ratio body. The lack of correlation in the near surface may indicate that the connectivity of the pores may break down towards the surface as quartz and other minerals are precipitated with decreasing pressure. These minerals can act to block viens and stop fluid flow and hence the lower the conductivity of the rocks. This should not influence the Poisson's ratio as the low pressure and high fluid content will still result in low Poisson's ratio regardless of fluid interconnectivity. The interconnectivity is inferred at depth to create a means for lowering the fluid pressure at depth. The resolution of the magnetotelluric study may also result in 
poor constraints in the near surface, as the project focuses on deep crustal imaging.

A further rock property that may contribute to the variations in observed Poisson's ratio is anisotropy of the rocks. As discussed in the previous chapter, laboratory measurements indicate that the Haast schist is anisotropic (Figure 3.2). However, shear wave splitting measurements from this study indicate crustal shear wave splitting is minimal. The low splitting values may be indicative of the angle between the ray path of the waves and the foliation of the anisotropic schist rocks or the complexity of deformation at depth. Investigation of the influence that the angle of the ray path to the foliation of the Haast schist has on the $V_{p} / V_{s}$ ratio is shown in Figure 4.11 (Godfrey et al., 2001).

The low Poisson's ratio of 0.15 corresponds to a $\mathrm{V}_{p} / \mathrm{V}_{s}$ ratio of 1.56 . Figure 4.11 indicates that to gain this ratio, as a result of having an anisotropic rock body rather than the assumed isotropic body, the angle of the ray path to the axis of symmetry needs to lie between $30-50^{\circ}$. This angle is based on the assumption that the waves are influenced by a uniformly dipping layer of schist in the crust (a very simple model for this complex area). To have both a $\mathrm{V}_{p} / \mathrm{V}_{S}$ ratio of 1.56 and minimal shear wave splitting the angle of incidence must be $\sim 50^{\circ}$ (Figures 3.2 and 4.11).

Ray tracing shows that the rays under the Southern Alps travel through the mid-crust at an angle of incidence of $63^{\circ}$ to the surface (Figure 4.3). If the angle of incidence of the ray to the symmetry axis of the schist is at an angle of $50^{\circ}$ (to create low $\sigma$ and no splitting), and if the rays travel purely within the sagiital plane with no lateral motion, then the schist foliation must dip at either $\sim 13^{\circ}$ to the east or $66^{\circ}$ to the west. Neither of these dips correspond to the orientation of the Haast schist, indicating that the anisotropy and Poisson's ratio in the crust are not likely the result of a uniformly oriented package of foliated rocks.

It is therefore concluded that the small S-wave splitting is most likely the result of deconstructive summation of shear wave delays caused by different structural alignments at depth or the presence of locally oriented cracking and fracturing in the top $10 \mathrm{~km}$ of the crust. Low values of Poisson's ratio under the Southern Alps are probably the result of low pore fluid pressure due to either inter-connectivity of equidimensional fluid filled pores 


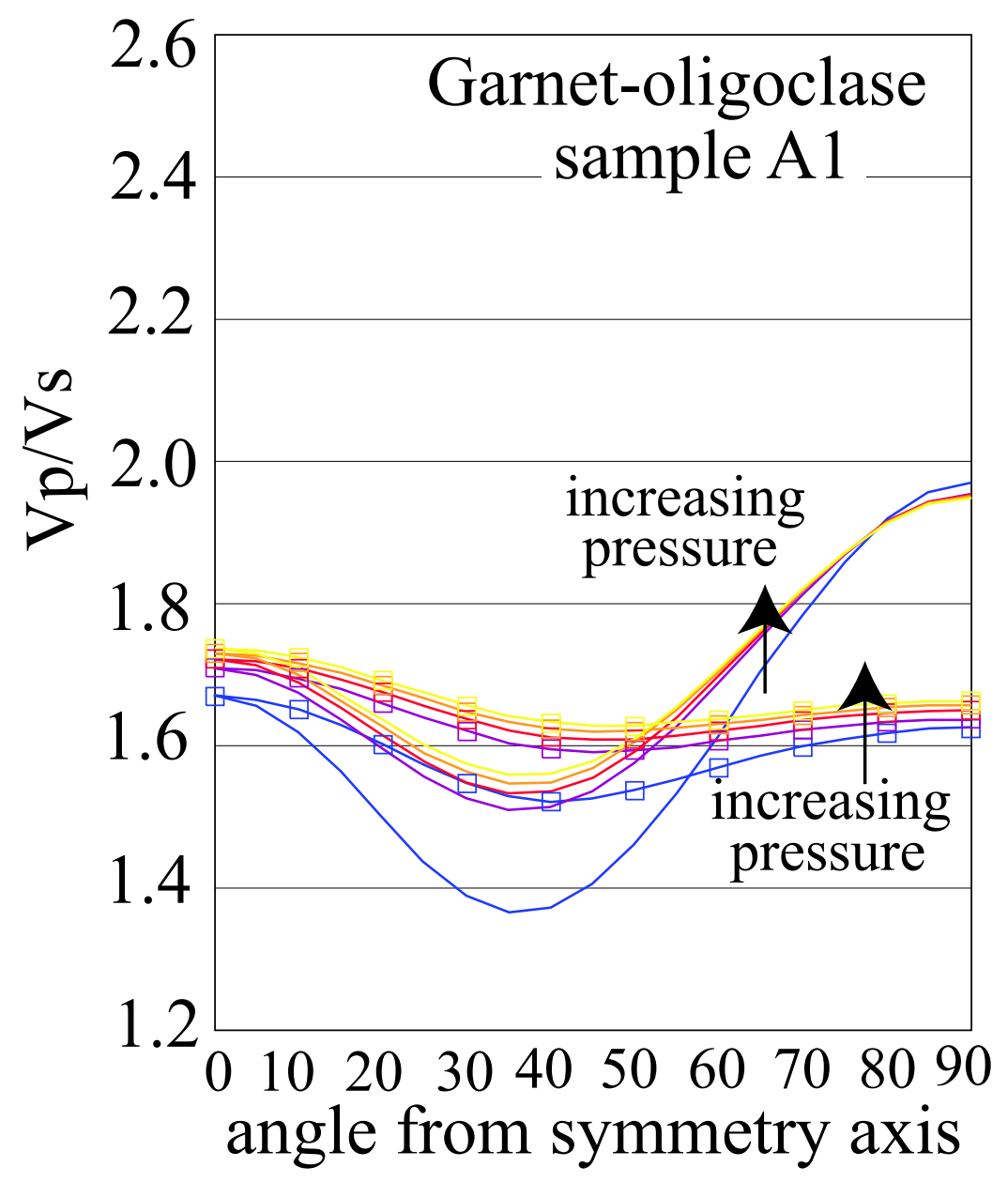

Fig. 4.11 Comparison of $V_{p} / V_{s}$ to the angle between ray propagation and the symmetry axis for the Haast schist, from Godfrey et al. (2001). The colour range indicates the confining pressure. The blue line represents the lowest pressure $(1 \mathrm{kbar})$ and the yellow line represents the highest pressure $(9 \mathrm{kbar})$, with lines incrementing by $2 \mathrm{kbar}$. The lines with open squares are calculations from $q V_{P}$ and $q V_{S} V$ and lines with no symbols for $q V_{P}$ and $V_{S} H$.

(Vry, in prep.), or a reduction from lithostatic to hydrostatic pore fluid pressure (Kleffmann et al., 1998; Stern et al., 2001; Wannamaker et al., in press) at around $20 \mathrm{~km}$ depth.

\subsection{Summary}

Low values of Poisson's ratio, as low as 0.16 , are seen in the upper crust off the west coast of South Island from both 2D and 1D Pg and Sg modelling. Estimations from phases that sample deeper in the crust (PmP and SmS) indicate higher mean Poisson's ratios of 0.21-0.24. The low Poisson's ratios off the west coast of South Island are probably due 
to down-warping of the crust resulting in aligned fluid filled cracks, with low pore fluid pressure, in the upper crust.

Seismic anisotropy of the schist rocks of the Southern Alps may result in a low Poisson's ratio. If the angle of ray paths to the foliation of the schist is $\sim 50^{\circ}$ then it is possible to produce a low $\mathrm{V}_{p} / \mathrm{V}_{s}$ ratio and little or no shear wave splitting, as is shown in the previous chapter. However, if the shear waves travel in the vertical plane from source to receiver then the foliation of the schist rocks would need to be dipping either $16^{\circ} \mathrm{E}$ or $66^{\circ} \mathrm{W}$, yet neither of these possibilities appears likely. Little et al. (2002) describe several phases of deformation, and this complex deformation has probably resulted in destructive summation of shear wave splitting.

A more likely interpretation, than due to an anisotropic rock body, for low Poisson's ratio under the Southern Alps is a fluid rich body at depth under low pore fluid pressure. Low Poisson's ratio $(\sigma=0.15)$ under the Southern Alps corresponds to a low P-wave velocity, high conductivity body inferred in other studies. The low Poisson's ratio does not fit with high pore fluid pressure as previously speculated for this area, but indicates a moderate/low pore fluid pressure and/or the presence of silica rich rocks at depth. A model of delayed inter-connectivity of fluid filled pores, which was put forward by Vry (in prep.), fits well with our observations and is the preferred model here. 


\section{TECTONIC AND GEOLOGIC BACKGROUND, CENTRAL NORTH ISLAND}

The topography of central North Island is elevated in a broad dome centred at the southern termination of the Central Volcanic Region (CVR) (Figure 5.1). Determination of the magnitude, wavelength and timing of the surface and rock uplift, can provide information and constraints on crustal and mantle processes creating the uplift. Domed topography is associated with regions of mantle up-welling due to extension and in some cases mantle plumes, (e.g. Yellowstone, USA, Spitsbergen and Italy - Pierce and Morgan, 1992; Vågnes and Amundsen, 1993; D'Agostino et al., 2001). Here we investigate the doming of central North Island and the relationship between this doming, the formation of the CVR, and the association with volcanism.

This chapter contains information about the tectonic and geologic setting of central North Island. Also included is a brief description of how the Digital Elevation Model (DEM) of New Zealand was created, so that its limitations can be understood. The following chapter examines exhumation and erosion rates derived both from the DEM and porosity measurements of mudstones and coal rank studies of other authors. Chapter 7 combines these data to examine and model the source of the vertical deformation.

\subsection{Tectonics and Background}

Relative motion between the Australian and Pacific Plates was predominantly strike slip from 25 to $6.4 \mathrm{Ma}$ (Walcott, 1998) becoming more convergent in recent times. The plate 


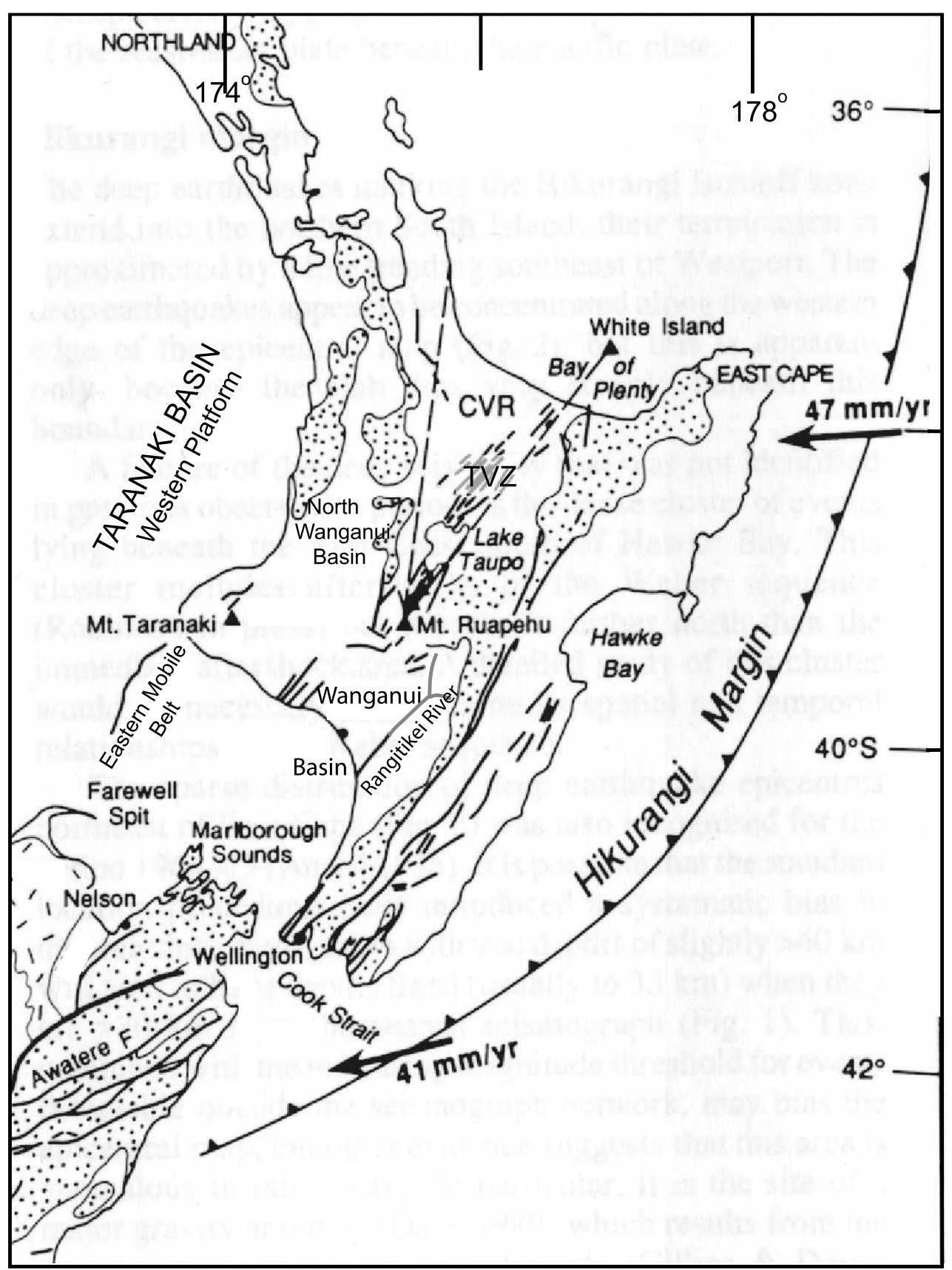

Fig. 5.1 Generalised tectonic map of North Island, New Zealand. The region of back-arc extension is identified as the CVR (Central Volcanic Region) shown with dashed lines. The currently more active eastern part is identified as the TVZ (Taupo Volcanic Zone). The major active faults are marked by black lines. Stippled regions identify areas of outcropping bedrock; the linear region along the eastern part of North Island is the Axial ranges. The direction of plate motion for the Pacific Plate relative to the Australian Plate is shown with an arrow, with a rate of motion in $\mathrm{mm} / \mathrm{yr}$, calculated from the DeMets et al. (1990) pole of rotation. Figure after Anderson and Webb (1994). 
motion has resulted in the rotation of eastern North Island relative to the western North Island (Walcott, 1984). This change in plate motion, combined with plate coupling forces along the plate interface, has resulted in back-arc extension in the continental lithosphere (Stern, 1987; Reyners et al., 1997; Reyners, 1998). Back-arc extension extends from the Bay of Plenty southwards and terminates south of Lake Taupo at the active volcanoes of Tongariro and Ruapehu (Figure 5.1) (Beanland and Haines, 1998; Reilly, 1990). Plate deformation style changes to the south of the termination of the CVR becoming compressional (e.g. Reilly, 1990; Wilson and McGuire, 1995; Melhuish et al., 1996). A deep sedimentary basin, the Wanganui Basin, has formed to the west of southern North Island in response to plate coupling forces (Stern et al., 1992). The plate boundary curves from the Hikurangi Trench through the continental lithosphere of the Marlborough region, in the north of South Island, where it splays into a series of strike slip faults (Figures 1.1 and 5.1).

\subsubsection{Back-arc extension and volcanism}

The wedge shaped CVR is characterised by negative gravity anomalies (Reilly et al., 1977), thin crust [15-25 km (Stern and Davey, 1987; Stern et al., 1987)], active andesitic and rhyolitic volcanism (Calhaem, 1973) and extension of $\sim 5-12 \mathrm{~mm} / \mathrm{yr}$ as determined by GPS measurements (Walcott, 1984; Beanland and Haines, 1998). The CVR appears to be a southward continuation of the Havre Trough, which is a back-arc basin formed behind the Tonga-Kermadec Trench system (Karig, 1970). The CVR has been classified as a backarc basin in continental lithosphere (e.g. Karig, 1971; Stern, 1985). Extension in the CVR started $\sim 5$ Ma most likely in response to a change in the pole of rotation (Walcott, 1998); prior to this, extension was occurring in the Coromandel and Northland (e.g. Sporli, 1982; King, 2000).

The present distribution of active andesitic and rhyolitic volcanism is aligned along the eastern part of the CVR and is defined as the Taupo Volcanic Zone (TVZ). Andesite volcanism has been dated using K/Ar analysis and indicates a southward progression of the source of low-potash andesites, terminating at the most recent volcanoes (Calhaem, 1973). Rotation of the line of active volcanism towards the east by $\sim 30^{\circ}$ accompanied the 
southward trend over the last $4 \mathrm{Ma}$ (Stern, 1987) (Figure 5.3). The CVR is a region of high heat output, estimated at $4 \pm 1 \times 10^{9} \mathrm{~W}$, this equates to a heat flow of $800 \mathrm{~mW} / \mathrm{m}^{2}$ for the eastern part (Stern, 1987). This magnitude is comparable to that observed in Yellowstone and Iceland on a basis of heat flow per $\mathrm{km}$ of strike. These regions are associated with mantle upwelling and mantle plumes. The heat flow is clearly greater than that associated with regions of continental rifting. For example, the Gregory rift, which is associated with the Kenya Rift system, has $~ 11-30 \mathrm{~mW} / \mathrm{m}^{2}$ (Crane and O'Connell, 1983).

\subsubsection{Wanganui Basin}

The Wanganui Basin contains over $4 \mathrm{~km}$ of shallow marine, Plio-Pleistocene sediments (Figure 5.2) (Anderton, 1981). This deep basin is associated with a negative gravity anomaly of -150 mgal which is greater than the expected -50 mgal for an uncompensated basin of this depth (Stern and Davey, 1989). A locally compensated basin can only obtain a maximum depth of around 2.5 times the original water depth, unless an external load is operating (Watts et al., 1982). There is no obvious super-crustal loading evident in the Wanganui Basin, apart from the Tararua Ranges along the basin's eastern margin. The modest relief of these ranges ( $1500 \mathrm{~m}$ in elevation) is not able to produce the magnitude of depth seen in the Wanganui Basin. The large gravity anomaly and thickness of sediments, with no other obvious source of loading, indicates that the driving mechanism forming the basin is probably due to coupling of the subducted Pacific Plate pulling the overlying Australian Plate downwards (Stern et al., 1992).

The Wanganui Basin is divided into two parts: the North Wanganui Basin extends from a line between Mt. Taranaki and the central volcanic plateau northwards and the South Wanganui Basin lies from the central volcanic plateau to the northern margin of the Marlborough Sounds (Figure 5.1). Here we refer to the South Wanganui Basin as the Wanganui Basin, and the northern basin as the North Wanganui Basin.

High-frequency, low-magnitude seismicity characterises the Wanganui Basin (Smith, 1979; Garrick and Gibowicz, 1983). The largest recorded shock that occurred in the offshore region was in $1966\left(\mathrm{M}_{L}=5.2\right)$. Four earthquakes of magnitude 5 have been recorded be- 
tween 1967-1972 in the onshore part of the basin (Smith, 1979). Focal mechanisms from the basin indicate extension within the central deepest part of the basin with larger compressional events occurring around this centre (Garrick and Gibowicz, 1983). The compression is sourced from coupling of the subducted Pacific and Australian plates along the eastern part of North Island. The coupling is also responsible for a series of anticlinal structures and thrust faults seen across the onshore Wanganui Basin (Wilson and McGuire, 1995; Melhuish et al., 1996). The combination of compressional and extensional focal mechanisms have been interpreted to be the result of bending stresses on the lithosphere due to plate coupling forces (Stern et al., 1992). Palaeomagnetic data from onshore Wanganui Basin indicate distributed deformation up to $290 \mathrm{~km}$ away from the plate boundary (Wilson and McGuire, 1995). These data support the idea that the Wanganui Basin formed in response to lithospheric flexure driven by high friction at the plate interface. Palaeomagnetic studies show that the deformation has been occurring since 2.5 Ma (Wilson and McGuire, 1995).

Sedimentary stratigraphy within the basin indicates that the depocentre of the Wanganui Basin is migrating at a rate of $20-30 \mathrm{~mm} / \mathrm{yr}$ south-eastward (Figure 5.3) (Anderton, 1981). The timing and rate of migration corresponds well with the progressive migration of lowpotash andesites across the CVR (Stern and Davey, 1987) (Figure 5.3). In between the back-arc extension and the Wanganui Basin there is a region of domed topography centred around the southern termination of the CVR (e.g. Figure 6.5). This domed topography is accompanied by a pattern of increasing exhumation towards the southern CVR of up to 2 km (Suggate, 1959; King and Thrasher, 1996; Armstrong et al., 1998). The exhumation has exposed some Wanganui Basin sediments deposited during Plio-Pleistocene times.

Evidence for either increasing uplift at the southern termination of the CVR, subsidence of the Wanganui Basin, or a progression southward of these features comes from the progressive tilt of terrestrial geomorphological features. Anticlines, formed parallel to the Axial ranges, initiated $\sim 3.1$ Ma (Melhuish et al., 1996) show a southward tilt rate of $4 \times 10^{-8} \mathrm{rad} / \mathrm{yr}$ (Jackson et al., 1998). Suites of fluvial terraces of the onshore Wanganui Basin, all younger than $300 \mathrm{ka}$, indicate steepening of the terraces southward with age (Te Punga, 1952) at a rate of $6.1 \times 10^{-8} \mathrm{rad} / \mathrm{yr}$ (Milne, 1973a; Pillans, 1990a). Te Punga (1952) identified a hinge line of rotation perpendicular to the tilt direction, around 


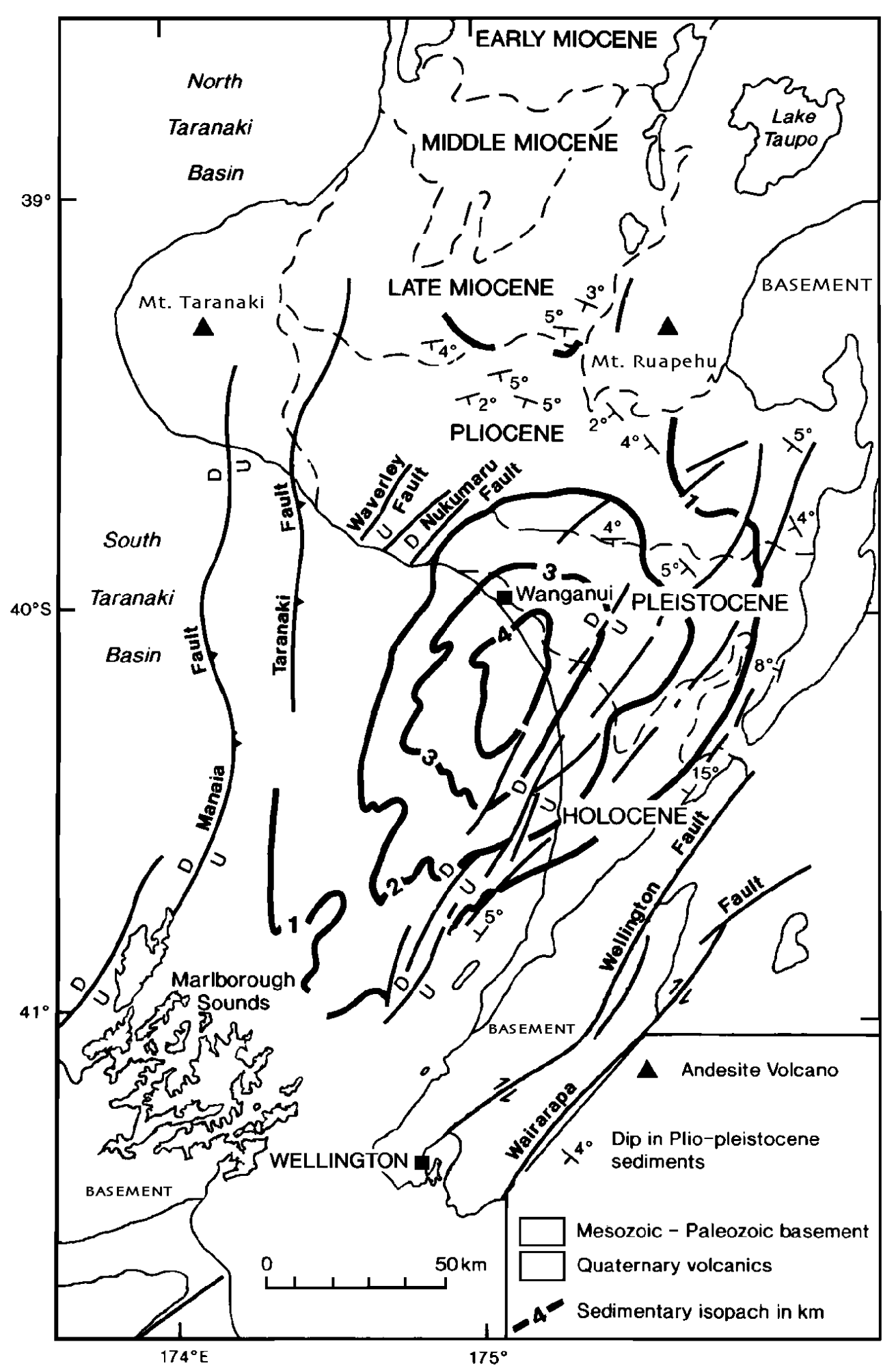

Fig. 5.2 Generalised geology of the Wanganui Basin. The dashed lines are the geological boundaries, the solid dark lines indicate the thickness of Pliocene-Pleistocene sediments that infill the Wanganui Basin (after Anderton, 1981). Dip symbols are taken from the 1:250 000 geological maps (sheet 10: Wanganui and sheet 11: Dannevirke). Figure after Stern et al. (1992). 
which the surfaces were rotating to increase their gradient, $\sim 8-16 \mathrm{~km}$ inland from the present Rangitikei River mouth. Marine terraces along the Wanganui-Taranaki coastline indicate uplift with rates of $0.2-0.65 \mathrm{~mm} / \mathrm{yr}$ and also indicate an increasing southward tilt (Pillans, 1986; Pillans, 1990b).

\subsubsection{Marlborough Sounds}

The Marlborough Sounds were first identified by Cotton (1913) to be a region of recently submerged river valleys and ranges. He estimated $\sim 100 \mathrm{~m}$ of subsidence for the Sounds. Reversal of drainage is seen through sediment transport and deposition (Cotton, 1913; Mortimer and Wopereis, 1997) and indicates that subsidence, causing the tilting of the Sounds towards the Wanganui Basin, is either increasing in magnitude or moving southward with time. Singh (2001) determined a subsidence rate for the central Marlborough Sounds of $\sim 1 \mathrm{~mm} / \mathrm{yr}$ and tilting rates down towards the Wanganui Basin of $\sim 1.11^{\circ} / \mathrm{Ma}$ in the Late Pleistocene and $\sim 3.9^{\circ} / \mathrm{Ma}$ since $12 \mathrm{ka}\left(1.9\right.$ and $6.8 \times 10^{-8} \mathrm{rad} / \mathrm{yr}$ respectively). The azimuth of tilting has rotated towards the north by $4^{\circ}$ to $029^{\circ}$ (Singh, 2001). He speculated that this change in direction is a result of motion of the Wanganui depocentre (e.g. Anderton, 1981)(Figure 5.3).

Reyners (1998) proposed that the Pacific Plate is "locked" with the Australian Plate in the Marlborough region (Reyners, 1998). By locked he means the high friction between the subducting and overlying plate results in no differential movement along the plate interface and the downward motion of the subducting plate is taken up through deformation of the overlying plate. This coupling in the Marlborough region has resulted in widespread crustal deformation. The boundary appears to be locked over at least a 100-10 000 yr timescale (Reyners, 1998), but shows evidence for slip over longer timescales with the Pacific Plate subducted to a depth of $\sim 200 \mathrm{~km}$ (Anderson et al., 1993). The strong coupling of the plates appears to be the source of the formation of the Wanganui Basin and subsidence of the Marlborough Sounds region (Stern et al., 1992; Stern et al., 1993). Migration of the Wanganui depocentre to the southeast in response to relative plate motions should result in the continued subsidence of the Marlborough Sounds. 


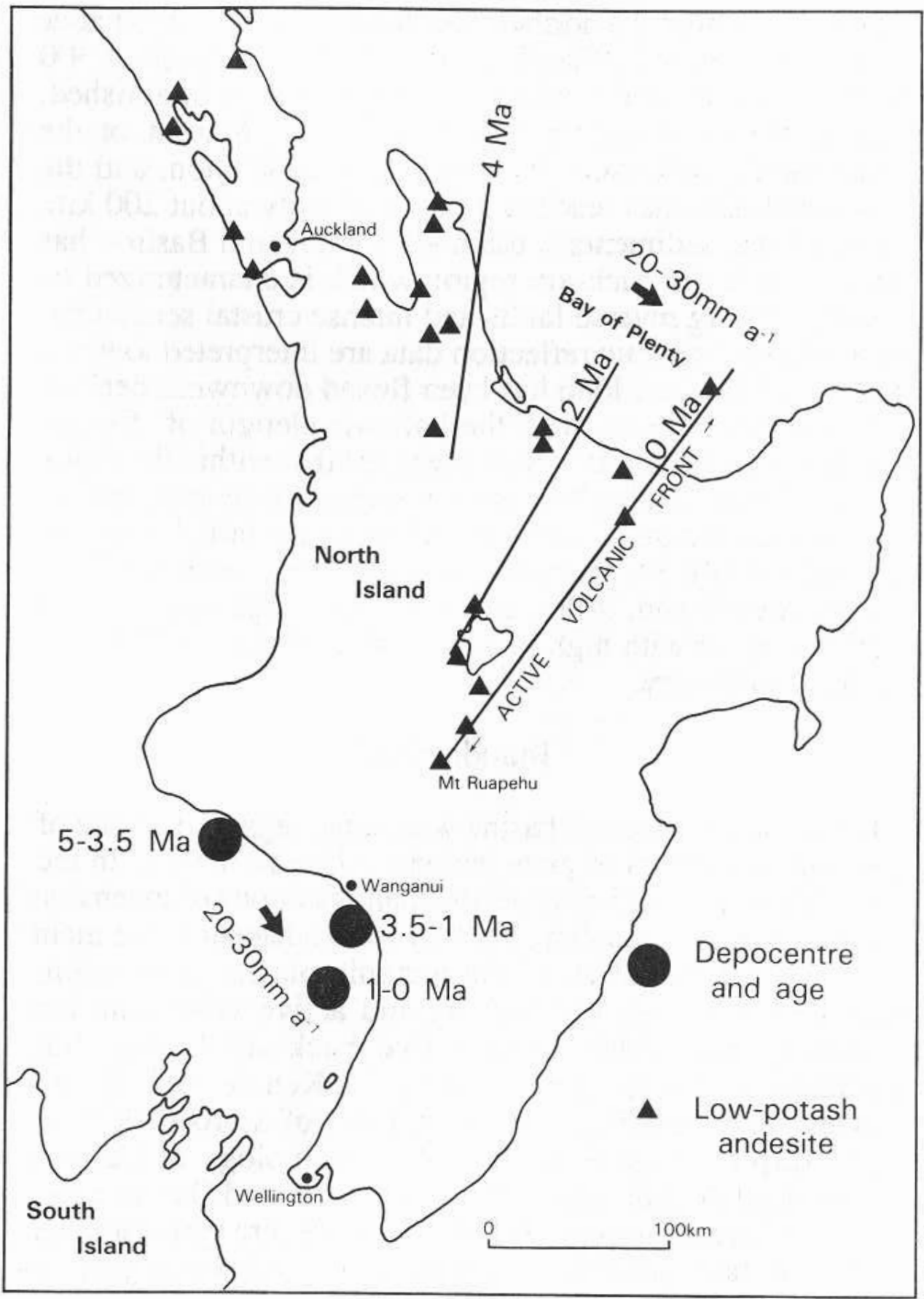

Fig. 5.3 Migration of the Wanganui Basin depocentre and the active region of volcanism. The centres of arc related volcanism are denoted with black triangles, a line has been fitted through these triangles to illustrate the age of the volcanism. These volcanic centres show a rate of migration of 20-30 mm/yr. The Wanganui Basin depocentres are shown with black circles and these show a similar rate and trend of migration to the volcanic centres. Figure from Stern and Davey (1989). 


\subsubsection{Compressional plate driven tectonics}

Subduction of the Pacific Plate under North Island has resulted in compression along the eastern part of the island. This compression has resulted in a series of folds and thrust faulting predominantly to the east of the CVR. The largest of these anticlines forms the Axial ranges, which run as an almost continuous mountain chain for $\sim 500 \mathrm{~km}$ from Wellington to East Cape (Figure 5.2). Dating of marine fossils from the summit of the Ruahine Range demonstrates the mountains are being uplifted at a rate of up to $1.3 \mathrm{~mm} / \mathrm{yr}$ (Beu et al., 1981) since at least $1 \mathrm{Ma}$ (Wells, 1989).

The younger deformation of the Axial ranges is not examined here and we focus on the larger wavelength features of the back-arc extension, domed topography of central North Island and subsidence of the Wanganui Basin.

\subsubsection{Overview}

It is proposed here that there is a common unifying process that has caused exhumation (Suggate, 1959; Edbrooke et al., 1994; King and Thrasher, 1996; Armstrong et al., 1998), surface uplift (Chappell, 1975; Pillans, 1990a) progressive tilting of geomorphological features (Te Punga, 1952; Milne, 1973a; Jackson et al., 1998; Singh, 2001) in central North Island and subsidence in the Wanganui Basin (Cotton, 1913; Singh, 2001), and that the processes responsible are either progressively increasing in magnitude or moving southward. Stern and Davey (1989) noted the similarity in rate and direction of migration of the line of active volcanism with the depocentre of the Wanganui Basin (Figure 5.3). The formation of the Wanganui Basin has been attributed by Stern et al. (1992) to high friction on the interface between the Pacific and Australian plates. If so, the rate of migration, or growth, should be related to relative plate motions. This should also be the case for the extension of the CVR, which is occurring above the less coupled northern part of the subduction zone.

Stern et al. (1992) proposed that the crustal doming, centred around the southern termination of the CVR, is the result of crustal and mantle processes that are occurring at the point of initiation of back-arc extension, as it migrates southward. 
The goal of this thesis is to quantify the exhumation and surface uplift to provide an estimate for rock uplift and to then model the processes responsible for the vertical deformation. Data pertaining to the extent and magnitude of tilt and rock uplift of the region will be presented. Information on surface tilting and tilt rates of geomorphological features, extracted from a $25 \mathrm{~m}$ DEM of New Zealand, are discussed in the following section. Exhumation, surface and rock uplift are investigated in the following chapter.

\subsection{Creating the Digital Elevation Model (DEM)}

The dataset used to create the DEM of New Zealand is sourced from the digitised 1:50 000, 20 m contour interval, terralink 260 New Zealand map series, which include elevation data from contours, spot heights and coastlines (the topographic equivalent of a zero contour). This dataset was interpolated onto a regular grid of heights using the splines in tension function of the Generic Mapping Tool (GMT) surface program (Smith and Wessel, 1990). The data were grided at 25, 50, 100, 250 and $500 \mathrm{~m}$. In regions of low gradient the sparse contours will result in interpolation of the splines being less well constrained and hence the resolution is poorer.

DEM data can be used in a number of tectonic settings to help quantify geomorphic and surface processes. In particular, the advent of powerful computers permits DEM analysis to be carried out over vast areas with optimum resolution.

An example of a method to extract tilt information from coastal plains and terraces is outlined in Appendix E. Due to low resolution of the DEM the method could not produce meaningful results. The DEM is employed in the following chapter to calculate incision erosion, differential erosion and surface uplift across central North Island.

\subsection{Summary}

Tilting and uplift of marine terraces, river terraces, anticlines in southern central North Island, tilting and subsidence in the Marlborough Sounds region, migration of arc volcanism, in the CVR, and the Wanganui depocentre appear to be linked to large scale plate motions. 
Exhumation of $2 \mathrm{~km}$ is observed in central North island and indicates a broad rock uplift not associated with the linear rock uplift along the spine of the axial ranges.

In the following chapter the broad rock uplift of central North Island is quantified using exhumation and surface uplift. The DEM is used to provide insight into incision erosion, surface and tectonic uplift. 
CHAPTER 6

\section{UPLIFT, EXHUMATION AND ROCK UPLIFT}

The amount of rock uplift that has occurred, since the time of deepest burial, can be determined through the simple relation (England and Molnar, 1990):

rock uplift $=$ exhumation + surface uplift

Here rock uplift is used to represent the upward motion of an individual rock particle within the rock sequence (Figure 6.1). Surface uplift is the uplift of the land surface, and is less than the rock uplift due to the process of erosion acting to lower the surface. Exhumation is used here to mean the amount of material eroded vertically from a surface. Exhumation differs from erosion in that this is purely a vertical measure. Elevations reported in the text and figures refer to the elevation above mean sea level.

Some of the calculated rock uplift will be a result of tectonic forces, e.g. mantle upwelling, however, there is also a portion of rock uplift which occurs in response to rebound due to erosion. To determine the tectonic uplift ( $\mathrm{T}$ ) that would be observed if no erosion occurred, and assuming isostatic equilibrium, the following relation can be used (e.g. Vågnes and Amundsen, 1993):

$T=S+E \frac{\rho_{m}-\rho_{s}}{\rho_{m}}$

Where $\mathrm{S}$ is the present topography, $\mathrm{E}$ is the exhumation, $\rho_{m}$ and $\rho_{s}$ are the mantle and sediment densities respectively. 


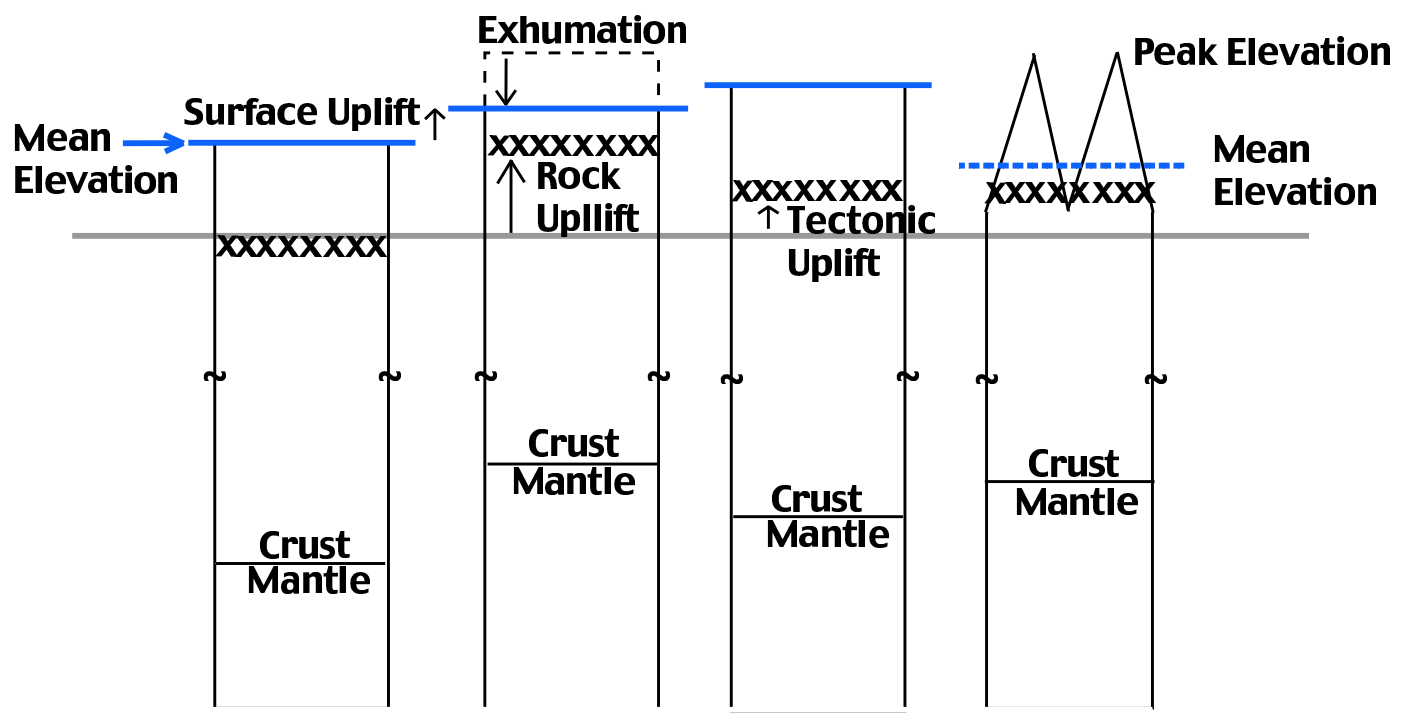

Fig. 6.1 Schematic illustration of a section of crust showing the relationship between rock, surface, tectonic uplifts, exhumation and incision erosion. The blue line represents the surface elevation, the crosses indicate the location of a geological horizon and the grey line is a reference level. a) Shows a crustal section with elevation above sea level, b) is the same section after erosion and allowed to rebound, this shows the relationship between rock uplift, surface uplift and exhumation (Equation 6.1). c) Shows the tectonic uplift, which would result from the forces creating the rock uplift of b), if there is no exhumation. $d$ ) Incision erosion acts to lower the mean elevation, but result in rock uplift which acts to raise peaks as well as the geological horizon. Based on figure of Molnar and England (1990).

\subsection{Exhumation of North Island}

Various techniques have been used to quantify the rate and magnitude of rock uplift and exhumation in North Island. Quaternary uplift around the coastline of North Island has been estimated from uplifted marine terraces (Chappell, 1975; Ota, 1986; Ota et al., 1988; Pillans, 1990a; Pillans, 1990b; Berryman, 1993). These estimates are based on the present elevation of abandoned marine benches, dated using tephrachronology and loess stratigraphy, and take into account the change in sea level with time (Pillans, 1990a). This method is of limited application insofar as surfaces older than $\sim 300$ ka have not been preserved, and for those surfaces that do survive, it is only possible to infer an average uplift rate since they were formed. These studies indicate that much of the coastline of North Island is uplifting at a rate of $0.2 \mathrm{~mm} / \mathrm{yr}-2.8 \mathrm{~mm} / \mathrm{yr}$ for the last $300 \mathrm{ka}$ (Figure 7.1).

Seismic reflection has been used extensively in basin research to estimate exhumation 
(e.g. Knox, 1982). Exhumation calculations are based on the amount of material eroded from the seismic section and requires an estimate of the thickness of the original sedimentary sequence. Exhumation estimates from unconformities in the Taranaki Basin indicate up to $1.5 \mathrm{~km}$ near the Taranaki Fault zone since the Miocene (Stagpoole, 1997). Knox (1982) estimated that erosion of 1350 m of section has occurred above the North Tasman-1 oil well (Figure 6.2), in the South Taranaki Basin, since the Pliocene. Apatite fission-track analysis (AFTA) results, also from North Tasman-1 well, show consistent results with slightly less erosion of up to $1 \mathrm{~km}$ since $12 \mathrm{Ma}$ (Kamp and Green, 1990). AFTA results from Kupe-1 well indicated little or no uplift while Surville-1 and Fresne-1 indicated a maximum of $\sim 2 \mathrm{~km}$ and $3 \mathrm{~km}$ respectively since the Miocene (Figure 6.2). These AFTA results also compare well with vitrinite reflectance analyses of coal from the above mentioned wells as discussed by Kamp and Green (1990).

Exhumation derived from porosity-depth relations for mudstones is a relatively new method, ideally suited to North Island due to the simple history of shallow marine sediment accumulation and burial followed by exhumation. Porosity-depth relations of sediments give an estimate of the depth to which sediments have been buried and hence how much material has since been removed through erosion (Wells, 1989; Armstrong et al., 1998). This method is founded on the assumption that the lithologies being examined were initially the same prior to burial and have not been influenced by local factors such as local heating or cementation. In the Taranaki Basin, adjacent to the study area, an extensive exhumation study was undertaken by Armstrong et al. (1998). They use depth-porosity trends from the tectonically stable Western Platform of the Taranaki Basin as a base against which to compare the profiles of the exhumed eastern Taranaki sediments. Armstrong et al. (1998) identified 1450 m of exhumation for North Tasman-1 well, 3000 m for Fresne-1 and $1620 \mathrm{~m}$ for Surville-1. Kupe-1 well indicated deposition or subsidence of $150 \mathrm{~m}$ since the Miocene (Armstrong et al., 1998). There is good agreement between these results and the estimates of exhumation using AFTA, vitrinite reflectance and seismic stratigraphy.

The method of Armstrong et al. (1998) is used to investigate the pattern and magnitude of exhumation from porosity of sediments in the adjacent onshore portion of the Wanganui Basin. The same depth-porosity trends and parameters, as determined by Armstrong et al. 
(1998), are used. Trends will not differ markedly between these two adjacent areas as the sediments have accumulated and been buried under the same conditions.

Also an independent local estimation of surface erosion is made close to the termination of the CVR. The comparison of the elevation of Tertiary sediments preserved under the volcanic cap of Mount Hauhungatahi and the uncovered sediments to the west (Section 6.6) allows an estimation of the exhumation since the deposition of the capping volcanics to be made.

Finally, incision erosion is calculated from the DEM of North Island. The rebound due to incision erosion can be calculated and this signal can be removed from the overall rock uplift (Section 6.7). Incision can also be used as a proxy for recent uplift and provides a contrast to the snap shot of rock uplift for the last 4 Ma derived from mudstone porosity analyses.

\subsubsection{Dataset and sample locations}

Data used in this study originate from siltstone and mudstone samples collected from road cuttings and river banks along the Turakina, Rangitikei, Mangawhero and Wanganui Rivers (Figure 6.2). Other porosity-exhumation data used in this study, shown in Figure 6.2, are kindly supplied by the Institute of Geological and Nuclear Sciences (IGNS), Armstrong et al. (1998) and King and Thrasher (1996). Exhumation data from coal vitrinite reflectance studies (Edbrooke et al., 1994; Armstrong et al., 1998), are also included (Figure 6.2).

Though this study combines data from two different sources, both the vitrinite reflectance of coal and mudstone porosities, the results are expected to be comparable as both methods describe exhumation since the early-Miocene in rocks of post Mesozoic age.

Mudstone porosity analyses for this study were made using saturation and helium porosity techniques. A description and discussion of these techniques are included in Appendix F along with the measured porosity values. 


\subsection{Exhumation}

Porosity-depth relations in mudstones are described using the exponential relation:

$$
\phi(z)=\phi_{0} \exp \left(\frac{-z}{D}\right)
$$

first derived by Athy (1930), where $\mathrm{z}$ is depth, $\phi_{0}$ is the surface porosity and D is an exponential decay constant. For depth sections that have been exhumed since the time of deepest burial a depth-porosity curve is fitted through the data. The depth-porosity curve has the same form as for an uneroded section (Eq 6.2 ).

$$
\phi\left(z^{\prime}\right)=\phi_{0}^{\prime} \exp \left(\frac{-z^{\prime}}{D}\right)
$$

$z^{\prime}$ is the depth of the sample, for this study samples were taken at the surface $z^{\prime}=0, \phi_{0}^{\prime}$ is the best fit surface porosity for the eroded section. Here this is our measured porosity. The difference between the depth at which the mudstone porosities were estimated to have formed and the present depth of the mudstone sample gives us the amount of exhumation that has occurred:

$$
\Delta z^{\prime}=z-z^{\prime}=\frac{\left[\ln \left(\phi_{0}\right)-\ln \left(\phi_{0}^{\prime}\right)\right]}{\left(\frac{1}{D}\right)}
$$

The error can be determined using the standard deviation of the data as described by Armstrong et al. (1998):

$$
\sigma\left(\Delta z^{\prime}\right)=\Delta z^{\prime} \sqrt{\frac{\sigma\left(\ln \left(\phi_{0}\right)\right)^{2}+\left(\sigma\left(\ln \left(\phi_{0}^{\prime}\right)\right)^{2}\right.}{\left(\ln \left(\phi_{0}\right)-\ln \left(\phi_{0}^{\prime}\right)\right)^{2}}+\frac{\sigma\left(\frac{1}{D}\right)^{2}}{\left(\frac{1}{D}\right)^{2}}}
$$

From analysis of the tectonically stable Western Platform off the west coast of North Island the following values were obtained and are used here (Armstrong et al., 1998): The surface porosity $\phi_{0}=50 \%$ from a standard porosity curve, D is $2265 \mathrm{~m} ; \sigma\left(\ln \left(\phi_{0}\right)\right)$ is \pm 0.05 and $\sigma\left(\frac{1}{D}\right)$ is $\pm 0.00005 \mathrm{~m}^{-1}$.

Sample locations and elevations were recorded using GPS. A minimum of three samples were taken at each sight. Results of exhumation calculations using the above formulae and variables of Armstrong et al. (1998) are recorded in Appendix F. 

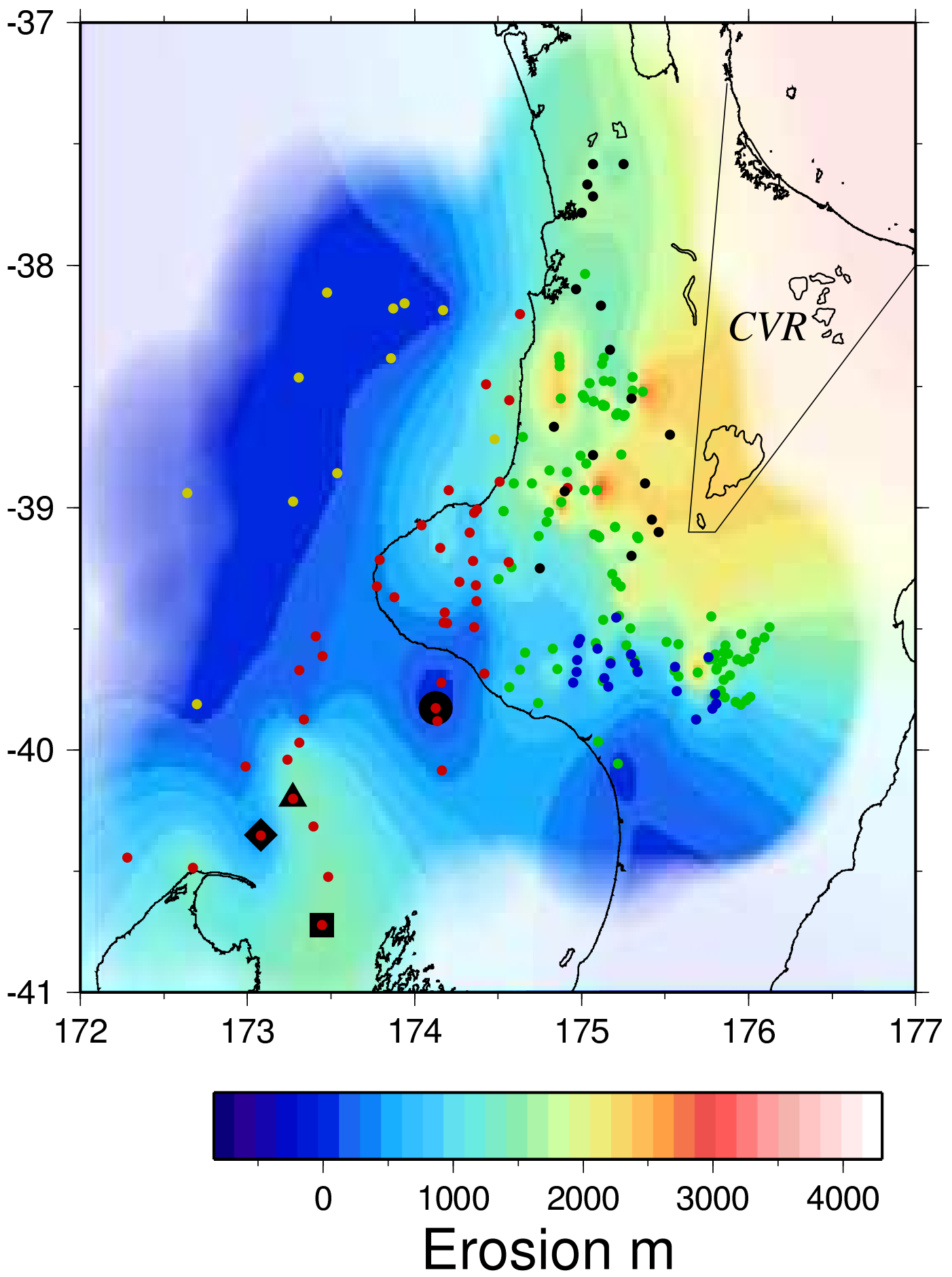

FiG. 6.2 Exhumation surface determined from whole dataset. Exhumation estimates from mudstone porosity measurements are shown with: green circles (IGNS siltstone and mudstone data), red circles (Armstrong et al., 1998), yellow circles ((King and Thrasher, 1996)) and blue circles (this study). Small black circles are locations of exhumation estimates from coal rank studies (Edbrooke et al., 1994; Armstrong et al., 1998). Large black shapes indicate the locations of wells mentioned in the text: Kupe-1 circle, Surville-1 square, Fresne-1 diamond and North Tasman-1 triangle. The surface is fitted to the erosion data points displayed in this figure using GMT surface function (Smith and Wessel, 1990). The intensity of colour indicates the number of data points within a radius of 0.7 degrees, with the brightest areas having the greatest number of data points. 


\subsubsection{Analysis and results of exhumation calculations}

Figure 6.2 shows the entire dataset with a surface fitted through all the data points. Surfacing was done using splines in tension, a function of the GMT surface program, with a tension of 0.25 (Smith and Wessel, 1990). The splines in tension function passes through all data points; a tension of 0 is a harmonic (natural spline) and can oscillate between data points and at the boundaries, a tension of 1 has maxima or minima only at the data nodes, with the curvature focused near the data points.

The fitted surface varies smoothly and describes an increase in exhumation towards the south of the CVR. To the west of the CVR are a few localised regions of anomalously high exhumation. These data points, from the IGNS dataset, are probably from underlying Mesozoic rocks that have undergone an earlier phase of deformation. Exhumation values calculated from vitrinite reflectance of coal are comparable to the younger Tertiary sediments as the coal units lie in the post-Mesozoic sedimentary units.

Figure 6.3 shows contoured exhumation from points calculated using Tertiary sediments only. The contours were determined using a Gaussian filter of $100 \mathrm{~km}$ passed over the dataset. The contours define a clear dome shape with maximum exhumation centred around the termination of the CVR. Coal rank data show a maximum of $2.3 \mathrm{~km}$, with a projected maximum uplift from the filtered dataset at Lake Taupo of $\sim 2 \mathrm{~km}$. Further north, there are no data to constrain the shape of the uplift because the exposed non-volcanic rocks are of Mesozoic age and the Axial ranges obscure any signal to the east, only half a dome can be constrained.

\subsection{Surface uplift}

The surface uplift is described by averaging the topographic elevation above sea level over regions of $10^{3}-10^{4} \mathrm{~km}^{2}$, due to the lithosphere having a finite flexural rigidity (England and Molnar, 1990). To create a smoothed topography, on the scale of $10^{3}-10^{4} \mathrm{~km}^{2}$, which does not take into account localised features such as the Axial ranges and volcanoes (Figure 6.4), a low pass Fourier filter is used. Topography of wavelength greater than 200- 


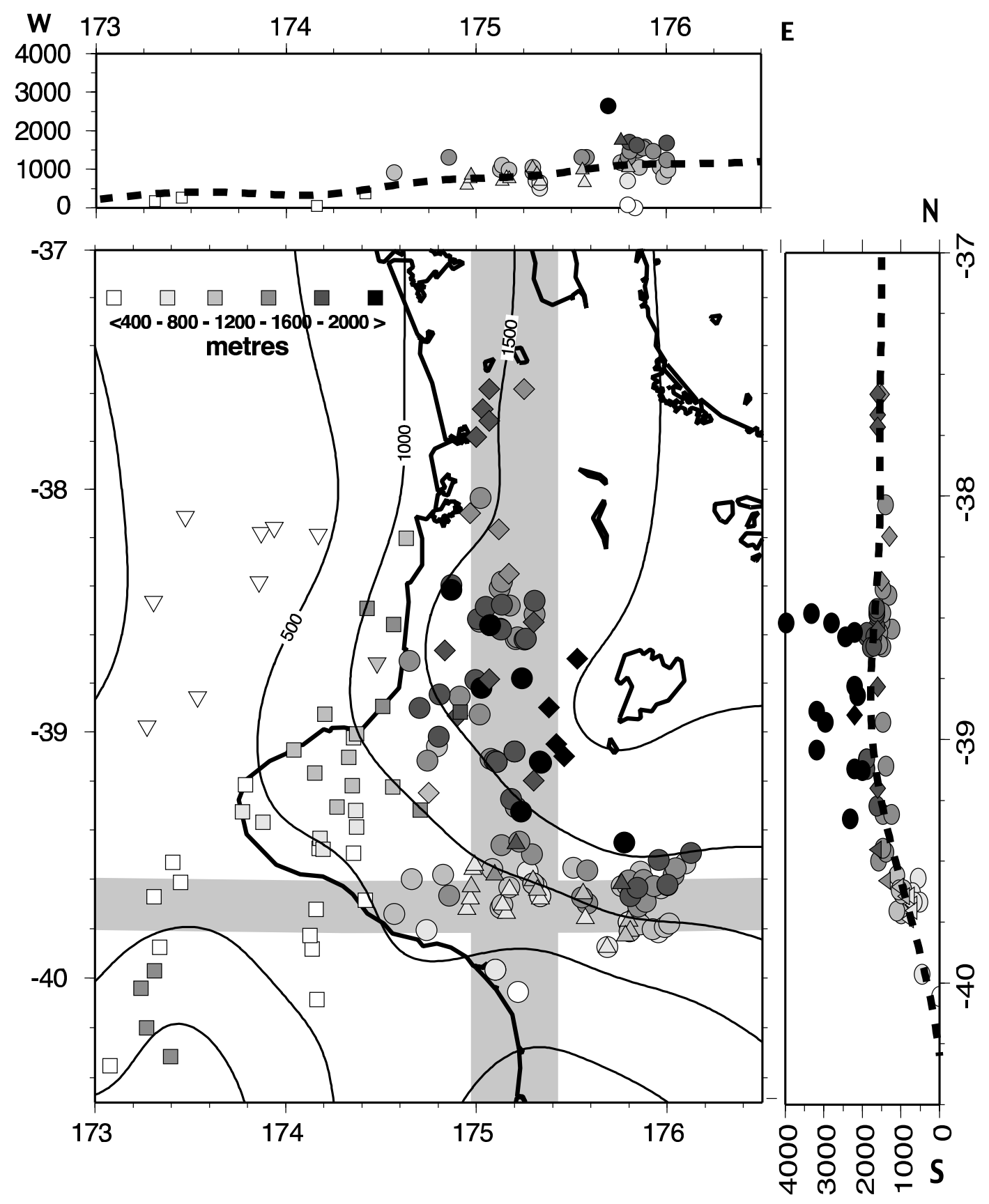

Fig. 6.3 Contoured exhumation data calculated from mudstone porosities and coal rank. Data from mudstone porosity analyses are shown with triangles (this study, calculated from He porosity analyses), circles (IGNS), squares (Armstrong et al., 1998) and inverted triangles (Point downwards) (King and Thrasher, 1996). Diamonds are exhumation data from coal rank studies (Edbrooke et al., 1994; Armstrong et al., 1998). The contours are calculated from the grid displayed in Figure 6.2 with Gaussian filter of $100 \mathrm{~km}$ passed over the data, and have a contour interval of $500 \mathrm{~m}$. Data points from the western North Island were removed before filtering as there were anomalously high values due to Mesozoic source rocks. The cross sections show data points within the grey swaths and provide an indication of the scatter in the data. The dashed lines in the cross sections is the Gaussian filtered topography along the centre of the swath. 


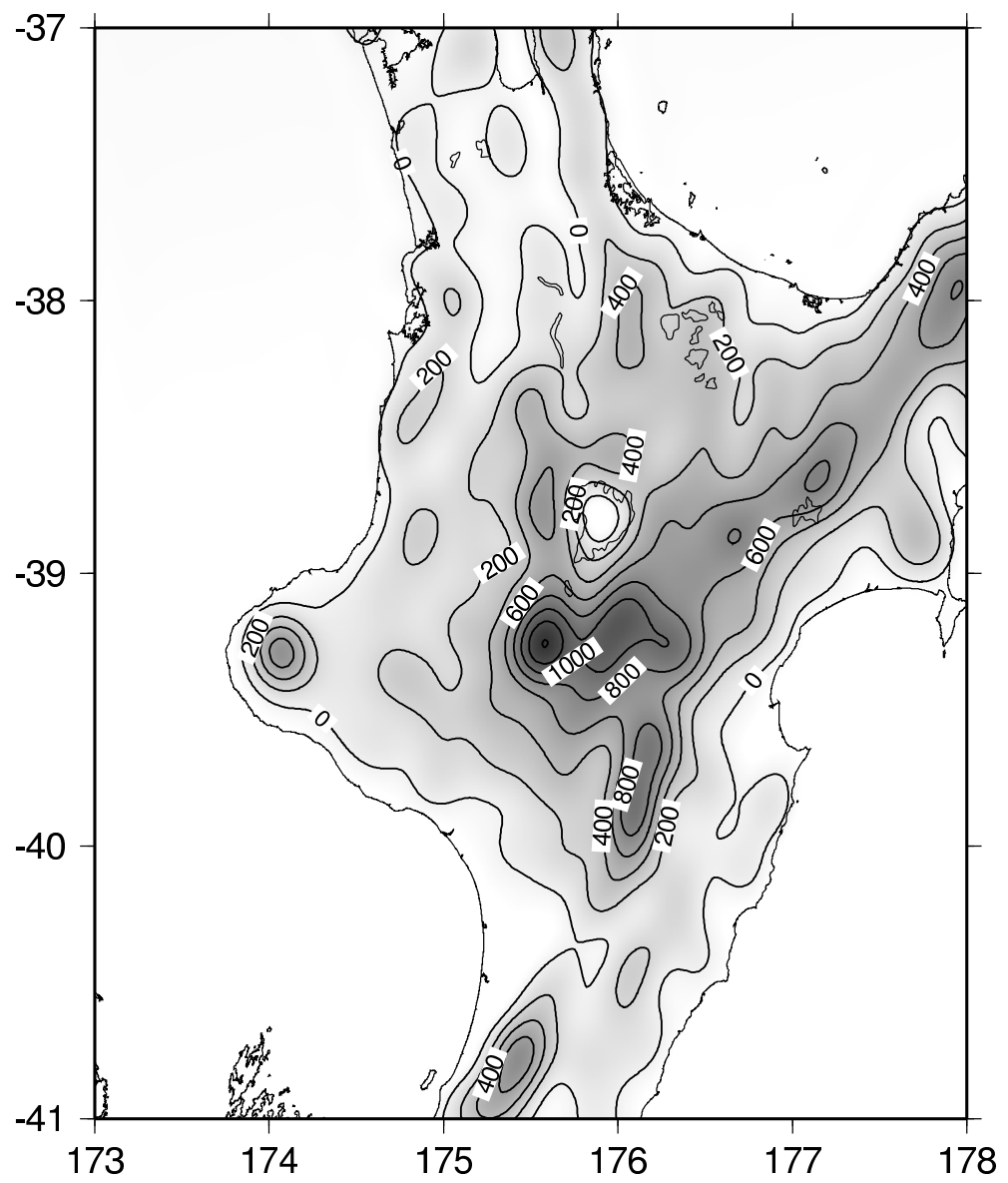

FIG. 6.4 Shading and contours describe topography with a wavelength greater than $50 \mathrm{~km}$ in North Island. The $1 \mathrm{~min}$ DEM of North Island was filtered using a low pass filter of 20 - $50 \mathrm{~km}$ to highlight features that are not related to the regional relief. Contours are in metres.

$300 \mathrm{~km}$ was extracted from the 1 min DEM of North Island using the GRDFFT function of GMT (Figures $6.5 \& 6.6$ ). The topography, like the exhumation, shows a dome shape with the maximum elevation of $500 \mathrm{~m}$ in central North Island. To confirm that the surface uplift, modelled here by Fourier filtering, accurately represents the surface uplift the volume of the topography is calculated and is compared to the volume of modelled surface uplift. The volume of the topography will show the mass of land which is exposed above sea level and hence how much material is supported by the uplift of the lithosphere above sea level. The volumes compare well (Surface Uplift: $8.3 \times 10^{10} \mathrm{~m}^{3}$, Topography: $7.7 \times 10^{10} \mathrm{~m}^{3}$ within $7 \%$ )and indicate that the Fourier filtered topography is a good way to describe the surface uplift. 


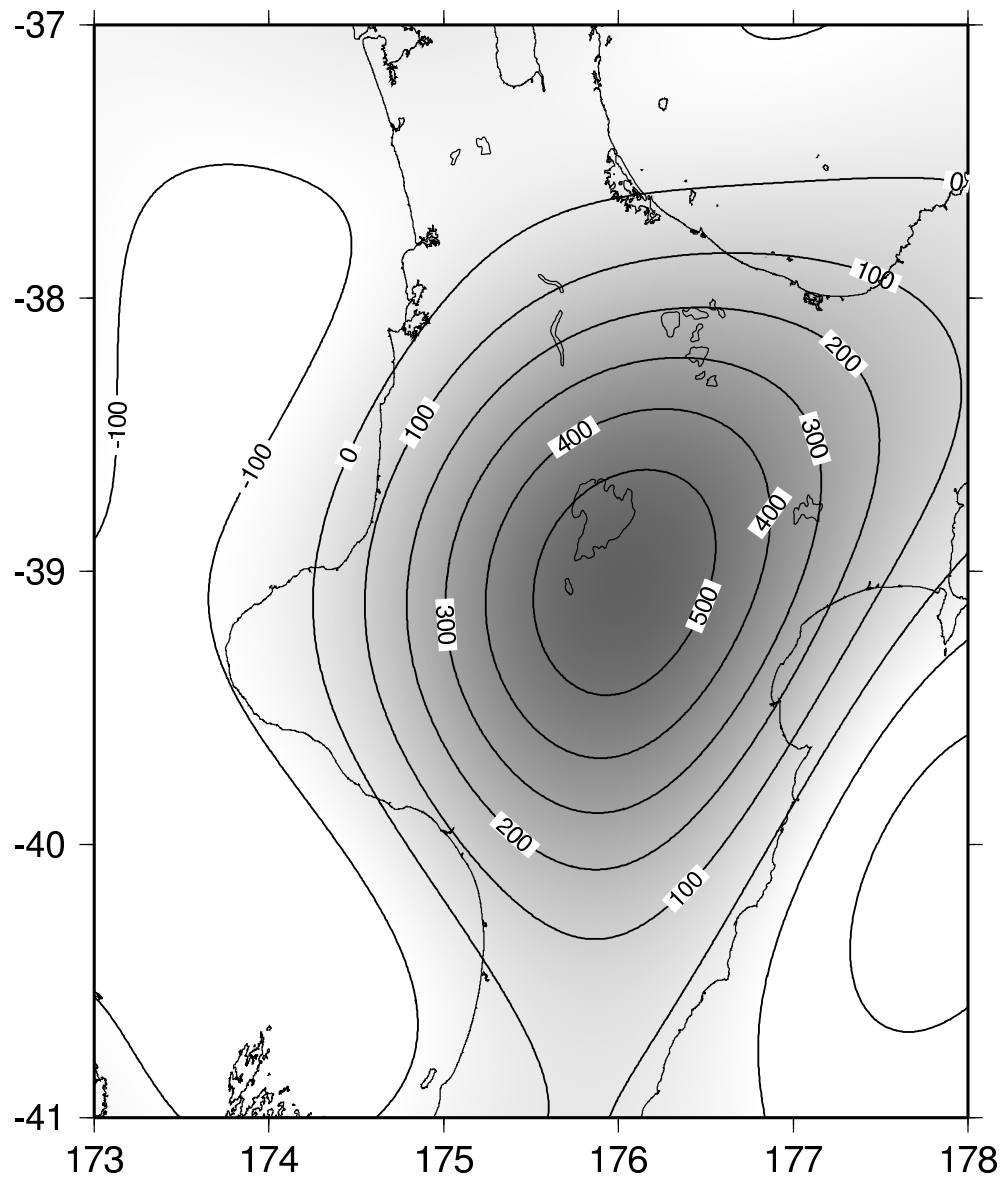

FIG. 6.5 Shading and contours describe topography of wavelength greater than $300 \mathrm{~km}$ in North Island. The 1 min DEM of North Island was filtered using a low pass filter of 200 $300 \mathrm{~km}$ to identify the long-wavelength surface topography of this region. Contours are in metres.

The smoothed topography represents surface uplift as the subhorizontal, shallow-water, marine sediments indicate that the initial topography was at sea level and has since uplifted to form the surface present today.

\subsection{Rock uplift}

Figure 6.7 displays the total amount of rock uplift of central North Island since the Late Miocene. The rock uplift is calculated by adding the smooth topography to the exhumation (Eq 6.1. The domed shape of the exhumation is enhanced by the surface uplift and gives a total rock uplift of $2.5 \pm 0.2 \mathrm{~km}$ in central North Island, $\sim 400 \mathrm{~m}$ near the Wanganui coast and 1-1.5 km on the northern Taranaki coast since the Late Miocene (4 Ma). These values 


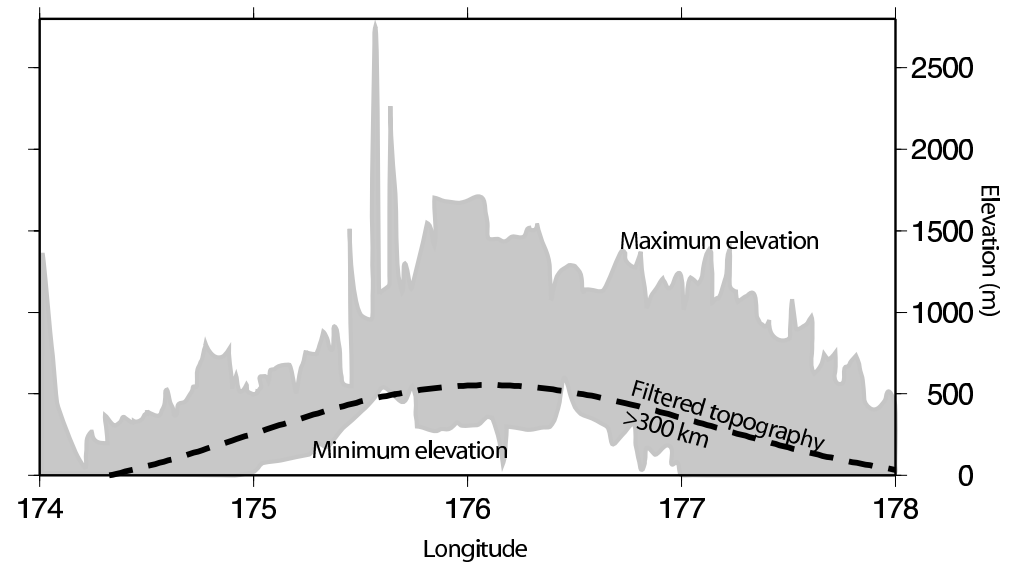

Fig. 6.6 Cross section of topography along a $\sim 50 \mathrm{~km}$ wide swath centred on latitude -39 $\circ$. The grey shading indicates the range of topographic elevations across the swath. The dashed line is the elevation of the filted topography along the $-39^{\circ}$ latitude and shows that the filtered topography is not influenced strongly by the presence of the volcanoes in central North island (Shown as the sharp peaks at 175.6 longitude).

equate to uplift rates of $0.1-0.63 \pm 0.05 \mathrm{~mm} / \mathrm{yr}$.

\subsection{Tectonic uplift}

Tectonic uplift is the rock uplift that occurs in response to tectonic forces. These forces do not include rebound due to erosion. Using Equation 6 and density values for the mantle and sediment of 3300 and $2200 \mathrm{~kg} / \mathrm{m}^{3}$, exhumation of $2 \mathrm{~km}$ and a surface uplift of $500 \mathrm{~m}$ a tectonic uplift of $1.17 \mathrm{~km}$ is calculated. This tectonic uplift value indicates that about $50 \%$ of the observed rock uplift occurs as a result of tectonic forces and the remainder is a result of rebound due to erosion.

\subsection{Differential erosion calculations from Mt. Hauhungatahi}

Tertiary sediments outcrop both at the surface to the west of the central volcanic plateau and under a volcanic cap on Mt. Hauhungatahi within the southern CVR. The volcanic cap effectively stopped erosion at $\sim 0.5 \mathrm{Ma}$, when the volcanic material was erupted (Graham and Hackett, 1987; Hackett and Houghton, 1989). Comparison of elevation between the protected and exposed Tertiary sediments provides an independent local estimation of ex- 


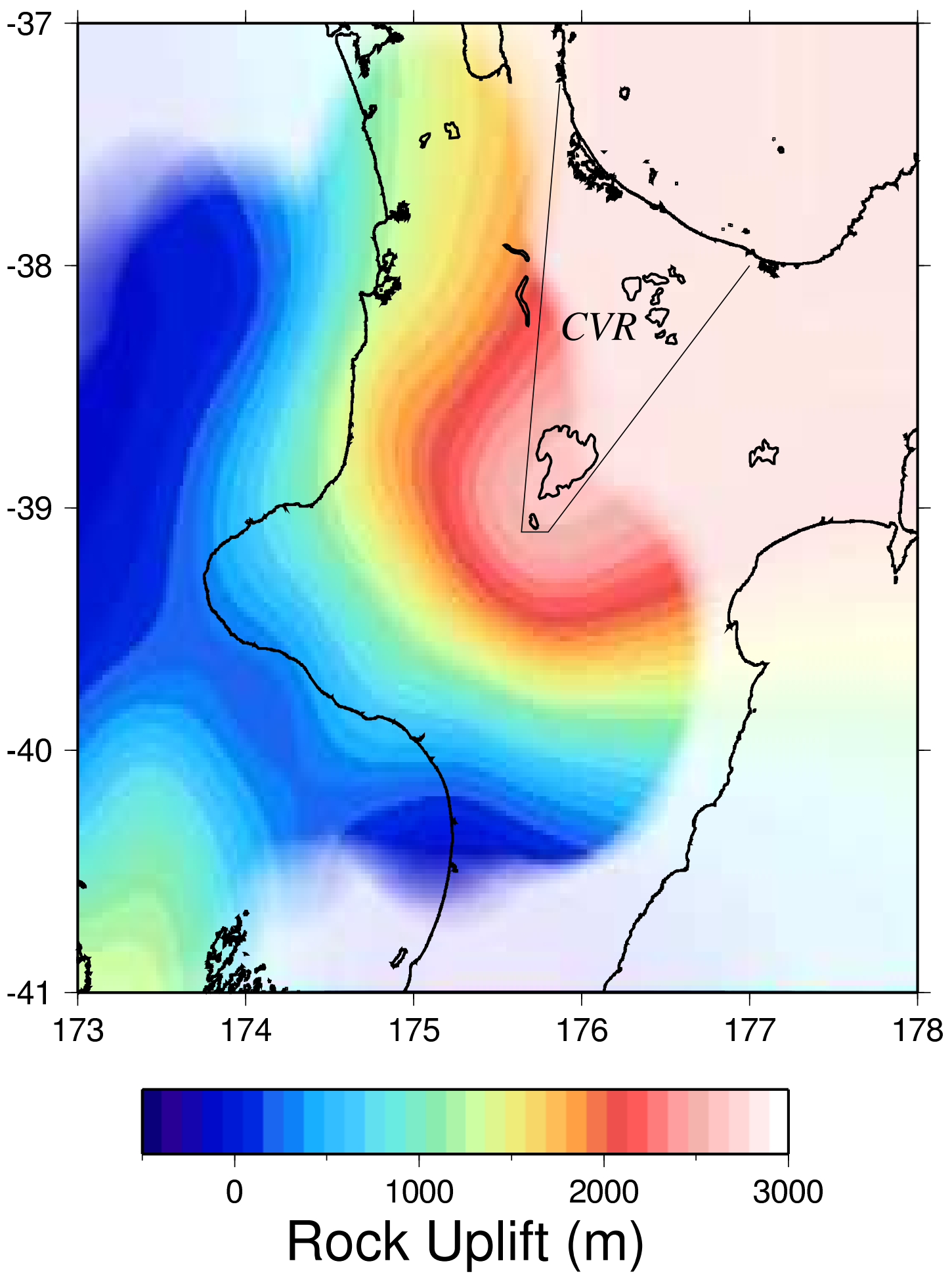

Fig. 6.7 Rock uplift of North Island since the Miocene. The grid displayed here was calculated by adding the grid of filtered exhumation (Figure 6.2) and the smoothed topography (Figure 6.5). 


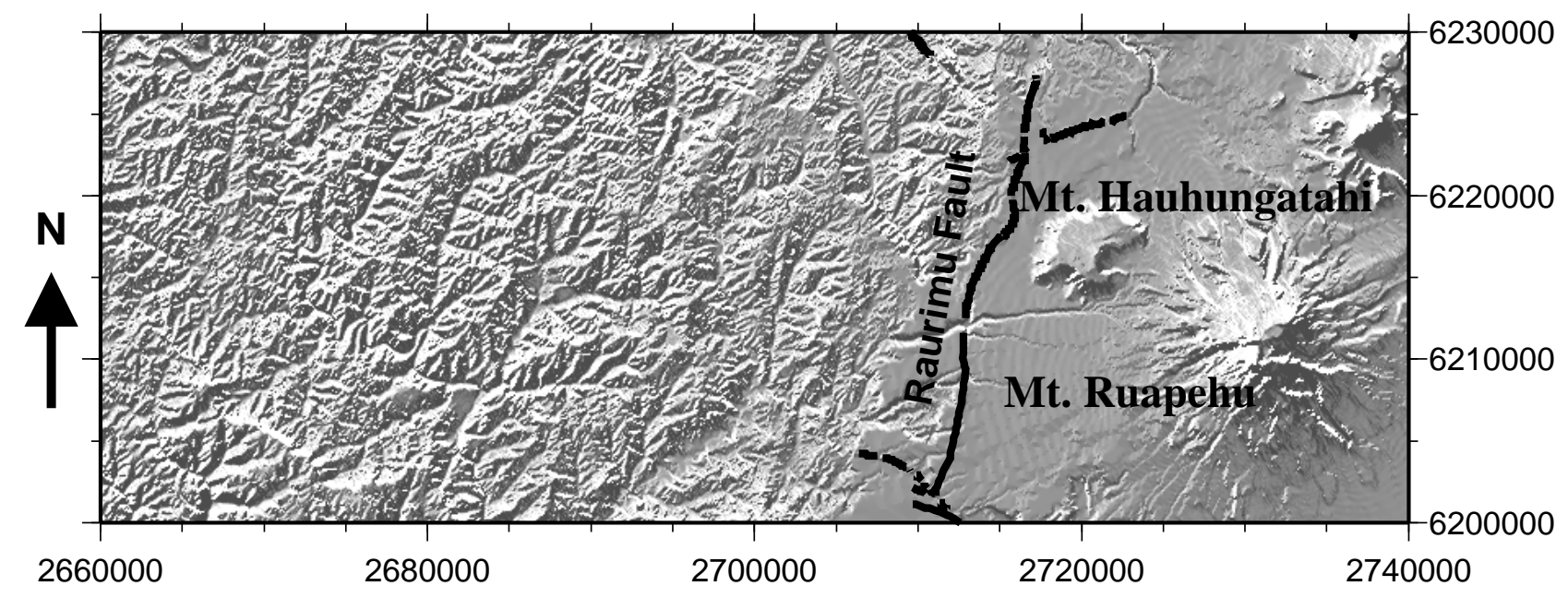

FiG. 6.8 Shaded relief image of the south-western margin of the CVR, from the New Zealand DEM. Tertiary sediments are preserved underneath the volcanic cap of Mt. Hauhungatahi and also crop out to the west of the Raurimu Fault indicated by the dissected topography. The smooth topography to the west of the fault is due to lava flows and volcanic debris from Mt. Ruapehu.

humation to compare with those obtained from mudstone porosity estimates.

Between the two outcrops of Tertiary material is a low lying region of much younger volcanic sediments and the north-south striking Raurimu (or Waimarino) normal fault (Figure 6.8. The fault is downthrown on the Mt. Hauhungatahi side. Estimates of dip-slip on the fault indicate $0.9 \mathrm{~mm} / \mathrm{yr}$ from the displacement of Porewan aged Lahars (70-80 ka) (LeCointre et al., 1998) and up to 1.35-1.55 mm/yr from a displaced lahar dated at $2080 \mathrm{a}$ (Villamor, in prep.). It is noted that these rates are likely to be maxima as the young age of the volcanics means that the displacement recorded is from one slip event only and does not allow for long earthquake recurrence time.

Despite Mt. Hauhungatahi occurring on the down-thrown side of the fault the Tertiary sediments crop out at higher elevations on Mt. Hauhungatahi than to the west. This difference in elevation is the result of differential erosion between the exposed Tertiary sediments in the west and those protected by the volcanic cap. The capping volcanic lava flows and breccia are not well constrained in age and have been given an approximate age of $\leq 500$ ka (Graham and Hackett, 1987; Hackett and Houghton, 1989). Nevertheless, the difference in elevation between the two outcrops of Tertiary marine sediments should provide a first order approximation of the amount and rate of exhumation of Tertiary sediments 
since the eruption of the lavas capping Mt. Hauhungatahi.

Calculation of the differential erosion between the two adjacent Tertiary sedimentary packages was done by averaging the topography in a region $10 \mathrm{~km}$ wide between NZ grid reference northings 6213000 to 6223000 (NZMG coordinates). This averaged topography shows the trend of summit elevations upwards towards the central volcanic plateau and Mt. Hauhungatahi (black line on Figure 6.9). Red data points on the fitted line of Figure 6.9 were picked by hand from the DEM where there is a marked change in slope indicating the change in lithology from the volcanic cap to the soft marine sediments. The difference between the black and red lines of Figure 6.9 is an approximation of the differential erosion and equates to $300 \mathrm{~m}$ since $\leq 500 \mathrm{ka}$, i.e. an exhumation rate of $\geq 0.6 \mathrm{~mm} / \mathrm{yr}$.

\subsubsection{Results}

An exhumation rate of $0.6 \mathrm{~mm} / \mathrm{yr}$ is in excellent agreement with the rates of uplift of $0.63 \mathrm{~mm} / \mathrm{yr}$ from the CVR, based on $2.5 \mathrm{~km}$ maximum exhumation and assuming the onset of exhumation was coeval with the start of the formation of the CVR at 4 Ma. The throw on the fault indicates that this exhumation rate is likely to be a minimum. The difference between the value estimated here and the actual exhumation will depend on how long the Raurimu Fault has remained active in its current sense. Villamor (in prep.) notes that faulting around the southern part of the CVR appears to have been active and moving at approximately constant rates for the last $200 \mathrm{ka}$. If we assume the fault has been moving at $0.9 \mathrm{~mm} / \mathrm{yr}$ since $200 \mathrm{ka}$, this equates to a relative subsidence of $180 \mathrm{~m}$. This would produce an overall exhumation of $480 \mathrm{~m}$ since $500 \mathrm{ka}$, a rate of $\sim 1 \mathrm{~mm} / \mathrm{yr}$, which is greater than that estimated from mudstone porosities. If there has been movement on the fault this indicates a higher rate of exhumation in the last $500 \mathrm{ka}$, than in the past. However, as the contribution of fault movement is poorly constrained, the exhumation rate of $\geq 0.6 \mathrm{~mm} / \mathrm{yr}$ is the best estimate that can be made using differential erosion on Mt. Hauhungatahi using these data. 


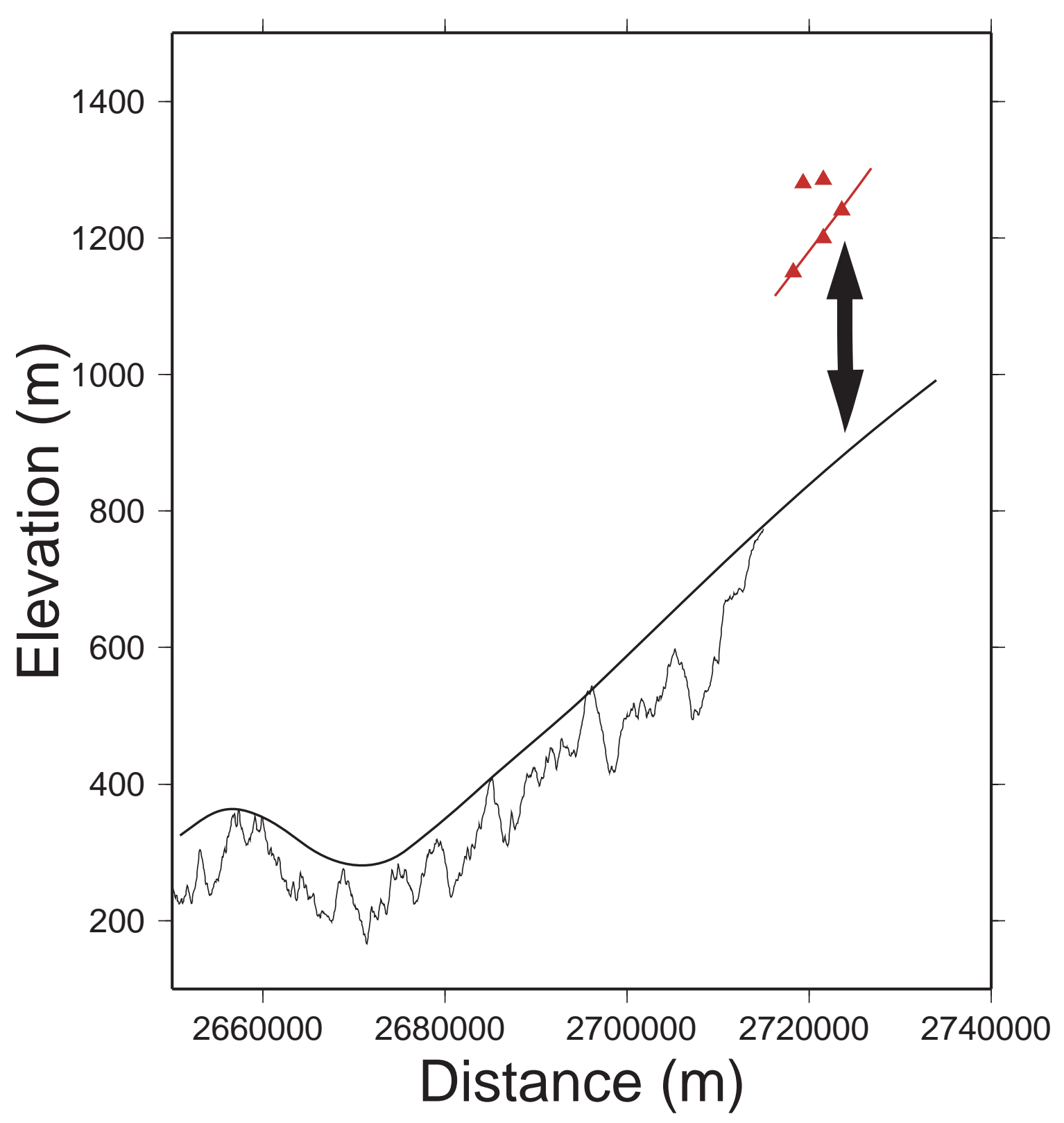

Fig. 6.9 Cross section directly E-W across Figure 6.8 showing the excess elevation of Mt. Hauhungatahi with respect to the dissected and eroded Tertiary sediments to the west. The lower black line represents elevations averaged from grid coordinates of 62130000 to 6223000 and projected onto the east-west line. The upper black line is a smoothed curve linking the summit elevations and projecting what the elevations are likely to be at the location of Mt. Hauhungatahi. The red triangles are elevation data points from the top of the Tertiary sediments cropping out on Mt. Hauhungatahi, extracted from the DEM, and projected onto an east-west line. A line is fitted to the lowest of these points. The elevation difference between the upper black line and the red line gives an estimate for the differential erosion since the depositions of volcanics at Mt. Hauhungatahi 


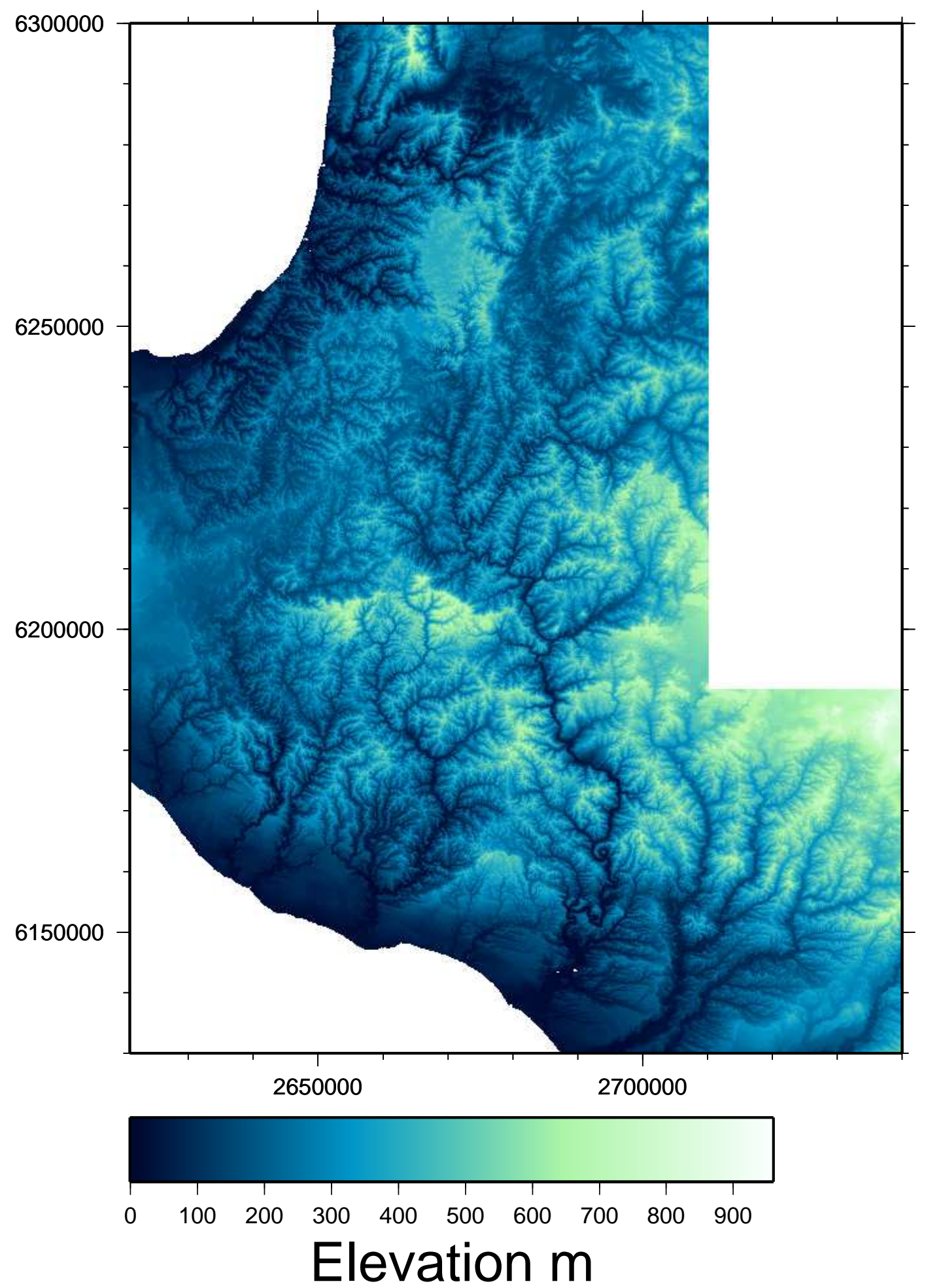

FiG. 6.10 DEM showing the topography of the region used for the calculation of incision erosion. The DEM has been sampled here at a resolution of $200 \mathrm{~m}$. The Volcanoes of the CVR have been masked. These volcanic peaks were formed by building up on top of the land surface, and if they were included in the grid a higher value of incision would be calculated. 


\subsection{Exhumation by fluvial incision}

The inland portion of the Wanganui Basin has been exhumed and exposed above sea level and has become progressively dissected with time (Flemming, 1953; Pillans, 1990b). Calculation of the volume of material removed from the landscape through stream incision allows the estimation of the amount of rock uplift that has occurred through isostatic rebound in response to lithospheric unloading. Once rebound from incision is estimated this can be removed from the rock uplift derived in Section 6.4 so that this uplift signal is not modelled as part of the rock uplift from large scale tectonic or thermal forces. The calculation of incision erosion, and its associated rebound, also provides a demonstration of the use of a DEM in a tectonic problem.

\subsubsection{Analysis}

Erosion by fluvial incision can be calculated by fitting a surface to the main summit heights of central North Island (not including the recently formed volcanoes) and subtracting the observed topography. Summit heights were identified from the $25 \mathrm{~m}$ DEM using the summit filter of the Demtool program (Davies, 1996), which searches the data for the highest peaks within a given radius (Here: Peaks greater than $10 \mathrm{~m}$ above average within Radius $=500 \mathrm{~m}$ )(Figure 6.10 shows the topography of the region chosen for these calculations). A surface was then fitted to these summit heights using splines in tension, a function of the GMT Surface program (Smith and Wessel, 1990). This surface of summit heights represents a reference surface below which the topography has been incised (Figure 6.11). The difference between the summit height surface and the present topography is the incision erosion (Figure 6.12). The total volume of material eroded is $2992 \mathrm{~km}^{3}$ over a region of $13982 \mathrm{~km}^{2}$. This equates to an average of $214 \mathrm{~m}$ of material removed over the entire region. These incision erosion estimates are conservative as they do not take into account lowering of the peaks and ridge tops.

The extent and shape of incision will influence the amount of rebound occurring due to the unloading. Wide glacial or mature shaped valleys will have the greatest influence as a large volume of material is removed over a relatively small region below the height of 


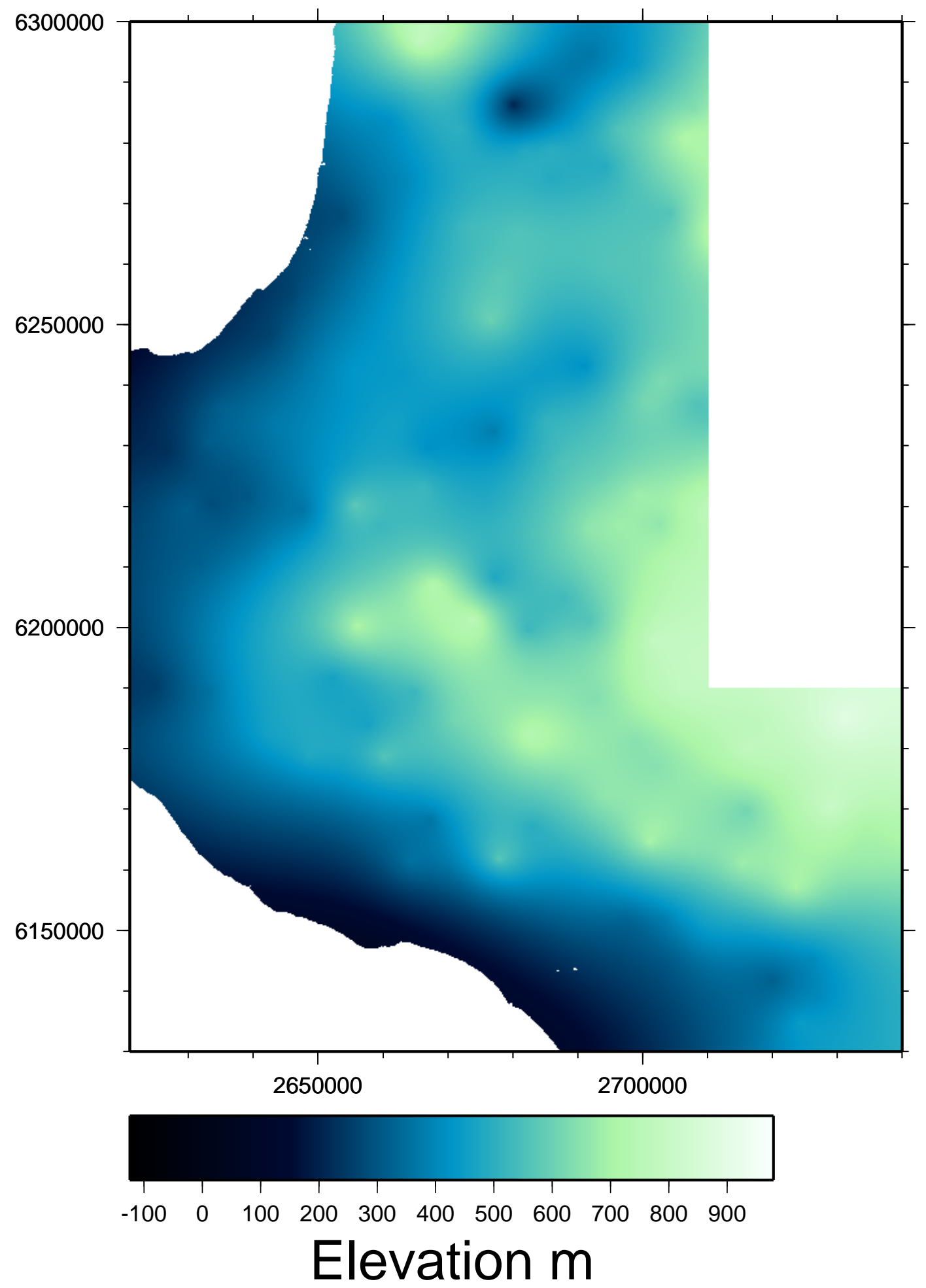

Fig. 6.11 Surface fitted through summit peaks in the region shown in Figure 6.10. The surface was created using the surface function of GMT to fit a surface through main summits, identified using a filter in the Demtool program (Davies, 1996). This grid has been sampled at $200 \mathrm{~m}$. 
the peaks. Where narrow valleys are eroded only a small amount of rebound will result as only a small volume of material is eroded. Incision of valleys, resulting in an increase in topographic relief, in a locally isostatically compensated region will result in an increased peak elevation and a reduction in the average elevation (Holmes, 1965).

If local isostatic compensation is assumed, the maximum potential uplift of the mountain peaks will be (Montgomery, 1994):

$$
\Delta Z_{p}=\left(A_{e} / W\right)\left(\rho_{c} / \rho_{m}\right)
$$

Where $A_{e}$ is the area of material eroded from a $2 \mathrm{D}$ section, $\mathrm{W}$ is the width of the section and $\rho_{c}$ and $\rho_{m}$ are the densities of the crust and mantle respectively. It follows that for a $3 \mathrm{D}$ section:

$$
\Delta Z_{p}=\left(V_{e} / A\right)\left(\rho_{c} / \rho_{m}\right)
$$

Where $V_{e}$ is the volume of material removed, $\mathrm{A}$ is the area over which material has been eroded.

In the Wanganui-Taranaki region, the assumption of increasing topographic relief holds because the recent exposure of the region above sea level indicates that the present drainage has been incised since it was exposed. Using typical crustal and mantle values: $\rho_{c}=2600 \mathrm{~kg} / \mathrm{m}^{3}$, $\rho_{m}=3300 \mathrm{~kg} / \mathrm{m}^{3}$, and $\mathrm{V}_{e}=2992 \mathrm{~km}^{3}, \mathrm{~A}=13982 \mathrm{~km}^{2}$ a peak uplift of $\sim 169 \mathrm{~m}$ is calculated using Equation 6.7. The average elevation of the summits in this region is $484 \mathrm{~m}$, calculated from the summit grid shown in Figure 6.11. The above calculations show that $35 \%$ of the current peak elevation may be attributed to valley incision, if local isostatic conditions are assumed.

Incision of topography can be used to identify areas of rapid uplift. Regions that have undergone the greatest uplift have the potential to have a greater amount of incision between the base stream level and the uplifted summit heights. Summerfield and Hulton (1994) identify a correlation between mean modal elevation over a drainage basin and mean local relief. By relief they mean the difference between the maximum and minimum elevation of an area. This indicates that as the landsurface is uplifted to higher elevations there is likely 


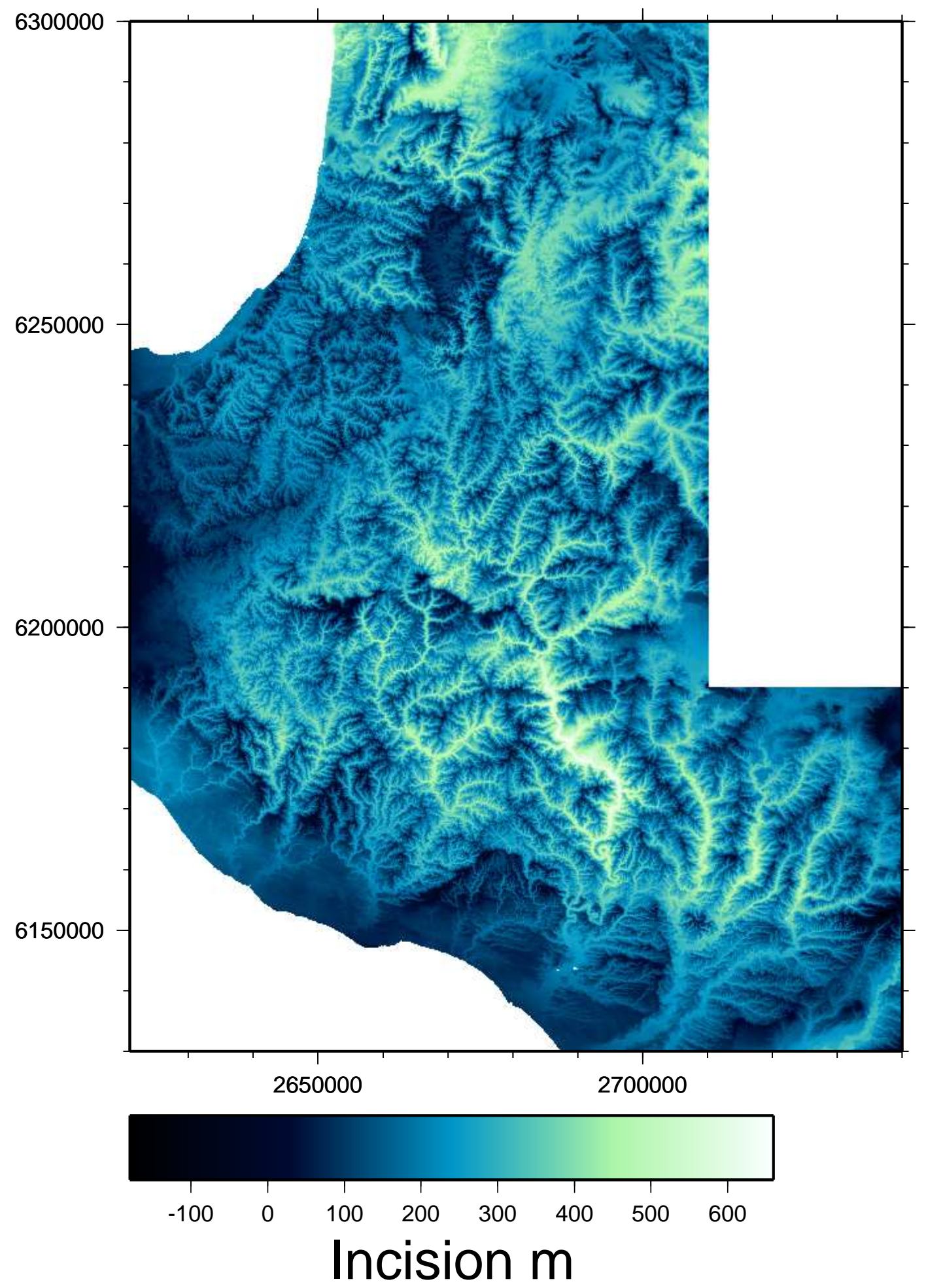

FIG. 6.12 The difference between the summit height surface (Figure 6.11) and the present topography (Figure 6.10) gives the amount of erosion that has occurred due to incision erosion. The volume of the grid is $2992 \mathrm{~km}^{3}$ over a region $13982 \mathrm{~km}^{2}$, which equates to an average depth of $214 \mathrm{~m}$ over the whole region. 


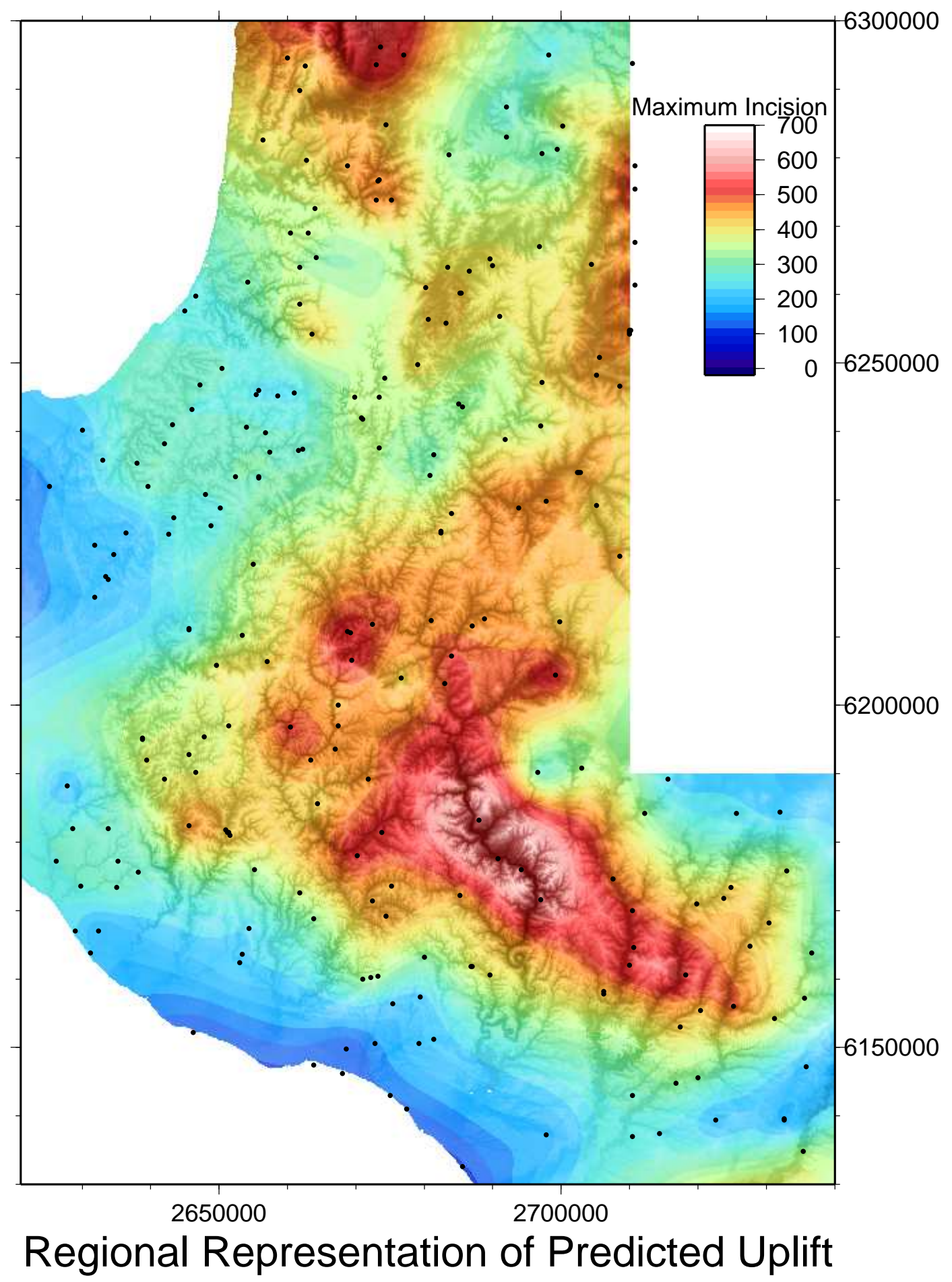

FiG. 6.13 Regional representation of predicted uplift from incision erosion. The image shows only the maximum incision erosion of the area, which can be used as a proxy for variations in recent rock uplift. Areas of greater incision erosion can indicate recent relatively strong rock uplift. Cells of maximum incision were extracted from the grid of incision (Figure 6.12) using the Demtool summit function. These points are displayed as black dots and demonstrate where the surface is constrained by input data. The colours describe a surface which was fitted through the maximum incision data points using the surface function of GMT. The shading is used to show the topography of the region and the location of the drainage. Note the maximum incision lies to the south of the region of maximum rock uplift and also south of the line between Mt. Ruapehu and Mt. Taranaki (Figure 6.7). 
to be an increase in relief and hence incision. This correlation appears to break down in regions of rapid uplift of $>2 \mathrm{~mm} / \mathrm{yr}$, where incision appears to be in equilibrium with rock uplift due to peak lowering through land-sliding (Burbank et al., 1996).

Maximum incision of the Taranaki-Wanganui region is focused along the Wanganui River and if incision has been initiated since $4 \mathrm{Ma}$ then the highest rate of incision is only $0.2 \mathrm{~mm} / \mathrm{yr}$, well below the threshold for rapid incision in response to rock uplift. However, it is noted that the Wanganui region is characterised by large landslides due to the soft nature of the sediments (Crozier and Pillians, 1991). Hence the increased incision signal in the Wanganui-Taranaki region, which is present despite peak lowering through landslides, indicates that this is a region of higher rock uplift rates than the surrounding landscape.

The extent of the region of high incision is examined more closely by extracting the areas of maximum incision from the incision erosion grid using the summit filter function of the Demtool program (as used above to determine the main peak elevations). A surface fitted through these points shows only maximum incision and is predominantly constrained along the rivers (Figure 6.13). There is a clear maximum due to the high incision of the Wanganui River, but this band of high incision is also seen across other rivers of the area.

The location of the region of high incision erosion appears not to be correlated with a region of higher than average rainfall over the last 30 years (Statistics, 2002), and hence is not likely to have produced the pattern of observed incision. River catchment size also appears not to contribute to incision erosion as the Wanganui River has a much greater catchment size than the rivers to the east and west, but all these rivers show an increase in incision erosion around $40 \mathrm{~km}$ from the coast. This pattern of high incision is not correlated with the region of high rock uplift and exhumation derived from mudstone porosity analyses (Section 6.4), indicating this incision may be a recent feature.

\subsubsection{Results of isostatic incision and erosion calculations}

Erosion due to incision varies from $0 \mathrm{~m}$ on ridge tops and summits to a maximum of $650 \mathrm{~m}$ in the Wanganui River. These values are conservative due to the assumption that ridge-tops have not lowered with time. Maximum incision is hypothesised to be a proxy 
for recent increased rock uplift in the Taranaki-Wanganui region. High incision and hence rapid rock uplift is identified parallel to the coast and around $50 \mathrm{~km}$ from the termination of the CVR. The spatial location of proposed increased rock uplift corresponds well with the seismic transmitting and attenuating boundary in the lithospheric mantle of Mooney (1970). Faulting in the Taranaki region indicates a change from compressional thrust faulting to the south and normal faulting to the north (King and Thrasher, 1996), with the change approximately aligned with the region of high incision. The hypothesis is put forward that the region of high incision, resulting from recent relatively high uplift rates, indicates that the centre of maximum rock uplift may be moving southwards with time and is currently centred $\sim 40 \mathrm{~km}$ from the Wanganui coastline.

Progressive tilting of fluvial terraces (Te Punga, 1952; Milne, 1973c), marine terraces (Pillans, 1990b), anticline axes (Jackson et al., 1998) and shallow marine sedimentary units also provide possible evidence for a southward migration of rock uplift.

The average incision of $214 \mathrm{~m}$ is small compared to that of the $\sim 2 \mathrm{~km}$ exhumation calculated in Section 6.2.1. Comparison of the peak uplift of $169 \mathrm{~m}$ to the average peak elevation indicates that $35 \%$ of this elevation is attributable to the rebound due to incision erosion. Nevertheless, isostatic rebound due to incision erosion plays a secondary role in the total rock uplift of central North Island.

\subsection{Conclusions}

Exhumation in central North Island has been described by compiling mudstone porosity data and coal vitrinite reflectance information (Edbrooke et al., 1994). Mudstone porosities reflect the depth to which the material has been buried and provides an indication of the amount of material that has since been removed. Calculated exhumation show over $2 \mathrm{~km}$ of exhumation centred at the southern termination of the CVR.

Filtered topography shows that the elevation of North Island, for features of over 200$300 \mathrm{~km}$ wavelength, reaches $\sim 500 \mathrm{~m}$ in the central north (Figure 6.5) and describe a similar pattern to that seen from the exhumation data (Figure 6.2). This is expected where rock uplift is continuing to the present day at a rate that is greater than the rate of exhumation. 
Isostatic rebound due to incision erosion can account for $35 \%$ of the surface elevation seen today using local isostatic compensation calculations.

For central North Island a maximum rock uplift of $\sim 2.5 \mathrm{~km}$ is estimated. Average uplift rates since $\sim 4 \mathrm{Ma}$ vary from $0.1 \mathrm{~mm} / \mathrm{yr}$ along the Wanganui coast to $0.6 \mathrm{~mm} / \mathrm{yr}$ at the termination of the CVR.

Variations in maximum incision erosion indicate a region of high incision $\sim 40 \mathrm{~km}$ from, and approximately parallel to, the Wanganui coastline. Incision can be used to elucidate regions of rapid and/or more recent rock uplift. It is proposed that this region of high incision occurs in response to the southward migration of the processes responsible for domed rock uplift in central North Island.

The calculated pattern of rock uplift estimated here provides constraints on a loading model of the lithosphere, discussed in the following chapter. The modelling allows constraints on the possible sources of rock uplift to be made.

summary 
CHAPTER 7

\section{INVESTIGATION OF THE SOURCE OF DEFORMATION IN CENTRAL NORTH ISLAND}

Modelling of the forces required to create and maintain a dome of rock uplift with wavelength $500 \mathrm{~km}$ and magnitude $2.5 \mathrm{~km}$ provides insight into the processes responsible for the vertical deformation. Constraints used for modelling come predominantly from estimates of rock uplift (Chapter 6), and also results from previous research which are summarised in Figure 7.1. Two models for uplift are investigated here. The first considers mantle upwelling and the buoyancy properties of the mantle, the second looks at crustal rebound due to the release of coupling forces along the subducted plate boundary. The first is expected to be the major contributor to the observed rock uplift. Rebound is likely to be a secondary process.

Other global occurrences of doming of this magnitude and wavelength are often associated with mantle processes, in particular the displacement of mantle lithosphere with asthenosphere. Broad-scale crustal doming as a result of mantle up-welling is proposed, for example, in Yellowstone in the USA (Smith and Braile, 1994), Spitsbergen to the north of Scandinavia (Vågnes and Amundsen, 1993), Italy (D'Agostino et al., 2001) and Western Antarctica / southern New Zealand (LeMasurier and Landis, 1996). The domed uplift at these locations, and attributed causes, will be briefly discussed. From these regions insight into the processes responsible for vertical movements in central North Island can be obtained. 


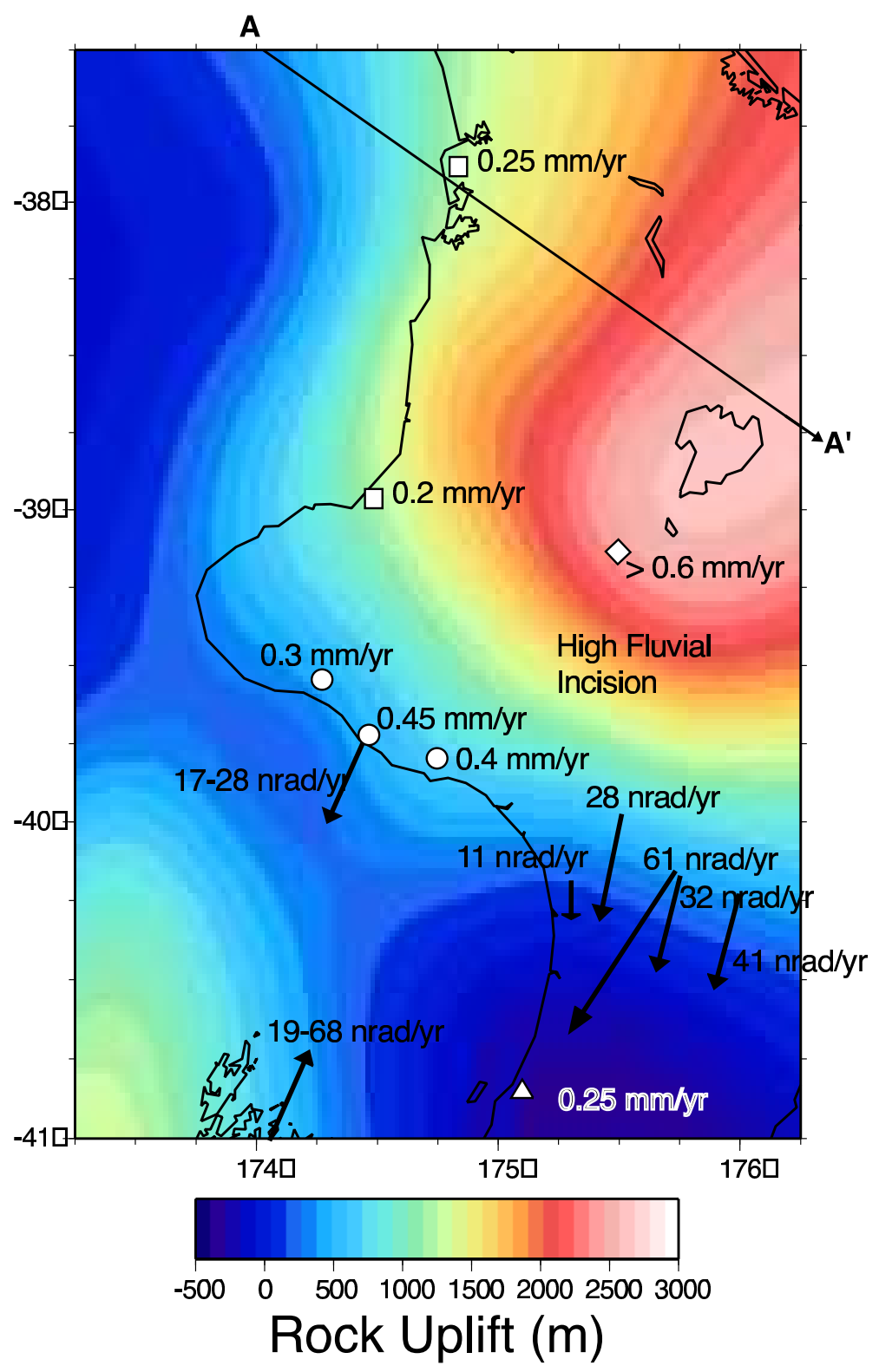

Fig. 7.1 Summary of uplift and tilt rates. The colour indicates the magnitude of rock uplift and is the same as Figure 6.7. The arrows indicate tilt direction of geomorphic surfaces, the length indicates the tilt rate (tilts from Milne (1973c), Pillans (1990b) and Jackson et al. (1998)). Data points indicate locations of estimates of uplift rates since the Quaternary. Data points from marine terrace uplift are shown with squares (Chappell, 1975), circles (Pillans, 1990b), and triangles (Pillans, 1990b). The diamond is the differential erosion estimate from Mt. Hauhungatahi, this study and the region of high fluvial incision, which may indicate recent rapid uplift, is also from this study. The line $A-A^{\prime}$ is the transect shown in Figure 7.7. 


\subsection{Source processes of lithospheric doming}

Lithospheric doming is often attributed to the buoyancy of an underlying mantle plume impinging on the base of the lithosphere. However, Huismans et al. (2001) show that similar doming can result from passive extension of the lithosphere. Up-welling of mantle asthenosphere into lithospheric mantle, as a result of extension, can lead to an instability that results in active spreading and uplift driven by buoyancy (Huismans et al., 2001). Regions of initially passive extension do not have flood basalts associated with the initial onset of a mantle plume but extensive silicic volcanism, due to the extension, will be present in both cases.

Mohr (1982) provides a global summary of the sequence of events which occur prior to and during continental rifting. In contrast to regions associated with mantle plumes, the initial phase of continental rifting is the development of broad shallow depressions. This subsidence is followed by a thermal pulse which reflects the injection of asthenosphere into the lithosphere. The thermal pulse will result in the formation of lithospheric doming and volcanism.

\subsection{Brief overview of some regions of lithospheric doming}

\subsubsection{Yellowstone Hotspot}

The track of the Yellowstone hotspot is defined by a line of calderas that extend from northern Nevada across Idaho to Montana. Smith and Braile (1994) describe the topographic doming of the crust associated with the Yellowstone hotspot as a $600 \mathrm{~m}$ high topographic bulge extending over a $600 \mathrm{~km}$ wide area. The bulge is parabolic in shape with a low lying region in the trail of the hotspot. Silicic volcanic rocks, predominantly rhyolites and andesites with some basalt, fill the low lying region. K/Ar dating of these rocks indicates a progression of volcanics at a rate of $\sim 4 \mathrm{~cm} / \mathrm{yr}$.

Fluvial terraces occurring at the front of the topographic bulge, draining away from the uplifting region, show a convergent pattern with an increase in tilt with time (Pierce and 
Morgan, 1992), similar to that seen in North Island (Te Punga, 1952; Milne, 1973c). A divergent pattern of fluvial terraces is seen for regions that have a downward slope towards the front of the topographic bulge. The tilt of the fluvial terraces provides strong evidence of either increased uplift or the progressive motion of the uplifting region.

There is no tectonic evidence for the formation of doming in response to extension in the Yellowstone hotspot region. Hence, it is thought that the Yellowstone hotspot uplift and deformation may be the result of a mantle plume impinging on the base of the crust (Smith and Braile, 1994).

\subsubsection{Appennines, Italy}

Crustal doming of wavelength $>150-200 \mathrm{~km}$ is seen in the Appennines, Italy. The region has undergone uplift at rates of $0.3-0.5 \mathrm{~mm} / \mathrm{yr}$ during the Quaternary as recorded by the stratigraphy (D'Agostino et al., 2001). Mantle derived magmatism, attenuated upper mantle seismic velocities and mantle derived helium in the ground waters, are evidence that mantle processes are the driving force of the domed uplift (D'Agostino et al., 2001). The use of free-air admittance, which compares the free-air gravity anomalies to the topography in the spatial domain, indicates that the long wavelength part of the topography is isostatically compensated by a subcrustal density contrast. The process responsible for the Quaternary uplift may either be a mantle plume or a convective mantle instability resulting in asthenospheric up-welling (D'Agostino et al., 2001).

\subsubsection{Spitsbergen}

Spitsbergen lies $650 \mathrm{~km}$ north of Scandinavia adjacent to the spreading ridge that passes through Iceland. In Spitsbergen, tectonic uplift, high heat flow and pressure-temperature estimates from volcanic rocks indicate a markedly thinned lithosphere (Vågnes and Amundsen, 1993). Coastal deposits are observed at elevations of $1000 \mathrm{~m}$ and 1-3 km of rock uplift is estimated for rocks of a range of ages from exhumation data. Rock uplift is attributed to mantle up-welling in response to boundary processes, occurring where a hot-spot influenced asthenosphere lies adjacent to cold continental lithosphere (Vågnes and Amundsen, 1993). 


\subsubsection{West Antarctica and South Island, New Zealand}

An extensive palaeosurface formed $\sim 80-100$ Ma exists both in West Antarctica and South Island, New Zealand, at locations that would have been adjacent prior to plate separation. The eroded surfaces indicate that the onset of plate spreading coincided with subsidence (LeMasurier and Landis, 1996). This is in contrast to most areas, which undergo uplift and extension prior to rifting. Once rifting was initiated a large structural dome of $2700 \mathrm{~m}$ above sea level was formed but because most of West Antarctica is below sea level $\sim 3200 \mathrm{~m}$ of uplift has occurred above the isostatically corrected bedrock of adjacent areas (LeMasurier and Landis, 1996). There is a close connection in time between volcanism and the onset of doming. The Antarctic plate has not moved significantly in the last $85 \mathrm{Ma}$ (Lawver et al., 1991) and as a result, if the uplift in Antarctica is the source of a mantle plume, a hotspot trail cannot be identified. Extension and rifting may be factors in the initiation of volcanism in Antarctica but due to the lack of plate motion this remains speculative (LeMasurier and Landis, 1996).

\subsection{Central North Island, New Zealand}

High heat flow values, reaching up to $800 \mathrm{~mW} / \mathrm{m}^{2}$ in the eastern CVR (Stern, 1987), high seismic attenuation (Satake and Hashida, 1989; Salmon, 2001) and low compressional wave mantle velocities $\sim 7.4 \mathrm{~km} / \mathrm{s}$ (Haines, 1979; Stern et al., 1987; Stratford and Stern, 2002) under central North Island indicate the presence of anomalously hot material in the mantle lithosphere. The scale of doming of the overlying crust with a wavelength of $\sim 500 \mathrm{~km}$ is similar to that observed in other regions around the world, as discussed above, that are being deformed due to mantle processes.

The absence of subsidence prior to the formation of lithospheric doming in central North Island indicates that although this is a region of back-arc extension, the sequence of events observed in North Island differs from that observed along continental rifts. The heat flow is greater for this region of back-arc extension than is observed in regions of continental rifting. These features indicate that although the extension of the lithosphere is likely to be 
a major driving force for the domed rock uplift that subduction related fluids and volcanism are significant contributors to the mantle processes responsible for the domed rock uplift.

Attenuation research indicates the presence of a region of low $\mathrm{Q}$ (high attenuation) attributed to hot material, possible partial melt, rising and ponding below the TVZ (the more active eastern part of the CVR) (Salmon, 2001). On a broader scale Mooney (1970) identified a change in seismic attenuation from low in the eastern part of North Island to moderate in the west at a depth between $75-125 \mathrm{~km}$. The boundary between the attenuating and transmitting regions lies along the line of active volcanism of the CVR and from the southern most active volcano of the CVR across to south of Mt. Taranaki (Figure 7.2). Hatherton (1970) noted the similarity in location of this seismic attenuating-transmitting boundary to a change in high heat flux, isostatic gravity anomaly (positive to the west and negative to the east (e.g. Reilly et al., 1977)), and the eastern margin is coincident with the onset of active volcanism. Gravity modelling by Stern et al. (1987) showed that the change could be explained by a $13 \mathrm{~km}$ jump in crustal thickness that is isostatically compensated by a $3 \%$ change in upper mantle density and a compensation depth of $100 \mathrm{~km}$.

Low Pn velocities were measured by Haines (1979) from crustal earthquake studies with Pn velocities of $\sim 7.4 \mathrm{~km} / \mathrm{s}$ in the CVR. Further constraints on low Pn wave speeds come from explosion seismology with values in the range 7.3-7.5 km/s (Stern and Davey, 1987; Stratford and Stern, 2002).

The forces required to form the observed domed uplift in North Island are estimated using a 3D loading model for the lithosphere. These modelled forces can be compared to the buoyancy forces expected for hot mantle material up-welling beneath central North Island. Comparison enables us to test if reasonable density changes in the mantle lithosphere can be the cause of the domed uplift. Flexure modelling is used because we are interested in both the extent and magnitude of lithospheric warping. Due to the finite rigidity of the lithosphere loading will be accommodated by both the region vertically aligned with the load and also by the surrounding lithosphere.

Previous flexure modelling for central North Island by Stagpoole (1997) indicated that a good fit to estimates of rock uplift can be obtained with negative loading confined to 


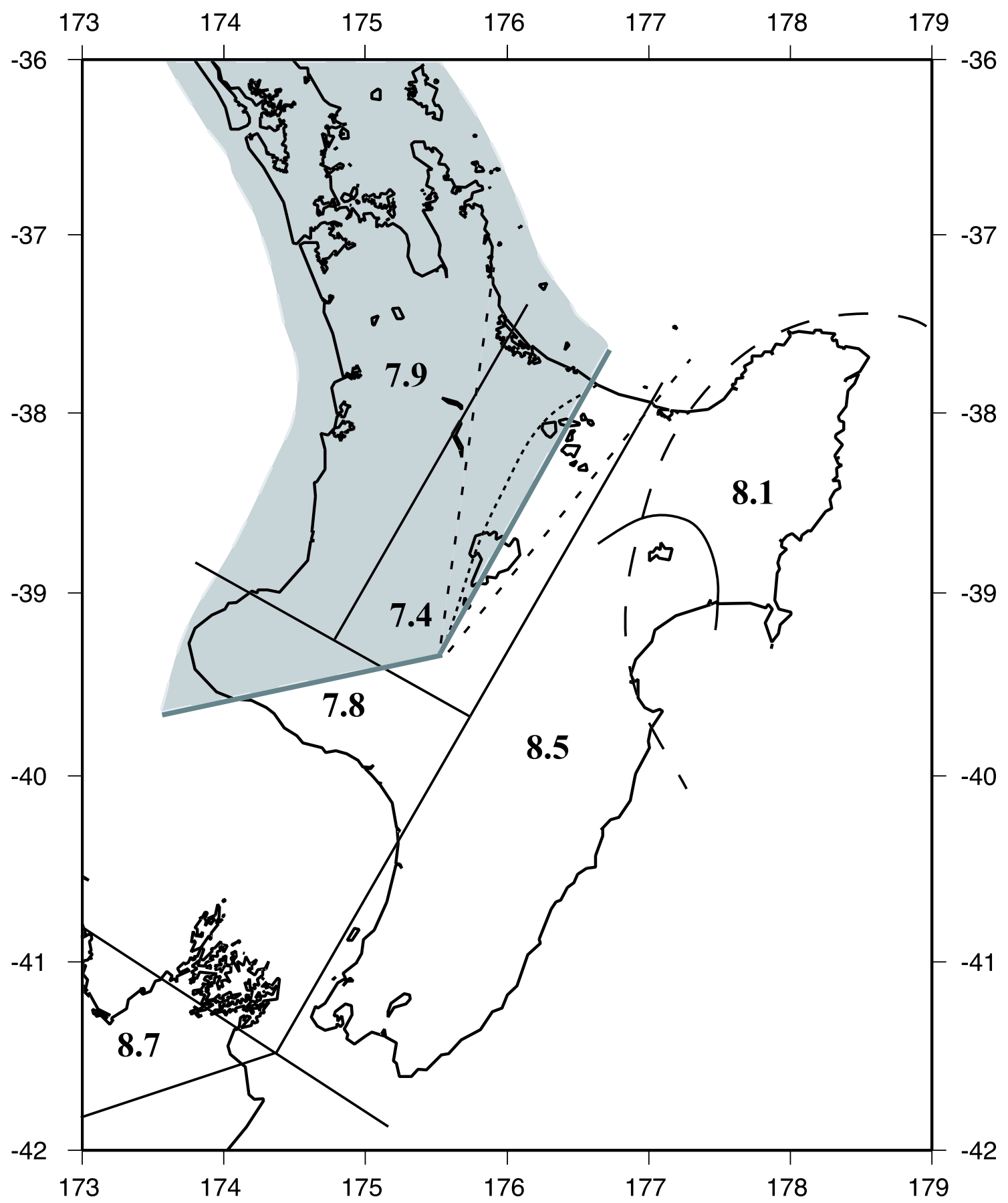

Fig. 7.2 Summary of seismic attenuation and Pn velocities under central North Island. The dark grey line denotes the high frequency attenuating- transmitting boundary of Mooney (1970), the grey shaded region is the attenuating region, to the east and south of the line there is much lower high frequency attenuation. The solid black lines and long dashed black line describes the boundaries between regions of different Pn velocities from Haines (1979), the values in black are the velocities in $\mathrm{km} / \mathrm{s}$. The fine dashed black lines define the CVR and the eastern more active part of the CVR: the TVZ (Boundaries from Stern (1987)). Salmon (2001) identified a region of high attenuation confined to below the TVZ. 
the CVR and the active volcanic region of Taranaki. He includes a region of weakened crust to represent the CVR in his lithospheric model. Here, further investigation of the spatial extent of the source region and magnitude of upward forces is undertaken. Negative loading was constrained to regions of slow mantle seismic velocities and moderate to high attenuation, as these are good indicators of thermal anomalies in the lithospheric mantle.

\subsection{Flexural modelling}

The lithosphere is modelled in 3D as an elastic rather than a visco-elastic plate overlying an inviscid fluid asthenosphere. Due to the young age of deformation the lithosphere is treated as a purely elastic plate, visco-elastic relaxation will play only a minor role over this time period (Beaumont, 1981). Here we use a modelling program used by Stern et al. (1992) for the Wanganui Basin.

\subsubsection{Boundary conditions}

The primary aim of the flexural modelling is to calculate the buoyancy forces and loading extent required to produce the observed rock uplift of central North Island (Section 6.4). Rock uplift from mudstone porosity analyses record uplift only from the deepest point of burial of the rocks to their present location. These data do not record initial subsidence and hence modelling is undertaken only using upward forces.

To estimate the forces that result from a thermal anomaly in the mantle, a model of tectonic force rather than rock uplift is needed, as rock uplift includes the uplift signal that results from erosion. Isostatic rebound from erosion serves to amplify the original rock uplift (King, 1955; Brown, 1991). Tectonic uplift has been estimated using a local isostatic model as $\sim 1.3 \mathrm{~km}$ in central North Island (Section 6.5). However, the rock uplift data provide better data coverage than the single tectonic uplift measurement. To use the rock uplift dataset to constrain our model an allowance needs to be made for the uplift that results from erosion. Restoring forces in flexural modelling can be adjusted to include the effect of erosion. In the case of tectonic uplift (no erosion) restoring forces are due to a density contrast between air and mantle, as lithosphere is displaced by an 
upward force, $\delta \rho=3300 \mathrm{~kg} / \mathrm{m}^{3}$. In regions of very efficient erosion rock uplift will include the amplification of uplift as a result of sediment rebound and hence the density contrast will be between the mantle and sediment (which is eroded $100 \%$ efficiently), $\delta \rho=3300-$ $2200 \mathrm{~kg} / \mathrm{m}^{3}=1100 \mathrm{~kg} / \mathrm{m}^{3}$. For example, Stern et al. (1992) in their study of the Wanganui Basin use a density contrast between sediments and mantle to represent highly efficient erosion. Tectonic uplift accounts for $\sim 50 \%$ of the rock uplift in central North Island (rock uplift $=2.5 \mathrm{~km}$ ). Using this percentage a restoring force that is halfway between the tectonic and rock uplift can be used to approximate the situation of central North Island ( $\delta \rho=2200 \mathrm{~kg} / \mathrm{m}^{3}$ or $22000 \mathrm{~Pa}$ per metre of vertical displacement).

Effective elastic thickness (Te) is a measure of how the lithosphere deforms and is related to the rheology. In regions of oceanic lithosphere Te is associated with the age of the lithosphere; as the lithosphere becomes cooler it becomes stiffer and the effective elastic thickness approximately follows the $450^{\circ} \mathrm{C}$ isotherm (Watts, 1992). Continental values of Te are not as easily related to lithospheric characteristics. Broadly, there is an age/temperature relationship with Te in the range $80-90 \mathrm{~km}$ for older cratons, while in younger areas Te is between 10-30 km (Watts, 1992; Burov and Diament, 1995). However, continental regions are also influenced by the radius of curvature of the plate due to loading, bending stresses, and also the inherent strength of the lithosphere, in particular the strength of coupling of the crust-mantle boundary.

\subsubsection{Local estimates of Te}

Thermal processes and extension in the CVR effectively reduce the strength of the lithosphere. The proposed replacement of lithospheric mantle with asthenosphere will result in lithospheric weakening due to the loss of rigidity. Stern (1982) estimated a Te of $\sim 6 \mathrm{~km}$ for the CVR based on the depth of the Curie point isotherm from a spectral analysis of magnetic anomalies. This value is adopted here.

The western Taranaki Basin has not undergone significant heating or bending and the Te of 20-28 km (Holt and Stern, 1991) estimated from forward modelling is thought to be representative of undeformed lithosphere in this region. Higher values of 30-35 km were 
estimated by (Stagpoole, 1997) using coherence of the gravity to the topography in the spectral domain. These high values of Te are most likely the result of either thin continental crust, creating a region that appears anomalously strong, or through the window size used for the spectral analyses.

An effective elastic thickness (Te) of $10 \pm 5 \mathrm{~km}$ has been estimated for the Wanganui Basin region (Stern et al., 1992). High radius of curvature and high bending stresses in the Wanganui Basin are most probably responsible for weakening the crust and creating the low Te values (e.g. Burov and Diament, 1995).

Modelling is undertaken here using both 15 and $25 \mathrm{~km}$ in the region outside the CVR. These values represent the most likely range, from undeformed to moderately deformed lithosphere, that occur in central North Island.

Stern et al. (1992) modelled the Wanganui Basin region with a free edge along the eastern margin of their model. They considered the bounding thrust of the Axial ranges to constitute a free edge and this is included along the eastern margin of our model. Also included from the model of Stern et al. (1992) is an inplane stress of $4 \times 10^{11} \mathrm{Nm}^{-1}$ per cell oriented east-west representing the horizontal compression seen in the crustal rocks of the Australian Plate due to subduction processes. In the north part of North Island the weaker plate coupling (Reyners et al., 1997) is best modelled as a free edge with only a small inplane stress, while to the south the strong coupling (Reyners et al., 1997) may be better approximated by either the absence of a free edge or stronger inplane forces. Both stronger inplane forces and a free edge will have the effect of increasing the magnitude and shortening the wavelength of plate deformations. To vary the inplane stress and free edge characteristics of this model a finite modelling approach would be needed. Here we have used a simplistic model with one inplane stress and a free edge as we are mainly focusing on the rock uplift of the centre of the island and not the region to the north or south. To accommodate more of North Island without needing a more complex model the effect of a free edge or greater inplane stress could be approximated by using variations Te, which can also influence the magnitude and frequency of the deformation.

The model grid size is $15 \times 15 \mathrm{~km}$ and for each grid point a load, an elastic thickness 

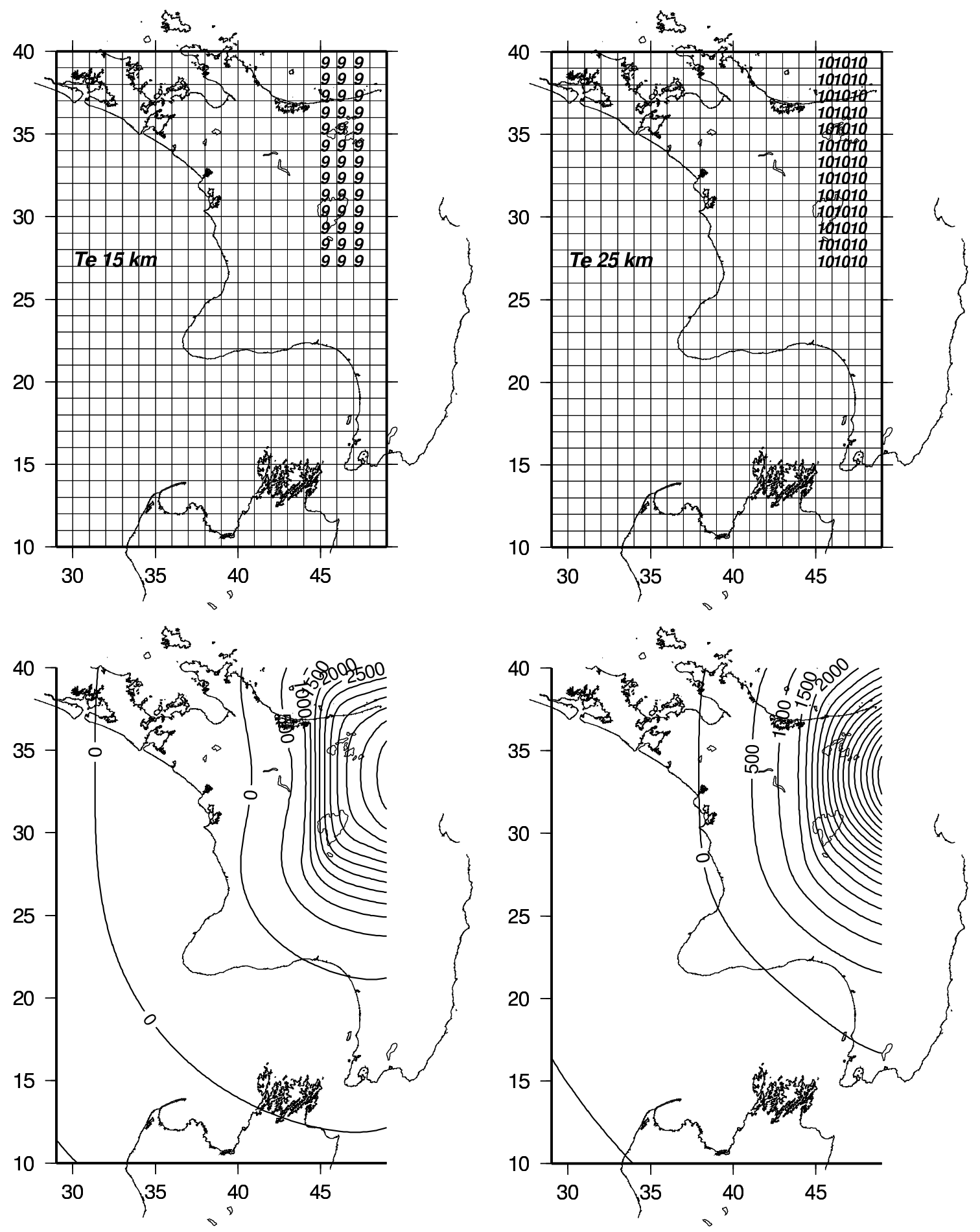

Fig. 7.3 Flexure models of the uplift of central North Island. The left hand model uses a Te of $15 \mathrm{~km}$ and the right a Te of $25 \mathrm{~km}$. Low Te is used in the region cols: 44,46 rows: 27,40 to simulate the weakened crust of the TVZ, a value of $6 \mathrm{~km}$ was used for the left model and $8 \mathrm{~km}$ for the right, a different value was used to produce a stable output. The top figures show the input loads for the flexure modelling and represent the loading pressure $(\times 10 \mathrm{MPa})$. The right hand side of the model is a free-edge as discussed in the text. The lower figures are the vertical motion resulting from flexure modelling. The contour interval is $500 \mathrm{~m}$. For all the models described in this chapter there is an isostatic restoring force of $2200 \mathrm{~kg} / \mathrm{m}^{3}$ as discussed in the text. Positive forces are directed upwards. 

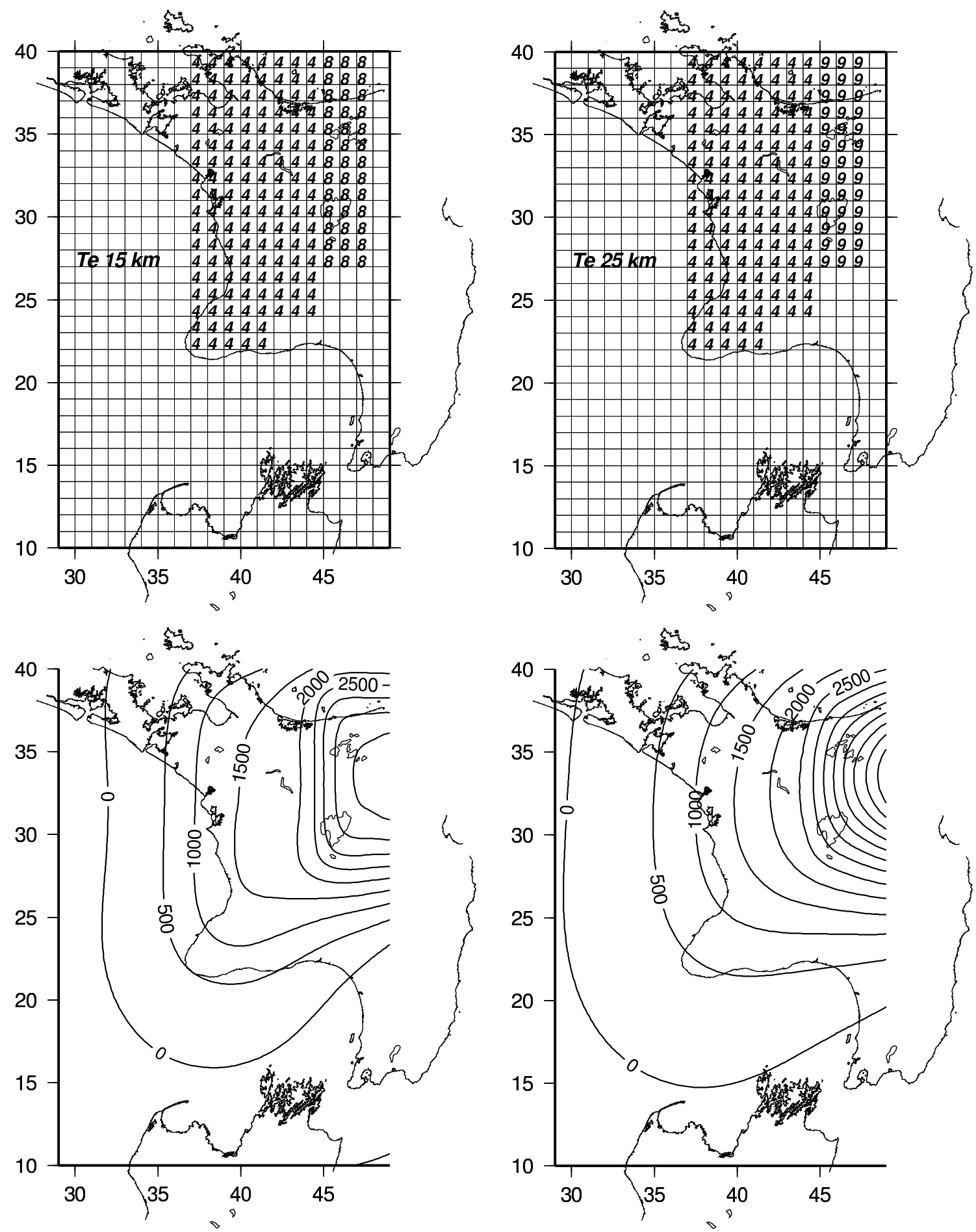

Fig. 7.4 The models are as described in Figure 7.3 again with a Te of $15 \mathrm{~km}$ and $6 \mathrm{~km}$ for the TVZ (left) and $25 \mathrm{~km}$ and $8 \mathrm{~km}$ for the TVZ (right). Loads denoted as $40 \mathrm{MPa}$ are rounded up from $35 \mathrm{MPa}$. A negative load was added to the western North Island to simulate uplift driven by a source in the attenuating part of the mantle (Mooney, 1970). 

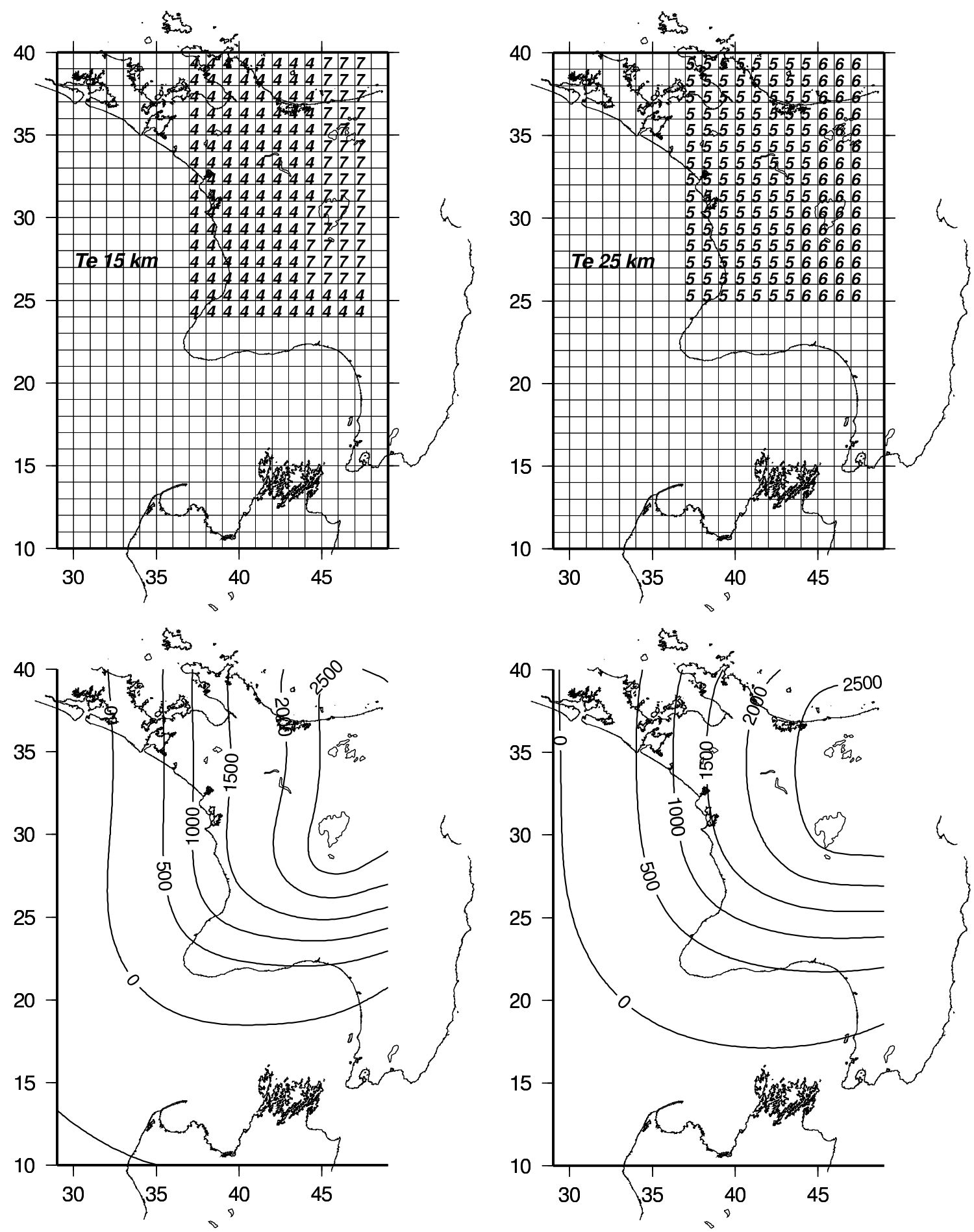

FIG. 7.5 The model is as described in Figure 7.3 with a broad weak negative load across the western North Island. Loading denoted as $40 \mathrm{MPa}$ is rounded up from $36 \mathrm{MPa}, 70$ from $65 \mathrm{MPa}, 50 \mathrm{MPa}$ is rounded up from $45 \mathrm{MPa}$, and $60 \mathrm{MPa}$ is not rounded. The region of weak uplift is not constrained by previous models for thermal anomalies in the mantle and is located to best fit the observed rock uplift. 
and a restoring force can be specified. For each variation in input load distribution two models are created with a Te of $15 \mathrm{~km}$ and $25 \mathrm{~km}$ respectively. A region of low Te is used in all models to represent the weakened crust of the CVR (Model coordinates : cols 44,47 \& rows 28,39$)$. The amplitudes of the loading used in each of the models are varied and only the best results are shown for each. It is noted that due to the coverage of the rock uplift measurements (figure 6.7) the entire grid area is not constrained by observations.

\subsubsection{Analysis and results}

The first model investigates negative loading constrained to the region of high heat flow (Stern, 1987) and high attenuation (Salmon, 2001), under the TVZ. Load distribution is shown in the upper two images of Figure 7.3, the left hand images have a Te of $15 \mathrm{~km}$ and the right $25 \mathrm{~km}$. Lower images display the model output and show the resulting rock uplift calculated from the input loads. The resulting pattern of modelled uplift is significantly narrower than that described by the rock uplift, as shown in Figures 6.7 and 7.6. Indicating that either, the width of the negative load is too small, or that the elastic thickness is too low. Te is constrained to $15-25 \mathrm{~km}$ as discussed above and hence the width of the input load is increased.

The second model retains the region of strong negative loading under the TVZ and has an added weakly negative load in western North Island. The weak loading is constrained by the location of the seismic attenuating-transmitting boundary of the mantle (Mooney, 1970) (Figure 7.4). Resulting modelled rock uplift compares well with the observed rock uplift. A reasonable fit between the model and observations is seen to the west and north of the island but the magnitude of rock uplift along the Wanganui coastline is too large, indicating that the buoyancy forces in the mantle do not extend as far south as the attenuating-transmitting boundary.

The third and final model investigates similar spatial loading, but the western load is not extended as far south as the attenuating-transmitting boundary and the uplift load under the TVZ is extended to the west and south under the southern part of the CVR (Figure 7.5). 


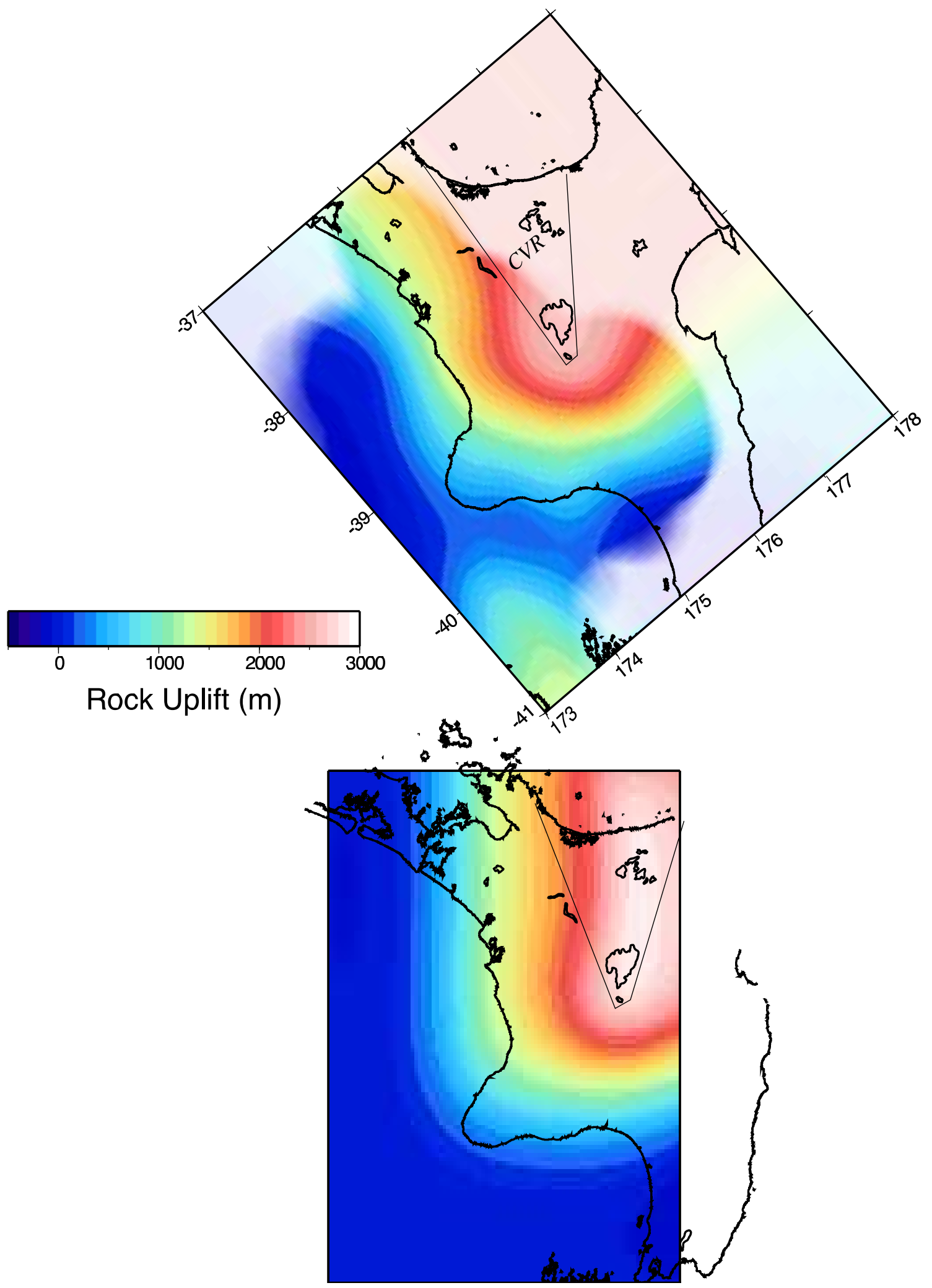

FIG. 7.6 The lower figure is the calculated rock uplift and is the left hand model of Figure 7.5 with the same input loads. The upper figure is the observed rock uplift from mudstone porosity analyses (Figure 6.7 rotated by $30^{\circ}$ ). Both the upper and lower figures are coloured using the same colour scheme. 
The best fit to the rock uplift was achieved with a Te of $\sim 15 \mathrm{~km}$, with a thin crust and an upward force of $65 \mathrm{MPa}$ under the CVR, and a force of $36 \mathrm{MPa}$ under central-western North Island. The spatial extent of loading in the final model resembles the variations in Pn velocity as denoted by Haines (1979)(Figure 7.2). This resemblance may be coincidental as the boundaries of the Pn velocity regions were not well constrained, however, the southern margin of the negative loading in the model coincides well with the change in mantle velocities from $7.8-7.9 \mathrm{~km} / \mathrm{s}$. Negative loading under the CVR spatially corresponds to the region of $7.4 \mathrm{~km} / \mathrm{s}$ Pn velocities (Haines, 1979) (Figure 7.2).

\subsection{Mantle buoyancy}

Upward buoyancy forces determined from flexural modelling are likely to represent the replacement of mantle lithosphere with hot asthenosphere (Section 7.3). Replacement of mantle lithosphere will result in a change in density from the, more dense, lithosphere to the hotter, less dense, asthenosphere. This cannot be done through conduction, due to the short time scale, and indicates that the replacement of lithosphere by asthenosphere is advective and achieved by either fluids and melting or extension and inflow. What follows is a calculation to estimate the expected change in density for the mantle underneath North Island so a comparison of the upward forces determined from the flexural model can be made.

We assume extension of the lithosphere under North Island has resulted in thinning of the lithospheric mantle from 100-120 km in west Taranaki (Holt and Stern, 1991) to close to zero under the CVR (Figure 7.7). This indicates that the region of replaced material would be of the order of $100 \mathrm{~km}$ thick.

Flexural modelling (Figure 7.5 and 7.6) indicates an upward force under the CVR of $65 \mathrm{MPa}$ or a pressure of $\mathrm{B}=0.66 \times 10^{7} \mathrm{~kg} / \mathrm{m}^{2}$. To estimate the density change that is required to produce the forces determined from flexural modelling, the following relation is used:

$\Delta \rho=B /$ thickness of material replaced 


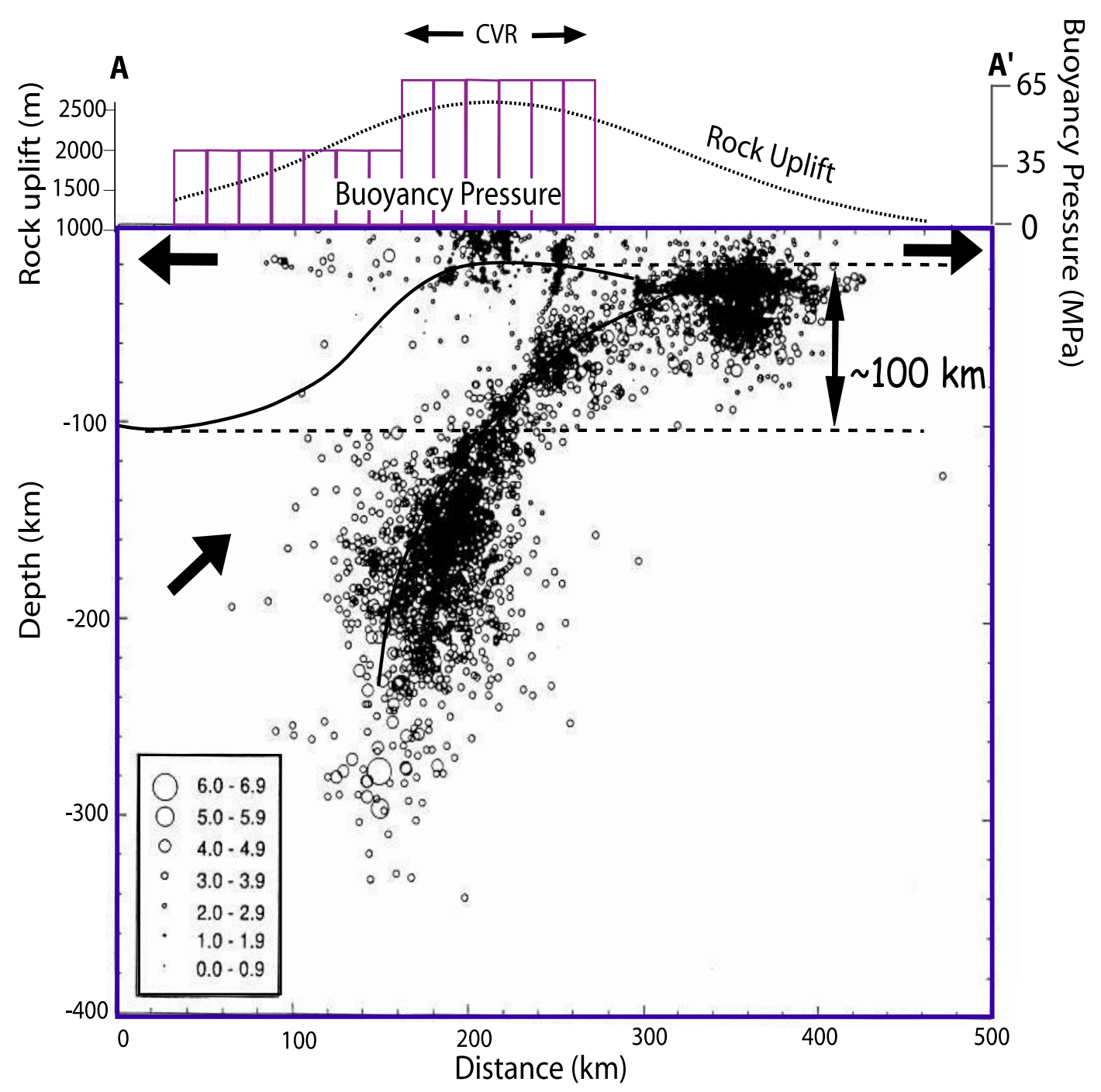

Fig. 7.7 Cross section across the CVR, along a NW-SE oriented transect (Figure 7.1). Circles are earthquake epicentres from (Anderson and Webb, 1994), scaled by magnitude. Solid black lines denote the approximate location of the base of the lithospheric mantle and the top of the subducting slab. The dashed lines indicate the amount of lithospheric thinning. The dotted line is the rock uplift, taken from the rock uplift grid (Figure 6.7. The purple bars indicate the spatial location and magnitude of negative loading required to produce the observed rock uplift. The arrows indicate direction of asthenospheric flow and lithospheric extension. 
$\Delta \rho=0.66 \times 10^{7} / 100000$

$\Delta \rho=66 \mathrm{~kg} / \mathrm{m}^{3}$

To test if this change in density is realistic for central North Island, the properties of the mantle are examined. For a hot mantle composed predominantly of olivine, the change in compressional velocity with temperature is $\mathrm{dV}_{p} / \mathrm{dT}=0.12 \mathrm{~km} / \mathrm{s} / 100^{\circ} \mathrm{C}$ (Goetze, 1977). Under the CVR compressional waves have been recorded with a velocity of 7.3-7.5 km/s (Haines, 1979; Stern and Davey, 1989; Stratford and Stern, 2002), this is significantly slower than that for normal mantle $(\sim 8 \mathrm{~km} / \mathrm{s})$. The change in temperature that would cause this lowering in Pn velocity of $0.6 \mathrm{~km} / \mathrm{s}$ is estimated:

$\Delta T=\Delta V / d V_{p} / d T$

$\Delta T=0.6 / 0.12$

$\Delta T=500^{\circ} \mathrm{C}$

It is noted that the velocity change with temperature does not take into account partial melting. The presence of partial melt will act to lower the temperature required to create the P-wave anomaly (Hammond and Humphreys, 2000) and hence the value of $500^{\circ}$ is a maximum.

Finally, the relationship between density and temperature is used to estimate the expected density change that would result from the calculated temperature anomaly under the CVR.

$$
\begin{aligned}
\Delta \rho & =\rho \alpha \Delta T \\
\Delta \rho & =3300 \times 3.51 \times 10^{-5} \times 500 \\
\Delta \rho & =60 \mathrm{~kg} / \mathrm{m}^{3}
\end{aligned}
$$

Where $\Delta \mathrm{V}$ is the change in velocity and $\alpha$ is the coefficient of thermal expansion. Comparison of the density anomaly estimated from the low seismic velocity under the CVR $\left(60 \mathrm{~kg} / \mathrm{m}^{3}\right)$ to that consistent with the flexure modelling $\left(66 \mathrm{~kg} / \mathrm{m}^{3}\right)$ shows good agree- 
a)

Sea

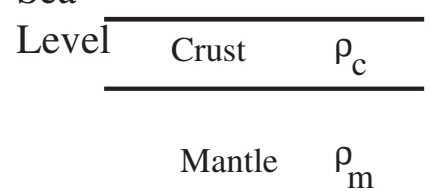

b)
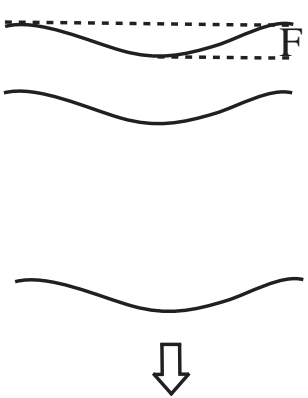

c)

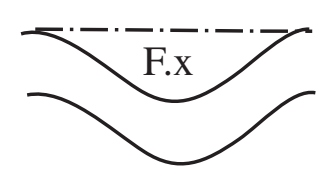

d) Erosion

\section{d) Erosion}
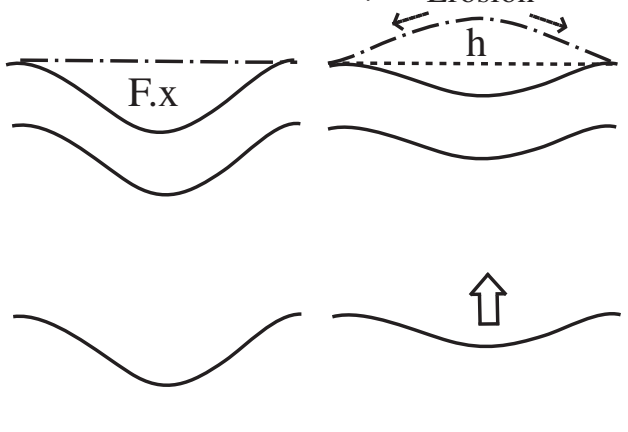

FIG. 7.8 Schematic of locally compensated isostatic model of the loading and unloading processes occurring in the large sedimentary basins of North Island. a) Initial model of an un-deformed lithosphere with an elevation close to sea level. b) A downward force, initiated through strong plate coupling, starts the formation of the basin of depth F. c) The basin depth is magnified (by some factor $\mathrm{x}$ ) over time through sediment accumulation in the basin. d) Once the force that created the basin is released the sediments will rebound by $h$ (Equation 7.1). Removal of exposed material through erosion will enable continued rock uplift as the lithosphere rebounds.

ment, and indicates that most of the observed rock uplift can be accounted for through a temperature anomaly in the mantle. For the change in densities to compare exactly, $110 \mathrm{~km}$ of mantle lithosphere would need to be replaced by hot asthenosphere. However, due to the approximate nature of these calculations, with only a $100 \mathrm{~km}$ of displaced mantle lithosphere there is good agreement between the modelled change in density and that from the seismic velocity anomaly under central North Island.

Another possible source of upward forces that may act on central North Island is investigated: crustal rebound. The mantle forces are likely to be the predominant cause of the uplift of central North Island, crustal rebound is a minor contributing factor.

\subsection{Rebound of basin sediments}

A simple model for isostatic rebound of a basin, once the slab pull forces that initiated basin formation have been released, is investigated. Release of the plate coupling forces will result in rebound and exposure of marine sediments above sea level (Figure 7.8). This lithospheric rebound will be recorded by the sediments as rock uplift. This rebound model is based on the assumption that the depocentre of the present Wanganui Basin, which is 
moving south eastwards (Anderton, 1981), has formed as a result of plate coupling and has been effective in creating deep basins to the north and releasing them as the region of strong plate coupling moves southwards. The palaeo-depocentres appear to have been located along the western side of North Island (Kamp, 1999) and hence, were uplift purely driven by the rebound of these basins, the maximum rock uplift would be centred in western North Island. Basin sediments become deep marine in character in the North Wanganui Basin and inhibit calculation of sediment rebound as sea level cannot be used as a reference. This model is best constrained in regions of shallow marine sediments, e.g. Wanganui Basin.

\subsubsection{Pre-erosion sediment thickness}

Initial sediment thickness, prior to rock uplift, for the onshore Wanganui Basin region is estimated by combining the exhumation (Figure 6.3) and the present sediment thickness taken from oil well data. In onshore Wanganui Basin there are only a few wells and hence the present thickness of sediments is poorly constrained with data only present for 9 wells: Puniwhakau-1, Tatu-1, Kiore-1, Manutahi-1, Stantiall-1, Whangaehu-1, Young-1, Santoft-1, and Parakino-1 (Figure 7.9). A surface was fitted through the data of the depth to basement from the well logs using the splines in tension function of GMT (Smith and Wessel, 1990) with a tension of 0.75 . This surface is poorly constrained but provides an estimation of sediment depth. It is noted here that the CVR does not contain any marine sediments but estimates are projected over this region.

Addition of the present sediment thickness to the exhumation gives an estimated maximum $2.5 \mathrm{~km}$ sediment thickness prior to the onset of lithospheric doming (Figure 7.9). The maximum estimated sediment thickness is $\sim 2.5 \mathrm{~km}$.

\subsubsection{Local isostatic rebound calculations}

Local isostatic calculations are used as a first-order approximation to estimate the amount of rebound that can be achieved through the release of plate coupling forces and erosion for a palaeo-basin $2.5 \mathrm{~km}$ deep. The assumption is made that the initial surface elevation prior to sediment loading was at sea level, as seen due to the thick sequence of shallow marine 


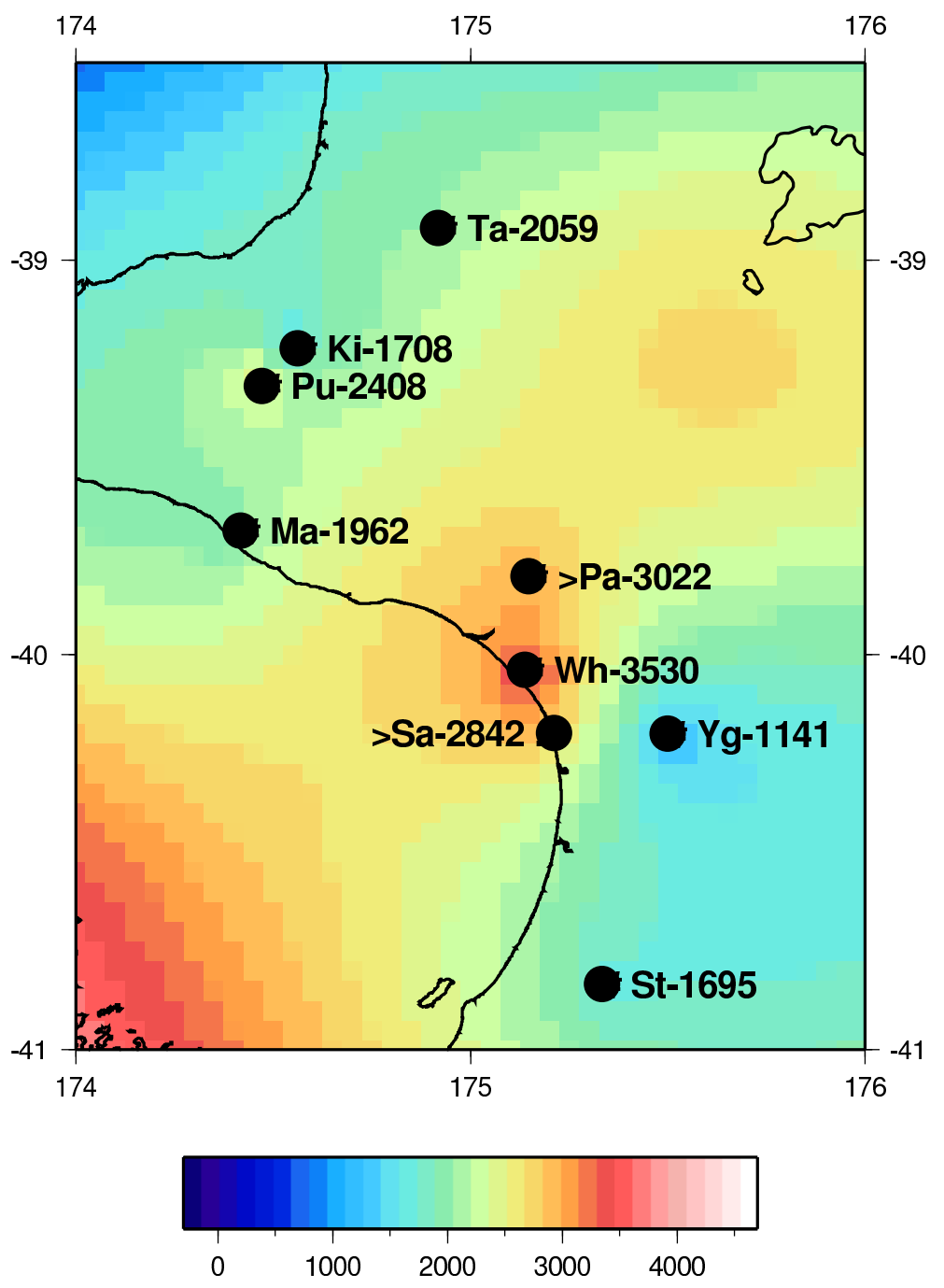

\section{Original sediment thickness $\mathrm{m}$}

Fig. 7.9 Estimation of the original sediment thickness of onshore Wanganui Basin. The sediment thickness is estimated by fitting a surface through values of depth to basement, taken from the indicated drill holes, and then adding this grid to the grid of exhumation (Figure 6.3). The drill holes shown are: $\mathrm{Pu}=$ Puniwhakau-1, Ta=Tatu-1, Ki=Kiore1, Ma=Manutahi-1, St=Stantiall-1, Wh=Whangaehu-1, Yg=Young-1, Sa=Santoft-1, $\mathrm{Pa}=$ Parakino -1 . 
sediments in the Wanganui Basin. The height (h) that sediments will be raise above sea level, as a result of rebound, can be calculated:

$$
h=\frac{A\left(\rho_{m}-\rho_{s}\right)}{\rho_{m}}
$$

Where A is the sediment thickness, $\rho_{m}$ and $\rho_{s}$ are the density of the mantle and sediments respectively. Taking $\mathrm{A}=2.5 \mathrm{~km}, \rho_{m}=3300 \mathrm{~kg} / \mathrm{m}^{3}$ and $\rho_{s}=2200 \mathrm{~kg} / \mathrm{m}^{3}$ an exposure of $\sim 850 \mathrm{~m}$ of sediment above sea level is gained, which is recorded by the rocks as a rock uplift of $\sim 850 \mathrm{~m}$. If these exposed sediments were eroded further then the section will continue to rebound until equilibrium is reached. Ignoring compaction of the sediments, the entire depth of sediments can rebound resulting in $2.5 \mathrm{~km}$ of rock uplift.

Uplift rates will decreases with time as the amount of sediment exposed above the surface decreases, and the total volume of sediment declines. The rate and magnitude of uplift will also decline away from the centre of the basin for the same reason. If central North Island was originally a basin, like the present Wanganui Basin, then it is possible to get the domed pattern of exhumation recorded by mudstone porosities through local isostatic rebound and erosional unloading. However, as the palaeo-depocentres lie to the west of the CVR and there are no marine sediments within the CVR this mechanism is not well constrained.

\subsection{Discussion - source of mantle up-welling}

Subsidence of the Marlborough Sounds region (Mortimer and Wopereis, 1997; Singh, 2001), the progression of the Wanganui Basin depocentre (Anderton, 1981), the increased tilt of fluvial terraces (Te Punga, 1952; Milne, 1973c) and the progression of arc volcanism (Calhaem, 1973) all appear to be linked to the relative plate motion and coupling along the plate interface between the Pacific and Australian Plates over the last 5 Ma. The relationship between the domed rock uplift and the relative plate motions is not known but this also appears to be linked.

Evidence also indicates that the centre of domed rock uplift is also migrating southward. Maximum incision can be used to elucidate regions of rapid recent rock uplift, with high 
incision indicating rapid uplift rates. High maximum river incision occurs $\sim 50 \mathrm{~km}$ to the south of the termination of active volcanism and doming. This region of high incision correlates well with the location of the seismic attenuating-transmitting boundary in the mantle of Mooney (1970). The proposed region of recent rapid rock uplift is not evident from the rock uplift seen over the last $4 \mathrm{Ma}$, estimated from mudstone porosity analyses. The location of recent fluvial incision may provide insight into the present configuration of rock uplift. Increasing slopes of river terraces (Te Punga, 1952; Milne, 1973c), anticline axes (Jackson et al., 1998) and bedrock units, with age, also provide evidence that the centre of rock uplift may be moving southwards.

The magnitude of $2.5 \mathrm{~km}$ and wavelength, $\sim 500 \mathrm{~km}$, of rock uplift in central North Island is similar to that seen in other parts of the world associated with mantle up-welling and mantle plumes (e.g. Yellowstone, USA, Spitsbergen and Italy; Pierce and Morgan, 1992; Vågnes and Amundsen, 1993; D'Agostino et al., 2001). The trigger for the formation of buoyancy forces in the mantle is not constrained in New Zealand, but the high heat flow (Stern, 1987) (similar to that observed in areas associated with mantle plume), low compressional wave velocities (Haines, 1979; Stern et al., 1987; Stratford and Stern, 2002) and high attenuation (Salmon, 2001) indicate a thermal anomaly and partial melting in the lithospheric mantle.

There is no clear evidence for a mantle plume in North Island and it appears that the thermal anomaly and resulting rock uplift are caused by relative plate motions and plate coupling. Plate coupling is shown to increase to the south of North Island due to the change in thickness of the Pacific Plate from oceanic into continental lithosphere (Reyners, 1998). Strong plate coupling can create a compressional regime in the overlying plate, while lower coupling allows for extension in the back-arc region (Uyeda and Kanamori, 1979). If rock uplift is the result of combined arc-related volcanism and lithospheric extension/asthenospheric up-welling then the location of regions of strong plate coupling, and hence extension in the overlying plate, will control the location of crustal doming. The oblique plate motion will result in southward migration of the region of extension and arc-related volcanism and hence the location of the thermal anomaly and rock uplift. 


\subsection{Summary}

- Domed rock uplift in central North Island has a wavelength of $\sim 500 \mathrm{~km}$ and an amplitude of $2.5 \mathrm{~km}$.

- This wavelength and magnitude of rock uplift is similar to that seen for regions associated with asthenospheric up-welling.

- Tectonic uplift shows that half of the observed rock uplift is due to isostatic rebound in response to erosion.

- A loading model for the lithosphere indicates that to best fit the pattern of rock uplift data, a broad region of uplift is required that covers most of onshore North Island combined with strong buoyancy forces focused on the CVR.

- The required upward force for the flexural model indicates that if the uplift is due to a change in buoyancy in the mantle over a depth of $100 \mathrm{~km}$ that a density change of $66 \mathrm{~kg} / \mathrm{m}^{3}$ is required. An estimate of the density contrast present under North Island from seismic velocities, and laboratory measurements of $\mathrm{dV}_{p} / \mathrm{dT}$ gives a density contrast of $60 \mathrm{~kg} / \mathrm{m}^{3}$.

- The spatial extent of negative loading on the lithosphere, required to emulate the rock uplift, roughly corresponds to the spatial Pn velocity variations of Haines (1979), but not with the seismic-attenuating boundary of Mooney (1970).

- Investigation of the regional pattern of high fluvial incision as a proxy for recent rock uplift indicates possible recent uplift $50 \mathrm{~km}$ south of the projected centre of rock uplift, estimated from combined surface uplift and exhumation from mudstone porosities, over the last 4 Ma.

- Rebound of sedimentary basins formed due to the down warping of the crust by plate coupling may account for some of the rock uplift observed in North Island, but this is difficult to ascertain from the available data. 
CHAPTER 8

\section{SUMMARY}

The oblique convergence along the plate boundary through New Zealand has resulted in two distinctly different modes of uplift in North and South Island. The combined convergence and subduction, in North Island have resulted in an extensional back-arc regime and domed uplift most likely as a result of thermal processes in the mantle lithosphere. The extension is the result of the density of the Pacific crust combined with the rate of convergence resulting in a downwarping of the subducted slab allowing the extension in the overlying Australian Plate. The obliquely compressional regime has more directly resulted in rock uplift in South Island where the more buoyant continental Pacific crust of the Chatham Rise, is being pushed into, and ramping up over, the Australian Plate resulting in complex crustal deformation. Despite these different modes of uplift, the oblique convergence and relative densities of the Pacific Plate have been responsible for the formation and exposure above sea level of much of New Zealand.

\subsection{South Island crustal structure from active source seis- mology}

Active source seismic data recording waves passing across the plate boundary were analysed to calculate the amount of crustal shear wave splitting. Due to the usually weak nature of S-wave arrivals from active source data the dataset was analysed with a range of methods including Silver and Chan (1991) method, cross-correlation and deconvolution. Broadly consistent results were calculated with splitting of 0-80 ms with the fast direction aligned with the transverse component. Variations between adjacent stations indicate that either 
the splitting is sensitive to slight variations in incidence angle between the incoming wave and the axis of symmetry of the body of anisotropy or that there are lateral changes in anisotropy on a scale of $1 \mathrm{~km}$. The crustal splitting may account for up to $5 \%$ of that seen for SKS phases in South Island. Low splitting is likely to result from the complex crustal structure, as is observed at the surface, which though on a small scale is strongly anisotropic may not add coherently.

Poisson's ratio estimated along a 2D transect across the crust of the South Island shows low Poisson's ratio $(\sigma=0.15)$ adjacent and below the Southern Alps and also off the west coast $(\sigma=0.2)$. A region of low values off the west coast, which is only sampled by both $\mathrm{P}$ and S-waves along its edge, is most likely result from downward flexing of the Australian Plate under the load of the Pacific Plate opening tensional, aligned, fluid filled cracks. Under the Southern Alps $\sigma=0.15$ in a location that corresponds to a body of low P-wave velocity and high conductivity (Kleffmann et al., 1998; Stern et al., 2001; Wannamaker et al., in press). The region of anomalous velocity and conductivity has been interpreted to be the result of fluids, produced through prograde metamorphism, under lithostatic pressure in the crust (Kleffmann, 1999; Stern et al., 2001; Wannamaker et al., in press). Vry (in prep.) interpreted the high conductivity body to indicate the depth at which fluid filled pores become inter-connected, through fluid expansion, as the rocks are brought towards the surface. This inter-connection of the pores will result in a lowering of pore fluid pressure and an increase in conduction. Low Poisson's ratio identified in the region of low $\mathrm{V}_{p}$ and high conductivity provides support for the connectivity model of Vry (in prep.), as low $\sigma$ is indicative of low-moderate pore fluid pressure rather than high pore fluid pressure (Spencer and Nur, 1976). However, the region of low Poisson's ratio is only constrained in the top 10-20 km and may indicate the depth of the change from the pore fluid pressure from lithostatic to hydrostatic pressure is deeper than previously determined.

\subsection{North Island domed rock uplift}

Rock uplift of $2.5 \mathrm{~km}$ centred at the termination of the CVR is estimated by combining exhumation, from mudstone porosity analyses, and surface uplift, obtained on a regional 
scale from a $25 \mathrm{~m}$ digital elevation model of New Zealand. A local estimation of differential denudation was made adjacent to the CVR with a rate of $0.6 \mathrm{~mm} / \mathrm{yr}$ over the last $500 \mathrm{ka}$. This rate is in excellent agreement with the value of $0.6 \mathrm{~mm} / \mathrm{yr}$ estimated for the CVR using exhumation derived from mudstone porosity analyses and assuming uplift was initiated 4 Ma.

The creation of a $25 \mathrm{~m}$ DEM for New Zealand provides a useful database from which we can extract information about geomorphic and surface processes in a range of tectonic settings. The DEM was used to estimate the incision erosion and possible recent rock uplift of central North Island and also differential erosion at the southern termination of the CVR.

Lithospheric rebound due to erosion from incision can account for $36 \%$ of the surface uplift of central North Island. A region of maximum incision occurs $\sim 50 \mathrm{~km}$ to the south of the termination of active volcanism. It is hypothesised that this region of high incision indicates the southward migration of the centre of rock uplift, and also the mantle processes responsible for the uplift. Further evidence for this southward migration of rock uplift is seen from the increasing tilt of geomorphic features. The region of high incision corresponds to the approximate location of the attenuating-transmitting boundary of Mooney (1970) and a change in faulting style in the Taranaki region.

The mantle processes responsible for the observed rock uplift are most likely the result of a combination of lithospheric extension and subduction related fluids, partial melting and volcanism. High heat flow combined with the absence of subsidence preceding rock uplift contrasts with regions undergoing continental rifting. The higher heat flow and initial uplift are probably the result of subduction related processes. 


\section{REFERENCES}

Anderson, H. And WebB, T. (1994), New Zealand seismicity: patterns revealed by the upgraded National Seismology Network, N. Z. J. Geol. Geophys. 37: 477-493.

Anderson, H., Webb, T. And Jackson, J. (1993), Focal mechanisms of large earthquakes in the South Island of New Zealand: implications for the accommodation of Pacific-Australia plate motion, Geophys. J. Int. 115: 1032-1054.

Anderton, P. W. (1981), Structural evolution of the south Wanganui Basin, New Zealand, N. Z. J. Geol. Geophys. 24: 39-63.

Armstrong, P. A., Allis, R. G., Funnell, R. H. and Chapman, D. S. (1998), Late Neogene exhumation patterns in Taranaki Basin (New Zealand): Evidence from offset porosity-depth trends, Geophys. J. Int. 103(B12): 30,269-30,282.

Aтну, L. F. (1930), Density, porosity and compaction of sedimentary rocks, AAPG Bull. 14: $1-24$.

Audoine, E. (2002), Upper mantle and crustal seismic anisotropy across the PacificAustralian plate boundary, New Zealand, PhD thesis, V.U.W.

Audoine, E., Savage, M. K. And Gledhill, K. (2000), Seismic anisotropy from local earthquakes in the transition region from a subduction to a strike-slip plate boundary, New Zealand, J. Geophys. Res. 105(B4): 8,013-8,033.

Beanland, S. And Haines, J. (1998), The kinematics of active deformation in the North Island, New Zealand determined from geological strain rates, N. Z. J. Geol. Geophys. 41: 311-323.

Beaumont, C. (1981), Foreland Basins, Geophys. J. Roy. Astr. Soc. 65: 291-329.

Berryman, K. (1993), Age, height, and deformation of Holocene marine terraces at Mahia Peninsula, Hikurangi subduction margin, New Zealand, Tectonics 12(6): 13471364 .

Beu, A. G., Browne, G. H. and Grant-Taylor, T. L. (1981), New Chlamys delicatula localities in the central North Island and uplift of the Ruahine Range, N. Z. J. Geol. Geophys. 24: 127-132.

Brown, E. H. (1967), The greenshcist facies in part of eastern Otago, New Zealand, Contributions to Mineralogy and Petrology 14: 259-292.

Brown, R. W. (1991), Backstacking apatite fission-track "stratigraphy": A method resolving erosional and isostatic rebound components of tectonic uplift histories, Geology 19: $74-77$. 
Burbank, D. W., Leland, J., Fielding, E., Anderson, R. S., Brozovic, N., Reid, M. R. AND Duncan, C. (1996), Bedrock incision, rock uplift, and threshold hillslopes in northwestern Himalaya, Nature 379: 505-510.

Burov, E. B. And Diament, M. (1995), The effective elastic thickness (Te) of continental lithosphere: what does it really mean?, J. Geophys. Res. 100(B3): 3905-3927.

Calhaem, I. M. (1973), Heat flow measurements under some lakes in North Island, New Zealand, PhD thesis, V.U.W.

Carcione, J. M. and Cavallini, F. (2002), Poisson's ratio at high pore pressure, Geophys. Prospecting 50(1): 97-106.

Carter, W., Shethra, R., Tuell, G., Bloomquist, D. and Satori, M. (2001), Airborne laser swath mapping shines new light on Earth's topography, EOS, Trans., Am. Geophys. Union 82(46): 549-555.

Chappell, J. (1975), Upper Quaternary warping and uplift rates in the Bay of Plenty and west coast, North Island, New Zealand, N. Z. J. Geol. Geophys. 18: 129-155.

Christensen, N. I. (1996), Poisson's ratio and crustal seismology, J. Geophys. Res. 101(B2): 3139-3156.

Cotton, C. A. (1913), The Turamarina Valley: A note on the Quaternary history of the Marlborough Sounds district, Tras. N. Z. Inst. 45: 316-322.

Cotton, C. A. (1942), Geomorphology: an introduction to the study of landforms, Whitcombe \& Tombs Limited, Wellington.

Crampin, S. (1994), The fracture criticality of crustal rocks, Geophys. J. Int. 118: 428-438.

Crane, K. And O'Connell, S. (1983), The distribution and implications of heat flow from the Gregory Rift in Kenya, Tectonophysics 94: 253-275.

Crozier, M. J. and Pillians, B. J. (1991), Geomorphic events and landform response in south-eastern Taranaki, New Zealand, Catena 18: 471-487.

D'Agostino, N., Jackson, J. A., Dramis, F. And Funiciello, R. (2001), Interactions between mantle upwelling, drainage evolution and active normal faulting: an example from the central Appennines (Italy), Geophys. J. Int. 147: 475-497.

Davey, F. J., Henyey, T., Holbrook, W. S., Okaya, D., Stern, T. A., Melhuish, A., Henrys, S., Anderson, H., Eberhart-Phillips, D., McEvilly, T., Uhrhammer, R., Wu, F., Jiracek, G. R., Wannamaker, P. E., Caldwell, G. And Christensen, N. (1998), Preliminary results from a geophysical study across a modern, continent-continent collision plate boundary - the Southern Alps, New Zealand, Tectonophysics 288: 221-235.

Davies, R. (1996), Geodetic and Morphometric studies of Active Deformation in Central and Southern Greece, $\mathrm{PhD}$ thesis, Oxford.

DeMets, C., Gordon, R. G., Argus, D. F. And Stein, S. (1990), Current plate motions, Geophys. J. Int. 101: 425-478.

Dorsch, J. And Katsube, T. J. (1999), Porosity characteristics of Cambrian mudrocks (Oak Ridge, East Tennessee, USA) and their implications for contaminant transport, in A. C. Alpin, A. J. Fleet and J. H. S. Macquaker (eds), Muds and Mudstones: Physical and Fluid Flow Properties, Vol. 158, Geological Society, London, Special Publications, pp. 157-173. 
Eberhart-Phillips, D. and Bannister, S. (in press), Three-dimensional crustal structure in the Southern Alps region of New Zealand from inversion of local earthquake and active source data, J. Geophys. Res. .

Edbrooke, S. W., Sykes, R. And Pocknall, D. T. (1994), Geology of the Waikato Coal Measures, Waikato Coal Region, New Zealand, Inst. Geol. and Nuc. Sci., Lower Hutt, N. Z.

England, P. And Molnar, P. (1990), Surface uplift, uplift of rocks, and exhumation of rocks, Geology 18: 1173-1177.

Flemming, C. A. (1953), The geology of the Wanganui Subdivision, N. Z. Geol. Surv. Bulletin 52: 362.

Garrick, R. A. And Gibowicz, S. J. (1983), Continuous swam-like seismicity: the Wanganui, New Zealand, earthquakes, Geophys. J. Roy. Soc. 75: 493-512.

Godfrey, N. J., Christensen, N. I. And Okaya, D. A. (2001), Anisotropy of schists: Contributions of crustal anisotropy to active source seismic experiments and shear wave splitting observations, J. Geophys. Res. 105(B12): 27,991-28,007.

Goetze, C. (1977), A brief summary of our present understanding of the effects of volatiles and partial melt on the mechanical properties of the upper mantle, in M. H. Manghnani and S. I. Akimoto (eds), High-Pressure Research, Applications to Geophysics, Academic, San Diego, Calif., pp. 3-23.

Graham, I. J. And Hackett, W. R. (1987), Petrology of calc-alkaline lavas from Ruapehu volcano and related vents, Taupo Volcanic Zone, New Zealand, J. Petrology 28(3): 531-567.

Grapes, R. H. (1995), Uplift and exhumation of Alpine Schist, Southern Alps, New Zealand: thermobarometric constraints, N. Z. J. Geol. Geophys. 38: 525-533.

Grapes, R. H. and Watanabe, T. (1992), Metamorphism and uplift of the Alpine Schist in the Franz Josef-Fox area of the Southern Alps, New Zealand, J. Metamorphic Petrology 10: 171-180.

Guest, W. S. And Thomson, C. J. (1992), A source of significant transverse arrivals from an isotropic-anisotropic interface, e.g. the Moho, Geophys. J. Int. 111: 309-318.

Guest, W. S., Thomson, C. J. And Spencer, C. P. (1993), Anisotropic reflection and transmission calculations with application to a crustal seismic survey from the East Greenland Shelf, J. Geophys. Res. 98(B8): 14,161-14,184.

Hackett, W. R. And Houghton, B. F. (1989), A facies model for Quaternary andesitic composite volcano: Ruapehu, New Zealand, Bull. Volcanology 51(1): 51-68.

Haines, A. J. (1979), Seismic wave velocities in the uppermost mantle beneath New Zealand, N. Z. J. Geol. Geophys. 22(2): 245-257.

Hammond, W. C. And Humphreys, E. D. (2000), Upper mantle seismic wave velocity: Effects of realistic partial melt geometries, J. Geophys. Res. 105(B5): 10,97510,986 .

Harrison, A. J. (1999), Multi-channel seismic and flexural analysis of the Westland Sedimentary Basin, South Island, New Zealand, Master's thesis, V.U.W.

Hatherton, T. (1970), Upper mantle inhomogeneity beneath New Zealand: surface manifestations, J. Geophys. Res. 75(2): 269-284. 
Hatherton, T. and Leopard, A. E. (1964), The densities of New Zealand rocks, N. Z. J. Geol. Geophys. 7: 605-625.

Holbrook, S. W., Gajewshi, D., Krammer, A. and Prodehl, C. (1988), An interpretation of wide-angle compressional and shear wave data in southwest Germany: Poisson's Ratio and petrological implications, J. Geophys. Res. 98(B8): 14,16114,184 .

Holmes, A. (1965), Principles of Physical Geology, Thomas Nelson \& Sons Ltd, London.

Holt, W. E. And Stern, T. A. (1991), Sediment loading on the Western Platform of the New Zealand continent: Implications for the strength of the continental margin, Earth Plan. Sci. Lett. 107: 523-538.

Huismans, R. S., Podladchikov, Y. Y. and Cloetingh, S. (2001), Transition from passive to active rifting: Relative importance of asthenospheric doming and passive extension of the lithosphere, J. Geophys. Res. 106(B6): 11,271-11,291.

Jackson, J., van Dissen, R. And Berryman, K. (1998), Tilting of active folds and faults in the Manawatu region, New Zealand: evidence from surface drainage patterns, N. Z. J. Geol. Geophys. 41: 377-385.

Kamp, P. J. J. (1986), The mid-Cenozoic Challenger rift system of western New Zealand and its implications for the age of Alpine Fault inception, Geol. Soc. Am. Bull. 97: $255-281$.

KAMP, P. J. J. (1999), Tracking crustal processes by FT thermochronology in a forearc high (Hikurangi margin, New Zealand) involving Cretaceous subduction termination and mid-Cenozoic subduction initiation, Tectonophysics 307: 313-343.

Kamp, P. J. J. and Green, P. F. (1990), Thermal and tectonic history of selected Taranaki Basin (New Zealand) wells assessed by apatite fission track analysis, AAPG Bull. 74(9): 1401-1419.

Karig, D. E. (1970), Kermadec arc-New Zealand tectonic confluence, N. Z. J. Geol. Geophys. 13: 21-29.

KARIG, D. E. (1971), Origin and development of marginal basins in the Western Pacific, J. Geophys. Res. 76: 2542-2561.

KING, L. C. (1955), Pediplanation and isostasy: an example from southern Africa, Quart. J. Geol. Soc. Lond. 111: 353-359.

KInG, P. (2000), Tectonic reconstruction of New Zealand: 40 Ma to the present, N. Z. J. Geol. Geophys. 43: 611-638.

King, P. R. And Thrasher, G. P. (1996), Cretaceous-Cenozoic Geology and Petroleum Systems of the Taranaki Basin, New Zealand, Vol. Institute of Geological and Nuclear Sciences Monograph 13, Institute of Geological and Nuclear Sciences Limited, Lower Hutt, N. Z.

Kleffmann, S. (1999), Crustal structure studies of a transpressional plate boundary - the central South Island of New Zealand, PhD thesis, V.U.W.

Kleffmann, S., Davey, F., Melhuish, A., Okaya, D., Stern, T. and the SIGHT Team (1998), Crustal structure in the central South Island, New Zealand, from the Lake Pukaki seismic experiment, N. Z. J. Geol. Geophys. 41: 39-49. 
Klosko, E. R., Wu, F. T., Anderson, H. J., Eberhart-Phillips, D., McEvilly, T. V., Audoine, E., Savage, M. K. And Gledhill, K. R. (1999), Upper Mantle Anisotropy in the New Zealand region, Geophys. Res. Lett. 26(10): 1497-1500.

Knox, G. J. (1982), Taranaki Basin, structural style and tectonic setting, N. Z. J. Geol. Geophys. 25: 125-140.

Lawver, L. A., Royer, J.-Y., Sandwell, D. T. and Scotese, C. R. (1991), Evolution of the Antarctic continental margins, in M. R. A. Thomson, J. A. Crame and J. W. Thomson (eds), Geological Evolution of Antarctica, Cambridge University Press, New York, pp. 533-539.

LeCointre, J. A., Neall, V. E. And Palmer, A. S. (1998), Quaternary lahar stratigraphy of the western Ruapehu ring plain, New Zealand, N. Z. J. Geol. Geophys. 41: $225-245$.

LEes, J. M. AND Wu, H. (2000), Poisson's ratio and porosity at Coso geothermal area, California, J. Volc. Geotherm. Res. 95: 157-173.

LeMasurier, W. E. And Landis, C. A. (1996), Mantle-plume activity recorded by low-relief erosion surfaces in West Antarctica and New Zealand, GSA Bulletin 108(11): 1450-1466.

Little, T. A., Holcombe, R. J. And Ilg, B. R. (2002), Kinematics of oblique continental collision inferred from ductile microstructures and strain in mid-crustal Alpine Schist, central South Island, New Zealand, J. Struct. Geol. 24: 219-239.

Luetgert, J. H. (1992), MacRay Interactive Two-dimensional Seismic Raytracing for the Machintosh, Open-File Report U. S. Geological Survey.

Marquis, G. And Hyndman, R. D. (1992), Geophysical support for aqueous fluids in the deep crust: seismic and electrical relationships, Geophys. J. Int. 110: 91-105.

Marson-Pidgeon, K., Savage, M. K., Gledhill, K. and Stuart, G. (1999), Seismic anisotropy beneath the lower half of the North Island, New Zealand, J. Geophys. Res. 104(B9): 20,277-20,286.

Meissner, R. (1986), The Continental Crust: A Geophysical Approach, Academic Press, New York.

Melhuish, A., Van Dissen, R. And Berryman, K. (1996), Mount Stewart-Halcombe Anticline: a look inside a growing fold in the Manawatu region, New Zealand, $N$. Z. J. Geol. Geophys. 39: 123-133.

Merritts, D. J., Vincent, K. R. And Wohl, E. E. (1994), Long river profiles, tectonism, and eustasy: a guide to interpreting fluvial rivers, J. Geophys. Res. 99(B7): 14,031-14,050.

Miller, V. And Savage, M. (2001), Changes in seismic anisotropy after volcanic eruptions: evidence from Mount Ruapehu, Science 293: 2231-2233.

Milne, J. D. G. (1973a), Late Quaternary geology of the Rangitikei drainage basin, North Island, New Zealand, PhD thesis, V.U.W.

Milne, J. D. G. (1973c), Map and sections of river terraces in the Rangitikei Basin, North Island, New Zealand, N. Z. Soil Survey Report 4.

Mohr, P. (1982), Musings on continental rifts, Continental and Oceanic Rifts, Vol. 8 of Geodynamics Series, American Geophysical Union, Geological Society of America. 
Molnar, P., Anderson, H. J., Audoine, E., Eberhart-Phillips, D., Gledhill, K. R., Klosko, E. R., McEvilly, T. V., Okaya, D., Savage, M. K., Stern, T. AND WU, F. T. (1999), Continuous deformation versus faulting through the continental lithosphere of New Zealand, Science 286: 516-519.

Molnar, P. And England, P. (1990), Late Cenozoic uplift of mountain ranges and global climate change: chicken or egg?, Nature 346: 29-34.

Molnar, P. And Lyon-Caen, H. (1988), Some simple physical aspects of the supoprt, structure, and evolution of mountain belts, Processes in Continental Lithospheric Deformation, Special Paper 218, Geological Society of America.

Montgomery, D. R. (1994), Valley incision and the uplift of mountain peaks, J. Geophys. Res. 99(B7): 13,913-13,921a.

Mooney, W. D. (1970), Upper mantle inhomogeneity beneath New Zealand: Seismic evidence, J. Geophys. Res. 75(2): 285-309.

Mortimer, N. And Wopereis, P. (1997), Change in direction of the Pelorus River, Marlborough, New Zealand: evidence from composition of Quaternary gravels, $N$. Z. J. Geol. Geophys. 40: 307-313.

Nathan, S., Anderson, H. J., Cook, R. J., Herzer, R. H., Hoskins, R. H., Raine, I. J. And Smale, D. (1986), Cretaceous and Cenozoic sedimentary basins of the west coast region, South Island, New Zealand, New Zealand Geological Survey Basin Studies, 1, DSIR Science Information Publishing Centre, Wellington, p. 90.

Neuberg, J. And Pointer, T. (2000), Effects of volcano topography on seismic broadband waveforms, Goephys. J. Int. 143: 239-248.

Norris, R. J. AND Cooper, A. F. (1995), Origin of small-scale segmentation and transpressional thrusting along the Alpine Fault, New Zealand, Bull. Geol. Soc. Am. 107: $231-240$.

Nur, A. And Simmons, G. (1969), The effect of saturation on velocity in low porosity rocks, Earth Plan. Sci. Lett. 7: 183-193.

O'Connell, R. J. and Budiansky, B. (1974), Seismic velocities in dry and saturdated cracked solids, J. Geophys. Res. 79: 5412-5426.

Okaya, D., Christensen, N. I., Stanley, D. and Stern, T. (1995), Crustal anisotropy in the vicinity of the Alpine fault zone, South Island, New Zealand, N. Z. J. Geol. Geophys. 38: 579-583.

OтA, Y. (1986), Marine terraces as reference surfaces in late Quaternary tectonics studies: examples from the Pacific Rim, Roy. Soc. N. Z. Bull. 24: 357-375.

Ota, Y., Berryman, K. R., Hull, A. G., Miyauchi, T. and Iso, N. (1988), Age and height distribution of Holocene transgressive deposits in eastern North Island, New Zealand, Palaeogeog. Palaeoclimat. Palaeoecol. 68: 135-151.

Pierce, K. L. And Morgan, L. A. (1992), The track of the Yellowstone hotspot: Volcanism, faulting and uplift, in P. K. Link, M. A. Kuntz and L. B. Platt (eds), Regional Geology of Eastern Idaho and Western Wyoming, Vol. Geological Society of America Memoir 179, Geological Society of America Inc., Colorado, pp. 1-53.

Pillans, B. (1986), A Late Quaternary uplift map for North Island, New Zealand, Roy. Soc. Bull. 24: 409-417. 
Pillans, B. (1990a), Pleistocene marine terraces in New Zealand: a review, N. Z. J. Geol. Geophys. 33: 219-231.

PILlans, B. (1990b), Late Quaternary marine terraces, South Taranaki-Wanganui., New Zealand and Geological Survey miscellaneous series map 18: 1-47.

Pillans, B. (1994), Direct marine-terrestrial correlations, Wanganui Basin, New Zealand: the last 1 million years, Quat. Sci. Reviews 13: 189-200.

Pillans, B., McGlone, M., Palmer, A., Mildenhall, D., Alloway, B. And Berger, G. (1993), The last glacial maximum in central and southern North Island, New Zealand: a paleoenvironmental reconstruction using the Kawakawa Tephra formation as a chronostraticgraphic marker, Palaeogeog. Palaeoclimat. Palaeoecol. 101: 283-304.

Polet, J. And Kanamori, H. (2002), Anisotropy beneath California: Shear wave splitting measurements using a dense broadband array, Geophys. J. Int. 149: 313-327.

Price, C. And Morgan, J. (2000), Lithospheric structure north of Scotland - II, Poisson's ratios and waveform modelling, Geophys. J. Int. 142: 737-754.

ReILly, W. I. (1990), Horizontal crustal deformation on the Hikurangi margin, N. Z. J. Geol. Geophys. 33: 393-400.

Reilly, W. I., Whiteford, C. M. And Doone, A. (1977), North Island: Gravity Map of New Zealand. 1:1 000000 Bouger and isostatic anomalies, 1st Edition, Department of Science and Industrial Research, New Zealand.

REyners, M. (1998), Plate coupling and the hazard of large thrust subduction earthquakes at the Hikurangi subduction zone, New Zealand, N. Z. J. Geol. Geophys. 41: 343354.

Reyners, M., Robinson, R. And McGinty, P. (1997), Plate coupling in the northern South Island and southernmost North Island, New Zealand, as illuminated by earthquake focal mechanisms, J. Geophys. Res. 102(B2): 15,197-15210.

RiBE, N. M. (1992), On the relation between seismic anisotropy and finite strain, J. Geophys. Res. 97: 8737-8747.

Salmon, M. (2001), Seismic attenuation in the Taupo Volcanic Zone, V.U.W., Honours Thesis.

Satake, K. And Hashida, T. (1989), Three-dimensional attenuation structure beneath North Island, New Zealand, Tectonophysics 159: 181-194.

Savage, M. K. (1999), Seismic anisotropy and mantle deformation: what have we learned from shear wave splitting?, Reviews Geophys. 37(1): 65-106.

Scherwath, M., Melhuish, A., Stern, T. And Molnar, P. (2002), Pn anisotropy and distributed upper mantle deformation associated with a continental transform fault, Geophys. Res. Lett. 29(8): 16-1-16-4.

Scherwath, M., Stern, T., Davey, F., Davies, R., Kleffmann, S. and Okaya, D. (submitted 2002), Lithospheric structure across oblique continental collision in New Zealand from wide-angle P-wave modelling, J. Geophys. Res. .

Sheehan, A. F., Jones, C. H., Savage, M. K., Ozalaybey, S. and Schneider, J. M. (1997), Contrasting lithosphere structure between the Colorado Plateau and Great 
Basin: Initial results from Colorado Plateau-Great Basin PASSCAL experiment, Geophysical Res. Lett. 24(21): 2609-2612.

Silver, P. G. And Chan, W. W. (1991), Shear-wave splitting and subcontinental mantle deformation, J. Geophys. Res. 96: 16,429-16,454.

Singh, L. J. (2001), Late Quaternary Sea Level and Tectonic History of Marlborough Sounds, PhD thesis, V.U.W.

Sircombe, K. N. And Kamp, P. J. J. (1998), The south Westland Basin: seismic stratigraphy, basin geometry and evolution of a foreland basin within the Southern Alps collision zone, New Zealand, Tectonophysics 300: 359-387.

Smith, E. G. C. (1979), A micro-earthquake survey of the Rangitikei and Manawatu Basins, N. Z. J. Geol. Geophys. 22: 473-478.

Smith, E. G. C., Stern, T. And O'Brien, B. (1995), A seismic velocity profile across the central South Island, New Zealand, from explosion data, N. Z. J. Geol. Geophys. 38: $565-570$.

Smith, R. B. And Braile, L. W. (1994), The Yellowstone hotspot, J. Volc. Geothermal Res. 61: 121-187.

Smith, W. And Wessel, P. (1990), Gridding with continuous curvature splines in tension, Geophysics 55: 293-305.

Spencer, J. W. And Nur, A. M. (1976), The effects of pressure, temperature, and pore water on velocities in westerly granite, J. Geophys. Res. 81(5): 899-904.

Sporli, K. B. S. (1982), Review of paleostrain/stress directions in Northland, New Zealand, and of the structure of the Northland Allocthon, Tectonophysics 87(14): $25-36$.

Stagpoole, V. M. (1997), A geophysical study in the northern Taranaki Basin, New Zealand, PhD thesis, V.U.W.

Statistics, N. Z. (2002), New Zealand Official Yearbook 2002, 103 edn, David Bateman Ltd., Auckland.

Stern, T. A. (1982), Seismic and gravity investigations of the Central Volcanic Region, North Island, New Zealand, PhD thesis, V.U.W.

Stern, T. A. (1985), A back-arc basin formed within continental lithosphere: Central Volcanic Region of New Zealand, Tectonophysics 112: 385-409.

Stern, T. A. (1987), Asymmetric back-arc spreading, heat flux and structure associated with the Central Volcanic Region of New Zealand, Earth Plan. Sci. Lett. 85: 265276 .

Stern, T. A. And Davey, F. J. (1987), A seismic investigation of crustal and upper mantle structure within the Central Volcanic Region of New Zealand, N. Z. J. Geol. Geophys. 30: 217-231.

Stern, T. A. And Davey, F. J. (1989), Crustal structure and origin for basins formed behind the Hikurangi suduction zone of New Zealand, Vol. 48, Am. Geophys. Union, Geophys. Monogr.

Stern, T. A., Kleffmann, S., Okaya, D., Scherwath, M. and Bannister, S. (2001), Low seismic-wave speeds and enhanced fluid pressure beneath the Southern Alps of New Zealand, Geology 29: 679-682. 
Stern, T. A., Quinlan, G. M. And Holt, W. E. (1992), Basin formation behind an active subduction zone: three-dimensional flexural modelling of Wanganui Basin, new Zealand, Basin Res. 4: 197-214.

Stern, T. A., Quinlan, G. M. And Holt, W. E. (1993), Crustal dynamics associated with the formation of Wanganui Basin, New Zealand, in P. F. Ballance (ed.), South Pacific Sedimentary Basins. Sedimentary Basins of the World, Vol. 2, Elsevier Science Publishers B. V., Amsterdam, pp. 213-223.

Stern, T. A., Smith, E., Davey, F. J. and Muirhead, K. J. (1987), Crustal and upper mantle structure of the northwestern North Island, New Zealand, from seismic refraction data, Geophys. J. R. Astr. Soc. 91: 913-936.

Stratford, W. And Stern, T. (2002), Crust and upper mantle structure in a continental back-arc spreading zone: central North Island, New Zealand, AGU-Western Pacific Meeting, Wellington, New Zealand.

Suggate, R. P. (1959), New Zealand Coals, DSIR Bull. N. Z. 134: 1-113.

Summerfield, M. A. And Hulton, N. J. (1994), Natural controls of fluvial denudation rates in major world drainage basins, J. Geophys. Res. 99: 13,871-13,883k.

Takanashi, M., Nishizawa, O., Kanagawa, K. and Yasunaga, K. (2001), Laboratory measurements of elastic anisotropy parameters for the exposed crustal rocks from the Hidaka Metamorphic Belt, Central Hokkaido, Japan, Geophys. J. Int. 145: 3347.

Te Punga, M. T. (1952), The geology of the Rangitikei valley, New Zealand, Geol. Surv. Memoir 8: 46.

Tippett, J. M. And Kamp, P. J. J. (1993), Fissions track analysis of Late Cenozoic vertical kinematics of continental Pacific crust, South Island, New Zealand, J. Geophys. Res. 98(B9): 16119-16148.

Uyeda, S. And Kanamori, H. (1979), Back-arc opening and the mode of subduction, $J$. Geophys. Res. 84: 1049-1061.

VÅgnes, E. And Amundsen, H. E. F. (1993), Late Cenozoic uplift and volcanism on Spitsbergen: Caused by mantle convection?, Geology 21: 251-254.

van Avendonk, H. J. A., Holbrook, W. S. and Austin, J. K. Okaya, D. (1999), Seismic velocity and wide-angle reflectivity structure of the AustralianPacific plate boundary, South Island, New Zealand, AGU Fall Meeting Abstracts http://www.agu.org/dbasetop.html(Poster T42B-03).

VRY, J. K. (in prep.), Development of fluid connectivity in collision orogenesis: Southern Alps, New Zealand.

Walcott, R. I. (1984), Reconstructions of the New Zealand region for the Neogene, Palaeogeog. Palaeoclimat. Palaeoecol. 46: 217-231.

Walcott, R. I. (1998), Modes of oblique compression: late Cenozoic tectonics of the South Island of New Zealand, Reviews Geophys. 36(1): 1-26.

Wannamaker, P. E., Jiracek, G. R., Stodt, J. A., Caldwell, T. G., Gonzalez, V. M., McKinght, J. D. And Porter, A. D. (in press), Fluid migration and movement beneath an active compressional orogen, the New Zealand Southern Alps, inferred from magnetotelluric data, J. Geophys. Res. . 
Watanabe, T. (1993), Effects of water and melt on seismic velocities and their application to characterization of seismic reflectors, Geophys. J. Int. 20(24): 2933-2936.

WatTs, A. B. (1992), The effective elastic thickness of the lithosphere and the evolution of foreland basins, Basin Res. 4: 169-178.

Watts, A. B., Karner, G. D. And Steckler, M. S. (1982), Lithospheric flexure and the evolution of sedimentary basins, Philos. Trans. Roy. Soc. London, Ser. A 305: 249-281.

Watts, A. B., McKerrow, W. S. And Fielding, E. (2000), Lithospheric flexure, uplift, and landscape evolution in south-central England, J. Geol. Soc. Lond. 157: 11691177.

Wellman, H. W. (1953), Data for the study of Recent and Late Pleistocene faulting in South Island of New Zealand, N. Z. J. Sci. Tech. 34B: 270-288.

Wellman, H. W. (1979), An uplift map of South Island, New Zealand, and a model for uplift of the Southern Alps, Roy. Soc. N. Z., Bull. 18: 13-20.

Wells, P. (1989), Burial history of Late Neogene sedimentary basins on pasts of the New Zealand convergent plate margin, Basin Res. 2: 145-160.

Wessel, P. And Smith, W. H. F. (2002), Generic Mapping Tools, http://gmt.soest.hawaii.edu .

Williams, G. E. And Gostin, V. A. (2000), Mantle plume uplift in the sedimentary record: origin of kilometre-deep canyons within late Neoproterozoic sucessions, South Australia, J. Geol. Soc. Lond. 157: 759-768.

Wilson, G. S. And McGuire, D. M. (1995), Distributed deformation due to coupling across a subduction thrust: Mechanism of young tectonic rotation within the south Wanganui basin, New Zealand, Geology 23(7): 645-648.

Yilmaz, O. (1987), Investigations in Geophysics, Seismic Data Processing, 2, Society of Exploration Geophysicists.

Zandt, G. And Ammon, C. J. (1995), Continental crust composition constrained by measurements of crustal Poisson's ratio, Nature 374: 152-154.

Zandt, G., Velasco, A. A. And Beck, S. L. (1994), Composition and thickness of the southern Altiplano crust, Bolivia, Geology 22: 1003-1005.

Zhu, L. And Kanamori, H. (2000), Moho depth variation in Southern California from teleseismic receiver functions, J. Geophys. Res. 105: 2969-2980. 
APPENDIX A

INCIDENCE ANGLE AND AZIMUTH OF PMP ARRIVALS 
Angle of incidence and azimuth of PmP

\begin{tabular}{|c|c|c|c|}
\hline Offset (m) & Azimuth $^{\circ}$ & Incidence angle $^{\circ}$ & rating \\
\hline \multicolumn{4}{|l|}{ STN1020 } \\
\hline 78024 & 30.44 & -39.48 & $\bar{M}$ \\
\hline \multicolumn{4}{|l|}{ STN1096 } \\
\hline 55040 & 19.55 & -25.80 & G \\
\hline 118991 & 20.31 & -26.77 & G \\
\hline 120039 & 4.21 & -6.17 & M \\
\hline 122977 & 23.12 & -30.35 & M \\
\hline 122977 & 13.36 & -17.81 & M \\
\hline 123999 & 32.19 & -41.60 & M \\
\hline 129039 & 21.92 & -28.83 & G \\
\hline \multicolumn{4}{|l|}{ STN1124 } \\
\hline 51034 & 12.60 & -16.81 & $\mathrm{M} / \mathrm{G}$ \\
\hline \multicolumn{4}{|l|}{ STN1136 } \\
\hline 98013 & 18.87 & -24.91 & $\mathrm{M} / \mathrm{G}$ \\
\hline 100040 & 25.82 & -33.77 & M \\
\hline \multicolumn{4}{|l|}{ STNSP10 } \\
\hline 71026 & 36.67 & -46.92 & $\mathrm{M} / \mathrm{G}$ \\
\hline 72008 & 11.40 & -15.19 & G \\
\hline 97048 & 18.38 & -24.30 & M \\
\hline 103016 & 34.82 & -44.75 & M \\
\hline 104048 & 17.81 & -23.55 & $\mathrm{M} / \mathrm{G}$ \\
\hline 106043 & 38.64 & -49.19 & $\mathrm{M}$ \\
\hline
\end{tabular}

TABle A.1

Azimuth and Incidence angle for PmP arrivals calculated from particle motion. Results are rated on the linearity of the particle motion used in the calculation, only good - $G$ and medium - $M$ results were recorded. The particle motion over the time of PmP phase arrival was observed time increments of $0.1 \mathrm{~s}$. The most linear particle motion was identified and a line was fitted to the data over this time interval. The azimuth of this line on the radial/transverse image gives the azimuth of the in-coming wave. The incidence angle is calculated in the same way, except an allowance was made for the amplification in the vertical direction due to the free surface using a $2 D$ plane wave approximation (see Neuberg and Pointer, 2000). Average values are: $\sim 331 \pm 12^{\circ}$ and $21 \pm 9^{\circ}$ on average for all stations. 
APPENDIX B

\section{SPLITTING RESULTS ON DECONVOLVED DATA}

\begin{tabular}{|c|c|c|c|c|c|c|c|c|}
\hline \multicolumn{9}{|c|}{ Single Trace Analysis } \\
\hline Offset (m) & $\phi\left(^{\circ}\right)$ & $\delta \mathrm{t}(\mathrm{s})$ & $\hat{\phi}\left(^{\circ}\right)$ & Grade & $\phi\left({ }^{\circ}\right)$ & $\delta \mathrm{t}(\mathrm{s})$ & $\hat{\phi}\left(^{\circ}\right)$ & Grade \\
\hline \multicolumn{9}{|l|}{ STN1124 } \\
\hline 72260 & 003 & 0.03 & 349 & $\mathrm{~A}$ & 344 & 0.04 & 317 & $\mathrm{~A}$ \\
\hline 72312 & 356 & 0.04 & 341 & B & 344 & 0.04 & 317 & B \\
\hline 72520 & 000 & 0.09 & 016 & B & 345 & 0.04 & 317 & B \\
\hline 72624 & 343 & 0.05 & 319 & A & 342 & 0.04 & 317 & A \\
\hline 72728 & 004 & 0.10 & 012 & B & 343 & 0.05 & 317 & A \\
\hline 72934 & 013 & 0.02 & 357 & A & 344 & 0.05 & 317 & A \\
\hline 72984 & 354 & 0.09 & 005 & B & 068 & 0.06 & 317 & $\mathrm{C}$ \\
\hline 73039 & 015 & 0.07 & 029 & B & 075 & 0.06 & 317 & $\mathrm{C}$ \\
\hline
\end{tabular}

TABLE B. 1

Silver and Chan results on data processed with deconvolution, STN1124. The data on the left are analysed with the Silver and Chan (1991) method, the data to the right of the double line are analysed with the same method but with the initial polarization set to radial. 


\begin{tabular}{|c|c|c|c|c|c|c|c|c|}
\hline \multicolumn{9}{|c|}{ Single Trace Analysis } \\
\hline Offset (m) & $\phi$ & $\delta \mathrm{t}(\mathrm{s})$ & $\hat{\phi}$ & Grade & $\phi$ & $\delta \mathrm{t}(\mathrm{s})$ & $\hat{\phi}$ & Grade \\
\hline \multicolumn{9}{|l|}{ STN1096 } \\
\hline $7 \overline{75235}$ & ב064 & $\overline{0.1}$ & 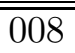 & $\overline{\mathrm{B}}$ & 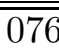 & 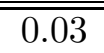 & "317 & $\overline{\mathrm{C}}$ \\
\hline 75290 & 048 & 0.1 & 355 & B & 072 & 0.16 & 317 & $\mathrm{D}$ \\
\hline 75805 & 007 & 0.03 & 047 & B & 083 & 0.03 & 317 & A \\
\hline 76017 & 056 & 0.1 & 003 & B & 074 & 0.16 & 317 & D \\
\hline 76069 & 043 & 0.09 & 354 & B & 073 & 0.03 & 317 & $\mathrm{D}$ \\
\hline 76220 & 062 & 0.09 & 014 & A & 083 & 0.03 & 317 & B \\
\hline 76868 & 060 & 0.03 & 288 & B & 085 & 0.03 & 317 & B \\
\hline
\end{tabular}

TABLE B.2

Silver and Chan results on data processed with deconvolution, STN1096

\begin{tabular}{|l|c|c|c|c||c|c|c|c|}
\hline \multicolumn{7}{|c|}{ Single Trace Analysis } \\
\hline Offset $(\mathrm{m})$ & $\phi\left(^{\circ}\right)$ & $\delta \mathrm{t}(\mathrm{s})$ & $\hat{\phi}\left({ }^{\circ}\right)$ & Grade & $\phi\left(^{\circ}\right)$ & $\delta \mathrm{t}(\mathrm{s})$ & $\hat{\phi}\left(^{\circ}\right)$ & Grade \\
\hline STN1136 \\
\hline \hline 76737 & 025 & 0.03 & 076 & $\mathrm{~B}$ & 017 & 0.08 & 318 & $\mathrm{C}$ \\
76903 & 036 & 0.09 & 352 & $\mathrm{~A}$ & 013 & 0.09 & 318 & $\mathrm{C}$ \\
76958 & 035 & 0.09 & 357 & $\mathrm{~B}$ & 006 & 0.08 & 318 & $\mathrm{C}$ \\
77016 & 027 & 0.09 & 342 & $\mathrm{~A}$ & 010 & 0.09 & 318 & $\mathrm{C}$ \\
77227 & 036 & 0.08 & 349 & $\mathrm{~B}$ & 017 & 0.08 & 318 & $\mathrm{~B}$ \\
77277 & 031 & 0.02 & 273 & $\mathrm{~B}$ & 024 & 0.08 & 318 & $\mathrm{~A}$ \\
77330 & 022 & 0.08 & 327 & $\mathrm{~B}$ & 016 & 0.08 & 318 & $\mathrm{~A}$ \\
77442 & 002 & 0.02 & 061 & $\mathrm{~B}$ & 012 & 0.08 & 318 & $\mathrm{~B}$ \\
77837 & 040 & 0.08 & 353 & $\mathrm{~A}$ & 019 & 0.08 & 318 & $\mathrm{C}$ \\
78052 & 038 & 0.08 & 347 & $\mathrm{~A}$ & 020 & 0.09 & 318 & $\mathrm{C}$ \\
78382 & 060 & 0.08 & 032 & $\mathrm{~B}$ & 019 & 0.07 & 318 & $\mathrm{C}$ \\
78500 & 049 & 0.07 & 006 & $\mathrm{~B}$ & 023 & 0.07 & 318 & $\mathrm{D}$ \\
79100 & 042 & 0.08 & 354 & $\mathrm{~B}$ & 021 & 0.07 & 318 & $\mathrm{D}$ \\
\hline
\end{tabular}

TABLE B.3

Silver and Chan results on data processed with deconvolution, STN1136 
APPENDIX C

DECONVOLVED DATA USED IN CROSS-CORRELATION 


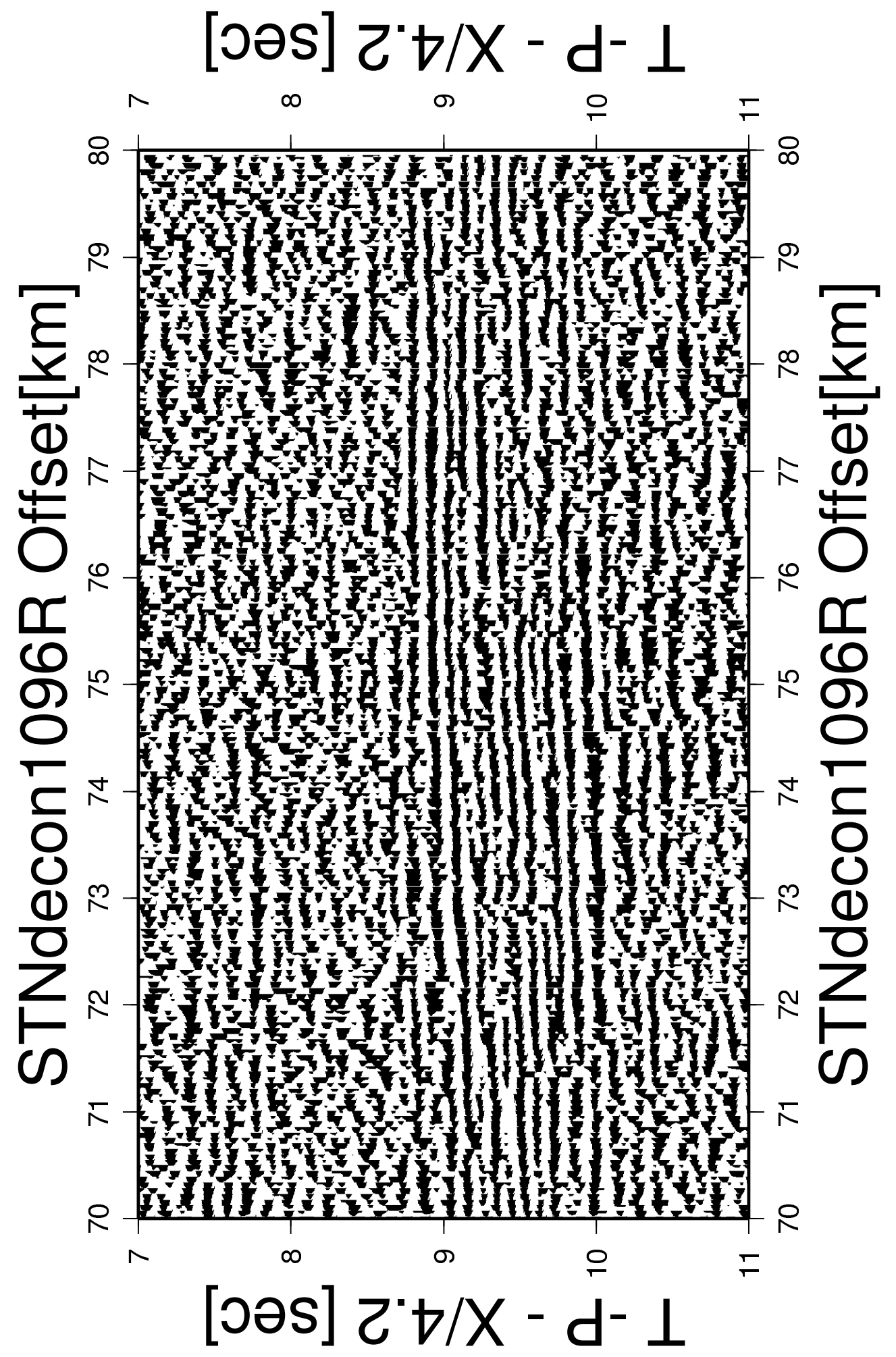

FiG. C.1 SmS arrival on the radial component of STN1096, using deconvovled data. The window of data shown is that used in the cross correlation calculation shown in the following figure. The data were deconvolved using a gap of 108 and a window of length $620 \mathrm{~ms}$. 


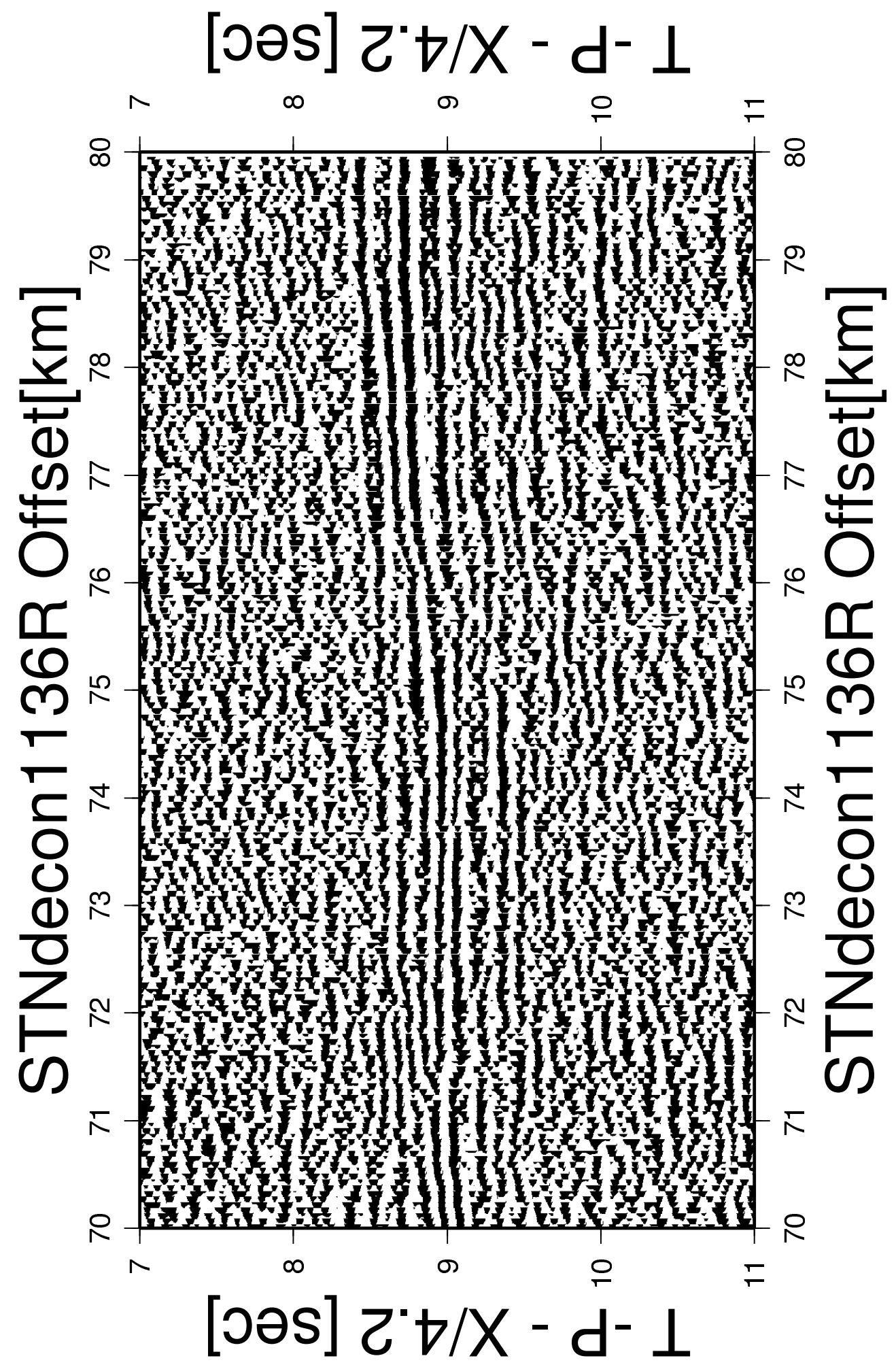

Fig. C.2 SmS arrival on the radial component of STN1136, using deconvovled data. The window of data shown is that used in the cross correlation calculation shown in the following figure. The data were deconvolved using a gap of $108 \mathrm{~ms}$ and a window of length $620 \mathrm{~ms}$. 


\section{SUMMARY OF PICK INFORMATION FOR VELOCITY}

Pick information for velocity models $(\lambda \sim 0.12$ s $)$

\begin{tabular}{|c|c|c|c|c|}
\hline Station & Phase & Offset $(\mathrm{km})$ & Pick Error $(\lambda)$ & Comment \\
\hline \multirow[t]{2}{*}{0792} & $\mathrm{Pg}$ & $83.7-111.5$ & 2 & Weak \\
\hline & $\mathrm{PmP}$ & $135-170$ & $\overline{1}$ & \\
\hline \multirow[t]{2}{*}{0804} & $\mathrm{Pg}$ & $82.4-109.8$ & 1 & Moderately immpulsive arrival \\
\hline & $\mathrm{PmP}$ & $134-168$ & 1 & \\
\hline \multirow[t]{2}{*}{0816} & $\mathrm{Pg}$ & $81.3-117$ & 1 & \\
\hline & $\mathrm{PmP}$ & $132-168$ & 1 & Not continuous \\
\hline \multirow[t]{2}{*}{0828} & $\mathrm{Pg}$ & $80-111.6$ & $\overline{1}$ & \\
\hline & $\mathrm{PmP}$ & $129.5-137$ & 1 & \\
\hline \multirow[t]{2}{*}{0840} & $\mathrm{Pg}$ & $78.8-117$ & 1 & \\
\hline & $\mathrm{PmP}$ & $120-138$ & 1 & \\
\hline \multirow[t]{3}{*}{0852} & $\mathrm{Pg}$ & $77.8-116.2$ & 1 & \\
\hline & $\mathrm{PmP}$ & $115-167$ & 1 & \\
\hline & SmS & $139-145.8$ & 2 & V. weak \\
\hline \multirow[t]{2}{*}{0912} & $\mathrm{Pg}$ & $71.7-105.8$ & 1 & \\
\hline & $\mathrm{PmP}$ & $117-167$ & 1 & \\
\hline \multirow[t]{3}{*}{0936} & $\mathrm{Pg}$ & $69-105$ & 1 & \\
\hline & $\mathrm{PmP}$ & $110-167.6$ & 1 & \\
\hline & SmS & $100-105.6$ & 2 & V. weak \\
\hline \multirow[t]{2}{*}{0944} & $\mathrm{Pg}$ & $68.5-101$ & 2 & Mod. weak \\
\hline & $\mathrm{PmP}$ & $114-166$ & 1 & \\
\hline \multirow[t]{3}{*}{0984} & $\mathrm{PmP}$ & $121-157$ & 2 & $\mathrm{P}$ arrivals weak \\
\hline & $\mathrm{Sg}$ & $85.7-97$ & 2 & Mod. strong Swave arrivals \\
\hline & SmS & $86.5-104$ & 2 & \\
\hline \multirow[t]{3}{*}{1008} & $\mathrm{Pg}$ & $62-87.4$ & 1 & \\
\hline & $\mathrm{PmP}$ & $99.6-154$ & 1 & \\
\hline & SmS & $84-95.8$ & 2 & Weak \\
\hline \multirow[t]{2}{*}{1020} & $\mathrm{Pg}$ & $61-92$ & 1 & \\
\hline & $\overline{\mathrm{PmP}}$ & $98-160.6$ & 1 & \\
\hline
\end{tabular}


Pick information for velocity models

\begin{tabular}{|c|c|c|c|c|}
\hline$\overline{\text { Station }}$ & Phase & Offset $(\mathrm{km})$ & Pick Error $( \pm \lambda)$ & Comment \\
\hline & $\mathrm{SmS}$ & $81-92.5$ & 2 & Not very continuous \\
\hline \multirow[t]{3}{*}{1036} & $\mathrm{Pg}$ & $59-97$ & 1 & \\
\hline & $\overline{\mathrm{PmP}}$ & $59-108.8$ & 1 & \\
\hline & SmS & $80.5-93.5$ & 2 & \\
\hline \multirow[t]{3}{*}{1052} & $\mathrm{Pg}$ & $57.6-90$ & 1 & \\
\hline & $\mathrm{PmP}$ & $96-157$ & 1 & \\
\hline & $\mathrm{SmS}$ & $79-84$ & 2 & \\
\hline \multirow[t]{2}{*}{1072} & $\mathrm{Pg}$ & $56-93$ & 2 & Weak \\
\hline & $\mathrm{PmP}$ & $91-146.5$ & 2 & weak \\
\hline \multirow[t]{3}{*}{1096} & $\mathrm{Pg}$ & $52.8-91$ & 1 & Strong first arrival \\
\hline & $\mathrm{PmP}$ & $92.6-152$ & 1 & \\
\hline & $\overline{\mathrm{SmS}}$ & $72.6-79$ & 1 & First coherent arrival \\
\hline \multirow[t]{3}{*}{ SP10 } & $\mathrm{Pg}$ & $65-99.8$ & 1 & \\
\hline & $\mathrm{PmP}$ & $104-161.5$ & 1 & \\
\hline & SmS & $86-91$ & 2 & Weak \\
\hline \multirow[t]{2}{*}{ SP11 } & $\mathrm{Pg}$ & $58-81.5$ & 2 & Weak \\
\hline & $\mathrm{PmP}$ & $95-156.6$ & 2 & Weak \\
\hline \multirow[t]{4}{*}{1124} & $\mathrm{Pg}$ & $50-83$ & 1 & \\
\hline & $\mathrm{PmP}$ & $98-149.6$ & 1 & \\
\hline & $\mathrm{Sg}$ & $78-81.4$ & 2 & \\
\hline & $\overline{\mathrm{SmS}}$ & $76-132$ & 1 & Discontinuous, picked where strong \\
\hline \multirow[t]{5}{*}{1136} & $\mathrm{Pg}$ & $48.7-74$ & 1 & \\
\hline & $\mathrm{PmP}$ & $107-145.5$ & 2 & Weak \\
\hline & $\overline{\mathrm{Sg}}$ & $62.4-79.4$ & 2 & Starts strongly, becomes weaker with offset \\
\hline & $\mathrm{SmS}$ & $71-86.9$ & 1 & \\
\hline & SmS & $93-100$ & 2 & \\
\hline \multirow[t]{5}{*}{1224} & $\mathrm{Pg}$ & $40.5-60$ & 2 & V. faint first arrival \\
\hline & $\overline{\mathrm{PmP}}$ & $62-93$ & 2 & weak \\
\hline & $\mathrm{SmS}$ & $67.5-69.6$ & 1 & From Radial component \\
\hline & $\mathrm{SmS}$ & $71.7-75.9$ & 1 & From Radial component \\
\hline & SmS & $104-107$ & 1 & From Radial component \\
\hline 1240 & $\mathrm{PmP}$ & $90.4-98.7$ & 2 & Weak \\
\hline \multirow[t]{2}{*}{1248} & $\mathrm{Pg}$ & $38-59.4$ & 2 & Weak \\
\hline & $\mathrm{SmS}$ & $100.5-105.5$ & 3 & V. weak \\
\hline \multirow[t]{2}{*}{1324} & $\mathrm{Pg}$ & $30.7-49.6$ & 2 & V. weak \\
\hline & $\mathrm{PmP}$ & $96-139.4$ & 2 & V. weak \\
\hline \multirow[t]{3}{*}{1328} & $\mathrm{Pg}$ & $30.5-51.4$ & 2 & V. weak \\
\hline & $\mathrm{PmP}$ & $86.3-108$ & 2 & Weak \\
\hline & $\mathrm{SmS}$ & $92.8-98.5$ & 2 & Weak \\
\hline 1332 & $\mathrm{Pg}$ & $30-51$ & 2 & Weak \\
\hline \multirow[t]{2}{*}{1336} & $\overline{\mathrm{SmS}}$ & $76.5-79.8$ & 2 & Lots of multiples \\
\hline & SmS & $92-95.8$ & 2 & Noisey \\
\hline \multirow[t]{2}{*}{1344} & $\mathrm{SmS}$ & $71.5-77.2$ & 2 & Weak \\
\hline & SmS & $90-96$ & 2 & Weak \\
\hline
\end{tabular}


Pick information for velocity models

\begin{tabular}{|c|c|c|c|c|}
\hline Station & Phase & Offset $(\mathrm{km})$ & Pick Error $( \pm \lambda)$ & Comment \\
\hline \multirow[t]{4}{*}{1360} & $\mathrm{Pg}$ & $27-43.6$ & 1 & \\
\hline & $\mathrm{PmP}$ & $96-113$ & 2 & Weak \\
\hline & SmS & $99.4-102$ & 2 & Weak \\
\hline & SmS & $81-92.5$ & 2 & Not very continuous \\
\hline \multirow[t]{3}{*}{1372} & $\mathrm{Pg}$ & $25.7-60$ & 1 & Mod. strong \\
\hline & $\mathrm{PmP}$ & $67-106$ & 2 & \\
\hline & $\mathrm{SmS}$ & $71.7-92$ & 2 & \\
\hline \multirow[t]{5}{*}{1396} & $\overline{\mathrm{Pg}}$ & $23.3-57.5$ & 1 & \\
\hline & $\mathrm{PmP}$ & $73-125$ & 3 & Start unclear due to PlP \\
\hline & $\mathrm{Pn}$ & $112-131$ & 2 & \\
\hline & SmS & $71.5-73$ & 3 & Weak \\
\hline & SmS & $87.8-90.7$ & 1 & Weak \\
\hline \multirow[t]{4}{*}{1404} & $\mathrm{Pg}$ & $22.7-52$ & 1 & \\
\hline & $\mathrm{PmP}$ & $87.8-130$ & 3 & Start unclear due to PlP \\
\hline & $\mathrm{Pn}$ & $114-130$ & 2 & \\
\hline & SmS & $87-90$ & 3 & V. V. weak \\
\hline \multirow[t]{2}{*}{1416} & $\mathrm{Pg}$ & $21.5-55.8$ & 1 & \\
\hline & $\mathrm{PmP}$ & $64-96.5$ & 3 & Data becomes noisey after $90 \mathrm{~km}$ offset \\
\hline \multirow[t]{2}{*}{1428} & $\mathrm{Pg}$ & $20-41.5$ & 2 & V. weak data \\
\hline & SmS & $65-69.5$ & 3 & Coherent but weak \\
\hline \multirow[t]{4}{*}{1452} & $\mathrm{Pg}$ & $26.4-55.5$ & 1 & Noisey \\
\hline & $\mathrm{PmP}$ & $82.8-112$ & 3 & Start unclear due to PlP \\
\hline & SmS & $82.4-84.5$ & 3 & V. weak \\
\hline & SmS & $97-100$ & 2 & Weak \\
\hline \multirow[t]{2}{*}{1464} & $\mathrm{Pg}$ & $16.7-43.7$ & 1 & Noisey data \\
\hline & $\mathrm{PmP}$ & $63-74.7$ & 3 & \\
\hline 1488 & $\mathrm{Pg}$ & $14-45.7$ & 2 & V. weak \\
\hline \multirow[t]{4}{*}{ SP14 } & $\mathrm{Pg}$ & $26.3-42$ & 1 & \\
\hline & $\mathrm{PmP}$ & $84-137$ & 3 & Gets inreasingly weak with offset \\
\hline & SmS & $81.7-93.7$ & 3 & V. weak \\
\hline & $\mathrm{SmS}$ & $106-112$ & 2 & V. weak \\
\hline \multirow[t]{2}{*}{ SP15 } & $\mathrm{Pg}$ & $15-43$ & 2 & \\
\hline & $\mathrm{PmP}$ & 99.6-137 & 4 & V. weak \\
\hline
\end{tabular}




\section{TILTING OF THE COASTAL PLAINS AND TERRACES OF THE RANGITIKEI RIVER VALLEY}

Progressive southwest surface tilting has been identified from river terraces of the Rangitikei River (Te Punga, 1952; Milne, 1973a)(Figure 1.2). Downstream profiles of the Rangitikei River show an increase in gradient of terrace surfaces with age, from 300 ka to the youngest $<12$ ka providing an average tilt rate of $6.1 \times 10^{-8} \mathrm{rad} / \mathrm{yr}$ (Milne, 1973a) (Figure 1.2). The increase in terrace gradient is related to tilt of the land surface based on the assumption that the terraces form at the same initial gradient and have been tilting in the same approximate direction since their formation.

The $25 \mathrm{~m}$ DEM is used here to estimate the maximum magnitude of tilt and tilt direction of the Rangitikei River terraces, rather than the downstream magnitude as previously determined. The progressive south-eastward motion of the Wanganui depocentre may indicate a possible relationship between the age of the terraces and the direction of terrace tilt. This is investigated through back-stripping of the dataset, where young terraces are found at lower elevations and have been only affected by the most recent deformation and older terraces (at higher elevations) show the summation of deformation over longer periods. For example, should we find that younger terraces are more steeply tilted than older ones, back-stripping would imply that some reversal of tilting must have occurred as the older terraces must have been subjected to all of the tilting that affected the younger ones. By a similar argument, back-stripping should allow us to quantify changes in direction of tilting, which might be expect if the depocentre of the Wanganui Basin has indeed migrated. 


\section{E.0.1 Regional setting}

The Rangitikei River basin lies in the central-south of North Island. The river runs roughly parallel to the Axial ranges, draining these ranges and also the central volcanic plateau (Figure 5.1). The Rangitikei River basin was selected for this study due to the extensive suite of 14 large terraces carved into the mudstone bedrock and capped with river gravels that flank the river. These terraces provide information on the timing and magnitude of tilting in this region since $\sim 300 \mathrm{ka}$ (Figure E.1).

\section{E.0.2 Terrace formation}

The fluvial terraces of the Rangitikei valley, though capped with large beds of river gravels, are predominantly carved out of marine sediment. These sediments are referred to as "bedrock" from here onwards. To preserve a large suite of uplifted bedrock terraces, lowering of the base-level or tilting must be involved.

The first model for terrace formation requires continuous relative uplift/tilt creating a continually steepening stream profile with high stream energy, which results in vertical incision into the bedrock. During times of high water flow, due to climatic changes, the stream has sufficient energy to incise laterally creating a flood plain (Merritts et al., 1994). Once the water flow drops again the stream will continue to incise vertically creating a new river bed leaving the previous one as a terrace.

The second model assumes discontinuous uplift. The uplift will initially steepen the river profile, increasing the energy of the stream, causing vertical incision. Once the stream has cut down into the bedrock to a graded stream profile, with insufficient energy to cut further downwards, the river will start to meander and cut into its banks. During high water this lateral erosion will increase. The next uplift will strand the old riverbed as a terrace.

The extensive nature of the terraces indicates the second model is more appropriate for this region and is used here. Assuming the second method for terrace formation, the main terraces should all form at the same initial gradient (Cotton, 1942). The Rangitikei 


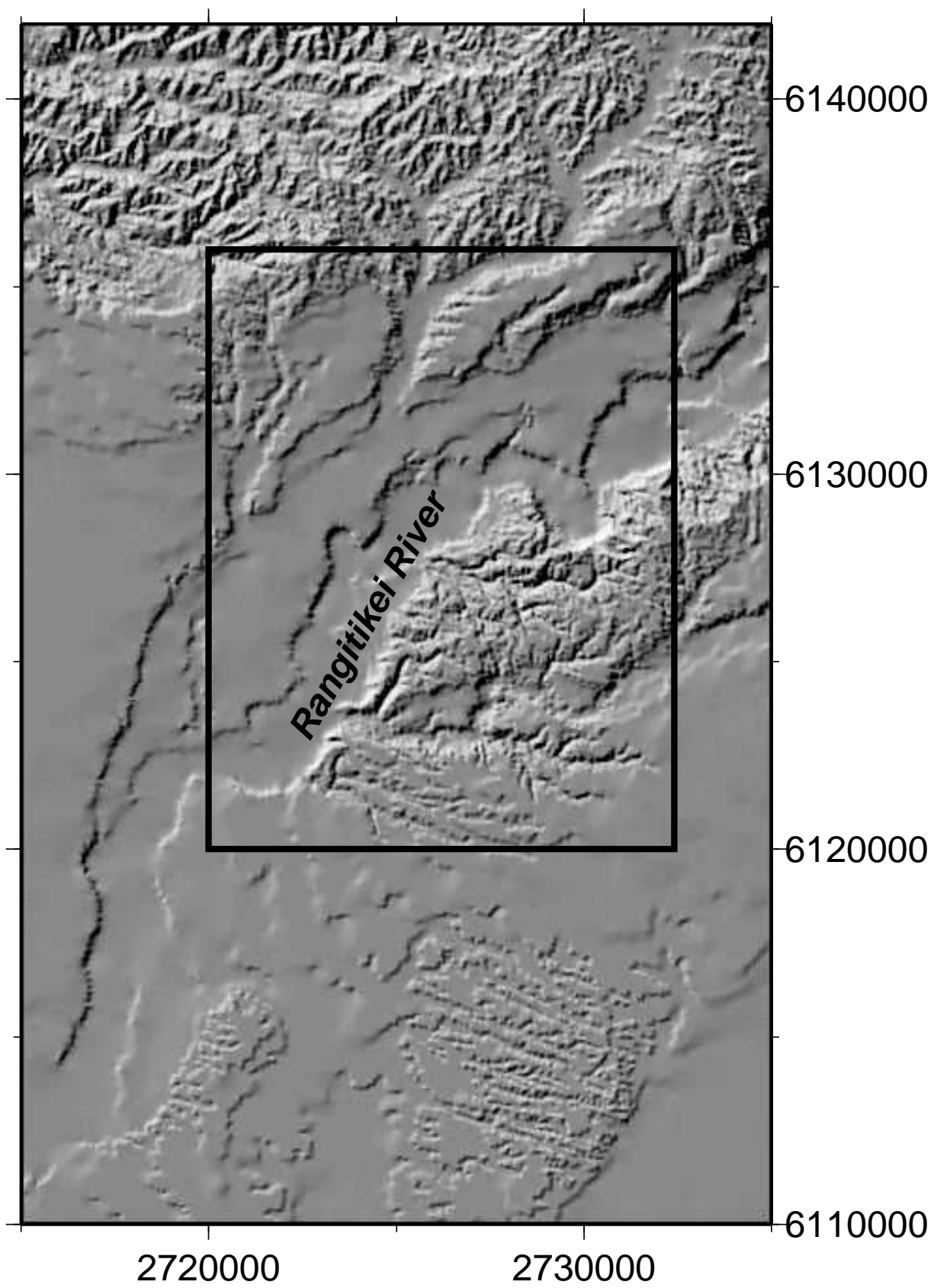

FIG. E.1 Shaded relief image of the Rangitikei River valley from the $50 \mathrm{~m}$ DEM. The fluvial terraces can be identified from this image by the flat step-like features along the edges of the river valley. The illumination for this image is $315^{\circ}$ from grid north. The coordinates are in NZ Map grid (metres). 
region is based on soft marine sediments and therefore stream incision is likely to be keeping pace with any uplift or tilting (Crozier and Pillians, 1991). To increase the gradient of the terraces some tectonic or flexural influence must be involved after their formation.

\section{E.0.3 Method of identification of planar regions from the DEM}

The DEM was interpolated from $20 \mathrm{~m}$ contour data and therefore in low gradient regions the accuracy of the dataset is insufficient to extract tilt information from individual terraces. Rather, the slope of several combined terraces was sampled. A more detailed DEM sourced from regularly spaced sampling of heights, such as gained from Airborne Laser Swath Mapping (ALSM) (e.g. Carter et al., 2001), would be able to provide information on how the slopes of the terraces change with time, but no ALSM data was available for the study area.

Following is a description of a method to analyse the terrace slopes. Note, however, the resolution of our dataset is not high enough and to complete a full investigation of this method, a finer resolution DEM is required.

Identification of planar surfaces such as marine and fluvial terraces was done automatically from the DEM using a filter in the Demtool program (Davies, 1996). A 3 by 3 filter determines whether or not the 9 adjacent points all lie on a plane, within the tolerance limits set. Where the filter identifies a planar area the centre pixel of the $3 \times 3$ filtered region is given an inplane number of 1 , otherwise it is recorded as a null value. For display purposes where the DEM has an inplane number of 1 , the image shows colour according to elevation. Where there is a null value, the image shows illuminated greyscale relief (Figure E.2). During filtering the slope magnitude and direction were recorded as slope vectors for each planar region.

Assuming the region has been continuously tilting southwards since at least the formation of the 300 ka marine terrace (e.g. Jackson et al., 1998), the oldest planar slopes will have the steepest gradient as they have been tilting for the longest period of time. The smallest slopes still dominantly record the gradient at which they formed, with only slight tectonic influence. Using this principle, the data were analysed to determine spatial and 


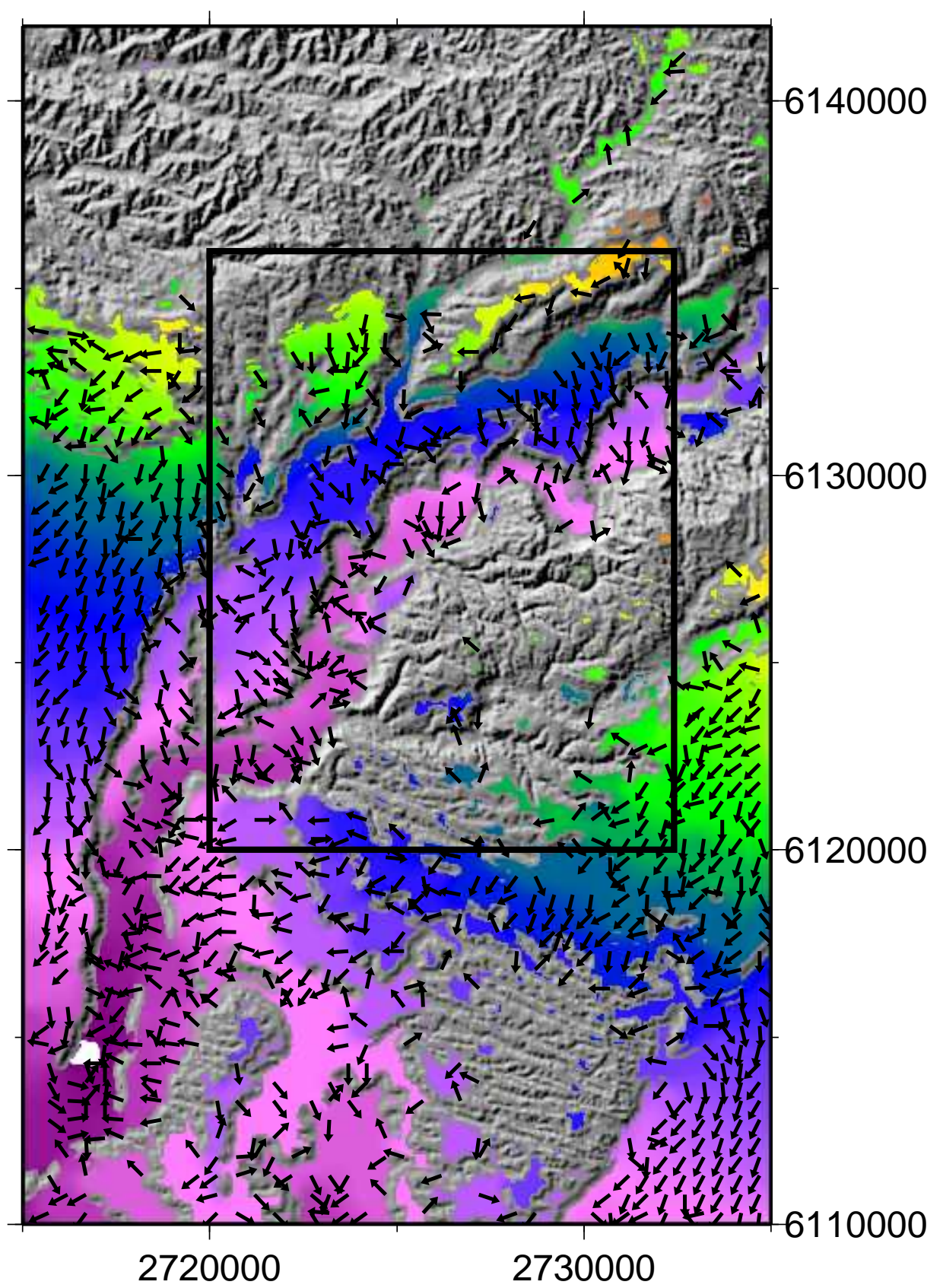

FIG. E.2 Planar regions and slope orientation in the Rangitikei valley. The planar surfaces of the grid displayed in Figure E.1 are identified and coloured according to elevation. The regions in grey shaded relief are not planar. The black arrows are vectors indicating the slope direction of the planar regions. 
temporal variations in tilt direction.

The slope vectors for the planar areas of the DEM were separated into 5 bins of different slope magnitude. This allows the examination of changes in direction of tilt with magnitude (and time). If it is assumed that the tilt magnitude is increasing, larger tilts represent older directions of tilting plus the present day signal. Back-stripping of the most recent tilting from the older, steeper, gradient slope vectors provides an estimation of the palaeo-tilt direction without the influence of more recent slope azimuths. Back-stripping of the data was undertaken by subtracting low-order $(<=3)$ polynomials fitted through the data from bins of adjacent magnitude. For example, a 2nd order polynomial fitted through grid points that have terrace slopes less than $1^{\circ}$ was subtracted from a polynomial (of the same order) fitted through points with slopes between 1-2 (The top left box in Figure E.3). This allowed us to estimate the component of slope that was present before the tilting signal observed today, and investigate any possible changes in this slope direction with time. The coverage of the data for each of the slope bins are shown by the shading of Figure E.3.

Although the data shown in Figure E.3 seems to show a valid result, as there is a change in slope direction to the east with decreasing slope gradient (and time), when this method is carried out in a series of adjacent regions the slope vector analysis showed inconsistent results. The slope bins were chosen to examine only small gradient slopes that are assumed to approximate the terrace gradients. However, many of the vectors represent more than one terrace and are not meaningful in determining an increase in tilt of individual terraces. The only region that showed consistent results was close to the Axial ranges where there was a uniform change in azimuth of slope with time. Close to the ranges, the larger magnitude slopes showed a more westerly tilt while the smaller magnitude slopes were more southerly, which is expected along a rapidly rising N-S oriented anticline with drainage parallel to the fold axis. Given a rate of migration of the Wanganui depocentre of $30 \mathrm{~mm} / \mathrm{yr}$, the depocentre will have migrated $9 \mathrm{~km}$ since the formation of the oldest terraces at $\sim 300 \mathrm{ka}$ (Figure 5.3). The small amount of lateral migration is not likely to have been recorded by the fluvial terraces and cannot be distinguished from this dataset.

Field studies with GPS confirmed that the raw topographic data does not record indi- 

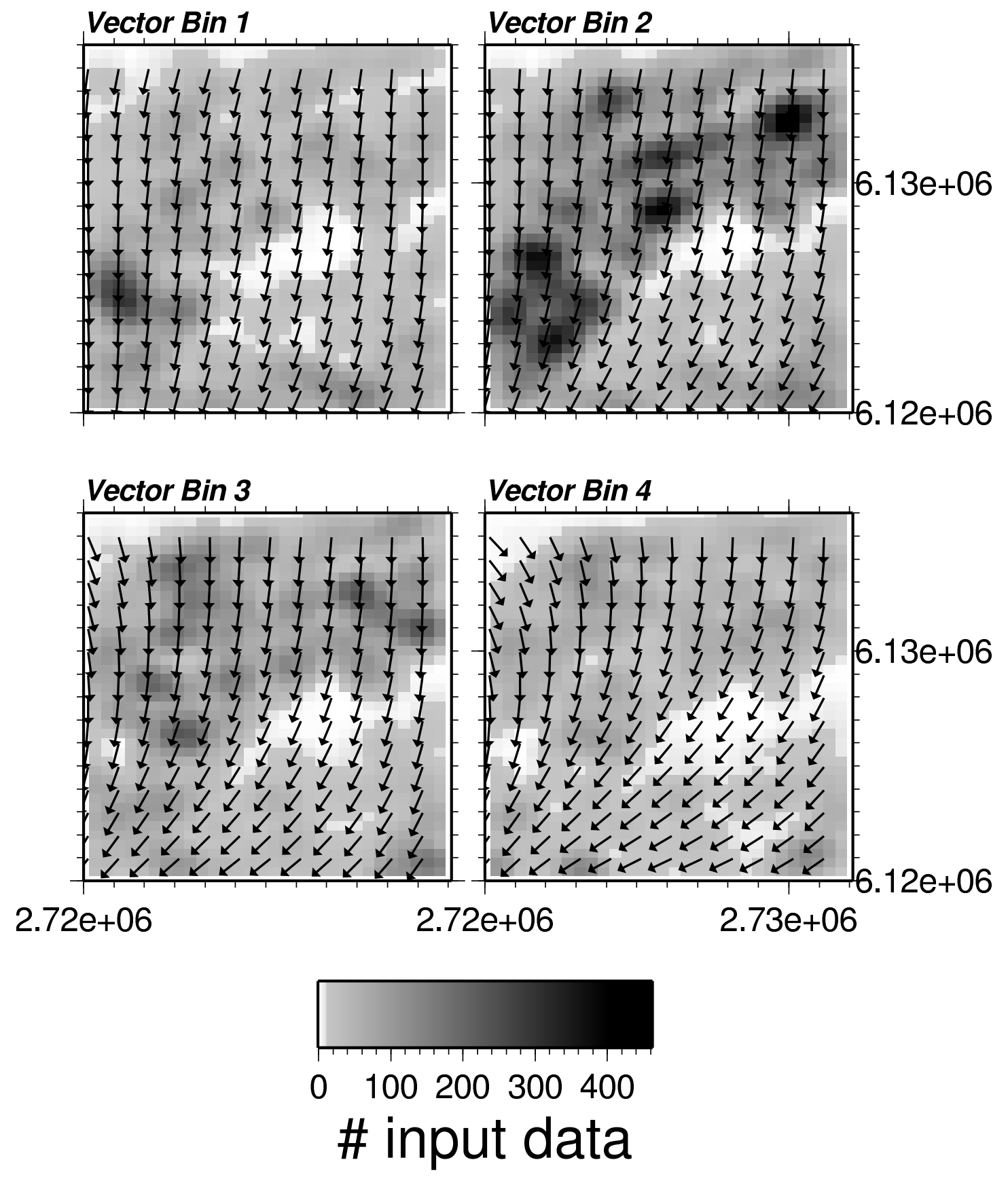

Fig. E.3 Back-stripping of slope with time. The vectors displayed in all bins show the orientation of slope of a second order polynomial that has been fitted to the back-stripped slope vector data; input slope vector data only sample the region inside the boxes on Figures E.1 and E.2. Vector Bin 1 shows the slope of a polynomial created through the subtraction of 2 polynomials, the first for slopes less than $1^{\circ}$, the second for slopes between 1 and $2^{\circ}$. Bin 2 shows the difference between slope bins $1-2^{\circ}$ and $2-3^{\circ}$. Bin 3 between $2-3^{\circ}$ and $3-4^{\circ}$ and finally bin 4 shows between $3-4^{\circ}$ and $4-5^{\circ}$. The shading illustrates the density of data points for each pair of bins; the darker the shading the more data points present and hence the more representative the polynomial will be. Comparison of the slope azimuth with magnitude, and theoretically age, illustrates there is a small change in terrace slope azimuth towards the east with time. 
vidual river terraces and therefore the slopes are over-estimated using this dataset. Nevertheless, the advent of ASLM, and the suitability of this open landscape to laser mapping, means that a useful tool has been developed to acquire detailed tilt histories in the near future.

\section{E.1 Summary}

The contour source for the $25 \mathrm{~m}$ DEM of New Zealand has resulted in low resolution data in regions of low gradient. The DEM was used to determine the magnitude and direction of tilting and to investigate the possibility of a change in terrace slope direction with age. This method works by extracting the terraced or planar regions using a filter. Slope azimuth and magnitude of these planar regions are recorded and these slope vectors can then be analysed for spatial variations or changes in azimuth with magnitude. However, due to the contour source of the data, the DEM is of insufficient resolution to use the terrace slope extraction method in the Rangitikei River valley. With the advent of new methods for obtaining detailed topographic information (e.g. ALSM), the method of tilt identification and back-stripping of tilts with time will be a useful tool in the determination of tectonic histories. 
APPENDIX F

\section{MUDSTONE POROSITY ANALYSES, METHOD AND RESULTS}

\section{F.0.1 Mudstone porosity determination}

Most samples collected for this study were grey massive siltstones of Plio-Pleistocene age (Mangaweka mudstone unit). Samples were collected predominantly from road cuttings with preference given to samples which were wet and recently exposed, as dry samples were more fractured. Where these rocks cropped out near concretions, samples were not taken, to avoid the risk of secondary porosity from cementation and/or solution. Samples with root casts and/or fossils were discarded.

Selected samples were cut into $3 \times 3 \mathrm{~cm}$ cubes using a diamond saw. The cubes were immersed in water under vacuum for approx $18 \mathrm{hrs}$ or until no more air bubbles came out of the samples. The saturated samples were then weighed suspended in water, surface dried and weighed in air, and then oven dried for 1 week and re-weighed. The densities and porosity are calculated using the following relations from Hatherton and Leopard (1964) and Wells (1989):

$$
\begin{array}{ll}
\text { Volume } & =\text { saturated weight }- \text { saturated weight in water } \\
\text { Dry Density } & =\text { dry weight } / \text { volume } \\
\text { Wet Density } & =\text { saturated weight } / \text { volume } \\
\text { Particle Density } & =\text { dry weight } /(\text { dry weight }- \text { saturated weight in water }) \\
\text { Porosity } & =1-(\text { dry density } / \text { particle density })
\end{array}
$$

Samples were disregarded if there was any appearance of cracking during processing. 
These results are tabulated below (Table titled: Porosity from Saturation Analysis). The results from this method showed poor repeatability between samples from the same location. Where this was the case the measurements were made at different times in the day or on different days. These discrepancies are mostly caused by variations in air pressure whilst measuring the weight of the sample suspended in water. Variations were also noted due to motion of the building on windy days with fluctuations of up to \pm 0.4 gms which equates to $\pm 0.2 \%$ porosity. These variations were difficult to reduce as the room could not be effectively sealed. The variation in air pressure between days was not quantified but could be as much as a few percent porosity. Due to the poor repeatability other methods were tried to gain more reliable measurements of the mudstone porosities.

Porosity can be determined by impregnating a sample with coloured resin which fills the pores. The sample is then thin-sectioned and the pores can be point counted under the microscope to determine the porosity. Two thin sections were made of samples from the Rangitikei River valley. One of these samples was poorly sorted with angular grains ranging from silt/fine sand with a matrix of fine, clay sized particles. Due to the fine size of the matrix material the pore spaces were too fine to be distinguished under $\times 100$ power microscope and could not be used to determine porosity. The second sample was moderately sorted and individual pores could be identified. However, the sample fractured during thin sectioning and the original pore space could not be determined accurately.

Further analyses were undertaken using helium porosity analysis. The rock sample is placed inside a steel cylinder of known volume. Helium of a known initial volume and pressure is allowed to isothermally expand into the steel chamber until equilibrium is reached. The grain volume of the sample is calculated by contrasting the new gas pressure in the steel cylinder. The bulk volume of the sample is determined separately by immersion of the sample in mercury (Since it does not invade small pore spaces). The effective porosity is then determined by taking the difference in grain and bulk volume.

This method shows better repeatability than the water saturation method. However, it is noted that some samples analysed with both He and saturation analysis show greater burial and lower porosity, using He analysis. Dorsch and Katsube (1999) also determined 
differences between samples measured using saturation methods and helium porosity analysis. They attribute this difference to the solution of some cement in the samples by fluids, which does not occur using the helium porosity method. However, a reduction in porosity was seen through using the saturation which indicates that rather than the removal of cement, the porosity is more likely influenced by the swelling of clay within the sample. Dorsch and Katsube (1999) determined a 10-20\% error in their porosity measurements from repeatability calculations; here we see less than $6 \%$ error between repeated measurements, however, the number of repeat measurements on each sample were significantly less with only 4 samples taken per site. Due to the improved repeatability, further sampling was done using only the He porosity analysis. These results are tabulated below (Table: Porosity from Helium Analysis). The analyses were done by Murray Helm, Core Laboratories Australia Pty Ltd.

Samples analysed at IGNS employed the saturation method. Their analyses were undertaken in a purpose built laboratory for porosity determination and fluctuations in air pressure and building motion are not as significant as for our analyses. It is noted that our analyses indicate that Helium-porosity analyses produce higher porosity measurements than the saturation method and hence the IGNS porosity results may be minimum values. These measurements are tabulated in Table labeled: Porosity data from IGNS. The IGNS data included samples with porosity values of $\leq 10 \%$ that are likely to have resulted from later cementation of the samples and not the amount of burial. Samples with porosities under $10 \%$ were not used in exhumation calculations or discussions.

Rock type: $\mathrm{M}=$ mudstone $\mathrm{S}=$ siltstone 
Porosity from Saturation analysis

\begin{tabular}{|l|l|l|l|c|c|c|c|c|}
\hline Locality & Latitude & Longitude & Elevation & $\phi 0^{\prime}(\%)$ & z'$^{\prime}(\mathrm{m})$ & $\phi 0^{\prime}$ ave & z ave $(\mathrm{m})$ & $\sigma \mathrm{z}(\mathrm{m})$ \\
\hline T2 & -39.795 & 175.49 & 230 & 42.3 & 377 & & & \\
\hline T3 & -39.758 & 175.57 & 358 & 38.2 & 607 & & & \\
\hline T3a & -39.758 & 175.57 & 358 & 37.5 & 654 & & & \\
\hline T3b & -39.758 & 175.57 & 358 & 37.0 & 682 & 37.6 & 648 & 129 \\
\hline T4 & -39.657 & 175.56 & 418 & 32.5 & 977 & & & \\
\hline T4a & -39.657 & 175.56 & 418 & 32.3 & 992 & 32.4 & 985 & 118 \\
\hline R1-1a & -39.874 & 175.69 & 230 & 37.3 & 664 & & & \\
\hline R1-1b & -39.874 & 175.69 & 230 & 37.8 & 636 & & & \\
\hline R1-2a & -39.874 & 175.69 & 230 & 45.2 & 231 & & & \\
\hline R1-2b & -39.874 & 175.69 & 230 & 38.2 & 607 & & & \\
\hline R1-2c & -39.874 & 175.69 & 230 & 37.9 & 627 & & & \\
\hline R1-2d & -39.874 & 175.69 & 230 & 38.5 & 595 & & & \\
\hline R1-2e & -39.874 & 175.69 & 230 & 37.9 & 626 & & & \\
\hline R1-3a & -39.874 & 175.69 & 230 & 38.4 & 597 & & & \\
\hline R1-3b & -39.874 & 175.69 & 230 & 37.9 & 628 & & & \\
\hline R1-3c & -39.874 & 175.69 & 230 & 38.4 & 596 & & & \\
\hline R1-3d & -39.874 & 175.69 & 230 & 38.9 & 568 & & & \\
\hline R1-3e & -39.874 & 175.69 & 230 & 39.2 & 552 & 38.8 & 557 & 318 \\
\hline R3-1a & -39.809 & 175.81 & 300 & 32.4 & 980 & & & \\
\hline R3-1b & -39.809 & 175.81 & 300 & 32.2 & 999 & & & \\
\hline R3-1c & -39.809 & 175.81 & 300 & 32.9 & 948 & & & \\
\hline R3-2a & -39.809 & 175.81 & 300 & 33.3 & 918 & & & \\
\hline R3-2b & -39.809 & 175.81 & 300 & 33.5 & 910 & & & \\
\hline R3-3a & -39.809 & 175.81 & 300 & 33.3 & 921 & & & \\
\hline R3-3b & -39.809 & 175.81 & 300 & 33.6 & 898 & & & \\
\hline R3-4a & -39.809 & 175.81 & 300 & 33.0 & 939 & & & \\
\hline R3-4b & -39.809 & 175.81 & 300 & 33.5 & 905 & & & \\
\hline R3-4c & -39.809 & 175.81 & 300 & 33.4 & 915 & 33.1 & 933 & \\
\hline
\end{tabular}


Porosity from Saturation analysis

\begin{tabular}{|l|l|l|l|c|c|c|c|c|}
\hline Locality & Latitude & Longitude & Elevation & $\phi 0^{\prime}(\%)$ & z' $^{\prime}(\mathrm{m})$ & $\phi 0^{\prime}$ ave & z ave $(\mathrm{m})$ & $\sigma$ z $(\mathrm{m})$ \\
\hline R4-1a & -39.769 & 175.80 & 500 & 34.3 & 851 & & & \\
\hline R4-1b & -39.769 & 175.80 & 500 & 33.7 & 851 & & & \\
\hline R4-1c & -39.769 & 175.80 & 500 & 34.3 & 855 & & & \\
\hline R4-1d & -39.769 & 175.80 & 500 & 33.1 & 938 & & & \\
\hline R4-2a & -39.769 & 175.80 & 500 & 33.7 & 893 & & & \\
\hline R4-2b & -39.769 & 175.80 & 500 & 34.1 & 867 & & & \\
\hline R4-2c & -39.769 & 175.80 & 500 & 33.8 & 889 & & & \\
\hline R4-2d & -39.769 & 175.80 & 500 & 34.4 & 845 & & & \\
\hline R4-2e & -39.769 & 175.80 & 500 & 33.8 & 887 & & & \\
\hline R4-3a & -39.769 & 175.80 & 500 & 33.6 & 900 & & & \\
\hline R4-3b & -39.769 & 175.80 & 500 & 34.1 & 871 & & & \\
\hline R4-3c & -39.769 & 175.80 & 500 & 34.2 & 858 & 33.9 & 879 & 135 \\
\hline R5-1b & -39.830 & 175.78 & 390 & 35.3 & 790 & & & \\
\hline R5-1c & -39.830 & 175.78 & 390 & 35.7 & 764 & & & \\
\hline R5-1d & -39.830 & 175.78 & 390 & 35.4 & 785 & & & \\
\hline R5-2a & -39.830 & 175.78 & 390 & 37.4 & 660 & & & \\
\hline R5-2b & -39.830 & 175.78 & 390 & 37.9 & 629 & & & \\
\hline R5-2d & -39.830 & 175.78 & 390 & 38.0 & 621 & & & \\
\hline R5-2e & -39.830 & 175.78 & 390 & 38.1 & 618 & & & \\
\hline R5-3a & -39.830 & 175.78 & 390 & 37.2 & 668 & & & \\
\hline R5-3b & -39.830 & 175.78 & 390 & 36.9 & 690 & & & \\
\hline R5-3c & -39.830 & 175.78 & 390 & 36.7 & 700 & & & \\
\hline R5-3f & -39.830 & 175.78 & 390 & 36.1 & 736 & & & \\
\hline R5-4a & -39.830 & 175.78 & 390 & 38.8 & 574 & & & \\
\hline R5-4c & -39.830 & 175.78 & 390 & 37.3 & 662 & 37.0 & 684 & 212 \\
\hline
\end{tabular}

Porosity from He analysis

\begin{tabular}{|l|c|c|c|c|c|c|c|c|}
\hline Locality & Latitude & Longitude & Elevation & $\phi 0^{\prime}(\%)$ & z $^{\prime}(\mathrm{m})$ & $\phi 0^{\prime}$ ave & z ave $(\mathrm{m})$ & $\sigma \mathrm{z}(\mathrm{m})$ \\
\hline R1-1a & -39.874 & 175.69 & 230 & 35.7 & 763 & & & \\
\hline R1-1b & -39.874 & 175.69 & 230 & 35.7 & 763 & 35.7 & 763 & 87 \\
\hline R3-1a & -39.809 & 175.81 & 300 & 32.8 & 955 & & & \\
\hline R3-1b & -39.809 & 175.81 & 300 & 32.7 & 962 & & & \\
\hline R3-3a & -39.809 & 175.81 & 300 & 33.2 & 927 & & & \\
\hline R3-3b & -39.809 & 175.81 & 300 & 33.2 & 927 & 33.0 & 943 & 125 \\
\hline R4-2a & -39.769 & 175.80 & 500 & 31.7 & 1032 & & & \\
\hline R4-2b & -39.769 & 175.80 & 500 & 31.5 & 1047 & & & \\
\hline R4-3a & -39.769 & 175.80 & 500 & 31.3 & 1061 & & & \\
\hline R4-3b & -39.769 & 175.80 & 500 & 31.9 & 1018 & 31.6 & 1039 & 138 \\
\hline R5-4a & -39.830 & 175.78 & 390 & 33.9 & 880 & & & \\
\hline R5-4b & -39.830 & 175.78 & 390 & 34.2 & 860 & 34.1 & 870 & 110 \\
\hline
\end{tabular}


Porosity from He analysis

\begin{tabular}{|c|c|c|c|c|c|c|c|c|}
\hline Locality & Latitude & Longitude & Elevation & $\phi 0^{\prime}(\%)$ & $\mathrm{z}^{\prime}(\mathrm{m})$ & $\phi 0^{\prime}$ ave & $\mathrm{z}$ ave $(\mathrm{m})$ & $\sigma \mathrm{z}(\mathrm{m})$ \\
\hline R6-1bA & -39.618 & 175.76 & 540 & 22.7 & 1789 & & & \\
\hline $\begin{array}{l}\text { R6-1bB } \\
\end{array}$ & $\begin{array}{l}-39.618 \\
\end{array}$ & 175.76 & 540 & 22.9 & 1769 & & & \\
\hline R6-1bC & -39.618 & 175.76 & 540 & 23.4 & 1720 & & & \\
\hline $\bar{R} 6-1 \mathrm{dA}$ & -39.618 & 175.76 & 540 & 23.1 & 1739 & & & \\
\hline R6-1dB & -39.618 & 175.76 & 540 & 23.1 & 1749 & 23.1 & 1753 & 235 \\
\hline M1-1aA & -39.605 & 175.30 & 236 & 32.2 & 997 & & & \\
\hline M1-1aB & -39.605 & 175.30 & 236 & 33.0 & 941 & & & \\
\hline M1-1cA & -39.605 & 175.30 & 236 & 32.2 & 997 & & & \\
\hline M1-1cB & -39.605 & 175.30 & 236 & 29.2 & 1218 & 31.7 & 1038 & 468 \\
\hline M2-1bA & -39.643 & 175.32 & 236 & 33.9 & 880 & & & \\
\hline M2-1bB & -39.643 & 175.32 & 236 & 33.9 & 880 & & & \\
\hline $\mathrm{M} 2-1 \mathrm{cA}$ & -39.643 & 175.32 & 236 & 33.8 & 887 & & & \\
\hline $\mathrm{M} 2-1 \mathrm{cB}$ & -39.643 & 175.32 & 236 & 33.8 & 887 & 33.9 & 884 & 102 \\
\hline M3-2A & -39.679 & 175.34 & 227 & 36.9 & 688 & & & \\
\hline M3-2B & -39.679 & 175.34 & 227 & 36.8 & 694 & 36.8 & 691 & 80 \\
\hline J3-1aA & -39.738 & 175.16 & 37 & 35.6 & 769 & & & \\
\hline J3-1aB & -39.738 & 175.16 & 37 & 35.5 & 776 & 35.6 & 773 & 89 \\
\hline J4-1a & -39.703 & 175.14 & 65 & 37.5 & 652 & & & \\
\hline J4-1cA & -39.703 & 175.14 & 65 & 35.9 & 750 & & & \\
\hline J4-1cB & -39.703 & 175.14 & 65 & 37.2 & 664 & 36.9 & 689 & 175 \\
\hline J6-1a & -39.642 & 175.17 & 97 & 37.1 & 676 & & & \\
\hline J6-1cA & -39.642 & 175.17 & 97 & 35.6 & 769 & & & \\
\hline J6-1cB & -39.642 & 175.17 & 97 & 34.8 & 821 & 35.8 & 755 & 157 \\
\hline J7-1 & -39.582 & 175.10 & 63 & $\mathrm{No}$ & Result & & & \\
\hline $\mathrm{J} 7-2 \mathrm{~A}$ & -39.582 & 175.10 & 63 & 27.2 & 1379 & & & \\
\hline J7-2B & -39.582 & 175.10 & 63 & 27.2 & 1379 & 27.2 & 1379 & 157 \\
\hline J9-1aA & -39.454 & 175.21 & 490 & 25.1 & 1561 & & & \\
\hline J9-1aB & -39.454 & 175.21 & 490 & 23.9 & 1672 & 24.5 & 1616 & 401 \\
\hline Rt3-1bA & -39.721 & 174.95 & 450 & 38.8 & 574 & & & \\
\hline Rt3-1bB & -39.721 & 174.95 & 450 & 38.4 & 598 & 38.6 & 586 & 80 \\
\hline Rt5-1bA & -39.679 & 174.97 & 422 & 36.2 & 732 & & & \\
\hline Rt5-1bB & -39.679 & 174.97 & 422 & 35.5 & 776 & 35.9 & 754 & 130 \\
\hline Rt7-1bA & -39.629 & 174.97 & 420 & 36.1 & 738 & & & \\
\hline Rt7-1bB & -39.629 & 174.97 & 420 & 33.1 & 934 & & & \\
\hline Rt7-1cA & -39.629 & 174.97 & 420 & 34.7 & 827 & & & \\
\hline Rt7-1cB & -39.629 & 174.97 & 420 & 33.9 & 880 & 34.5 & 845 & 298 \\
\hline Rt10-1bA & -39.559 & 174.98 & 616 & 39.3 & 545 & & & \\
\hline Rt10-1bB & -39.559 & 174.98 & 616 & 39.3 & 545 & & & \\
\hline Rt10-1cA & -39.559 & 174.98 & 616 & 34.6 & 834 & & & \\
\hline Rt10-1cB & -39.559 & 174.98 & 616 & 35.1 & 801 & 37.1 & 682 & 464 \\
\hline Rt11-1A & -39.544 & 174.99 & 668 & 36.6 & 707 & & & \\
\hline Rt11-1B & -39.544 & 174.99 & 668 & 36.7 & 700 & 36.5 & 704 & 81 \\
\hline
\end{tabular}


Porosity data from IGNS

\begin{tabular}{|l|l|l|c|c|c|c|c|}
\hline Cat No. & Latitude & Longitude & $\phi 0(\%)$ & $\mathrm{z}^{\prime}(\mathrm{m})$ & $\sigma(\mathrm{m})$ & Exhumation $(\mathrm{km})$ & Rock type \\
\hline 8317 & -39.294 & 174.504 & 31 & 1083 & 202 & 1.11 & $\mathrm{M}$ \\
\hline 8313 & -39.016 & 174.532 & 27 & & & 1.39 & $\mathrm{M}$ \\
\hline 8314 & -39.016 & 174.532 & 34 & 1120 & 241 & 0.93 & $\mathrm{M}$ \\
\hline 8316 & -39.247 & 174.581 & 28 & 1313 & 219 & 1.31 & $\mathrm{M}$ \\
\hline 8312 & -38.900 & 174.596 & 27 & 1396 & 225 & 1.39 & $\mathrm{M}$ \\
\hline 8221 & -39.668 & 174.632 & 37 & 682 & 176 & 0.76 & $\mathrm{M}$ \\
\hline 8310 & -38.708 & 174.649 & 27 & 1396 & 225 & 1.39 & $\mathrm{M}$ \\
\hline 8222 & -39.599 & 174.661 & 36 & 744 & 181 & 0.81 & $\mathrm{M}$ \\
\hline 8309 & -38.679 & 174.712 & 13 & 3051 & 381 & 2.85 & $\mathrm{M}$ \\
\hline 8225 & -39.805 & 174.739 & 37 & 682 & 178 & 0.76 & $\mathrm{M}$ \\
\hline 8172 & -39.117 & 174.744 & 28 & 1313 & 219 & 1.31 & $\mathrm{M}$ \\
\hline 8169 & -39.058 & 174.792 & 31 & 1083 & 202 & 1.11 & $\mathrm{M}$ \\
\hline 8168 & -39.019 & 174.803 & 24 & 1662 & 247 & 1.62 & $\mathrm{M}$ \\
\hline 8163 & -38.846 & 174.808 & 23 & 1759 & 256 & 1.71 & $\mathrm{M}$ \\
\hline 8224 & -39.581 & 174.826 & 36 & 744 & 181 & 0.81 & $\mathrm{M}$ \\
\hline 8223 & -39.666 & 174.856 & 28 & 1313 & 219 & 1.31 & $\mathrm{M}$ \\
\hline 9028 & -38.376 & 174.864 & 16 & 2581 & 333 & 2.43 & $\mathrm{M}$ \\
\hline 9026 & -38.396 & 174.868 & 20 & 2075 & 284 & 1.99 & $\mathrm{M}$ \\
\hline 9024 & -38.417 & 174.870 & 17 & 2444 & 320 & 2.31 & $\mathrm{M}$ \\
\hline 8164 & -38.854 & 174.912 & 26 & 1481 & 232 & 1.46 & $\mathrm{M}$ \\
\hline 9023 & -38.442 & 174.917 & 5 & 5215 & 612 & 4.76 & $\mathrm{M}$ \\
\hline 9034 & -38.188 & 174.931 & 10 & 3645 & 443 & 3.37 & $\mathrm{M}$ \\
\hline 9035 & -38.157 & 174.948 & 10 & 3645 & 443 & 3.37 & $\mathrm{M}$ \\
\hline 8148 & -38.590 & 174.964 & 12 & & & 3.01 & $\mathrm{M}$ \\
\hline 8149 & -38.590 & 174.964 & 9 & 3535 & 426 & 3.58 & $\mathrm{M}$ \\
\hline
\end{tabular}


Porosity data from IGNS

\begin{tabular}{|c|c|c|c|c|c|c|c|}
\hline Cat No. & Latitude & Longitude & $\phi 0(\%)$ & $\mathrm{z}^{\prime}(\mathrm{m})$ & $\sigma(\mathrm{m})$ & Exhumation $(\mathrm{km})$ & Rock type \\
\hline 8152 & -38.786 & 174.995 & 22 & & $\mathrm{~V}$ & 1.8 & $\mathrm{M}$ \\
\hline 8153 & -38.786 & 174.995 & 14 & 2314 & 292 & 2.7 & $\mathrm{M}$ \\
\hline 9032 & -38.226 & 174.997 & 13 & 3051 & 381 & 2.85 & $\mathrm{M}$ \\
\hline 9267 & -38.485 & 175.002 & 2 & 7291 & 841 & 6.59 & $\mathrm{M}$ \\
\hline 9273 & -38.536 & 175.007 & 3 & 6372 & 739 & 5.78 & $\mathrm{M}$ \\
\hline 9275 & -38.536 & 175.007 & 24 & 1662 & 247 & 1.62 & $\bar{M}$ \\
\hline 8160 & -39.929 & 175.018 & 26 & 1481 & 232 & 1.46 & $\mathrm{M}$ \\
\hline 9019 & -38.464 & 175.029 & 3 & 62372 & 739 & 5.78 & $\mathrm{M}$ \\
\hline 9270 & -38.486 & 175.049 & 24 & 1662 & 247 & 1.62 & $\mathrm{M}$ \\
\hline 9037 & -38.146 & 175.052 & 9 & 3884 & 468 & 3.58 & $\mathrm{M}$ \\
\hline 8143 & -38.561 & 175.071 & 25 & & & 1.54 & $\mathrm{M}$ \\
\hline 8145 & -38.561 & 175.071 & 18 & & & 2.2 & $\mathrm{M}$ \\
\hline 8146 & -38.561 & 175.071 & 21 & 1929 & 269 & 1.89 & $\mathrm{M}$ \\
\hline 8187 & -39.110 & 175.074 & 27 & 1396 & 225 & 1.39 & $\bar{M}$ \\
\hline 8214 & -39.559 & 175.084 & 31 & 1083 & 202 & 1.11 & $\bar{M}$ \\
\hline 8188 & -39.116 & 175.095 & 21 & 1965 & 274 & 1.89 & $\mathrm{M}$ \\
\hline 8318 & -39.965 & 175.100 & 56 & -257 & -163 & 0.07 & $\mathrm{M}$ \\
\hline 8184 & -39.122 & 175.106 & 20 & & & 1.99 & $\mathrm{M}$ \\
\hline 8185 & -39.122 & 175.106 & 21 & 2019 & 282 & 1.89 & $\mathrm{M}$ \\
\hline 1893 & -38.884 & 175.121 & 11 & 3430 & 420 & 3.18 & $\mathrm{M}$ \\
\hline 9263 & -38.408 & 175.121 & 28 & 1313 & 219 & 1.71 & $\mathrm{M}$ \\
\hline 8142 & -38.580 & 175.130 & 23 & 1759 & 256 & 1.71 & $\mathrm{M}$ \\
\hline 8212 & -39.462 & 175.130 & 27 & 1396 & 225 & 1.39 & $\mathrm{M}$ \\
\hline 9271 & -38.477 & 175.134 & 24 & 1662 & 247 & 1.62 & $\mathrm{M}$ \\
\hline 9262 & -38.382 & 175.134 & 26 & 1481 & 232 & 1.46 & $\bar{M}$ \\
\hline 8216 & -39.704 & 175.135 & 31 & 1083 & 202 & 1.11 & $\mathrm{M}$ \\
\hline 8141 & -38.579 & 175.140 & 16 & 2581 & 333 & 2.43 & $\mathrm{M}$ \\
\hline 8215 & -39.633 & 175.172 & 33 & 941 & 192 & 0.99 & $\mathrm{M}$ \\
\hline 9259 & -38.480 & 175.175 & 26 & 1481 & 232 & 1.46 & $\mathrm{M}$ \\
\hline 8198 & -39.273 & 175.182 & 24 & 1662 & 247 & 1.62 & $\mathrm{M}$ \\
\hline 8190 & -39.080 & 175.200 & 21 & 1965 & 274 & 1.89 & $\mathrm{M}$ \\
\hline 8201 & -39.307 & 175.206 & 26 & & & 1.46 & $\mathrm{M}$ \\
\hline 8202 & -39.307 & 175.206 & 29 & 1354 & 233 & 1.24 & $\mathrm{M}$ \\
\hline 9277 & -38.619 & 175.207 & 26 & 1481 & 232 & 1.46 & $\mathrm{M}$ \\
\hline 8139 & -38.611 & 175.216 & 25 & 1570 & 239 & 1.54 & $\mathrm{M}$ \\
\hline 8320 & -40.055 & 175.218 & 54 & -174 & -161 & 0 & $\mathrm{M}$ \\
\hline 8211 & -39.447 & 175.225 & 26 & 1481 & 231 & 1.46 & $\mathrm{M}$ \\
\hline 8204 & -39.325 & 175.234 & 17 & 2444 & 320 & 2.31 & $\mathrm{M}$ \\
\hline 8155 & -38.781 & 175.238 & 18 & 2314 & 307 & 2.2 & $\mathrm{M}$ \\
\hline 9006 & -38.115 & 175.240 & 2 & 7291 & 841 & 6.59 & $\mathrm{M}$ \\
\hline 1894 & -38.893 & 175.247 & 7 & & & 4.09 & $\mathrm{M}$ \\
\hline 1897 & -38.893 & 175.247 & 5 & 4802 & 564 & 4.76 & $\mathrm{M}$ \\
\hline 9278 & -38.621 & 175.252 & 22 & 1860 & 265 & 1.80 & $\mathrm{M}$ \\
\hline 9279 & -38.617 & 175.259 & 23 & 1759 & 256 & 1.71 & $\mathrm{M}$ \\
\hline
\end{tabular}


Porosity data from IGNS

\begin{tabular}{|c|c|c|c|c|c|c|c|}
\hline Cat No. & Latitude & Longitude & $\phi 0(\%)$ & $\mathrm{z}^{\prime}(\mathrm{m})$ & $\sigma(\mathrm{m})$ & Exhumation $(\mathrm{km})$ & Rock type \\
\hline 8206 & $\begin{array}{l}-39.569 \\
\end{array}$ & 175.269 & 41 & 449 & 168 & 0.55 & $\bar{M}$ \\
\hline 9010 & -38.343 & 175.282 & 1 & 8861 & 1016 & 7.98 & $\bar{M}$ \\
\hline 1661 & -39.618 & 175.298 & 34 & & & 0.93 & $\mathrm{M}$ \\
\hline 1662 & -39.618 & 175.298 & 32 & 941 & 183 & 1.05 & $\mathrm{M}$ \\
\hline 9248 & -38.461 & 175.304 & 24 & 1662 & 247 & 1.62 & $\mathrm{M}$ \\
\hline 1892 & -38.885 & 175.310 & 5 & 5215 & 612 & 4.76 & $\bar{M}$ \\
\hline 8207 & -39.628 & 175.315 & 38 & 622 & 175 & 0.70 & $\mathrm{M}$ \\
\hline 1873 & -39.644 & 175.326 & 6 & 4802 & 567 & 4.39 & $\mathrm{M}$ \\
\hline 8195 & -39.121 & 175.332 & 18 & 2314 & 307 & 2.2 & $\mathrm{M}$ \\
\hline 8208 & -39.669 & 175.331 & 42 & & & 0.50 & $\bar{M}$ \\
\hline 8209 & -39.669 & 175.331 & 39 & 477 & 146 & 0.65 & $\bar{M}$ \\
\hline 8178 & -39.035 & 175.338 & 11 & 3430 & 420 & 3.18 & $\mathrm{M}$ \\
\hline 9014 & -38.560 & 175.356 & 3 & 6372 & 739 & 5.78 & $\mathrm{M}$ \\
\hline 9254 & -38.501 & 175.431 & 5 & 5215 & 612 & 4.76 & $\mathrm{M}$ \\
\hline 8130 & -39.554 & 175.507 & 30 & 1157 & 207 & 1.18 & $\bar{M}$ \\
\hline 8128 & -39.673 & 175.554 & 28 & 1313 & 219 & 1.31 & $\bar{M}$ \\
\hline 8129 & -39.563 & 175.581 & 27 & 1396 & 225 & 1.39 & $\mathrm{M}$ \\
\hline 11110 & -39.875 & 175.686 & 39 & 563 & 172 & 0.65 & $\mathrm{M}$ \\
\hline 8125 & -39.627 & 175.761 & 30 & 1157 & 207 & 1.18 & $\mathrm{M}$ \\
\hline 8124 & -39.624 & 175.791 & 30 & 1157 & 207 & 1.18 & $\bar{M}$ \\
\hline 8119 & -39.774 & 175.798 & 38 & & & 0.70 & $\mathrm{M}$ \\
\hline 8120 & -39.774 & 175.798 & 52 & 239 & 432 & 0.08 & $\mathrm{M}$ \\
\hline 11056 & -39.605 & 175.798 & 52 & 239 & 219 & 1.31 & $\mathrm{M}$ \\
\hline 11111 & -39.810 & 175.803 & 34 & 874 & 188 & 0.93 & $\mathrm{M}$ \\
\hline 11058 & -39.668 & 175.807 & 23 & 1759 & 256 & 1.71 & $\bar{M}$ \\
\hline 11057 & $-39,663$ & 175.809 & 26 & 1481 & 232 & 1.46 & $\mathrm{M}$ \\
\hline 11059 & -39.636 & 175.844 & 24 & 1662 & 247 & 1.62 & $\mathrm{M}$ \\
\hline 11055 & -39.597 & 175.849 & 30 & 1157 & 207 & 1.18 & $\mathrm{M}$ \\
\hline 11112 & -39.784 & 175.858 & 32 & 1011 & 197 & 1.05 & $\mathrm{M}$ \\
\hline 11054 & -39.784 & 175.860 & 30 & 1157 & 207 & 1.18 & $\mathrm{M}$ \\
\hline 11060 & -39.602 & 175.876 & 25 & 1570 & 239 & 1.54 & $\mathrm{M}$ \\
\hline 11113 & -39.803 & 175.923 & 36 & 744 & 181 & 0.81 & $\mathrm{M}$ \\
\hline 11120 & -39.627 & 175.931 & 26 & 1481 & 232 & 1.46 & $\mathrm{M}$ \\
\hline 11114 & -39.814 & 175.953 & 38 & 622 & 175 & 0.70 & $\mathrm{M}$ \\
\hline 11121 & -39.636 & 175.967 & 32 & 1011 & 197 & 1.05 & $\mathrm{M}$ \\
\hline 11115 & -39.794 & 175.987 & 36 & 744 & 181 & 0.81 & $\mathrm{M}$ \\
\hline 11122 & -39.623 & 176.002 & 29 & 1234 & 213 & 1.24 & $\mathrm{M}$ \\
\hline 11116 & -39.780 & 176.010 & 33 & 941 & 192 & 0.99 & $\mathrm{M}$ \\
\hline 11123 & -39.584 & 176.033 & 26 & 1481 & 232 & 1.46 & $\mathrm{M}$ \\
\hline 11124 & -39.555 & 176.044 & 28 & 1313 & 219 & 1.31 & $\mathrm{M}$ \\
\hline 11125 & -39.536 & 176.096 & 30 & 1157 & 207 & 1.18 & $\mathrm{M}$ \\
\hline 727 & -39.450 & 175.775 & 21 & 1965 & 275 & 2.12 & $\bar{S}$ \\
\hline
\end{tabular}


Porosity data from IGNS

\begin{tabular}{|c|c|c|c|c|c|c|c|}
\hline Cat No. & Latitude & Longitude & $\phi 0(\%)$ & $\overline{z^{\prime}(\mathrm{m})}$ & $\sigma(\mathrm{m})$ & Exhumation $(\mathrm{km})$ & Rock type \\
\hline 1350 & -38.523 & 175.365 & 9 & & & 4.24 & $\bar{S}$ \\
\hline 1351 & -38.523 & 175.365 & 10 & & & 3.97 & $\mathrm{~S}$ \\
\hline 1352 & -38.523 & 175.365 & 16 & 3296 & 426 & 2.80 & $\mathrm{~S}$ \\
\hline 1757 & -39.127 & 175.340 & 22 & 1860 & 265 & 2.00 & $\mathrm{~S}$ \\
\hline 2090 & -39.716 & 175.127 & 33 & 941 & 192 & 0.99 & $\mathrm{~S}$ \\
\hline 5795 & -38.547 & 175.018 & 30 & 1157 & 207 & 1.23 & $\mathrm{~S}$ \\
\hline 8122 & -39.622 & 176.003 & 25 & 1570 & 239 & 1.68 & $\mathrm{~S}$ \\
\hline 8126 & -39.680 & 175.694 & 17 & 2444 & 320 & 2.65 & $\mathrm{~S}$ \\
\hline 8217 & -39.698 & 175.581 & 29 & 1234 & 213 & 1.31 & $\mathrm{~S}$ \\
\hline 8147 & -38.551 & 174.874 & 18 & 2314 & 307 & 2.50 & $\mathrm{~S}$ \\
\hline 8154 & -38.819 & 175.027 & 21 & 1965 & 274 & 2.12 & $\bar{S}$ \\
\hline 8159 & -38.928 & 175.091 & 15 & 2727 & 347 & 2.96 & $\mathrm{~S}$ \\
\hline 8174 & -38.978 & 174.879 & 16 & 2581 & 333 & 2.80 & $\mathrm{~S}$ \\
\hline 8191 & -39.080 & 175.199 & 23 & 1759 & 256 & 1.89 & $\bar{S}$ \\
\hline 8194 & -39.121 & 175.332 & 8 & 4151 & 497 & 4.53 & $\mathrm{~S}$ \\
\hline 8210 & -39.499 & 175.291 & 26 & 1481 & 232 & 1.59 & $\mathrm{~S}$ \\
\hline 8219 & -39.740 & 174.569 & 34 & 874 & 188 & 0.91 & $\bar{S}$ \\
\hline 8311 & -38.901 & 174.702 & 23 & 1759 & 256 & 1.89 & $\mathrm{~S}$ \\
\hline 8319 & -39.965 & 175.100 & 41 & 449 & 168 & 0.45 & $\mathrm{~S}$ \\
\hline 9000 & -38.050 & 175.464 & 1 & 8861 & 1016 & 9.73 & $\mathrm{~S}$ \\
\hline 9003 & -38.116 & 175.338 & 1 & 8861 & 1016 & 9.73 & $\mathrm{~S}$ \\
\hline 9004 & -38.137 & 175.284 & 1 & 8861 & 1016 & 9.73 & $\mathrm{~S}$ \\
\hline 9008 & -38.287 & 175.358 & 2 & 7291 & 841 & 8.00 & $\mathrm{~S}$ \\
\hline 9021 & -38.457 & 174.927 & 7 & 4453 & 529 & 4.87 & $\mathrm{~S}$ \\
\hline 9025 & -38.411 & 174.843 & 14 & 2883 & 364 & 3.13 & $\mathrm{~S}$ \\
\hline 9031 & -38.373 & 175.016 & 1 & 8861 & 1016 & 9.73 & $\mathrm{~S}$ \\
\hline 9038 & -38.149 & 175.127 & 4 & 5721 & 667 & 6.26 & $\bar{S}$ \\
\hline 9041 & -38.035 & 175.021 & 28 & 1313 & 219 & 1.40 & $\mathrm{~S}$ \\
\hline 9255 & -38.517 & 175.306 & 27 & 1396 & 225 & 1.49 & $\mathrm{~S}$ \\
\hline 9256 & -38.483 & 175.233 & 13 & 3051 & 381 & 3.32 & $\mathrm{~S}$ \\
\hline 9266 & -38.490 & 174.968 & 8 & 4151 & 467 & 4.53 & $\mathrm{~S}$ \\
\hline 9276 & -38.575 & 175.125 & 23 & 1759 & 256 & 1.89 & $\mathrm{~S}$ \\
\hline 11052 & -39.522 & 175.957 & 24 & 1662 & 247 & 1.79 & $\mathrm{~S}$ \\
\hline 11117 & -39.755 & 175.835 & 29 & 1234 & 213 & 1.31 & $\mathrm{~S}$ \\
\hline 11118 & -39.711 & 175.849 & 27 & 1396 & 225 & 1.49 & $\mathrm{~S}$ \\
\hline 11119 & -39.692 & 175.888 & 26 & 1481 & 232 & 1.59 & $\bar{S}$ \\
\hline 11126 & -39.493 & 176.124 & 25 & 1570 & 239 & 1.68 & $\mathrm{~S}$ \\
\hline
\end{tabular}




\section{IGNS DATA - MUDSTONE POROSITIES}

Rock type: $\mathrm{M}=$ mudstone $\mathrm{S}=$ siltstone

Porosity data from IGNS

\begin{tabular}{|l|l|l|c|c|c|c|c|}
\hline Cat No. & Latitude & Longitude & $\phi 0(\%)$ & z'$^{\prime}(\mathrm{m})$ & $\sigma(\mathrm{m})$ & Exhumation $(\mathrm{km})$ & Rock type \\
\hline 8317 & -39.294 & 174.504 & 31 & 1083 & 202 & 1.11 & $\mathrm{M}$ \\
\hline 8313 & -39.016 & 174.532 & 27 & & & 1.39 & $\mathrm{M}$ \\
\hline 8314 & -39.016 & 174.532 & 34 & 1120 & 241 & 0.93 & $\mathrm{M}$ \\
\hline 8316 & -39.247 & 174.581 & 28 & 1313 & 219 & 1.31 & $\mathrm{M}$ \\
\hline 8312 & -38.900 & 174.596 & 27 & 1396 & 225 & 1.39 & $\mathrm{M}$ \\
\hline 8221 & -39.668 & 174.632 & 37 & 682 & 176 & 0.76 & $\mathrm{M}$ \\
\hline 8310 & -38.708 & 174.649 & 27 & 1396 & 225 & 1.39 & $\mathrm{M}$ \\
\hline 8222 & -39.599 & 174.661 & 36 & 744 & 181 & 0.81 & $\mathrm{M}$ \\
\hline 8309 & -38.679 & 174.712 & 13 & 3051 & 381 & 2.85 & $\mathrm{M}$ \\
\hline 8225 & -39.805 & 174.739 & 37 & 682 & 178 & 0.76 & $\mathrm{M}$ \\
\hline 8172 & -39.117 & 174.744 & 28 & 1313 & 219 & 1.31 & $\mathrm{M}$ \\
\hline 8169 & -39.058 & 174.792 & 31 & 1083 & 202 & 1.11 & $\mathrm{M}$ \\
\hline 8168 & -39.019 & 174.803 & 24 & 1662 & 247 & 1.62 & $\mathrm{M}$ \\
\hline 8163 & -38.846 & 174.808 & 23 & 1759 & 256 & 1.71 & $\mathrm{M}$ \\
\hline 8224 & -39.581 & 174.826 & 36 & 744 & 181 & 0.81 & $\mathrm{M}$ \\
\hline 8223 & -39.666 & 174.856 & 28 & 1313 & 219 & 1.31 & $\mathrm{M}$ \\
\hline 9028 & -38.376 & 174.864 & 16 & 2581 & 333 & 2.43 & $\mathrm{M}$ \\
\hline 9026 & -38.396 & 174.868 & 20 & 2075 & 284 & 1.99 & $\mathrm{M}$ \\
\hline 9024 & -38.417 & 174.870 & 17 & 2444 & 320 & 2.31 & $\mathrm{M}$ \\
\hline 8164 & -38.854 & 174.912 & 26 & 1481 & 232 & 1.46 & $\mathrm{M}$ \\
\hline 9023 & -38.442 & 174.917 & 5 & 5215 & 612 & 4.76 & $\mathrm{M}$ \\
\hline 9034 & -38.188 & 174.931 & 10 & 3645 & 443 & 3.37 & $\mathrm{M}$ \\
\hline 9035 & -38.157 & 174.948 & 10 & 3645 & 443 & 3.37 & $\mathrm{M}$ \\
\hline 8148 & -38.590 & 174.964 & 12 & & & 3.01 & $\mathrm{M}$ \\
\hline 8149 & -38.590 & 174.964 & 9 & 3535 & 426 & 3.58 & $\mathrm{M}$ \\
\hline
\end{tabular}


Porosity data from IGNS

\begin{tabular}{|c|c|c|c|c|c|c|c|}
\hline Cat No. & Latitude & Longitude & $\phi 0(\%)$ & $\mathrm{z}^{\prime}(\mathrm{m})$ & $\sigma(\mathrm{m})$ & Exhumation $(\mathrm{km})$ & Rock type \\
\hline 8152 & -38.786 & 174.995 & 22 & & $\mathrm{~V}$ & 1.8 & $\mathrm{M}$ \\
\hline 8153 & -38.786 & 174.995 & 14 & 2314 & 292 & 2.7 & $\mathrm{M}$ \\
\hline 9032 & -38.226 & 174.997 & 13 & 3051 & 381 & 2.85 & $\mathrm{M}$ \\
\hline 9267 & -38.485 & 175.002 & 2 & 7291 & 841 & 6.59 & $\mathrm{M}$ \\
\hline 9273 & -38.536 & 175.007 & 3 & 6372 & 739 & 5.78 & $\mathrm{M}$ \\
\hline 9275 & -38.536 & 175.007 & 24 & 1662 & 247 & 1.62 & $\bar{M}$ \\
\hline 8160 & -39.929 & 175.018 & 26 & 1481 & 232 & 1.46 & $\mathrm{M}$ \\
\hline 9019 & -38.464 & 175.029 & 3 & 62372 & 739 & 5.78 & $\mathrm{M}$ \\
\hline 9270 & -38.486 & 175.049 & 24 & 1662 & 247 & 1.62 & $\mathrm{M}$ \\
\hline 9037 & -38.146 & 175.052 & 9 & 3884 & 468 & 3.58 & $\mathrm{M}$ \\
\hline 8143 & -38.561 & 175.071 & 25 & & & 1.54 & $\mathrm{M}$ \\
\hline 8145 & -38.561 & 175.071 & 18 & & & 2.2 & $\mathrm{M}$ \\
\hline 8146 & -38.561 & 175.071 & 21 & 1929 & 269 & 1.89 & $\mathrm{M}$ \\
\hline 8187 & -39.110 & 175.074 & 27 & 1396 & 225 & 1.39 & $\bar{M}$ \\
\hline 8214 & -39.559 & 175.084 & 31 & 1083 & 202 & 1.11 & $\bar{M}$ \\
\hline 8188 & -39.116 & 175.095 & 21 & 1965 & 274 & 1.89 & $\mathrm{M}$ \\
\hline 8318 & -39.965 & 175.100 & 56 & -257 & -163 & 0.07 & $\mathrm{M}$ \\
\hline 8184 & -39.122 & 175.106 & 20 & & & 1.99 & $\mathrm{M}$ \\
\hline 8185 & -39.122 & 175.106 & 21 & 2019 & 282 & 1.89 & $\mathrm{M}$ \\
\hline 1893 & -38.884 & 175.121 & 11 & 3430 & 420 & 3.18 & $\mathrm{M}$ \\
\hline 9263 & -38.408 & 175.121 & 28 & 1313 & 219 & 1.71 & $\mathrm{M}$ \\
\hline 8142 & -38.580 & 175.130 & 23 & 1759 & 256 & 1.71 & $\mathrm{M}$ \\
\hline 8212 & -39.462 & 175.130 & 27 & 1396 & 225 & 1.39 & $\mathrm{M}$ \\
\hline 9271 & -38.477 & 175.134 & 24 & 1662 & 247 & 1.62 & $\mathrm{M}$ \\
\hline 9262 & -38.382 & 175.134 & 26 & 1481 & 232 & 1.46 & $\bar{M}$ \\
\hline 8216 & -39.704 & 175.135 & 31 & 1083 & 202 & 1.11 & $\mathrm{M}$ \\
\hline 8141 & -38.579 & 175.140 & 16 & 2581 & 333 & 2.43 & $\mathrm{M}$ \\
\hline 8215 & -39.633 & 175.172 & 33 & 941 & 192 & 0.99 & $\mathrm{M}$ \\
\hline 9259 & -38.480 & 175.175 & 26 & 1481 & 232 & 1.46 & $\mathrm{M}$ \\
\hline 8198 & -39.273 & 175.182 & 24 & 1662 & 247 & 1.62 & $\mathrm{M}$ \\
\hline 8190 & -39.080 & 175.200 & 21 & 1965 & 274 & 1.89 & $\mathrm{M}$ \\
\hline 8201 & -39.307 & 175.206 & 26 & & & 1.46 & $\mathrm{M}$ \\
\hline 8202 & -39.307 & 175.206 & 29 & 1354 & 233 & 1.24 & $\mathrm{M}$ \\
\hline 9277 & -38.619 & 175.207 & 26 & 1481 & 232 & 1.46 & $\mathrm{M}$ \\
\hline 8139 & -38.611 & 175.216 & 25 & 1570 & 239 & 1.54 & $\mathrm{M}$ \\
\hline 8320 & -40.055 & 175.218 & 54 & -174 & -161 & 0 & $\mathrm{M}$ \\
\hline 8211 & -39.447 & 175.225 & 26 & 1481 & 231 & 1.46 & $\mathrm{M}$ \\
\hline 8204 & -39.325 & 175.234 & 17 & 2444 & 320 & 2.31 & $\mathrm{M}$ \\
\hline 8155 & -38.781 & 175.238 & 18 & 2314 & 307 & 2.2 & $\mathrm{M}$ \\
\hline 9006 & -38.115 & 175.240 & 2 & 7291 & 841 & 6.59 & $\mathrm{M}$ \\
\hline 1894 & -38.893 & 175.247 & 7 & & & 4.09 & $\mathrm{M}$ \\
\hline 1897 & -38.893 & 175.247 & 5 & 4802 & 564 & 4.76 & $\mathrm{M}$ \\
\hline 9278 & -38.621 & 175.252 & 22 & 1860 & 265 & 1.80 & $\mathrm{M}$ \\
\hline 9279 & -38.617 & 175.259 & 23 & 1759 & 256 & 1.71 & $\mathrm{M}$ \\
\hline
\end{tabular}


Porosity data from IGNS

\begin{tabular}{|c|c|c|c|c|c|c|c|}
\hline Cat No. & Latitude & Longitude & $\phi 0(\%)$ & $\mathrm{z}^{\prime}(\mathrm{m})$ & $\sigma(\mathrm{m})$ & Exhumation $(\mathrm{km})$ & Rock type \\
\hline 8206 & $\begin{array}{l}-39.569 \\
\end{array}$ & 175.269 & 41 & 449 & 168 & 0.55 & $\bar{M}$ \\
\hline 9010 & -38.343 & 175.282 & 1 & 8861 & 1016 & 7.98 & $\bar{M}$ \\
\hline 1661 & -39.618 & 175.298 & 34 & & & 0.93 & $\mathrm{M}$ \\
\hline 1662 & -39.618 & 175.298 & 32 & 941 & 183 & 1.05 & $\mathrm{M}$ \\
\hline 9248 & -38.461 & 175.304 & 24 & 1662 & 247 & 1.62 & $\mathrm{M}$ \\
\hline 1892 & -38.885 & 175.310 & 5 & 5215 & 612 & 4.76 & $\bar{M}$ \\
\hline 8207 & -39.628 & 175.315 & 38 & 622 & 175 & 0.70 & $\mathrm{M}$ \\
\hline 1873 & -39.644 & 175.326 & 6 & 4802 & 567 & 4.39 & $\mathrm{M}$ \\
\hline 8195 & -39.121 & 175.332 & 18 & 2314 & 307 & 2.2 & $\mathrm{M}$ \\
\hline 8208 & -39.669 & 175.331 & 42 & & & 0.50 & $\bar{M}$ \\
\hline 8209 & -39.669 & 175.331 & 39 & 477 & 146 & 0.65 & $\bar{M}$ \\
\hline 8178 & -39.035 & 175.338 & 11 & 3430 & 420 & 3.18 & $\mathrm{M}$ \\
\hline 9014 & -38.560 & 175.356 & 3 & 6372 & 739 & 5.78 & $\mathrm{M}$ \\
\hline 9254 & -38.501 & 175.431 & 5 & 5215 & 612 & 4.76 & $\mathrm{M}$ \\
\hline 8130 & -39.554 & 175.507 & 30 & 1157 & 207 & 1.18 & $\bar{M}$ \\
\hline 8128 & -39.673 & 175.554 & 28 & 1313 & 219 & 1.31 & $\bar{M}$ \\
\hline 8129 & -39.563 & 175.581 & 27 & 1396 & 225 & 1.39 & $\mathrm{M}$ \\
\hline 11110 & -39.875 & 175.686 & 39 & 563 & 172 & 0.65 & $\mathrm{M}$ \\
\hline 8125 & -39.627 & 175.761 & 30 & 1157 & 207 & 1.18 & $\mathrm{M}$ \\
\hline 8124 & -39.624 & 175.791 & 30 & 1157 & 207 & 1.18 & $\bar{M}$ \\
\hline 8119 & -39.774 & 175.798 & 38 & & & 0.70 & $\mathrm{M}$ \\
\hline 8120 & -39.774 & 175.798 & 52 & 239 & 432 & 0.08 & $\mathrm{M}$ \\
\hline 11056 & -39.605 & 175.798 & 52 & 239 & 219 & 1.31 & $\mathrm{M}$ \\
\hline 11111 & -39.810 & 175.803 & 34 & 874 & 188 & 0.93 & $\mathrm{M}$ \\
\hline 11058 & -39.668 & 175.807 & 23 & 1759 & 256 & 1.71 & $\bar{M}$ \\
\hline 11057 & $-39,663$ & 175.809 & 26 & 1481 & 232 & 1.46 & $\mathrm{M}$ \\
\hline 11059 & -39.636 & 175.844 & 24 & 1662 & 247 & 1.62 & $\mathrm{M}$ \\
\hline 11055 & -39.597 & 175.849 & 30 & 1157 & 207 & 1.18 & $\mathrm{M}$ \\
\hline 11112 & -39.784 & 175.858 & 32 & 1011 & 197 & 1.05 & $\mathrm{M}$ \\
\hline 11054 & -39.784 & 175.860 & 30 & 1157 & 207 & 1.18 & $\mathrm{M}$ \\
\hline 11060 & -39.602 & 175.876 & 25 & 1570 & 239 & 1.54 & $\mathrm{M}$ \\
\hline 11113 & -39.803 & 175.923 & 36 & 744 & 181 & 0.81 & $\mathrm{M}$ \\
\hline 11120 & -39.627 & 175.931 & 26 & 1481 & 232 & 1.46 & $\mathrm{M}$ \\
\hline 11114 & -39.814 & 175.953 & 38 & 622 & 175 & 0.70 & $\mathrm{M}$ \\
\hline 11121 & -39.636 & 175.967 & 32 & 1011 & 197 & 1.05 & $\mathrm{M}$ \\
\hline 11115 & -39.794 & 175.987 & 36 & 744 & 181 & 0.81 & $\mathrm{M}$ \\
\hline 11122 & -39.623 & 176.002 & 29 & 1234 & 213 & 1.24 & $\mathrm{M}$ \\
\hline 11116 & -39.780 & 176.010 & 33 & 941 & 192 & 0.99 & $\mathrm{M}$ \\
\hline 11123 & -39.584 & 176.033 & 26 & 1481 & 232 & 1.46 & $\mathrm{M}$ \\
\hline 11124 & -39.555 & 176.044 & 28 & 1313 & 219 & 1.31 & $\mathrm{M}$ \\
\hline 11125 & -39.536 & 176.096 & 30 & 1157 & 207 & 1.18 & $\mathrm{M}$ \\
\hline 727 & -39.450 & 175.775 & 21 & 1965 & 275 & 2.12 & $\bar{S}$ \\
\hline
\end{tabular}


Porosity data from IGNS

\begin{tabular}{|c|c|c|c|c|c|c|c|}
\hline Cat No. & Latitude & Longitude & $\phi 0(\%)$ & $\overline{z^{\prime}(\mathrm{m})}$ & $\sigma(\mathrm{m})$ & Exhumation $(\mathrm{km})$ & Rock type \\
\hline 1350 & -38.523 & 175.365 & 9 & & & 4.24 & $\bar{S}$ \\
\hline 1351 & -38.523 & 175.365 & 10 & & & 3.97 & $\mathrm{~S}$ \\
\hline 1352 & -38.523 & 175.365 & 16 & 3296 & 426 & 2.80 & $\mathrm{~S}$ \\
\hline 1757 & -39.127 & 175.340 & 22 & 1860 & 265 & 2.00 & $\mathrm{~S}$ \\
\hline 2090 & -39.716 & 175.127 & 33 & 941 & 192 & 0.99 & $\mathrm{~S}$ \\
\hline 5795 & -38.547 & 175.018 & 30 & 1157 & 207 & 1.23 & $\mathrm{~S}$ \\
\hline 8122 & -39.622 & 176.003 & 25 & 1570 & 239 & 1.68 & $\mathrm{~S}$ \\
\hline 8126 & -39.680 & 175.694 & 17 & 2444 & 320 & 2.65 & $\mathrm{~S}$ \\
\hline 8217 & -39.698 & 175.581 & 29 & 1234 & 213 & 1.31 & $\mathrm{~S}$ \\
\hline 8147 & -38.551 & 174.874 & 18 & 2314 & 307 & 2.50 & $\mathrm{~S}$ \\
\hline 8154 & -38.819 & 175.027 & 21 & 1965 & 274 & 2.12 & $\bar{S}$ \\
\hline 8159 & -38.928 & 175.091 & 15 & 2727 & 347 & 2.96 & $\mathrm{~S}$ \\
\hline 8174 & -38.978 & 174.879 & 16 & 2581 & 333 & 2.80 & $\mathrm{~S}$ \\
\hline 8191 & -39.080 & 175.199 & 23 & 1759 & 256 & 1.89 & $\bar{S}$ \\
\hline 8194 & -39.121 & 175.332 & 8 & 4151 & 497 & 4.53 & $\mathrm{~S}$ \\
\hline 8210 & -39.499 & 175.291 & 26 & 1481 & 232 & 1.59 & $\mathrm{~S}$ \\
\hline 8219 & -39.740 & 174.569 & 34 & 874 & 188 & 0.91 & $\bar{S}$ \\
\hline 8311 & -38.901 & 174.702 & 23 & 1759 & 256 & 1.89 & $\mathrm{~S}$ \\
\hline 8319 & -39.965 & 175.100 & 41 & 449 & 168 & 0.45 & $\mathrm{~S}$ \\
\hline 9000 & -38.050 & 175.464 & 1 & 8861 & 1016 & 9.73 & $\mathrm{~S}$ \\
\hline 9003 & -38.116 & 175.338 & 1 & 8861 & 1016 & 9.73 & $\mathrm{~S}$ \\
\hline 9004 & -38.137 & 175.284 & 1 & 8861 & 1016 & 9.73 & $\mathrm{~S}$ \\
\hline 9008 & -38.287 & 175.358 & 2 & 7291 & 841 & 8.00 & $\mathrm{~S}$ \\
\hline 9021 & -38.457 & 174.927 & 7 & 4453 & 529 & 4.87 & $\mathrm{~S}$ \\
\hline 9025 & -38.411 & 174.843 & 14 & 2883 & 364 & 3.13 & $\mathrm{~S}$ \\
\hline 9031 & -38.373 & 175.016 & 1 & 8861 & 1016 & 9.73 & $\mathrm{~S}$ \\
\hline 9038 & -38.149 & 175.127 & 4 & 5721 & 667 & 6.26 & $\bar{S}$ \\
\hline 9041 & -38.035 & 175.021 & 28 & 1313 & 219 & 1.40 & $\mathrm{~S}$ \\
\hline 9255 & -38.517 & 175.306 & 27 & 1396 & 225 & 1.49 & $\mathrm{~S}$ \\
\hline 9256 & -38.483 & 175.233 & 13 & 3051 & 381 & 3.32 & $\mathrm{~S}$ \\
\hline 9266 & -38.490 & 174.968 & 8 & 4151 & 467 & 4.53 & $\mathrm{~S}$ \\
\hline 9276 & -38.575 & 175.125 & 23 & 1759 & 256 & 1.89 & $\mathrm{~S}$ \\
\hline 11052 & -39.522 & 175.957 & 24 & 1662 & 247 & 1.79 & $\mathrm{~S}$ \\
\hline 11117 & -39.755 & 175.835 & 29 & 1234 & 213 & 1.31 & $\mathrm{~S}$ \\
\hline 11118 & -39.711 & 175.849 & 27 & 1396 & 225 & 1.49 & $\mathrm{~S}$ \\
\hline 11119 & -39.692 & 175.888 & 26 & 1481 & 232 & 1.59 & $\bar{S}$ \\
\hline 11126 & -39.493 & 176.124 & 25 & 1570 & 239 & 1.68 & $\mathrm{~S}$ \\
\hline
\end{tabular}

